2. To: (Receiving Organization) Distribution

5. Proj./Prog./Dept./Div.:

Technical Basis for the Determination. . Waste

Management/Process

Engineering

8. Originator Remarks:

This document is being released into the supporting document system for retrievability purposes.

11. Receiver Remarks: 11A. Design Basel ine Document? [] Yes [X] No For release.
3. From: (Originating Organization) Process Engineering

6. Design Authority/ Design Agent/Cog. Brett C. Simpson
4. Related EDT NO.:

$\mathrm{N} / \mathrm{A}$

7. Purchase Order No.:

$N / A$

9. Equip./Component No.:

$\mathrm{N} / \mathrm{A}$

10. System/Bldg./Facility: N/A

12. Major Assm. Dwg. No.: $\mathrm{N} / \mathrm{A}$

13. Permit/Permit Application No.: $\mathrm{N} / \mathrm{A}$

14. Required Response Date: $06 / 23 / 99$

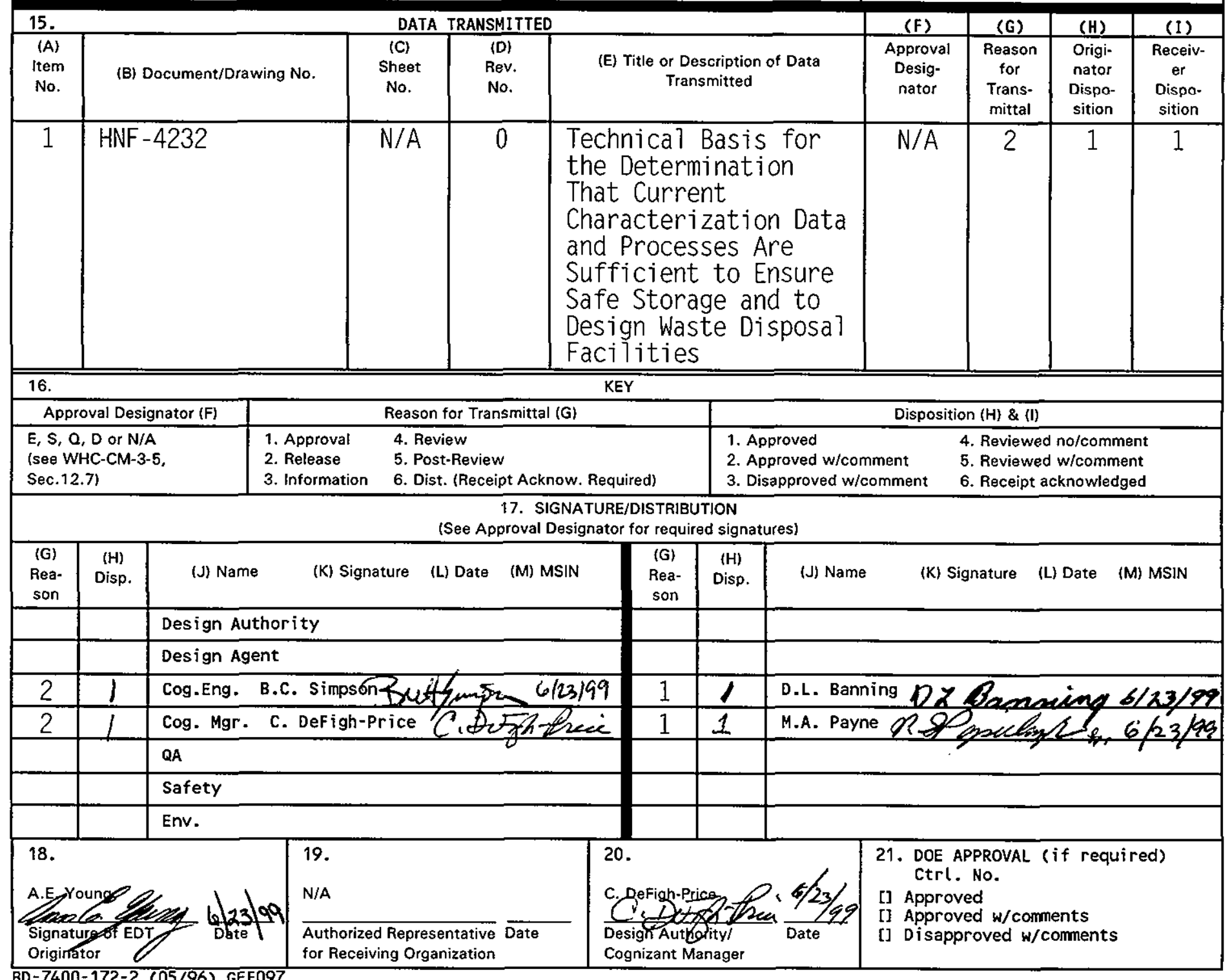




\title{
Technical Basis for the Determination That Current Characterization Data and Processes Are Sufficient to Ensure Safe Storage and to Design Waste Disposal Facilities
}

Brett C. Simpson

Lockheed Martin Hanford Corp., Richland, WA 99352

U.S. Department of Energy Contract DE-AC06-96RL13200

\author{
EDT/ECN: EDT-611472 UC: 2070 \\ Org Code: 74B00 CACN/COA: 108373/EI00 \\ B\&R Code: EW 3120074 Total Pages: 244
}

Key Words: Closure of Recommendation 93-5, Recommendation 93-5, 93-5, Technical Basis, Characterization Data, Characterization Processes, Data, Processes, Storage, Waste Disposal Facilities, Waste Disposai

Abstract: N/A

TRADEMARK DISCLAIMER. Reference herein to any specific commercial product, process, or service by trade name, trademark, manufacturer, or otherwise, does not necessarily constitute or imply its endorsement, recommendation, or favoring by the United States Government or any agency thereof or its contractors or subcontractors.

Printed in the United States of America. To obtain copies of this document, contact: Document Control Services, P.0. Box 950, Mailstop H6-08, Richland WA 99352, Phone (509) 372-2420; Fax (509) 376-4989.
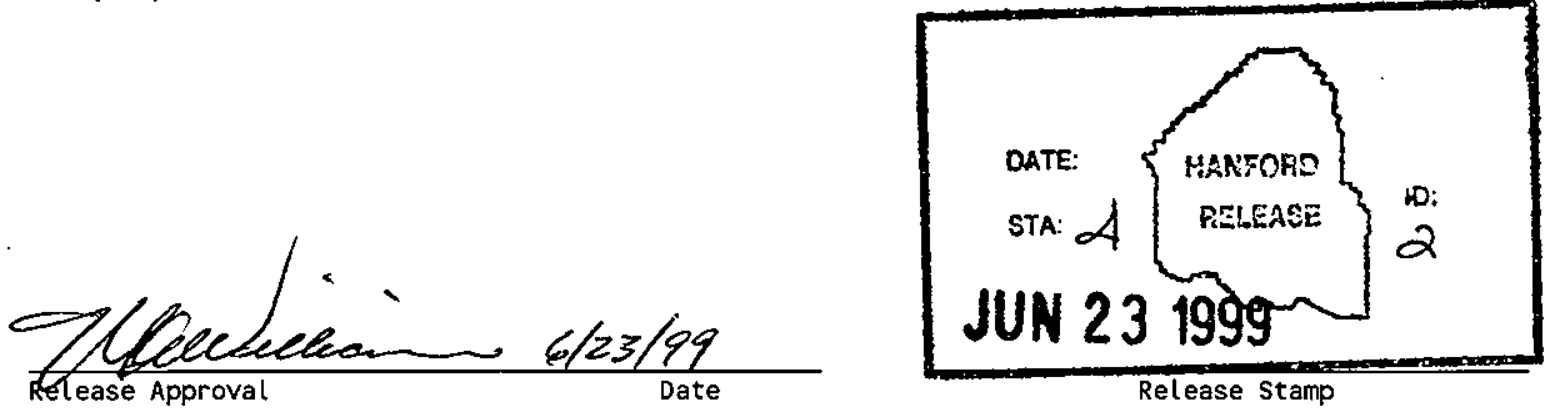
HNF-4232

Revision 0

Technical Basis for the Determination That Current

Characterization Data and Processes Are Sufficient to Ensure Safe Storage and to Design Waste Disposal Facilities

B. C. Simpson

C. DeFigh-Price

D. L. Banning

Lockheed Martin Hanford Corporation

Date Published

June 1999

Prepared for the U. S. Department of Energy

Assistant Secretary for Environmental Management

Project Hanford Management Contractor for the

U.S. Department of Energy under Contract DE-AC06-96RL13200

Approved for public release 


\section{EXECUTIVE SUMMARY}

This document presents the technical basis for closure of Defense Nuclear Facilities Safety Board (DNFSB) Recommendation 93-5 Implementation Plan milestone 5.6.3.1j, "Core sample all tanks by 2002" (DOE-RL 1996). The milestone was based on the need for characterization data to ensure safe storage of the waste, to operate the tanks safely, and to plan and implement retrieval and processing of the waste. Sufficient tank characterization data have been obtained to ensure that existing controls are adequate for safe storage of the waste in the 177 waste tanks at the Hanford Site. In addition, a process has been developed, executed, and institutionalized to systemically identify information needs, to integrate and prioritize the needs, and to reliably obtain and analyze the associated samples.

This document provides a technical case that the remaining 45 incompletely sampled tanks no longer require sampling to support the intent of the Implementation Plan milestone. Sufficient data have been obtained to close the Unreviewed Safety Questions (USQs), and to ensure that existing hazard controls are adequate and appropriately applied. However, in the future, additional characterization of tanks at the site will be required to support identified information needs. Closure of this milestone allows sampling and analytical data to be obtained in a manner that is consistent with the integrated priority process.

As of October 1, 1998, 132 of the 177 tanks were sampled and analyzed for safety screening (Reynolds et al. 1999). The task of capturing and analyzing process and historical information has been completed. This led to a more usable record of the wastes that were produced at various facilities on site and the transfers between tanks. Adequate characterization data, needed to build a foundation for closure of the major USQs that existed at the time the Recommendation 93-5, was obtained. The knowledge gained from characterizing 132 of the tanks was sufficient to support closing the major USQs. Because of the broader, more comprehensive knowledge of the waste, an updated safety analysis was created, resulting in an approved Basis for Interim Operation (BIO) (Noorani 1999). The BIO defines appropriate controls for the tanks. Characterization activities will continue on a schedule to support technical needs.

This document summarizes the scientific and technical data to confirm assumptions, evaluate models, and measure safety-related phenomenological characteristics of the waste. A summary of the change in the tank waste retrieval and disposal strategy is presented and describes how that change affects information needs. An evaluation of the 45 incompletely sampled tanks is presented to technically justify they have been characterized by other means. This document also provides the basis for concluding the waste content of the incompletely sampled tanks is within the authorization basis established by the accident analyses. 
HNF-4232 Rev. 0

\section{TABLE OF CONTENTS}

EXECUTIVE SUMMARY i

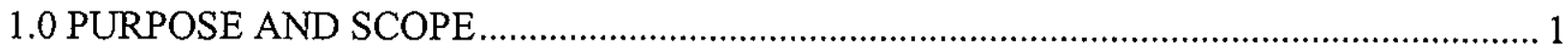

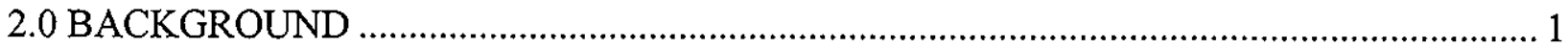

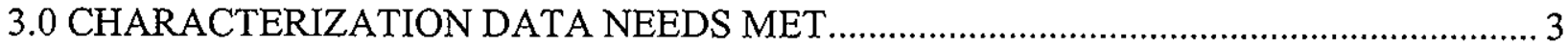

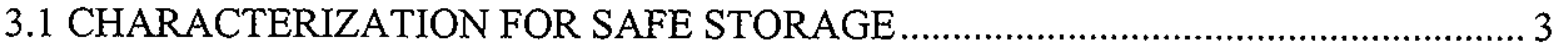

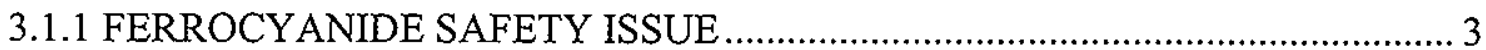

3.1.2 ORGANIC SOLVENTS SAFETY ISSUE ……................................................ 5

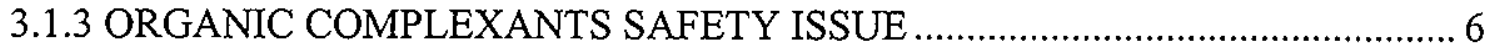

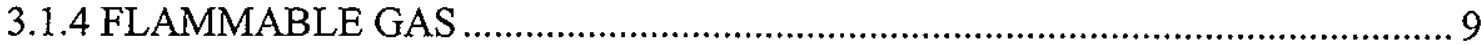

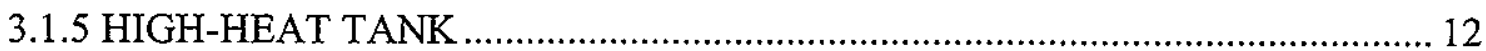

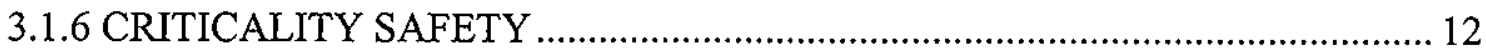

3.1.7 IMPROVEMENTS TO OVERALL TANK KNOWLEDGE ………................. 13

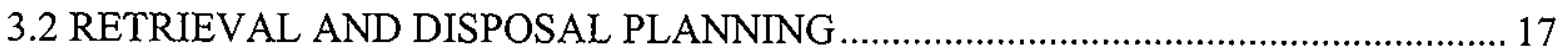

3.2.1 EVOLUTION OF THE DISPOSAL PROGRAM …….................................... 17

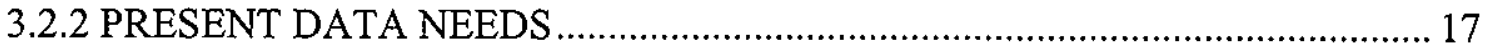

4.0 INSTITUTIONALIZING THE PROCESS TO DEFINE AND OBTAIN

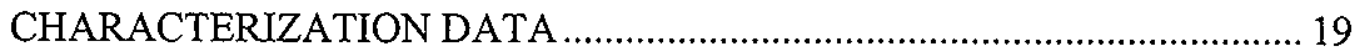

4.1 EMBEDDING SYSTEMS ENGINEERING PRICIPLES INTO THE RIVER

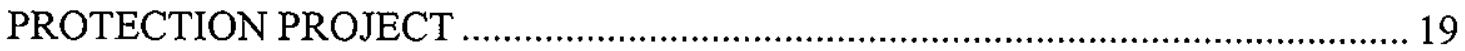

4.2 PROCESS FOR IDENTIFYING CHARACTERIZATION DATA ……......................20

4.3 OBTAINING SAMPLES AND ANALYZING DATA .............................................. 22

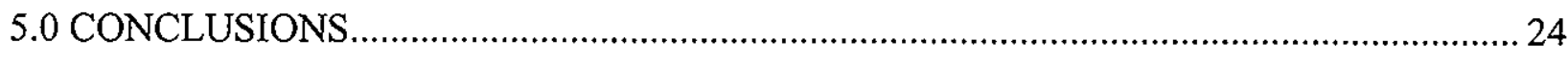

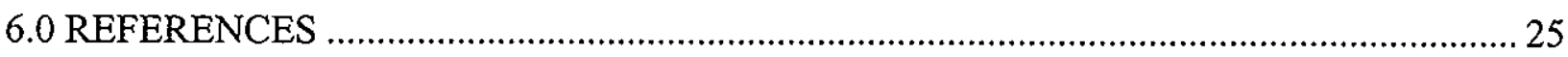


HNF-4232 Rev. 0

\section{APPENDICES}

APPENDIX A. SUMMARY OF TANKS WITH COMPLETED CORE SAMPLING

A1.0 INTRODUCTION

A2.0 METHOD FOR DETERMINING ADEQUACY OF TANK SAMPLING A-3

A2.1 LOGIC USED TO SATISFY MILESTONE 5.6.3.1j ..................................... A-6

A3.0 TANKS SATISFYING MILESTONE 5.6.3.1j ................................................... A-9

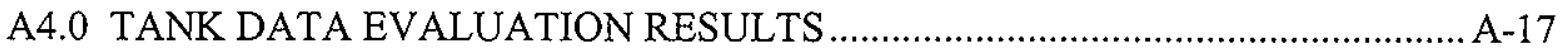

A5.0 REFERENCES …………………

APPENDIX B. SUMMARY OF UNSAMPLED OR INSUFFICIENTLY SAMPLED

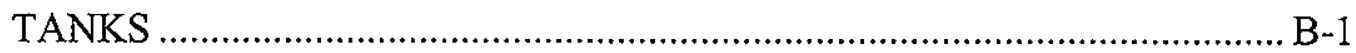

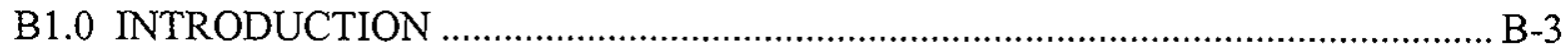

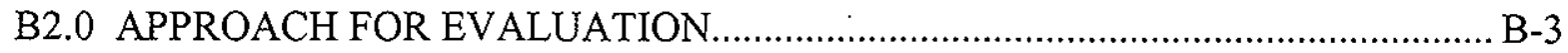

B2.1 LOGIC USED TO EVALUATE TANKS .................................................. B-4

B2.2 SAFETY ISSUE AND ACCIDENT EVALUATION …….......................... B-8

B3.0 TANK CHEMISTRY AND DATA OBSERVATIONS …………....................... B-11

B3.1 TANK WASTE VARIATION LIMITS ……........................................... B-11

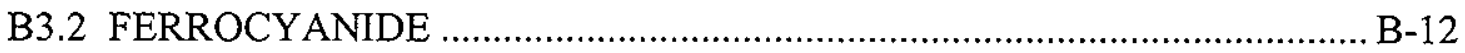

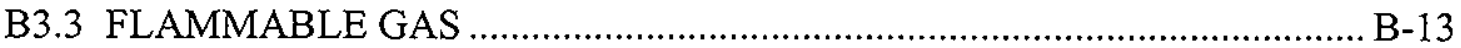

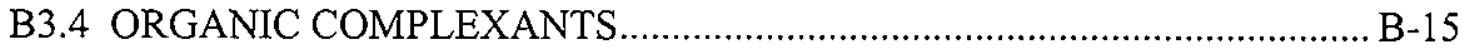

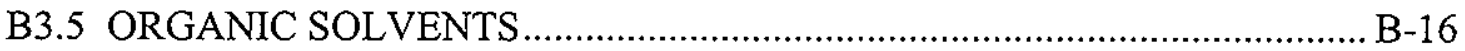

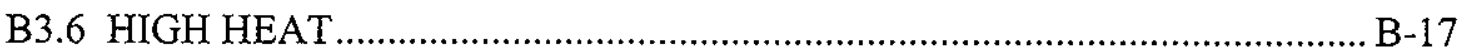

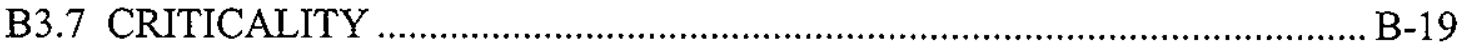

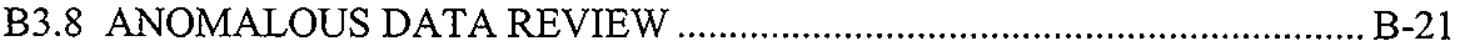

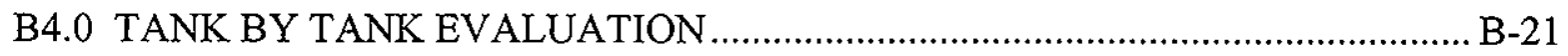

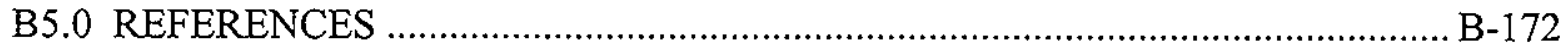




\section{LIST OF FIGURES}

Figure 4-1. Integrated Safety Management Functions Within Characterization Project..............2 21

Figure A-1. Logic for Assessing Tank Data for Safety Screening ........................................... A-7

Figure A-2. Total Alpha for Liquid Samples................................................................... A-22

Figure A-3. Total Alpha for Solid Samples....................................................................

Figure A-4. Energetics for Liquid Samples ....................................................................... A-22

Figure A-5. Energetics for Solid Samples ........................................................................ A-22

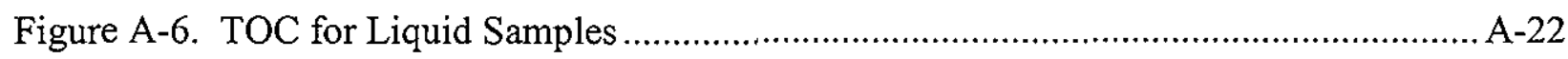

Figure A-7. TOC for Solid Samples ……………….....................................................

Figure A-8. Oxalate for Liquid Samples........................................................................

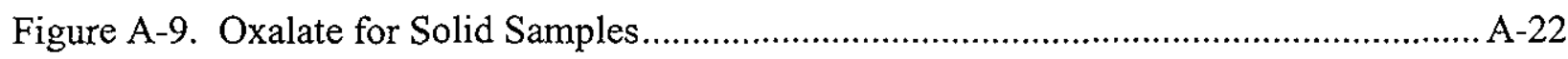

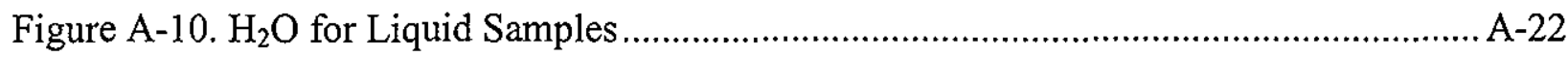

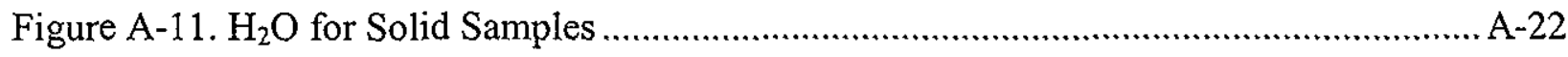

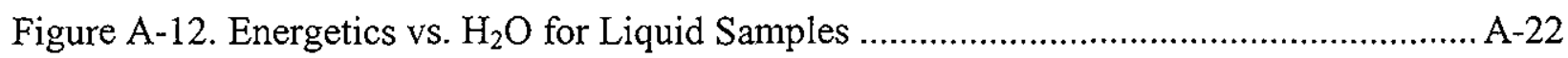

Figure A-13. Energetics vs. $\mathrm{H}_{2} \mathrm{O}$ for Solid Samples.......................................................... A-22

Figure A-14. TOC vs. $\mathrm{H}_{2} \mathrm{O}$ for Liquid Samples …………................................................ A-22

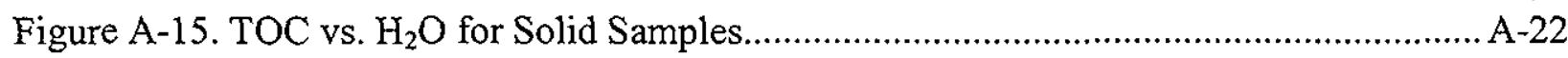

Figure B-1. Logic for Assessing Tank Data for Safety Screening .......................................... B-5 
HNF-4232 Rev. 0

\section{LIST OF TABLES}

Table 3-1. Results of Ferrocyanide Waste Analyses .................................................................. 4

Table 3-2. Single-Shell Tank Organic Complexant Tank Groupings.......................................... 8

Table 3-3 Flammable Gas Tank Groupings............................................................................... 10

Table 3-4. Number of Tanks Where Flammable Gas Equipment Was Installed or Activity Performed ............................................................................................. 10

Table 3-5. Tanks Sampled for Each High Priority Tank Question............................................. 15

Table 3-6. Retrieval and Disposal Sampling for Phase 1 ......................................................... 18

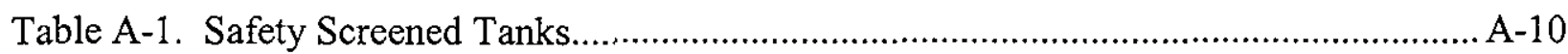

Table A-2. Waste Types Sampled ..................................................................................

Table B-1. Representative Accidents Evaluated in the Authorization Basis............................ B-9

Table B-2. Limits of Concern for Safety Issues ……......................................................... B-10

Table B-3. Remaining Tanks to be Sampled ………..................................................... B-22

Table B-4. Safety Issue Logic for Tank A-103 .................................................................. B-26

Table B-5. Safety Issue Logic for Tank A-104 ……......................................................... B-29

Table B-6. Safety Issue Logic for Tank A-105 ................................................................ B-32

Table B-7. Safety Issue Logic for Tank A-106 ……………............................................ B-35

Table B-8. Safety Issue Logic for Tank B-105 .................................................................... B-39

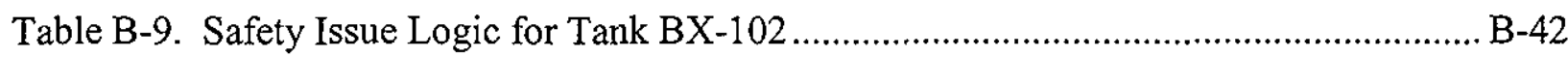

Table B-10. Safety Issue Logic for Tank BY-105 …..................................................... B-45

Table B-11. Safety Issue Logic for Tank BY-106 ……….............................................. B-48

Table B-12. Safety Issue Logic for Tank C-102 ……....................................................... B-52

Table B-13. Safety Issue Logic for Tank S-103 ……......................................................... B-55

Table B-14. Safety Issue Logic for Tank S-105 ………..................................................... B-58

Table B-15. Safety Issue Logic for Tank S-108 ……........................................................ B-61 
Table B-16. Safety Issue Logic for Tank S-112 …........................................................... B-64

Table B-17. Safety Issue Logic for Tank SX-104 ……...................................................... B-67

Table B-18. Safety Issue Logic for Tank SX-107 ………................................................ B-70

Table B-19. Safety Issue Logic for Tank SX-109 ……….................................................. B-73

Table B-20. Safety Issue Logic for Tank SX-110 ……..................................................... B-76

Table B-21. Safety Issue Logic for Tank SX-111 ……….................................................. B-79

Table B-22. Safety Issue Logic for Tank SX-112 …....................................................... B-82

Table B-23. Safety Issue Logic for Tank SX-114 ............................................................. B-85

Table B-24. Safety Issue Logic for Tank T-101 …….......................................................... B-89

Table B-25. Safety Issue Logic for Tank T-103 ……......................................................... B-93

Table B-26. Safety Issue Logic for Tank TX-101 …......................................................... B-96

Table B-27. Safety Issue Logic for Tank TX-102 ………................................................... B-99

Table B-28. Safety Issue Logic for Tank TX-103 …..................................................... B-102

Table B-29. Safety Issue Logic for Tank TX-105 …….................................................... B-105

Table B-30. Safety Issue Logic for Tank TX-106 …….................................................. B-108

Table B-31. Safety Issue Logic for Tank TX-108 ……................................................... B-111

Table B-32. Safety Issue Logic for Tank TX-109 ……................................................. B-114

Table B-33. Safety Issue Logic for Tank TX-110 ……................................................. B-117

Table B-34. Safety Issue Logic for Tank TX-111 …..................................................... B-120

Table B-35. Safety Issue Logic for Tank TX-112 …..................................................... B-123

Table B-36. Safety Issue Logic for Tank TX-113 …....................................................... B-127

Table B-37. Safety Issue Logic for Tank TX-114 ……................................................. B-131

Table B-38. Safety Issue Logic for Tank TX-115 …..................................................... B-134

Table B-39. Safety Issue Logic for Tank TX-116 ……................................................. B-137

Table B-40. Safety Issue Logic for Tank TX-117 …….................................................... B-141 
Table B-41. Safety Issue Logic for Tank TX-118 …......................................................... B-145

Table B-42. Safety Issue Logic for Tank TY-101 ……................................................... B-150

Table B-43. Safety Issue Logic for Tank TY-102 …....................................................... B-154

Table B-44. Safety Issue Logic for Tank TY-103 ……….............................................. B-158

Table B-45. Safety Issue Logic for Tank TY-105 …….......................................................... B-161

Table B-46. Safety Issue Logic for Tank U-101 ............................................................... B-164

Table B-47. Safety Issue Logic for Tank U-104 .............................................................. B-167

Table B-48. Safety Issue Logic for Tank U-111 .......................................................... B-170 


\section{LIST OF TERMS}

$\begin{array}{ll}\text { ALARA } & \text { as low as reasonably achievable } \\ \text { BIO } & \text { Basis for Interim Operation } \\ \text { DNFSB } & \text { Defense Nuclear Facilities Safety Board } \\ \text { DOE } & \text { U.S. Department of Energy } \\ \text { DOE-RL } & \text { U.S. Department of Energy, Richland Operations Office } \\ \text { DOE-ORP } & \text { U.S. Department of Energy, Office of River Protection } \\ \text { DSC } & \text { differential scanning calorimetry } \\ \text { DST } & \text { double-shell tank } \\ \text { FSAR } & \text { Final Safety Analysis Report } \\ \text { gal } & \text { gallon } \\ \text { HSTD } & \text { Hanford Site Technical Database } \\ \text { ISM } & \text { Integrated Safety Management } \\ \text { ISMS } & \text { Integrated Safety Management System } \\ \text { LANL } & \text { Los Alamos National Laboratory } \\ \text { LFL } & \text { lower flammability limit } \\ \text { LMHC } & \text { Lockheed Martin Hanford Corporation } \\ \% & \text { percent } \\ \text { PUREX } & \text { plutonium uranium reduction and extraction } \\ \text { REDOX } & \text { reduction and oxidation } \\ \text { RPP } & \text { River Protection Project } \\ \text { RSST } & \text { Reactive Systems Screening Tool } \\ \text { SHMS } & \text { Standard Hydrogen Monitoring System } \\ \text { SST } & \text { single-shell tank } \\ \text { TGA } & \text { thermogravimetric analysis } \\ \text { TOC } & \text { total organic carbon } \\ \text { Tri-Party Agreement } & \text { Hanford Federal Facility Agreement and Consent Order } \\ \text { TSR } & \text { technical safety requirement } \\ \text { TWINS } & \text { Tank Waste Information Database System } \\ \text { TWRS } & \text { Tank Waste Remediation System } \\ \text { USQ } & \text { unreviewed safety question } \\ \text { wt \% } & \text { weight percent } \\ { }^{\circ} \text { C } & \text { degrees Celsius } \\ \text { } F & \\ & \text { degrees Fahrenheit } \\ \text { DF } & \end{array}$


HNF-4232 Rev. 0

\subsection{PURPOSE AND SCOPE}

Technical data supporting proposing closure of the DNFSB Recommendation 93-5 Implementation Plan (DOERL 1996) milestone 5.6.3.1j, "Core Sample All Tanks by 2002 " is presented in this report. Specifically, a technical basis that the remaining 45 incompletely sampled tanks do not need to be sampled to determine waste content important to resolve safety issues and near term disposal process requirements.

Section 2.0 provides background to the initial DNFSB concerns. Section 3.0 discusses how the characterization needs were met for identified needs. Section 3.1 contains a summary of the characterization information gathered to support closure of specific safety issues and how the data needs were met to ensure adequate interim storage controls for all tanks. Section 3.2 addresses the recent changes in retrieval and disposal data needs, and how those data needs are being met.

Section 4.0 addresses the process for integrating future characterization data needs, particularly to support waste retrieval and disposal, to assure that resources are being focused to obtain the data in a technically based priority. This section also summarizes improvements to the infrastructure of the characterization program to ensure timely collection of data.

Appendix A provides the list of tanks that have been satisfactorily safety screened to date and the logic used to determine whether sufficient material and analyses were obtained to consider the tank sampled per this milestone. The process used to apply the logic is also described. It also presents summary information on the results from the chemical analyses that have been performed.

Appendix B presents the logic and approach used to evaluate the remaining 45 singleshell tanks that had not been core sampled by October 1, 1999, or where insufficient sample material was obtained to perform safety screening. It provides the general information used in this assessment as well as tank specific evaluations. This assessment provides the basis for the determination that near term core sampling of the remaining 45 tanks is not necessary for safe interim storage.

\subsection{BACKGROUND}

On July 19, 1993, the DNFSB transmitted Recommendation 93-5 on the Hanford Waste Tank Characterization Studies for the U.S. Department of Energy (DOE) (Conway 1993). The Recommendation was accepted on August 31, 1993 (O'Leary 1993).

Recommendation 93-5 noted that there was insufficient tank waste technical information to ensure Hanford wastes could be safely stored, and future disposal data requirements could be met. At the time the recommendation was issued, gaps existed in the Safety Basis for the Tanks Farms. Identified safety issues related to inadequate safety analyses and high levels of uncertainty regarding the risks to workers, the public, and the environment. Potential radioactive and toxic chemical releases from propagating 
exothermic chemical reactions, criticalities, or high heat induced tank structural failures had not been adequately evaluated. Data generated by sampling was inconsistent and sampling techniques and analytical methods were inadequate. When Recommendation 93-5 was issued, controls were only placed on tanks suspected to involve safety issues. However, the existing characterization information was not adequate to identify tanks with safety issues.

Prior to the formation of the Tank Waste Characterization Project in February 1995, characterization performance in meeting the 93-5 Implementation Plan was poor. Information needs had not been systematically determined, sampling truck availability was less than $16 \%$, sample recovery was poor, and analytical methods and reports were inadequate. Conduct of Operations deficiencies resulted in repeated work stoppages and equipment was not able to obtain core samples from other than relatively soft wastes.

As a result of the revision of the Department's Implementation Plan for DNFSB Recommendation 93-5, improvements in characterization operations and management were defined and implemented. Today, nearly $75 \%$ of the tanks have been core sampled. Information needs have been systematically identified using systems engineering techniques. Sampling equipment availability and sample recovery has improved. For example, in fiscal year 1998 thirty core samples were obtained, exceeding the goal for the fiscal year. Equipment have been developed, tested, and placed in service to obtain samples from the various types of tank wastes. Analytical methods have improved and laboratory analysis turnaround times have decreased. The data from these samples is broadly available in both electronic and hardcopy form. More detailed documentation and information regarding tank characterization can be found in the references of this document, or on the Internet at http://twins.pnl.gov.

No additional characterization data from the 39 unsampled and 6 incompletely sampled tanks are needed to resolve safety issues, close USQs, or evaluate safety controls. In addition, the process to identify programmatic information needs, prioritize the needs, obtain the associated samples, and conduct the laboratory analyses has been institutionalized and is repeated annually. This process has been successfully repeated for the last three years. All of the 45 remaining tanks will be sampled on a schedule to support specific retrieval and disposal needs.

This report explains how the information needs have been satisfied and provides the technical justification to propose closure of Recommendation 93-5 Implementation Plan milestone 5.6.3.1j. 
HNF-4232 Rev. 0

\subsection{CHARACTERIZATION DATA NEEDS MET}

In the Department's analysis of Recommendation 93-5 (DOE-RL 1996), it was concluded that two general safety issues existed. There was insufficient tank waste technical information and the pace of acquiring additional information was too slow to ensure that:

- wastes could be safely stored and that operations could be conducted safely, and

- future disposal program data requirements could be met.

Section 3.1 discusses how characterization information obtained from tank sampling has been used to demonstrate the capability to safely store waste. Section 3.2 discusses how near term disposal needs have been satisfied. Section 4.0 describes the institutionalized process to support emerging characterization data needs.

\subsection{CHARACTERIZATION FOR SAFE STORAGE}

The major safety issues related to tank contents included ferrocyanide, organic complexants, organic solvents, flammable gases, high heat, and criticality. The following sections describe the current status, controls, and approach to issue resolution for the major safety issues. Also, data obtained in safety screening and in historical modeling to support authorization basis upgrades are discussed.

\subsubsection{Ferrocyanide Safety Iss ue}

Ferrocyanide was used to scavenge cesium from tank waste liquids. Ferrocyanide, in the presence of oxidizing material such as sodium nitrate, can react exothermically if heated to sufficiently high temperatures or subjected to a credible initiator of sufficient energy. Under certain conditions, reactions of this material can result in explosive energy releases. Because the scavenging process precipitated ferrocyanide from solutions containing nitrate, an intimate mixture of ferrocyanide and nitrate was established in some regions of the ferrocyanide tanks. The use of ferrocyanide at the Hanford Site is well documented, specific to a set of tanks, and associated with a known waste processing period. This information was used to compile a definitive list of tanks and analytical measurements associated with the issue. The information presented in Postma et al. (1994) was used to close the USQ. Closure of the USQ is documented in the letter from T. R. Sheridan (1994).

The ferrocyanide safety issue was the first major safety issue at Hanford to be closed. The methodology used for closing this issue served as a model for resolving many of the other safety concerns. It demonstrated the best approach to resolve a safety issue is a combined application of theory, laboratory simulations, record reviews, and laboratory analyses on tank waste samples. In this case, the approach included: 
- Using process records to identify tanks that contained ferrocyanide (18 tanks identified);

- Developing the criteria for safe storage;

- Performing theoretical and simulant studies to demonstrate criteria adequacy;

- Developing models for ferrocyanide decomposition (aging of the material to less energetic states);

- Identifying and characterizing bounding tanks (tanks with the greatest potential hazard) to confirm ferrocyanide concentrations; and

- Updating the analyses and closing the issue.

The waste in ten of the eighteen ferrocyanide tanks was sampled and analyzed. The analytical results are presented in Table 3-1. Since this analysis was completed, three additional ferrocyanide waste tanks have been sampled and analyzed. Their findings agree with previous sample data.

Table 3-1. Results of Ferrocyanide Waste Analyses

\begin{tabular}{|c|c|c|c|}
\hline Tank & $\begin{array}{c}\text { Original } \\
\text { Ferrocyanide } \\
\text { (wt \%) }\end{array}$ & $\begin{array}{c}\text { Measured } \\
\text { Ferrocyanide } \\
\text { (wt \%) }\end{array}$ & $\begin{array}{c}\text { Extent of Aging } \\
\text { (\%) }\end{array}$ \\
\hline BY-104 & $4.0-8.3$ & $<0.01$ & $99+$ \\
\hline BY-106 & $5.2-8.3$ & $<0.01$ & $99+$ \\
\hline BY-108 & $5.0-8.3$ & $0.01-0.5$ & $90-99+$ \\
\hline BY-110 & $5.7-8.3$ & $0.00-0.4$ & $98-99+$ \\
\hline C-108 & $10.4-22.6$ & $0.3-1.1 .0$ & $89-99$ \\
\hline C-109 & $14.0-22.6$ & $0.7-1.6$ & $89-97$ \\
\hline C-111 & $8.9-22.6$ & $0.02-0.05$ & $99+$ \\
\hline C-112 & $16.1 .0-25.5$ & $1.2-1.5$ & $91-95$ \\
\hline T-107 & $6.3-8.3$ & $0.00-0.02$ & $99+$ \\
\hline TY-104 & $1.6-10.7$ & $0.00-0.03$ & $98-99+$ \\
\hline
\end{tabular}

Testing of simulants and the tank waste from the ten tanks listed in Table 3.1 confirmed:

- A minimum of eight weight percent of ferrocyanide is required for propagation;

- Ferrocyanide degrades to ammonia and formate due to high $\mathrm{pH}$ and radiation in the tanks; and

- Moisture levels greater than $17 \%$ prevent reaction regardless of fuel quantity.

The ten tanks sampled were selected to evaluate this safety issue because they had process histories that were the least conducive for aging and the highest concentrations 
of ferrocyanide based on historical records (Meacham 1996). The analytical results demonstrated that the ferrocyanide had aged to concentrations more than a factor of 10 below original concentrations and 10 to 40 times lower than what is needed for sustaining a propagating reaction. In addition, the nickel analyses confirmed the tanks previously contained sodium nickel ferrocyanide. This finding confirmed historical records correctly identified the tanks that had received the ferrocyanide.

Based on the characterization data obtained, the topical report (Meacham 1996) supporting resolution of the safety issue and closure of DNFSB Recommendation 90-7 was completed in July 1996, and the safety issue was closed in December 1996.

\subsubsection{Organic Solvents Safety Issue}

Various separation processes involving organic solvents were used at the Hanford Site. Some of these solvents were sent to the storage tanks (Sederburg and Reddick 1994). Given a sufficient ignition source, there are two potential hazards associated with organic solvent: (1) an organic solvent pool fire; and (2) ignition of organic solvent entrained in waste solids (a wick fire).

The approach to resolution of the organic solvent safety issue has matured since the implementation plan was revised. The original accident scenario assumed catastrophic failure of the tank dome during an organic solvent burn if a single-shell tank (SST) did not have an adequate vent path. Failure of the dome led to large radiological consequences, and calculations showed that the solvent pool area would have to be larger than one square meter to create enough pressure to collapse the tank dome. The original approach required vapor sampling to identify tanks containing significant quantities (i.e., greater than a one square meter pool) of organic solvent, and then providing an adequate vent path to release the pressure from hypothetical solvent fires.

Headspace vapor samples were taken in 110 tanks. Of these, 13 tanks were found to have the potential for a solvent surface puddle greater than one square meter. Three of the 13 tanks were core sampled. These core samples confirmed solvents were present and the vapor measurements accurately identified them (Cowley et al. 1998).

The solvents contain a mixture of primarily normal paraffin hydrocarbons (NPH) and tributyl phosphate (TBP). Small amounts of other solvents and diluents were used but their contribution to the solvent issue is minor. Ignition of a pool fire requires significant heat; therefore, a high-energy igniter would be required to start a fire. Because highenergy igniters are not likely to be introduced into waste tanks, solvent pool fires are low probability accidents. The organic solvent hazard can be safely managed through the use of controls for preventing vehicle fuel fires and for limiting the use of flame cutting in areas where hot metal can fall on the waste surface. The required controls are given in the Tank Waste Remediation System Technical Safety Requirements (Noorani 1997b).

Tank structural integrity was reexamined in 1996 as part of the BIO (Noorani 1997a). Analyses showed that the tank dome would not fail catastrophically under the pressures 
developed during an organic solvent fire. Instead, the dome would develop cracks and fissures to release the internal pressure but would not collapse. The new analysis was accepted and incorporated into the BIO.

Existing controls will continue to be required for this safety issue and additional tank characterization will not change that requirement. No additional core sampling is required to resolve this safety issue.

\subsubsection{Organic Complexants Sa fety Issue}

Organic complexants were sent to the high level waste tanks during the defense mission at the Hanford Site. These compounds and their decomposition products have the potential to react exothermically when combined with nitrate/nitrite oxidizer. The organic complexant hazard is represented by two distinct types of reactions:

(1) spontaneous chemical runaway (self-heating) reactions through the waste mass, and

(2) propagating chemical reactions typified by a passing reaction front stimulated by a single point ignition.

The consequences of such reactions are similar to those described in the discussion of the ferrocyanide issue. However, unlike ferrocyanide, organic complexants were used in many of the chemical separation processes and had the potential to be found in many of the tanks. Because of the pervasive use of organic complexants, ignition controls were applied to all 177 tanks.

A systematic approach was applied in addressing the organic complexant issue. This approach was similar to the approach used to address the ferrocyanide issue. Tank wastes were initially screcned by reviewing their process history. These included:

- Applying ignition source controls to all tanks;

- Developing analytical models to predict waste behavior;

- Conducting tests on tank waste to confirm,

- Total organic carbon (TOC) limits are conservative,

- Organics are water soluble,

- Organics age to lower energy products with radiation and high $\mathrm{pH}$;

- Demonstrating bounding tanks (tanks with the greatest potential hazard) are representative and broadly applicable; and

- Updating analyses and closing the USQ.

Analysis indicates that (with the exception of tank C-106 which requires cooling water additions) spontaneous conditions leading to a chemical runaway reaction throughout the waste mass are highly unlikely under current storage conditions (Fauske 1996). This conclusion is reached by evaluating the energy balance for storage tanks. For a spontaneous chemical runaway reaction to occur, the radionuclide and chemical heating 
rate must exceed the tank cooling rate (Gygax 1990). This condition can be evaluated by comparing the characteristic time of cooling (i.e., the time required to reach a new equilibrium temperature following an instantaneous change in the heating rate) with the waste storage time.

Based on methods derived from the energy balance, calculations (Meacham et al. 1998) indicate that the characteristic time of cooling ranges from a few hours to 3.1 years. Some waste has been stored for more than 40 years, and there have been no transfers of waste into the SSTs for about 15 years. Several characteristic times of cooling have passed over the last 15 years of storage; consequently, bulk runaway reactions are highly unlikely to be a hazard under current storage conditions. In addition, no credible mechanisms to increase tank temperatures to chemical runaway reaction levels have been identified. Drying the wastes can decrease the thermal conductivity; however, this decrease would not be sufficient to lead to an adiabatic runaway reaction. Post interim stabilization waste temperatures (in all 119 interim stabilized tanks) have continued to decline consistent with radioactive decay rates.

Table 3-2 presents the summary of SSTs grouped by fuel concentration (based on process records) of organic complexants, the main type of waste (saltcake or sludge), and whether the waste is wet or dry. Eleven tanks were categorized as "special cases," because they had unique process histories; all were sampled and analyzed for TOC and water. In Table 3-2, the first number is the number of tanks sampled while the second number is the number of tanks in the subcategory. For example, seven of seven tanks, categorized as high complexant, saltcake, and dry, were sampled and screened for TOC and water. Of the 149 SSTs, 113 were sampled, including all high complexant category tanks. Analytical results confirmed that the groupings were correct, and no tanks were found that should be in a higher category.

Conditions that could support propagation were examined theoretically. The minimum TOC concentration necessary to sustain propagation is 4.5 weight $\%$ (dry basis). For TOC concentrations between 4.5 and 7.9 weight $\%$, the theoretical water concentration necessary to prevent propagation varies linearly from 0 to 20 weight $\%$. Above 20 weight $\%$, the fuel-water linear relationship no longer holds because the mixture becomes liquid continuous and propagation is not possible at any TOC concentration.

Propagation testing confirmed that the theoretical criterion was conservative (Meacham et al. 1998). Waste tank sample data and combustion indicate that propagation is not possible in the SST waste. Waste samples would not propagate even when the water was removed by drying at $105^{\circ} \mathrm{C}$. Fuel (organic complexants) was added to the two tank waste samples with highest TOC and energetic measurements (AX-102 and U-106) to determine how much additional fuel would be required before a dried waste sample would propagate. The dried $\mathrm{AX}-102$ waste sample required $31 \%$ more fuel, and the dried U-106 waste sample required $42 \%$ more fuel to support propagation.

The dry conditions used in the propagation tests cannot occur under tank waste storage conditions. The wastes contain hygroscopic salts, e.g., sodium hydroxide, that retain a significant quantity of water. Experiments on waste samples and modeling indicate that 
the organic complexant wastes will retain significant water during interim storage. Tank U-106 waste will retain more than 20 weight \% water, and theory shows that 20 weight $\%$ water prevented propagation at all TOC concentrations. Tank AX-102 waste will retain approximately 17 weight $\%$ water. This amount of water increases the theoretical requirement for propagation to 7.4 weight $\%$ TOC. This is twice as much as the highest measured TOC concentration in AX-102 (3.7 weight \%) (Meacham et al. 1998).

Table 3-2. Single-Shell Tank Organic Complexant Tank Groupings

\begin{tabular}{|l|c|c|c|c|}
\hline \multirow{2}{*}{ Complexant Load } & \multicolumn{2}{|c|}{ Dry } & \multicolumn{2}{c|}{ Wet } \\
\cline { 2 - 5 } & Saltcake & Sludge & Saltcake & Sludge \\
\hline High Complexant & $7 / 7^{*}$ & $3 / 3$ & $7 / 7$ & $4 / 4$ \\
\hline Medium Complexant & $5 / 6$ & $1 / 1$ & $6 / 9$ & $1 / 1$ \\
\hline Low Complexant & $23 / 43$ & $17 / 23$ & $5 / 5$ & $16 / 18$ \\
\hline No Complexant & $1 / 3$ & $5 / 7$ & $0 / 0$ & $1 / 1$ \\
\hline Special Cases & & \multicolumn{2}{|c}{$11 / 11$} \\
\hline
\end{tabular}

Number of tanks sampled/Number of tanks in the category

Both bulk runaway and propagation are ruled out for double-shell tanks (DSTs). According to Meacham et al. (1998), bulk runaway is not possible in the DSTs because they contain predominantly aqueous wastes. Analytical data and calculations show the available latent heat of water vaporization exceeds the theoretical chemical energy potential for these tanks. Likewise, propagation is not possible in the DSTs because they contain significant water. Theoretical analyses and combustion testing show that propagation is not possible when the water concentration exceeds 20 weight $\%$. Sample characterization data show the water in the DSTs is greater than 20 weight \% (Meacham et al. 1998).

Characterization data confirmed phenomena that provide additional safety margin between tank waste conditions and the conditions that support propagation. Organic speciation of waste samples showed that the organic complexants remain soluble. Soluble complexants in SSTs are transferred to DSTs during interim stabilization. Furthermore, radiolysis and high temperatures oxidize the complexants to low energy products (e.g., formate, oxalate, and carbonate) that cannot support propagation. 
HNF-4232 Rev. 0

\subsubsection{Flammable Gas}

Radiolytic and chemical decomposition reactions occurring in tank waste produce flammable gases (principally hydrogen and ammonia) and an oxidizer (nitrous oxide). The hazard is related to two phenomena: (1) slow, steady accumulation of flammable gases in the tank headspace, and (2) episodic releases of flammable gases at comparatively high rates and concentrations.

When Recommendation 93-5 was issued, the gas generation, retention, and release mechanisms in the tank environment were not well quantified. The potential consequences associated with an ignition were not understood. Ignition controls were initially applied to only selected tanks. The worst of the flammable gas tanks was SY-101. In the past, this tank had gas releases that exceeded $25 \%$ of the lower flammability limit (LFL), and, on at least two occasions, gas releases exceeded $100 \%$ of the LFL.

The approach for resolution of the flammable gas issue included:

- Defining data needs for evaluation of the behavior of the tanks,

- Developing and implementing equipment/instrumentation to provide requisite data,

- Sampling of selected tanks,

- Developing behavior models to support closure of the USQ and to support the development of controls,

- Developing mitigation concepts and implementation, as appropriate,

- Closing the flammable gas USQ,

- Providing the administrative basis for resolving the safety issue, and

- Providing the technical and administrative path for removing tanks from the Watch List.

In 1996, controls were applied to all tanks as part of the initial resolution strategy. Parallel to applying controls, analytical models were developed to predict waste behavior. Experimental and actual tank sampling results were used to verify the models and close the USQ (DOE-RL 1998). The USQ evaluation (DOE-RL 1998) indicated that the hazard would remain until the waste is removed, and the flammable gas work controls will be maintained until waste is retrieved and treated.

Tanks, with the exception of SY-101, were placed into one of three groupings. The first group was comprised of tanks that exhibit large episodic releases. The second group of tanks could exhibit large releases only if induced (e.g., a large intrusive event would be required to cause a large gas release). Remaining SSTs (107) were placed into the final 
group, which could exhibit small, induced releases. Table 3-3 summarizes the number of tanks in each of the groupings. Tank SY-101, has a separate authorization basis and controls.

Table 3-3 Flammable Gas Tank Groupings

\begin{tabular}{|l|c|c|}
\hline \multicolumn{1}{|c|}{ Attributes } & Facility Group & Number of Tanks \\
\hline Large Episodic Releases & Group 1 & 5 DSTs \\
\hline Large Releases Only if Induced & Group 2 & $\begin{array}{l}\text { 42 SSTs } \\
\text { 22 DSTs }\end{array}$ \\
\hline All Remaining SSTs & Group 3 & 107 SSTs \\
\hline
\end{tabular}

Note: SY-101 has a separate Authorization Basis and is not included in the facility groups.

Since 1993, as part of the characterization program, specialized equipment was developed and deployed to support resolution of this safety issue. These included:

- Hydrogen monitoring cabinets [Standard Hydrogen Monitoring System (SHMS) and Gas Characterization Systems (GCS)] for continuous gas monitoring;

- Retained gas samplers (both the equipment to take the sample and to analyze it in the laboratory);

- Void Fraction Instruments (to measure voids in the waste); and

- Viscometer (measurement of fluid flow properties such as viscosity and yield strength).

Table 3-4 displays the characterization activities associated with tanks in each of the facility groups. The number of SSTs and DSTs in each facility group, where the characterization activity was performed or the equipment was deployed, is shown in comparison with the total number of tanks in that facility group.

Table 3-4. Number of Tanks Where Flammable Gas Equipment Was Installed or Activity Performed (2 Sheets)

\begin{tabular}{|l|c|c|c|}
\hline Activity or Equipment & $\begin{array}{c}\text { Facility } \\
\text { Group }\end{array}$ & $\begin{array}{c}\text { Number of } \\
\text { Single-Shell Tanks }\end{array}$ & $\begin{array}{c}\text { Number of } \\
\text { Double-Shell } \\
\text { Tanks }\end{array}$ \\
\hline Standard Hydrogen Monitoring System (SHMS) & 1 & N/A & $\begin{array}{c}5 / 5 \\
\text { and SY-101 }\end{array}$ \\
\hline Standard Hydrogen Monitoring System (SHMS) & 2 & $22 / 42$ & $6 / 22$ \\
\hline Standard Hydrogen Monitoring System (SHMS) & 3 & $6 / 107$ & N/A \\
\hline
\end{tabular}


Table 3-4. Number of Tanks Where Flammable Gas Equipment Was Installed or Activity Performed (2 Sheets)

\begin{tabular}{|l|c|c|c|}
\hline \multicolumn{1}{|c|}{ Activity or Equipment } & $\begin{array}{c}\text { Facility } \\
\text { Group }\end{array}$ & $\begin{array}{c}\text { Number of } \\
\text { Single-Shell Tanks }\end{array}$ & $\begin{array}{c}\text { Number of } \\
\text { Double-Shell } \\
\text { Tanks }\end{array}$ \\
\hline Gas Characterization System & 1 & N/A & $3 / 5$ \\
\hline Vapor Gas Sample & 2 and 3 & $134 / 149$ & $7 / 22$ \\
\hline Ventilation Rate (Tracer Gas) & 2 and 3 & $13 / 149$ & $0 / 22$ \\
\hline Retained Gas Sample & 1 & N/A & $\begin{array}{c}4 / 5 \\
\text { and SY- } 101\end{array}$ \\
\hline Retained Gas Sample & 2 & $8 / 42$ & N/A \\
\hline Retained Gas Sample & 3 & $1 / 107$ & N/A \\
\hline Void Fraction Instrument & 1 & N/A & and SY-101 \\
\hline Viscometer & 1 & N/A & $\begin{array}{c}5 / 5 \\
\text { and SY-101 }\end{array}$ \\
\hline Laboratory Tests on Gas Generation & 1 & N/A & $3 / 5$ \\
and SY-101
\end{tabular}

Number of tanks sampled/Number of tanks in the Facility Group

$\mathrm{N} / \mathrm{A}=$ not applicable

As can be seen from Table 3-4, the Facility Group 1 tanks, which have been identified as the highest hazard, have the greatest level of monitoring and characterization. The Facility Group 2 tanks received a lower level of investigation, while the Facility Group 3 tanks received the lowest level of flammable gas evaluation. The results of the characterization have been consistent with the expected hazard for the three facility groups. Characterization work for the flammable gas issue has been completed.

Characterization results have been used to ensure that the tanks were placed into the correct facility group. Detailed sampling and data monitoring resulted in only two tanks being moved into a different facility group. One tank was moved from Facility Group 2 to Facility Group 3 and one from Facility Group 3 to Facility Group 2. The data used to group the tanks supports the grouping of the unsampled tanks and the established flammable gas controls.

Flammable gas controls have been established (Noorani 1999) for three separate zones: the waste intrusive zone (i.e., the tank waste), the in-tank zone (i.e., in the headspace), and the ex-tank zone (near but external to the tank). Examples of the ex-tank zone are near an open riser, near a breather filter, etc. Key focus areas were ventilation, monitoring, and qualification of equipment (to reduce or remove the concern of ignition sources). Though much of the controls are identical, the level of review and number of controls are greater for the tanks in Facility Groups 1 and 2. 
HNF-4232 Rev. 0

\subsubsection{High-Heat Tank}

Several SSTs received high concentrations of strontium and cesium. High heating rates in the SSTs could lead to accelerated degradation of the tanks and result in release of radioactive materials to the environment. Furthermore, an accident scenario in the BIO describes a situation that can result in a rapid pressurization of the dome space leading to an aerosol release to the environment. This condition is referred to as a tank bump. Tank temperature measurements and thermal modeling were used to identify tanks that may have high heat loads.

Single-shell tank C-106 is the only single-wall tank that requires both water additions and active ventilation to maintain adequate cooling. Hence, it is the only tank involved in this safety issue on a watch list.

The strategy for tank C-106 is straightforward: remove sufficient heat generating isotopes (cesium and strontium) so future water additions will not be required. Characterization data needed for this safety issue focused on waste compatibility and support for retrieval of the waste (e.g., physical waste parameters such as specific gravity and solubility). Sluicing the waste from tank C-106 into a DST designed for the additional heat load started in November 1998. Removal of sufficient material (approximately 2 feet of material (Ogden et al. 1998)) from tank C-106 to allow cessation of water additions is scheduled for fiscal year 1999. Waste samples are obtained following the transfer of each batch of sluiced waste to ensure continued waste compatibility and to support heat transfer calculations.

There are several tanks with heat loads that require specific controls in the Technical Safety Requirements (Noorani 1997b). These tanks require active ventilation to maintain acceptable temperatures. Core sampling will not affect the need for maintaining tank ventilation. Temperature measurements and ventilation flow rates are the key control parameters to maintain the tanks in a safe condition per the limits established in the BIO.

\subsubsection{Criticality Safety}

The criticality safety issue involves the lack of definitive knowledge of the tank waste fissile material and neutron absorber inventory and distribution.

The initial approach was to obtain definitive knowledge of the fissile and absorber material inventory and distribution in the tanks. This would be accomplished by obtaining additional empirical data (tank waste characterization). As of October 1, 1999, 132 of the 177 Hanford Site waste tanks have been characterized for safety issues, including criticality safety. Analysis of the distribution and inventory of the tank waste fissile material was performed using the characterization results (Braun et al. 1994; Serne et al. 1996; and Bratzel et al. 1996). The evaluation and conclusions concerning the 
fissile material and absorber content of the waste being stored in the Hanford Site tanks are discussed in the USQ closure report (Braun et al. 1994) and the technical basis reports (Serne et al. 1996 and Bratzel et al. 1996).

A refined approach was developed in 1996 by an expert criticality review team in support of the BIO development. This approach, defined in the following paragraph, was more comprehensive than the approach of obtaining additional empirical data. From this refined approach, a technical basis report was developed (Bratzel et al. 1996). The technical basis report discussed the nuclear criticality technical basis for the BIO (Noorani 1999) as well as the basis for resolution of the technical portion of the Nuclear Criticality Safety Issue.

The chemical and physical phenomena and mechanisms were evaluated to ensure present waste storage conditions did not affect the form and distribution of fissile or neutron absorber material. This evaluation was necessary to ensure the tank waste would remain subcritical. The scope of the technical basis report provided a baseline for understanding the chemical and physical phenomena and mechanisms in relationship to operational activities performed within the tank farms. The technical basis examined the neutronics of the waste tank system, chemical and hydraulic factors related to initial deposition of waste in the tanks, aging of the wastes, and behavior of the wastes under established operating conditions. The topical report discusses the basis to show that:

- Fissile material in the waste tanks is distributed at subcritical concentrations.

- No physical or chemical phenomena or mechanisms were identified that could concentrate fissile material at sufficient quantities or concentrations to result in an accidental nuclear criticality.

Therefore, the technical basis concludes that, under current plutonium inventories and operating conditions, a nuclear criticality accident is incredible in any of the Hanford Site SSTs, DSTs, or double-contained receiver tanks.

Administrative Control (AC) 5.7 contained in the authorization basis (Noorani 1999b), implements the controls that ensure waste received is consistent with the authorization basis.

\subsubsection{Improvements to Overa Il Tank Knowledge}

In addition to the six safety issues discussed earlier in this section, there was a general concern that insufficient data existed to ensure that proper controls were in place for each tank. In 1993, there was not a uniform set of tank controls, and the controls in place were not based on actual tank characterization data. This was apparent in late 1993 when additional characterization data was evaluated. The 1993 evaluation found that several tanks had higher energetics in the waste matrix than was indicated by a review of historical information. This resulted in several tanks being added to the Wyden Bill Watch List (Public Law 101-510 1990) which had special safety controls applied to them. 
It was clear that rapid screening and a better overall knowledge of tank contents was required to support necessary updates to the tank interim storage authorization basis. The strategy to address this deficiency was to capture and analyze process and historical information in parallel with implementing a safety screening process. This led to a more usable record of the wastes that were produced at various facilities on site and the transfers between tanks. Data obtained from safety screening and the upgraded historical modeling were used to ensure that tanks were categorized appropriately and that no additional issues were overlooked.

\subsubsection{Historical Data Integration}

A review, organization, and consolidation of process and waste transfer information was completed by Los Alamos National Laboratory (LANL) and Hanford technical personnel to support modeling past waste transfers. The resulting set of documentation and software provided a tool for increasing general understanding of the waste (Agnew et al. 1997a and Agnew et al. 1997b). The transaction records were reviewed and reconciled. Resolution of unexplained level changes was closed using an established set of rules documented in Agnew et al. (1997a). Resolution of these changes was performed only for discrepancies in excess of 50,000 gal. The software code allows input changes and output reporting as a function of time. This enables specific questions about modeling inputs, assumptions, or outputs to be answered. The Hanford Defined Waste model (Agnew et al. 1997a) allows sensitivity analyses or experiments to be run. This provides a way to examine tank waste inventories without sampling. This effort also documented several limits and constraints involving the use of historical data to resolve problems or issues.

The historical information has proven useful in providing an understanding of the uncertainties and the sensitivity to assumptions involved in interpreting both the sampling data and the historical data. Historical data are qualitative in nature. This type of information can be used to categorize tanks and to infer characteristics or observations that might be expected. The historical information lacks the necessary quantitative data to evaluate safety issues, establish proper controls, and address disposal and regulatory requirements and should not be used for individual analyte concentrations on a particular tank. However, the historical model, which is based on transfer records can be used to screen tanks for USQs, establish global controls, provide input to support closure of safety issues, and provide data for disposal requirements when it is used with a comprehensive analytical database.

Based on the historical data, a number of high priority tanks were selected for early characterization. These tanks were expected to contain relatively higher amounts of key chemicals or combinations of chemicals that may cause concern. The high priority tanks identified in Recommendation 93-5 Implementation Plan (DOE-RL 1996) were selected using these general guidelines. This set of tanks was reasonably sized and included a number of different safety and disposal issues across a range of waste types. Analysis of the waste from these tanks provided specific information regarding each of the phenomenon-related and composition-related issues identified in the Implementation 
Plan. This identification and selection process is more completely described in Brown et al. (1995). Brown et al. (1998b) presents the most recent update of this process.

Table 3-5 presents a summary of the sampling of tanks identified in Recommendation 93-5 Implementation Plan (DOE-RL 1996). Twenty-six of the 28 high priority tanks identified in the Implementation Plan have been sampled and analyzed.

Table 3-5. Tanks Sampled for Each High Priority Tank Question

\begin{tabular}{|l|c|c|c|}
\hline $\begin{array}{c}\text { Focused Question from } \\
\text { High Priority Tank Report }\end{array}$ & $\begin{array}{c}\text { High Priority } \\
\text { Tanks Sampled } \\
\text { for Each Issue }\end{array}$ & $\begin{array}{c}\text { Other Tanks } \\
\text { Sampled within } \\
\text { Scope of the Issue }\end{array}$ & $\begin{array}{c}\text { Total Tanks } \\
\text { Sampled for Each } \\
\text { Issue }\end{array}$ \\
\hline Ferrocyanide Aging & 4 & 6 & 10 \\
\hline Complexant Aging & 14 & 18 & 32 \\
\hline Complexant Solubility & 16 & 50 & 66 \\
\hline Organic Solvent Location & 20 & 62 & 82 \\
\hline Organic Solvents Composition & 2 & 3 & 5 \\
\hline Moisture Retention & 26 & 107 & 132 \\
\hline Energetics Behavior & 26 & 107 & 132 \\
\hline Retained Gas & 6 & 3 & 9 \\
\hline
\end{tabular}

Efforts by the Department to develop a standard best-basis tank waste inventory, with access through the Tank Waste Information Network System (TWINS) (LMHC 1999), improved data accessibility and provides concise data summaries with detailed backup. Waste wash/leach data are presented in TWINS. The combination of the best-basis inventory data and the sludge washing tests resulted in the issuance of reports summarizing the testing of enhanced sludge washing and related tank waste pretreatment methods for samples of tank waste sludge (Temer and Villarreal 1997, Lumetta et al. 1997, and Colton et al. 1995).

\subsubsection{Safety Screening}

The process of safety screening is one of the principal functions of the sampling and analysis effort utilized to satisfy Recommendation 93-5. Obtaining enough of the condensed phase material to meet the requirements for safety screening was determined to be the minimum requirement for stating that a tank was core sampled (Reynolds et al. 1999). The series of analyses required for safety screening (Dukelow et al.1995) provides the information needed to determine a tank's safety status. There are three measurements taken in the condensed phase, with additional tests performed if certain thresholds are exceeded. They are energy content as measured by differential scanning calorimetry (DSC), water content as measured by thermogravimetric analysis (TGA), and criticality potential as measured by total alpha content. These measurements provide information with regard to potential hazardous conditions, such as criticality and chemical reactivity. They are sufficient to satisfactorily establish a tank's safety status 
and the appropriate controls needed to operate and maintain the tank safely. In addition, vapor sampling in the tank dome space is used to determine if there are toxic, noxious, or combustible gases present.

Data in Appendix A presents the summary charts from the statistical evaluation of the results from the safety screening analyses obtained to date. The data show the bulk of the tanks fall below the thresholds established for further evaluation, and all data are less than the values used for the BIO safety analyses to establish technical safety requirement (TSR) controls.

Appendix B presents the evaluation of the 45 unsampled or incompletely sampled tanks. This evaluation demonstrates that sufficient related information exists about the 45 tanks to negate the need for near term safety screening characterization and ensures existing TSR controls are adequate.

\subsubsection{Updates To Safety Basis}

Almost 30 separate safety analysis documents covering the tank farms existed in 1993. Because of the regulatory and operational status of the tank farms, it was not always clear which of these documents (and their associated requirements) applied to which tank. These documents had developed over 20 years of operation, and sometimes conflicted with each other. Furthermore, because of the change in the mission and evolving regulatory environment, there was no assurance that the documentation in place was appropriate for planned work.

Adequate controls on field activities and tank farm operations were not in place to deal with the newly emerging safety issues. In addition, the controls were not uniformly applied. In many cases, the controls were not based on actual data and were often so prescriptive they precluded performing or completing safety related work in the tank farms. Safety controls derived from the analyses were selectively applied to tanks based characterization data existing in 1993. However, the available data in 1993 were not sufficient to justify selective controls. In addition, with the deficiencies in the safety documentation, there was no assurance in 1993 that any activity was satisfactorily defined and controlled by the safety envelope.

TWRS has implemented a BIO as the authorization basis (Noorani 1999). Based on the hazards, postulated accidents were analyzed and controls implemented to protect the public and onsite workers. Details for hazards resulting from the waste form came from the analyses developed to support the safety issue resolution work described in Section 3.1. In addition, information came from the historical reviews performed by LANL and others, and safety screening results (see Section 3.1.7).

Operations under the BIO have become more streamlined. Appropriate tools and training for workers have been developed. Specific controls governing work in the tank farms that cover sparking and ignition sources have been developed and implemented.

Flammable gas watch list tanks have been successfully sampled since the implementation 
of the BIO. In addition, on April 15, 1999, the final safety analysis report (FSAR) was approved (DOE-ORP 1999). Work has begun to implement this FSAR.

A program based on Integrated Safety Management System (ISMS) principles exists to ensure the authorization basis calculations are either not affected or updated as new characterization data are obtained. One element is the "flagging" of data by the analytical laboratory. The laboratory alerts RPP operations and engineering any time pre-set limits on specific measurements are exceeded. Operations on the involved tank are suspended while engineering evaluates the new information to determine if it affects the analyzed safety envelope. If there are no new impacts caused by the new data, operations restrictions are removed. If there is some question about the new data, a formal USQ evaluation occurs to determine the next required action.

\subsection{RETRIEVAL AND DISPOSAL PLANNING}

When DNFSB Recommendation 93-5 was issued, the disposal planning strategy was to build one large plant that could vitrify the waste from all 177 tanks. The strategy required characterization data to meet regulatory data needs, process data needs, and tank waste physical properties. Few tanks were being sampled, and the regulatory data needs were not focused on technical issues related to safe storage and disposal of waste. The designers for retrieval and disposal facilities had to rely on historical records and estimates, which had known limitations.

\subsubsection{Evolution of the Disposal Program}

Since 1993, the strategy has evolved to a two-phase approach with a demonstration plant to initially address a limited number of tanks. This will be followed with a scale up to support the remainder of the tanks. This requires the Department to primarily focus on the near term characterization needs for disposal of a limited number of tanks. Plans are to commence hot start of the pretreatment and vitrification facilities between fiscal years 2006 and 2008.

\subsubsection{Present Data Needs}

The new strategy for the disposal of tank waste includes disposing of the waste in phases. This strategy focused the near term retrieval and disposal characterization needs on selecting a number of tanks to be used as candidate feed sources for "Phase 1" disposal and a longer-term strategy for disposal of the waste in the remaining tanks (Phase 2). In Phase 1, approximately $13 \%$ of the waste will be processed.

In fiscal year 1998, the Phase 1 Waste Feed Delivery and feed staging strategy was updated and the feed tanks were selected. Phase 1 candidate feed tanks include: AZ-101, AZ-102, C-106, AY-102, AN-107, AN-105, C-104, AN-102, AN-104, AW-101, AN-103, and C-102 (Acree 1998). All of these tanks have been sampled for safety screening and have archive material that is being used for additional retrieval and 
disposal analysis. As the retrieval program progresses, changes in the double-shell tank retrieval sequences are expected. It is not anticipated any of the remaining 45 incompletely sampled tanks will be moved into Phase 1. The Characterization Project operations have all tools, equipment, and procedures to obtain samples to support retrieval. Requests for analytical needs and sample material are in the process of being met. The disposal program's primary need in fiscal year 1999 and fiscal year 2000 is for larger liter-size volumes of waste from early feed tanks for process testing. The characterization program has developed and implemented a large-volume sampler to meet this need.

Data needs for Phase 2 are still being defined. It is not anticipated that they will be finalized until Phase 1 proof of process is demonstrated. Since Phase 2 processing will begin in approximately fiscal year 2012 , the disposal program does not require the sampling of the remaining 45 tanks prior to December 2002. Additional characterization of tanks will be required to support final disposal and will be scheduled according to programmatic needs. The timing and scope of these needs are being defined using a systems engineering approach that evaluates all stages of design, construction, and operation. The near-term focus is primarily on DST wastes.

Liter-sized volumes of Phase 1 tank material for process testing and chemical analysis have been provided. Table 3-6 presents a summary of the retrieval and disposal characterization needs for Phase 1 and shows how they are being met.

Table 3-6. Retrieval and Disposal Sampling for Phase 1

\begin{tabular}{|c|c|}
\hline \multicolumn{2}{|c|}{ Low Activity Waste } \\
\hline Tank & Sampling $^{\mathbf{1}} \mathbf{L}=$ liters $)$ \\
\hline AN-107 & $5.0 \mathrm{~L}(7 / 96) ; 1.5 \mathrm{~L}(4 / 98) ; 2.0 \mathrm{~L}(6 / 98)$ \\
\hline AN-105 & 2 cores $(6 / 96) ; 1$ core $(12 / 99)^{2}$ \\
\hline AN-102 & $5.0 \mathrm{~L}(2 / 98) ; 7.5 \mathrm{~L}(7 / 98) ; 7.5 \mathrm{~L}(8 / 98)$ \\
\hline AN-104 & 2 cores $(9 / 96) ; 1$ core $(8 / 99)^{2}$ \\
\hline AW-101 & 2 cores $(5 / 96) ; 1.0 \mathrm{~L}(4 / 98) ; 2.0 \mathrm{~L}(6 / 98)$ \\
\hline AN-103 & 2 cores $(9 / 96) ; 1$ core $(11 / 99)^{2}$ \\
\hline SY-101 & 3 cores $(3 / 99)$ \\
\hline Early Pretreatment High Level Waste and Low Activity Waste \\
\hline Tank & Sampling $(\mathbf{L}=$ liters $)$ \\
\hline AZ-101 & $8 / 99^{2}$ \\
\hline AZ-102 & 1 core $(10 / 98 ; 6 / 99)^{2}$ \\
\hline C-106 (SST Retrieval) & $2.0 \mathrm{~L}(6 / 96)$ \\
\hline AY-102 (feed staging, mixer pump operation) & $9 / 95 ;$ core $(7 / 00)^{2}$ \\
\hline Grab samples unless otherwise designated & 2Near term planned
\end{tabular}


HNF-4232 Rev. 0

\subsection{INSTITUTIONALIZING THE PROCESS TO DEFINE AND OBTAIN CHARACTERIZATION DATA}

Over the last four years, a process has been developed and institutionalized to systematically identify information needs, to integrate and prioritize the needs, and to reliably obtain and analyze the associated samples. This process was developed by embedding systems engineering principles into RPP and into every phase of the characterization process. Although the process predated the implementation of the integrated safety management system, it mirrors the Integrated Safety Management (ISM) process. The process is defined in contractor procedures, and the effectiveness is being evaluated via DOE's formal verification process.

\subsection{EMBEDDING SYSTEMS ENGINEERING PRICIPLES INTO THE RIVER PROTECTION PROJECT}

An overall systems approach has been applied to the River Protection Project (RPP) Mission. This approach has resulted in detailed action plans and schedules for mission accomplishment. The approach follows the guidelines outlined in DOE-Order-430.1A; "Life Cycle Asset Management."

The systems approach includes the development of RPP Level-0 Program Logic. This logic is a tool that establishes a clear direction of logical relationships and sequences of activities necessary to achieve the integrated mission of the RPP project. The program Level-0 Logic outlines the RPP mission including storage and disposal, Phase 1 vitrification demonstration, Phase 2 full scale production, storage of immobilized wastes, and tank and facility closure.

Each area of the RPP mission was decomposed to Level 1 Logic. From the Level 1 Logic (Work Breakdown Structure level 7), work scopes, and schedules were developed. Technical Basis Review documents were completed for each Level 1 Logic element to further define the work scope at Work Breakdown Structure level 8. It is important to note that the resulting schedules include work necessary to complete RPP, including testing necessary to verify that the developed systems meet the imposed requirements.

Systems engineering techniques are used within each program to determine what and when sample data is needed. For example, as part of an operating and maintenance concept document being prepared, the waste feed delivery program identifies characterization long-term needs.

This logic-based planning system is reflected in RPP procedures and forms the foundation for more detailed analyses to define characterization information needs. 
HNF-4232 Rev. 0

\subsection{PROCESS FOR IDENTIFYING CHARACTERIZATION DATA}

The process for identifying characterization data is consistent with the ISM process. Figure 4-1 illustrates the ISM functions with the steps used for sampling and waste characterization identified. The first step in the process involves translation of mission direction into work scope. This is accomplished through application of the systems approach as outlined in Section 4.1 . 
Figure 4-1. Integrated Safety Management Functions Within Characterization Project

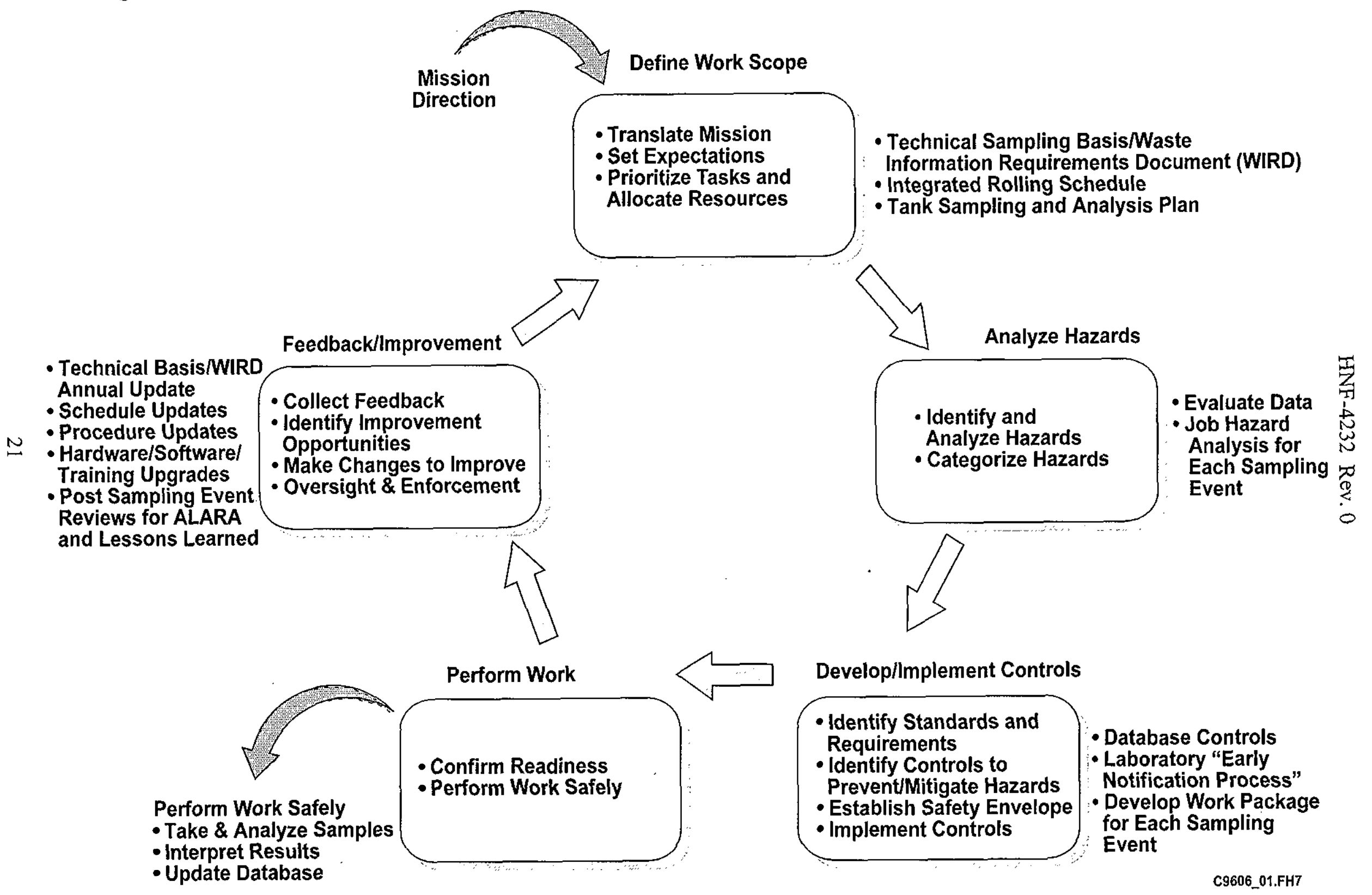


The work scope is then integrated and prioritized and documented in the Technical Sampling Basis (Brown et al. 1998b). The sampling basis is updated at least yearly and is developed by a series of facilitated meetings to identify and prioritize issues. The technical staff from each program identifies, integrates, and prioritizes the issues and also selects applicable tanks for each issue. Contractor staff, DOE, and the regulators participate in the process. The final output identifies sampling needs by tank in priority order. The output of the integrated priority list feeds into the development of multi-year sampling schedules and the multi-year budget planning process.

The process is also institutionalized in the Hanford Federal Facility Agreement and Consent Order (Tri-Party Agreement). The agreement requires that the results of the technical sampling basis form the foundation for the characterization requirements identified in the Waste Information Requirements Document (Adams et al. 1998). This document is used to obtain agreement with the end data users and the regulators and to drive detailed annual schedules. The Waste Information Requirements Document describes why the characterization information is being collected and also projects characterization needs for the out years. The Waste Information Requirements Document is updated at least annually. Quarterly status reports address progress and required changes.

The process, though strictly controlled, is flexible and can be rapidly changed if a new safety issue develops during the year. For example, when the surface level of tank SY-101 started to grow and it was determined in late 1998 that a transfer should be planned, key scientific and engineering staff were gathered to evaluate the problem. They determined what data were needed to support the various options being considered and the reasons for the surface level growth. At that point, the scope was known and the staff mobilized to obtain the information. Obtaining the data required the fabrication of additional sample hardware to collect the needed retained gas samples. The process, from the determination of the required data to obtaining the first sample, took less than six weeks.

\subsection{OBTAINING SAMPLES AND ANALYZING DATA}

The tools to obtain and analyze samples have been upgraded and demonstrated. In 1993 sample truck reliability was less than $16 \%$. Sampling operations were often terminated to due to events caused by poor conduct of operations or lack of resources. Sample recovery was sporadic. Laboratory capacity and analytical capability was not sufficient to meet analysis turnaround times or information precision requirements. Today, the picture is dramatically different.

Sampling equipment has been upgraded via a series of systematic evaluations of failures and then designing improvements to enhance reliability. These sampling equipment failure evaluations are summarized and documented quarterly. As a result, truck availability has increased. This was demonstrated by obtaining thirty cores in fiscal year 1998. The trucks have been upgraded for sampling in flammable atmospheres and rotary 
mode sampling has been implemented. Core sampling techniques were evaluated and real time feed back regarding core recovery was provided using field deployable sample $\mathrm{X}$-ray systems. Sample recovery has improved in all waste types. Equipment outages were shortened by developing integrated, resource loaded schedules. Sampling and laboratory procedures were streamlined. Conduct of operations has been improved by clearly defining expectations and involving sampling crews and laboratory technicians in efforts to improve the processes. The laboratory turnaround time has improved dramatically since 1993. In addition, as discussed above, a program is in place for the laboratory to notify RPP operations and engineering when pre-set limits on specific measurements are exceeded.

In parallel, additional sampling and laboratory tools have been developed. When new information needs are identified that require different tools, the existing ones are modified or new tools are developed. Examples include:

- Retained Gas Samplers and associated laboratory equipment that capture and analyze gas concentrations.

- Expanding the core sampling capability from one push mode truck unit to four units. All four can perform push mode; two can perform rotary sampling in flammable gas atmospheres.

- Redesigning the universal sampler to accommodate operating the sample trucks in push or rotary mode.

- Developing a large volume liquid sampler to supply vendor needs for large quantities of tank material for process testing.

- Developing a void fraction instrument to measure the amount of space occupied by gas in the waste.

- Developing a viscometer to determine in-situ viscosity and a ball rheometer to determine in-situ density.

- Developing several instruments to measure headspace gas concentrations. These include continuous hydrogen monitors and both truck and cart mounted gas sampling systems.

- Deploying inductively coupled plasma mass spectroscopy.

- Laboratory methods and data reporting are now standardized and data transfer to the Tank Characterization Database automated.

- Establishing Web-based data access to a large number of customers, facilitating easy data search and information exchange.

- Adding new hot cells with specialized equipment to support special analytical requests. 


\subsection{CONCLUSIONS}

Between fiscal years 1989 and 1998, 132 tanks were successfully core sampled, using a defined set of safety-driven requirements. Analyses of these samples was timely and the laboratory automatically reported anomalies beyond established limits. Currently, sampling events are routinely planned and executed to meet program requirements. A number of sampling methods are in use and can be deployed when needed.

Results from the analysis of these samples have been used to address and close the major tank safety issues. The combination of improved historical record reviews, increased understanding of the anticipated chemical changes, and tank waste characterization data from approximately $75 \%$ of the tanks has lead to improved understanding of waste properties. This understanding supported an updated safety analysis and placement of appropriate controls on all 177 tanks.

The remaining 45 unsampled SSTs have been evaluated in Appendix B and determined to be bounded in terms of defining hazards and safety controls by information obtained from tanks that were sampled and characterized. In addition, none of these tanks are identified for retrieval and disposal until after Phase 1 Disposal is successfully demonstrated. By that time, knowledge gained from the Phase 1 vitrification demonstration will result in a better understanding of the characterization needs required for Phase 2 tank waste.

Sufficient characterization data now exists to resolve the safety issues, ensure safe storage and to support presently requested vitrification project needs. The infrastructures and tools are now in place to support future tank data needs. Tank sampling will continue on an as-needed basis to support operational and disposal needs in a timely manner. 


\subsection{REFERENCES}

Acree, C. D., Jr., 1998, Tank Waste Remediation System Mission Analysis Report, HNF-SD-WM-MAR-008, Rev. 3, Lockheed Martin Hanford Corp. for Fluor Daniel Hanford, Inc., Richland, Washington.

Adams, M. R., T. M. Brown, and J. W. Hunt, 1998, Fiscal Year 1999 Waste Information Requirements Document, HNF-2884, Rev. 0, Lockheed Martin Hanford Corp. for Fluor Daniel Hanford, Inc., Richland, Washington.

Agnew, S. F., F. J. Boyer, R. A. Corbin, T. B. Duran, J. R. FitzPatrick, K. A. Jurgensen, T. P. Ortiz, and B. L. Young, 1997a, Hanford Tank Chemical and Radionuclide Inventories: HDW Model Rev. 4, LA-UR-96-3860, Los Alamos National Laboratory, Los Alamos, New Mexico.

Agnew, S. F., R. A. Corbin, T. B. Duran, K. A. Jurgensen, T. P. Ortiz, and B. L. Young, 1997b, Waste Status and Transaction Record Summary (WSTRS Rev. 4), LA-UR-97-311, Rev. 0, Los Alamos National Laboratory, Los Alamos, New Mexico.

Bratzel, D. R., W. W. Schulz, and R. Vornehm, 1996, Tank Farm Nuclear Criticality Review, WHC-SD-WM-TI-725, Rev. 0, Westinghouse Hanford Company, Richland, Washington.

Braun, D. J., L. D. Muhlestein, T. B. Powers, and M. D. Zentner, 1994, High-Level Waste Tank Subcriticality Safety Assessment, WHC-SD-WM-SARR-003, Rev. 0, pp. B-9 to B-20 Westinghouse Hanford Company, Richland, Washington.

Brown, T. M., S. J. Eberlein, and T. J. Kunthara, 1995, Tank Waste Characterization Basis, WHC-SD-WM-TA-164, Rev. 1, Westinghouse Hanford Company, Richland, Washington.

Brown, T. M. J. W. Hunt, and L. J. Fergestrom, 1998b, Tank Characterization Technical Sampling Basis, HNF-SD-WM-TA-164, Rev. 4, Lockheed Martin Hanford Corporation, Richland, Washington.

Colton, N. G., G. S. Anderson, and A. J. Villegas, 1995, Pretreatment Chemistry Evaluation: A Status Report, TWRSPP-95-024, Pacific Northwest Laboratory, Richland, Washington.

Conway, J. T., 1993, Hanford Waste Characterization Studies, DNFSB Recommendation 93-5, Defense Nuclear Facilities Safety Board, Washington, District of Columbia. 
Cowley, W. L., J. E. Meacham, J. M. Grigsby, and A. K. Postma, 1999, Organic Solvent Topical Report, HNF-4240, Rev. 0, Fluor Daniel Hanford, Inc., Richland, Washington.

DOE-ORP, 1999, Defense Nuclear Facilities Safety Board (DNFSB) Recommendation 93-5 Implementation Plan (IP), Revision 1.0, Milestone 5.4.3.1.0.d, "Approved Final Safety Analysis Report (FSAR)", (Letter 99-TSD-028 from R. T. French to J. T. Conway, DNFSB, April 6), U.S. Department of Energy, Office of River Protection, Richland, Washington.

DOE-RL, 1996, Recommendation 93-5 Implementation Plan, DOE/RL 94-0001, Rev. 1, Change 2, U.S. Department of Energy, Richland Operations Office, Richland, Washington.

DOE-RL, 1998, Completion of Hanford Federal Facility Agreement and Consent Order Milestone M-40-09, "Close All Unreviewed Safety Questions for Double Shell and Single Shell Tanks", Letter 98-SCD-125, from G. H. Sanders to Washington State Department of Ecology, U.S. Department of Energy, Richland, Washington.

Dukelow, G. T., J. W. Hunt, H. Babad, and J. E. Meacham, 1995, Tank Safety Screening Data Quality Objective, WHC-SD-WM-SP-004, Rev. 2, Westinghouse Hanford Company, Richland, Washington.

Fauske, H. K. 1996, Assessment of Chemical Vulnerabilities in the Hanford High Level Tank Wastes, WHC-SD-WM-ER-543, Rev. 0, Westinghouse Hanford Company, Richland, Washington.

Gygax, R. W., 1990, Scaleup Principles for Assessing Thermal Runaway Risks, Chemical Engineering Progress, February 1990.

LMHC 1999, Tank Characterization Database, Internet at http://wins.pnl.gov:8001/TCD/main.html.

Lumetta, G. J., I. E. Burgeson, M. J. Wagner, J. Liu, and Y. L. Chen, 1997, Washing and Caustic Leaching of Hanford Tank Sludge: Results of FY 1997 Studies, PNNL-11636, Pacific Northwest National Laboratory, Richland, Washington.

Meacham, J. M., 1996, Assessment of the Potential for Ferrocyanide Propagating Reaction Accidents, WHC-SD-WM-SARR-038, Rev. 1, Westinghouse Hanford Company, Richland, Washington

Meacham, J. E., W. L. Crowley, A. B. Webb, N. W. Kirch, J. A. Lechelt, D. A. Reynolds, L. A. Stauffer, D. B. Bechtold, D. M. Camaioni, F. Gao, R. T. Hallen, P G. Heasler, J. L. Huckaby, R. D. Scheele, C. S. Simmons, J. J. Toth, and L. M. Stock, 1998, Organic Complexant Topical Report, HNF-3588, Rev. 0, Fluor Daniel Hanford, Inc., Richland, Washington. 
Noorani, Y. G., 1997a, Tank Waste Remediation System Basis for Interim Operation, HNF-SD-WM-BIO-001, Rev. 0, Fluor Daniel Hanford Corp., Richland, Washington.

Noorani, Y. G., 1997b, Tank Waste Remediation System Technical Safety Requirements, HNF-SD-WM-TSR-006, Rev. 0, Fluor Daniel Hanford, Inc., Richland, Washington.

Noorani, Y. G., 1999, Tank Waste Remediation System Basis for Interim Operation, HNF-SD-WM-BIO-001, Rev. 1-A, Fluor Daniel Hanford, Inc., Richland, Washington

Ogden, D. M., K. Sathyanarayana, B. A. Crea, B. C. Fryer, and M. J. Thurgood, 1998, Project $W$-320 SAR and Process Control Thermal Analyses, HNF-SD-W320-ER-004, Rev. 1, Numatec Hanford Corporation for Fluor Daniel Hanford, Inc., Richland, Washington.

O'Leary, H. R., 1993, letter to J. T. Conway, DNFSB, August 31, U.S. Department of Energy, Washington, District of Columbia.

Postma, A. K., J. E. Meacham, G. S. Barney, G. L. Borsheim, R. J. Cash, M. D. Crippen, D. R. Dickinson, J. M. Grigsby, D. W. Jeppson, M. Kummerer, J. M. McLaren, C. S. Simmons, and B. C. Simpson, 1994, Ferrocyanide Safety Program: Safety Criteria for Ferrocyanide Watch List Tanks, WHC-EP-0691, Westinghouse Hanford Company, Richland, Washington.

Public Law 101-510, 1990, "Safety Measures for Waste Tanks at Hanford Nuclear Reservation," Section 3137 of National Defense Authorization Act for Fiscal Year 1991.

Reynolds, D. A., W. T. Cowley, J. Lechelt, and B. C. Simpson, 1999, Evaluation of Tank Data for Safety Screening, HNF-4217, Lockheed Martin Hanford Corporation, Richland, Washington.

Sederburg, J. P., and J. A. Reddick, 1994, TBP and Diluent Mass Balances in the Purex Plant at Hanford 1955 - 1991, WHC-MR-0483, Rev. 0, Westinghouse Hanford Company, Richland, Washington.

Serne, R. J., G. A. Whyatt, S. V. Mattigod, Y. Onishi, P. G. Doctor, B. N. Bjornstad, M. R. Powell, L. M. Liljegren, J. H. Westsik, N. J. Aimo, K. P. Recknagle, G. R. Golcar, T. B. Miley, G. R. Holdren, D. W. Jeppson, R. K. Biyani, and G. S. Barney, 1996, Fluid Dynamic Particulate Segregation, Chemical Processes, and Natural Ore Analog Discussions that Relate to the Potential for Criticality in Hanford Tanks, WHC-SD-WM-TI-757, Rev. 0, Westinghouse Hanford Company, Richland, Washington. 
HNF-4232 Rev. 0

Sheridan, T. R., 1994, Closure of the Ferrocyanide Unreviewed Safety Question, letter 9401180 to A. L. Trego, WHC, March 4, U.S. Department of Energy, Richland, Washington.

Temer, D. J., and R. Villarreal, 1997, Sludge Washing and Alkaline Leaching Tests on Actual Hanford Tank Sludge: FY 1997 Results, LAUR 97-2889, Los Alamos National Laboratory, Albuquerque, New Mexico. 
HNF-4232 Rev. 0

APPENDIX A

SUMMARY OF TANKS WITH COMPLETED CORE SAMPLING 
HNF-4232 Rev. 0

This page intentionally left blank. 


\section{A1.0 INTRODUCTION}

This appendix summarizes condensed phase sampling and uses a logical approach to determine whether the sampling was sufficient to meet the DNFSB Recommendation 93-5 Implementation Plan milestone 5.6.3.1j. Milestone 5.6.3.1j states "Core sample all tanks by 2002" (DOE/RL 1996). The milestone was based on the need for characterization data for safe storage of the waste, to operate the tanks and their infrastructure safely, and to plan and implement retrieval and processing of the waste.

From 1989 through October 1998, 295 core, auger, and grab samples of the condensed phase tank waste have been obtained. The logic used to determine if the sampling was sufficient is presented in Section A2.0. In Section A3.0 the tanks that met the criteria for being considered core-sampled are presented. In total, 138 tanks had been sampled. Sampling from six tanks did not contain sufficient material to meet the criteria. There are 132 tanks that met the criteria. Section A4.0 presents results of the sampling analysis as it applies to safety screening criteria. Very few individual data points approach the Basis for Interim Operation (BIO) safety limits. The few data points which had elevated total organic carbon also had greater than 20 percent water, thus putting all waste samples within the safety limits. The data is graphically portrayed in Section A4.0.

\section{A2.0 METHOD FOR DETERMINING ADEQUACY OF TANK SAMPLING}

To assess if a tank was adequately sampled to meet Milestone 5.6.3.1j, the first step was to define the scope of the sampling and analysis. The requirements of the milestone 5.6.3.1j were focused on safe interim storage and resolution of safety concerns. For a tank to be declared "sampled" per the DNFSB Recommendation 93-5 Implementation Milestone 5.6.3.1j, the sampling and data requirements of the safety screening data quality objective (DQO) (Dukelow et al. 1995) must be met.

The minimum set of analyses or samples needed to meet milestone 5.6.3.1j had not been established to ensure appropriate safety categorization, relative to the known safety issues, for the tanks until the safety screening DQO was issued in February 1994 (Babad 1994). Because of the changes in the characterization program between 1989 and 1999 , a consistent set of criteria was established to evaluate the sampling and analysis data to determine if sufficient information for safety screening had been obtained. The safety screening DQO specified measurements to determine energetics, criticality-related material, and flammable gases.

Additional sampling and analysis to address safety issues beyond safety screening, such as organic complexant or flammable gas, was required from select tanks to resolve those safety issues. These analyses have been completed and are briefly described in Section 3.1, and in detail in the references that address closure of those safety issues. All tanks will likely be analyzed in the future, using archive materials or additional sample material to support emerging retrieval and disposal needs. 
The tanks that were evaluated for meeting milestone 5.6.3.1j had been sampled between 1989 and October 1998 . The 1989 start date was selected because the sampling and analyses performed on tank wastes before 1989 often did not have complete documentation and quality assurance records, and because the analyses were frequently performed on composites or process samples. October 1998 was selected as an end date because, at the time this document was written, final analytical results were not available from tanks sampled after October 1998.

The determination of whether a specific tank had been adequately sampled to meet the intent of milestone 5.6.3.1.j focused on the following considerations:

- Sampling Method: Although the milestone states "Core sample all tanks by 2002," other sampling methods were used, where appropriate, to obtain samples from individual tanks. For double-shell tanks (DSTs), the process history is more recent and better documented, and many of the tanks contain only liquid waste. In such instances, grab sampling is appropriate for obtaining samples of the tank contents. Grab sampling was used in place of core sampling for 14 of the 28 DSTs.

In single-shell tanks (SSTs) with a waste depth less than 2 core segments (38 inches), auger sampling was used in place of core sampling (approximately 23 of the 104 sampled SSTs). There was one SST (BY-103) where a combination of grab and auger sampling was used and considered acceptable, although the waste depth in that tank was the equivalent of 9 core segments. The combined auger and grab sampling for BY-103 was considered acceptable because that tank contained only one waste type, and analyses of the auger and grab samples supported the process history information.

There are 3 SSTs with less than 5,000 gallons of waste and highly variable waste depths that contain very dry and powdery waste material. Core and auger sampling was attempted unsuccessfully in these tanks. In these 3 SSTs, a new type of grab sample device (the "finger trap" grab sampler) was used to obtain the necessary sample material.

- Sample Recovery: Sample recovery is important for two considerations. First, sufficient sample material must be obtained to perform the safety screening analyses. The actual amount of material used for safety screening analyses was very low. Normally, about 25 grams of material is needed for safety screening analyses, including sample preparation and sample losses that may occur during hot cell sample preparation. The analyses could be done on significantly less material ( 2 to 5 grams) if great care was used in sample preparation. This was necessary with some auger samples of tanks with a shallow waste layer. Secondly, sufficient sample material must be obtained to provide reasonable assurance that the vertical profile of the tank is understood within the context of the documented process history.

Liquid grab samples were taken in bottles that hold between $10-125 \mathrm{~mL}$ resulting in sufficient sample volumes for analysis. Recently large volume samplers have been 
deployed which obtain 500-mL samples for disposal process development. With respect to representativeness, results from one $125-\mathrm{mL}$ grab sample bottle or several 10 -mL bottles were considered acceptable if the tank had a mixer pump in it that provided a homogeneous waste matrix in the tank during sampling. In DSTs without active mixing, grab samples at different sample depths were required. The number of samples and levels depended on the tank's operating history. In most cases samples were taken at 3 different depths, but if there was process history or previous sample data to indicate there were. few types of waste, then 2 or even 1 sample (for a dilute feed tank) was considered acceptable. To ensure there were grab samples at the appropriate levels, the staff reviewed where the sample was taken and how the results from the chemical properties compared to what was expected at that level from process history information.

Auger sample recovery varied with the depth, dryness and hardness of the waste. Typical sample recovery per auger was between 10-100 grams. The higher numbers were typical in sludge tanks and tanks with layers of waste greater than 20 inches. Some of the tanks had only a few inches of material under the riser. For these situations, the lower sample amount range represents a reasonable amount of material recovered.

Core samples are taken in 19-inch segments. A 19-inch segment contains between 230-350 grams of material depending on the waste density. If sample recovery in a particular segment was poor (e.g., less than half of a segment, about 150 grams of material), further review of the sampling data was necessary. Adequate was normally 25-50 grams of material, particularly if there was compositional consistency observed between segments.

Considerations regarding core sample evaluation included:

- Sufficient sample material for analysis: Within the segment or layer, was sufficient material available to get a complete analysis? Between 5-25 grams of the waste in a segment is used for the initial safety screening analyses. If the threshold values were exceeded for total alpha or energetics, then was sufficient additional sample material from that segment available to complete the secondary analyses?

- Comprehensive vertical profile: Was there low or no recovery in one segment of one core, but good recovery of the same layer of waste from a second core in the tank? The criterion was to sample each waste layer, not to obtain multiple samples from each waste layer.

- Sample representativeness: Did the material appear physically (color, texture) and chemically similar above and below the sample gap? Photographs or videotapes are taken of every core extrusion. The different types of process material have different colors and textures. Therefore, staff can assess if the material appears to be consistent (e.g., same color and texture) or if there is an 
indication that there was a change in material. In addition, analytical results were reviewed to determine if the key analytes (not just those used for safety screening) were consistent above and below the sample gap using the more general sample analysis (ion chromatography/inductively coupled plasma [IC/ICP]) of the waste constituents.

- Agreement with process history: Was the data obtained by analysis of the waste consistent with what was expected from historical records? If there was partial recovery of a 19-inch segment and the data was consistent with what was expected, then the reviewers determined that the sample met the requirements. This evaluation was most often used at the bottom of the tank where it was difficult to assess if the recovery problems were due to failed equipment obstructing the sampler, the tank bottom buckled or raised in that area, or if the material was hard enough to trigger the downward force sampler shut-off. The reviewers used IC/ICP data or other analyses to confirm if the material had the same characteristic properties as the expected material would have.

- Sample Analyses: The portion of the Safety Screening Data Quality Objective document that applies to condensed phase (i.e. liquids and solids) samples requires analyses for criticality, fuel energy content, and moisture content. The analytic requirements and decision logic are arranged stepwise. The primary screening criteria are the minimum set of necessary analytic data, namely total alpha for criticality, thermogravimetric analyses for moisture content, and differential scanning calorimetry for fuel energy content. These analyses were performed on each sample or segment for grabs, augers, and cores of liquid waste, and on half-segments for cores in solids (sludge or saltcake).

Secondary screening, utilizing more specific analyses, are performed on samples for which analytic results exceeded the primary safety screen criteria. These included analyses for Pu-239/240 and neutron absorbers (criticality safety issue), total organic carbon (organic safety issue), and total cyanide (ferrocyanide safety issue). When analytic results exceeded the secondary screening criteria, safety issue-specific data quality objectives were applied to that tank.

In some instances, sample analyses skipped the primary screen and proceeded directly to the secondary requirements (e.g., analyses for the criticality safety issue proceeded directly into Pu-239/240 analyses without first analyzing for total alpha). In some other instances, alternate analytical methods were used to satisfy particular criteria (e.g., gravimetric water measurements were used instead of thermogravimetric analysis to quantify moisture content).

\section{A2.1 LOGIC USED TO SATISFY MILESTONE 5.6.3.1j}

Figure A-1 presents the logic for assessing tank data for Safety Screening. Each of the steps is described in more detail in this section. 
HNF-4232 Rev. 0
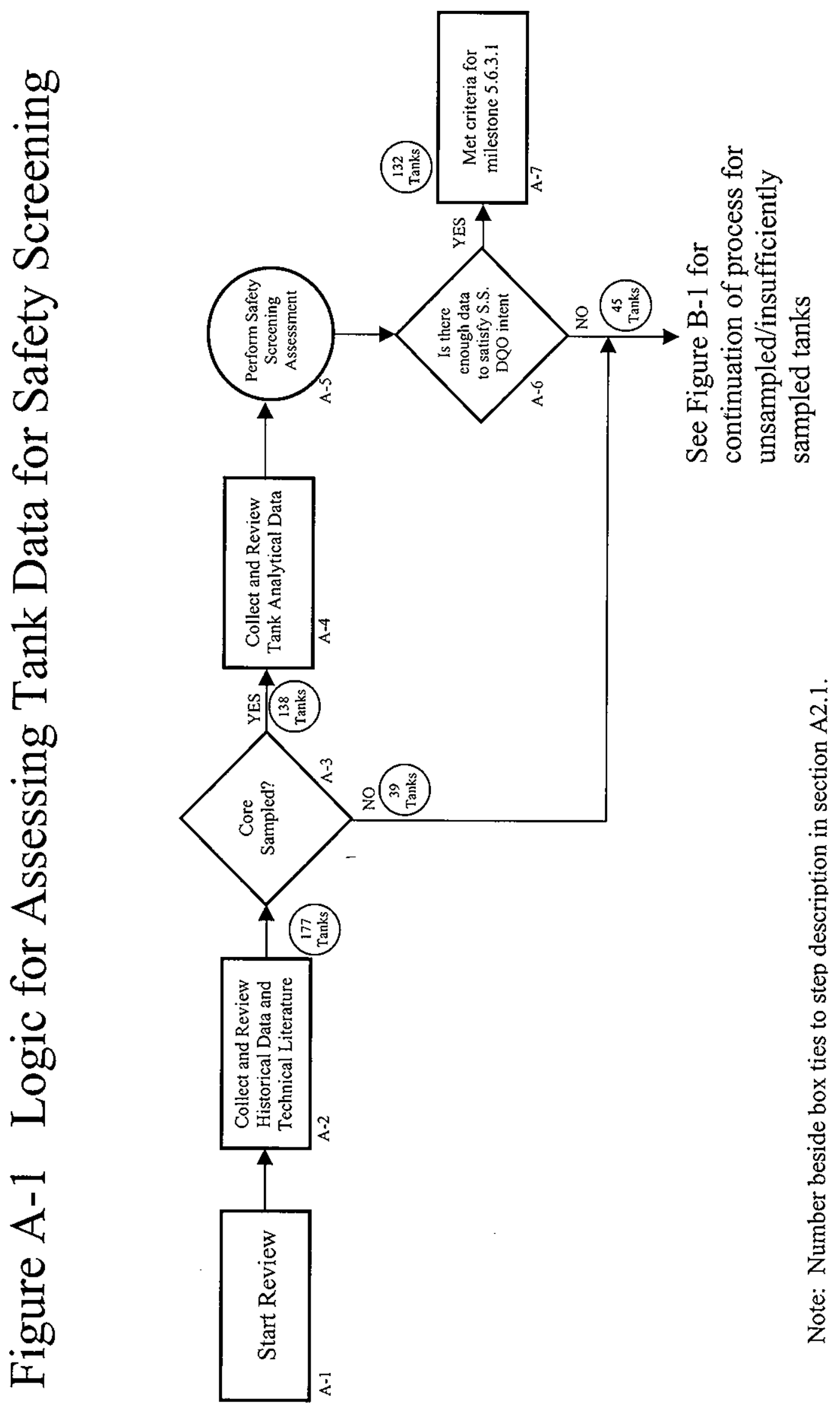
Step A-1: This is the start of the review process. All 177 tanks are included in the evaluation. For the tanks that had been sampled since 1989, the sampling and analytical data is in the tank characterization reports (TCRs). The TCR is a document that contains information about the tank and its contents, the process history, the sampling events, and the analytical results from the sampling. It has been reviewed and approved by contractor and DOE staff prior to issuance.

Step A- 2: Technical staff reviewed the TCR of the tank in question and any related information deemed necessary, such as analytical reports and sampling logs. Additional process information, including documentation about the chemical separation processes, waste transfers, and layering of wastes in a tank was also available for review. Brevick et al. (1997a, b, c, and d) and Agnew et al. (1997a and b) were reviewed if the material in the TCR required clarification with regard to safety screening.

Step A-3: Those tanks that had solid or liquid samples taken since 1989 were identified. At this step, 39 tanks were identified that have no recent (post-1989) sampling events (Reynolds et al.1999). These tanks are evaluated in Appendix B. The 138 tanks that had been sampled were then evaluated for adequacy of sampling.

Step A-4: Of the 138 remaining tanks, 91 tanks (Reynolds et al.1999) were determined to have satisfied the minimum requirements of the safety screening DQO. The remaining 47 tanks required further evaluation.

Step A-5: Further review of the 47 tanks from step A-4 showed that there were several issues associated with the various tank sampling and analysis events. Fifteen tanks had more than one issue, as described below, involved in their evaluation (Reynolds et al. 1999).

It was determined from the backup analytical and sampling logs that 9 tanks had met the safety screening DQO with analyses performed as specified in the safety screening DQO. Seven of these tanks had other issues (discussed below) associated with them (Reynolds et al. 1999).

The remaining 38 tanks were then evaluated to determine whether specific analyses had been performed instead of the broader analyses identified in the primary screening criteria of the safety screening DQO. In 8 cases it was determined that TOC analyses had been substituted for DSC, or that $\mathrm{Pu}-239 / 240$ analyses had been substituted for total alpha.

There were 30 tanks (including some mentioned above) for which it was necessary to review the sampling data to determine whether sample recovery was adequate, using the criteria presented in Section A2.0. For tanks that were auger sampled, such as B-102 and SX-108, and only small amounts of sample material were recovered (5 to 10 grams), there was similar recovery from more than one riser and there was sufficient material to perform all safety screening analyses. Given the small volume of the waste in these 
tanks, and the consistency of the IC/ICP data from different risers, the sampling was considered adequate. All but eleven tanks met the criteria presented in Section A2.0.

There were five tanks that were determined to meet the requirements of the Safety Screening although they did not fit one of the above criteria. Of these 5 tanks, 4 were DSTs in active use (e.g., evaporator feed and receipt tanks and aging waste tanks) where there was extensive grab sampling of waste material being added or removed from the tank to support compatibility analyses and evaporator feed analyses. The evaporator feed and receipt tanks are routinely emptied and filled to support evaporator runs. The sampling and analyses requirements of the Evaporator DQO are more extensive and encompass the safety screening analyses requirements.

The remaining tank was single-shell tank C-106. This tank has been sampled several times in support of retrieval. Sampling the hard bottom layer was not possible using conventional tools. Evaluations of the sample material obtained and the process records were performed to support sluicing activities (Reynolds 1997). Safety evaluations determined that it was acceptable to sluice this material to tank AY-102. The sampling and analyses performed in support of this sluicing encompass the safety screening analyses requirements.

Step A-6: Using the criteria outlined in Steps 4 and 5, each tank sampled since 1989 was reviewed, and a determination was made regarding whether the safety screening DQO was met (Reynolds et al. 1999). The tanks that met the criteria are shown in Table A-1. Of the 138 tanks that had samples and analyses since 1989, 6 did not meet the minimum acceptable criteria. These were all determined to be inadequate because insufficient sample material was obtained to assure that all layers of the waste were evaluated. They are evaluated in Appendix B.

\section{A3.0 TANKS SATISFYING MILESTONE 5.6.3.1j}

Based on the review process and logic described in Section A2.0, 132 tanks were identified as meeting the requirements of milestone $5.6 .3 .1 \mathrm{j}$. These are listed in Table A-1. The following 6 tanks were determined to be incompletely sampled and are addressed in Appendix B: BY-105, BY-106, C-102, T-103, U, 101, and TX-118. The remaining 39 tanks were not sampled between 1989 to 1998 and are also addressed in Appendix B.

The first column of Table A-1 shows the tank number and the type of tank. The second column of the table lists the document number of the TCR. This is the prime reference presenting both sampling and analytical results for the tank listed. Data can also be obtained from the TWINS database (LMHC 1999)

The comments identify when the sampling technique was something other than core sampling (e.g., liquid grabs or augers) and if the safety screening analysis performed used some other method than the basic techniques (e.g., using TOC instead of DSC). If no 
comments are listed, the tank had standard core sampling and analysis, with at least 2 cores with satisfactory recovery.

Table A-1. Safety Screen Tanks (8 Sheets)

\begin{tabular}{|c|c|c|}
\hline Tank 241- & TCR No. & Comments \\
\hline $\begin{array}{c}\text { A-101 } \\
\text { SST }\end{array}$ & HNF-SD-WM-ER-673 & \\
\hline $\begin{array}{l}\mathrm{A}-102 \\
\mathrm{SST}\end{array}$ & WHC-SD-WM-ER-597 & Used auger samples. \\
\hline $\begin{array}{l}\text { AN-101 } \\
\text { DST }\end{array}$ & WHC-SD-WM-ER-578 & Used liquid grab samples. \\
\hline $\begin{array}{l}\text { AN-102 } \\
\text { DST }\end{array}$ & WHC-SD-WM-ER-545 & \\
\hline $\begin{array}{l}\text { AN-103 } \\
\text { DST }\end{array}$ & HNF-SD-WM-ER-702 & \\
\hline $\begin{array}{l}\text { AN-104 } \\
\text { DST }\end{array}$ & HNF-SD-WM-ER-690 & \\
\hline $\begin{array}{l}\text { AN-105 } \\
\text { DST }\end{array}$ & HNF-SD-WM-ER-678 & \\
\hline $\begin{array}{l}\text { AN-106 } \\
\text { DST }\end{array}$ & WHC-SD-WM-ER-569 & Used liquid grab samples. \\
\hline $\begin{array}{l}\text { AN-107 } \\
\text { DST }\end{array}$ & WHC-SD-WM-ER-600 & $\begin{array}{l}\text { Used grab samples. RSST analysis performed } \\
\text { (propagation test). }\end{array}$ \\
\hline $\begin{array}{l}\text { AP-101 } \\
\text { DST }\end{array}$ & HNF-SD-WM-ER-357 & Used liquid grab samples. \\
\hline $\begin{array}{l}\text { AP-102 } \\
\text { DST }\end{array}$ & HNF-SD-WM-ER-358 & $\begin{array}{l}\text { Used liquid grab samples. Substituted TOC and } \\
\text { 239/240 } \mathrm{Pu} \text { analyses. }\end{array}$ \\
\hline $\begin{array}{l}\text { AP-103 } \\
\text { DST }\end{array}$ & HNF-SD-WM-ER-359 & $\begin{array}{l}\text { Used liquid grab samples. Substituted }{ }^{239 / 240} \mathrm{Pu} \\
\text { and gravimetric water analyses. }\end{array}$ \\
\hline $\begin{array}{l}\text { AP-104 } \\
\text { DST }\end{array}$ & WHC-SD-WM-ER-596 & Used liquid grab samples. \\
\hline $\begin{array}{l}\text { AP-105 } \\
\text { DST }\end{array}$ & HNF-SD-WM-ER-360 & $\begin{array}{l}\text { Used liquid grab samples. Substituted }{ }^{239 / 240} \mathrm{Pu} \text {, } \\
\text { and gravimetric water analyses. }\end{array}$ \\
\hline $\begin{array}{l}\text { AP-106 } \\
\text { DST }\end{array}$ & HNF-SD-WM-ER-361 & $\begin{array}{l}\text { Used liquid grab samples. Substituted }{ }^{239 / 240} \mathrm{Pu} \\
\text { and gravimetric water analyses. }\end{array}$ \\
\hline $\begin{array}{l}\text { AP-107 } \\
\text { DST }\end{array}$ & HNF-SD-WM-ER-362 & $\begin{array}{l}\text { Used liquid grab samples. Water content } \\
\text { determined from IC/ICP data. }\end{array}$ \\
\hline $\begin{array}{l}\text { AP-108 } \\
\text { DST }\end{array}$ & WHC-SD-WM-ER-593 & Used liquid grab samples. \\
\hline $\begin{array}{l}\text { AW-101 } \\
\text { DST }\end{array}$ & HNF-SD- & \\
\hline
\end{tabular}


Table A-1. Safety Screen Tanks (8 Sheets)

\begin{tabular}{|c|c|c|}
\hline Tank 241- & TCR No. & Comments \\
\hline $\begin{array}{l}\text { AW-102 } \\
\text { DST }\end{array}$ & HNF-SD-WM-ER-363 & $\begin{array}{l}\text { Used liquid grab samples. Tank AW-102 is the } \\
\text { evaporator feed tank typically filled and emptied } \\
\text { annually. The tank samples were analyzed to } \\
\text { the evaporator DQO, which is more } \\
\text { comprehensive and encompasses the safety } \\
\text { screening DQO information. No other samples } \\
\text { are necessary for this tank. The DQO that } \\
\text { supports evaporator campaigns exceeds all } \\
\text { requirements of the safety screening DQO. }\end{array}$ \\
\hline $\begin{array}{l}\text { AW-103 } \\
\text { DST }\end{array}$ & WHC-SD-WM-ER-455 & \\
\hline $\begin{array}{l}\text { AW-104 } \\
\text { DST }\end{array}$ & WHC-SD-WM-ER-453 & \\
\hline $\begin{array}{l}\text { AW-105 } \\
\text { DST }\end{array}$ & HNF-SD-WM-ER-364 & \\
\hline $\begin{array}{l}\text { AW-106 } \\
\text { DST }\end{array}$ & HNF-SD-WM-ER-365 & $\begin{array}{l}\text { Tank AW-106 is the active evaporator slurry } \\
\text { receiver and receives additional waste every } \\
\text { time the evaporator is run. The slurry is allowed } \\
\text { to settle. The supernatant is pumped off to other } \\
\text { tanks after the slurry settles. The supernatant is } \\
\text { sampled for compatibility prior to pumping, } \\
\text { after each fill and prior to each evaporator } \\
\text { campaign. The solids are not typically sampled. } \\
\text { However, an understanding of the waste is } \\
\text { derived from the } 242-\mathrm{A} \text { Evaporator feed samples } \\
\text { and the evaporative process, including } \\
\text { evaporator boil-down tests of actual feed stock. } \\
\text { No other samples are necessary for this tank. }\end{array}$ \\
\hline $\begin{array}{c}\mathrm{AX}-101 \\
\mathrm{SST}\end{array}$ & HNF-SD-WM-ER-649 & \\
\hline $\begin{array}{c}\text { AX-102 } \\
\text { SST }\end{array}$ & HNF-SD-WM-ER-472 & Used auger samples. \\
\hline $\begin{array}{c}\text { AX-103 } \\
\text { SST }\end{array}$ & HNF-SD-WM-ER-685 & \\
\hline $\begin{array}{l}\text { AX-104 } \\
\text { SST }\end{array}$ & HNF-SD-WM-ER-675 & $\begin{array}{l}\text { Used auger samples. Substituted TOC and Pu- } \\
239 / 240 \text { analyses. }\end{array}$ \\
\hline $\begin{array}{c}\text { AY-101 } \\
\text { DST }\end{array}$ & WHC-SD-WM-ER-605 & Used liquid grab samples. \\
\hline $\begin{array}{l}\text { AY-102 } \\
\text { DST }\end{array}$ & WHC-SD-WM-ER-454 & $\begin{array}{l}\text { Used liquid grab samples. Substituted TOC in } \\
\text { sludge. Substituted gravimetric water and } \\
{ }^{239 / 240} \mathrm{Pu} \text {. }\end{array}$ \\
\hline
\end{tabular}


Table A-1. Safety Screen Tanks (8 Sheets)

\begin{tabular}{|c|c|c|}
\hline Tank 241- & TCR No. & Comments \\
\hline $\begin{array}{l}\text { AZ-101 } \\
\text { DST }\end{array}$ & WHC-SD-WM-ER-410 & $\begin{array}{l}\text { Used grab samples and core samples. } \\
\text { Substituted TOC and gravimetric water in } \\
\text { sludge. }\end{array}$ \\
\hline $\begin{array}{l}\mathrm{AZ}-102 \\
\mathrm{DST}\end{array}$ & WHC-SD-WM-ER-411 & \\
\hline $\begin{array}{c}\text { B-101 } \\
\text { SST }\end{array}$ & WHC-SD-WM-ER-528 & \\
\hline $\begin{array}{c}\text { B-102 } \\
\text { SST }\end{array}$ & WHC-SD-WM-ER-405 & Used auger samples. \\
\hline $\begin{array}{c}\text { B-103 } \\
\text { SST }\end{array}$ & WHC-SD-WM-ER-488 & Used auger samples. \\
\hline $\begin{array}{c}\text { B-104 } \\
\text { SST }\end{array}$ & WHC-SD-WM-ER-552 & \\
\hline $\begin{array}{c}\text { B-106 } \\
\text { SST }\end{array}$ & WHC-SD-WM-ER-601 & \\
\hline $\begin{array}{c}\text { B-107 } \\
\text { SST }\end{array}$ & HNF-SD-WM-ER-723 & \\
\hline $\begin{array}{c}\text { B-108 } \\
\text { SST }\end{array}$ & HNF-SD-WM-ER-674 & Two cores together provided a vertical profile. \\
\hline $\begin{array}{c}\text { B-109 } \\
\text { SST }\end{array}$ & HNF-SD-WM-ER-677 & \\
\hline $\begin{array}{c}\text { B-110 } \\
\text { SST }\end{array}$ & HNF-SD-WM-ER-368 & \\
\hline $\begin{array}{c}\text { B-111 } \\
\text { SST }\end{array}$ & HNF-SD-WM-ER-549 & \\
\hline $\begin{array}{c}\text { B-112 } \\
\text { SST }\end{array}$ & HNF-SD-WM-ER-549 & Used auger samples. \\
\hline $\begin{array}{c}\text { B-201 } \\
\text { SST }\end{array}$ & HNF-SD-WM-ER-550 & \\
\hline $\begin{array}{c}\mathrm{B}-202 \\
\mathrm{SST}\end{array}$ & WHC-SD-WM-ER-371 & \\
\hline $\begin{array}{c}\text { B-203 } \\
\text { SST } \\
\end{array}$ & WHC-SD-WM-ER-587 & \\
\hline $\begin{array}{c}\text { B-204 } \\
\text { SST }\end{array}$ & WHC-SD-WM-ER-581 & \\
\hline $\begin{array}{c}\text { BX-101 } \\
\text { SST }\end{array}$ & WHC-SD-WM-ER-408 & Used auger samples. \\
\hline $\begin{array}{c}\text { BX-103 } \\
\text { SST }\end{array}$ & WHC-SD-WM-ER-535 & \\
\hline $\begin{array}{c}\mathrm{BX}-104 \\
\mathrm{SST}\end{array}$ & WHC-SD-WM-ER-599 & \\
\hline $\begin{array}{c}\text { BX-105 } \\
\text { SST }\end{array}$ & WHC-SD-WM-ER-406 & Used auger samples. \\
\hline
\end{tabular}


HNF-4232 Rev. 0

Table A-1. Safety Screen Tanks (8 Sheets)

\begin{tabular}{|c|c|l|}
\hline Tank 241- & TCR No. & \multicolumn{1}{|c|}{ Comments } \\
\hline BX-106 & WHC-SD-WM-ER-570 & Used auger samples. \\
SST & & \\
\hline BX-107 & HNF-SD-WM-ER-539 & \\
SST & & \\
\hline BX-108 & WHC-SD-WM-ER-407 & Used auger samples. \\
SST & & \\
\hline BX-109 & WHC-SD-WM-ER-572 & \\
SST & & \\
\hline BX-110 & WHC-SD-WM-ER-566 & \\
SST & & \\
\hline BX-111 & HNF-SD-WM-ER-653 & \\
SST & & \\
\hline BX-112 & WHC-SD-WM-ER-602 & \\
SST & & \\
\hline BY-101 & HNF-SD-WM-ER-647 & \\
SST & & \\
\hline BY-102 & HNF-SD-WM-ER-630 & \\
SST & & \\
\hline BY-103 & HNF-SD-WM-ER-663 & Used auger and grab samples. \\
SST & & \\
\hline BY-104 & WHC-SD-WM-ER-608 & \\
SST & & \\
\hline BY-107 & HNF-SD-WM-ER-637 & \\
SST & & \\
\hline BY-108 & WHC-SD-WM-ER-533 & \\
SST & & \\
\hline BY-109 & HNF-SD-WM-ER-648 & \\
SST & & \\
\hline BY-110 & WHC-SD-WM-ER-591 & \\
SST & & \\
\hline BY-111 & HNF-SD-WM-ER-687 & \\
SST & & \\
\hline BY-112 & WHC-SD-WM-ER-441 & \\
SST & & \\
\hline C-101 & WHC-SD-WM-ER-473 Used auger samples. \\
SST & & \\
\hline C-103 & WHC-SD-WM-ER-558 & \\
SST & & \\
\hline C-104 & HNF-SD-WM-ER-679 & \\
\hline
\end{tabular}


HNF-4232 Rev. 0

Table A-1. Safety Screen Tanks (8 Sheets)

\begin{tabular}{|c|c|c|}
\hline Tank 241- & TCR No. & Comments \\
\hline $\begin{array}{l}\text { C-105 } \\
\text { SST }\end{array}$ & WHC-SD-WM-ER-489 & \\
\hline $\begin{array}{l}\text { C-106 } \\
\text { SST }\end{array}$ & WHC-SD-WM-ER-615 & $\begin{array}{l}\text { Used liquid and solid grab samples. Tank C-106 } \\
\text { is currently being sluiced. Extensive safety } \\
\text { documentation was prepared prior to sluicing. } \\
\text { The chemical aspects are summarized in } \\
\text { Reynolds (1997). The sluicing operation calls } \\
\text { for sampling of the waste in the receiving tank } \\
\text { (AY-102). No samples are required. }\end{array}$ \\
\hline $\begin{array}{l}\text { C-107 } \\
\text { SST }\end{array}$ & WHC-SD-WM-ER-474 & \\
\hline $\begin{array}{l}\text { C-108 } \\
\text { SST }\end{array}$ & WHC-SD-WM-ER-503 & Used auger samples. \\
\hline $\begin{array}{l}\text { C-109 } \\
\text { SST }\end{array}$ & HNF-SD-WM-ER-402 & \\
\hline $\begin{array}{l}\mathrm{C}-110 \\
\text { SST }\end{array}$ & HNF-SD-WM-ER-367 & \\
\hline $\begin{array}{l}\text { C-111 } \\
\text { SST }\end{array}$ & WHC-SD-WM-ER-475 & \\
\hline $\begin{array}{l}\text { C-112 } \\
\text { SST }\end{array}$ & HNF-SD-WM-ER-541 & \\
\hline $\begin{array}{l}\text { C-201 } \\
\text { SST }\end{array}$ & HNF-2866 & $\begin{array}{l}\text { Used finger-trap grab samples. RSST analyses } \\
\text { (Propagation test). }\end{array}$ \\
\hline $\begin{array}{l}\text { C-202 } \\
\text { SST }\end{array}$ & HNF-2866 & $\begin{array}{l}\text { Used finger-trap grab samples. RSST analyses } \\
\text { (Propagation test). }\end{array}$ \\
\hline $\begin{array}{l}\mathrm{C}-203 \\
\text { SST }\end{array}$ & WHC-SD-WM-ER-478 & Used auger and RSST. \\
\hline $\begin{array}{c}\text { C-204 } \\
\text { SST }\end{array}$ & WHC-SD-WM-ER-479 & $\begin{array}{l}\text { Used auger samples. RSST analyses } \\
\text { (Propagation test). }\end{array}$ \\
\hline $\begin{array}{l}\text { S-101 } \\
\text { SST }\end{array}$ & WHC-SD-WM-ER-613 & \\
\hline $\begin{array}{l}\text { S-102 } \\
\text { SST }\end{array}$ & WHC-SD-WM-ER-611 & \\
\hline $\begin{array}{l}\text { S-104 } \\
\text { SST }\end{array}$ & HNF-SD-WM-ER-370 & \\
\hline $\begin{array}{l}\text { S-106 } \\
\text { SST }\end{array}$ & HNF-SD-WM-ER-645 & \\
\hline $\begin{array}{l}\text { S-107 } \\
\text { SST }\end{array}$ & WHC-SD-WM-ER-589 & \\
\hline $\begin{array}{l}\text { S-109 } \\
\text { SST }\end{array}$ & HNF-SD-WM-ER-627 & \\
\hline
\end{tabular}


Table A-1. Safety Screen Tanks (8 Sheets)

\begin{tabular}{|c|c|l|}
\hline Tank 241- & TCR No. & \multicolumn{1}{|c|}{ Comments } \\
\hline S-110 & HNF-SD-WM-ER-642 & \\
SST & & \\
\hline S-111 & WHC-SD-WM-ER-507 & \\
SST & & \\
\hline SX-101 & HNF-SD-WM-ER-660 & \\
SST & & \\
\hline SX-102 & HNF-SD-WM-ER-661 & \\
SST & & \\
\hline SX-103 & HNF-SD-WM-ER-662 & \\
SST & & \\
\hline SX-105 & HNF-SD-WM-ER-644 & \\
SST & & \\
\hline SX-106 & HNF-SD-WM-ER-645 & \\
SST & & \\
\hline SX-108 & WHC-SD-WM-ER-582 & Used auger samples. \\
SST & & \\
\hline SX-113 & WHC-SD-WM-ER-480 & Used auger samples. \\
SST & & \\
\hline SX-115 & HNF-SD-WM-ER-684 & Used auger samples and finger trap grab \\
SST & & samples. \\
\hline SY-101 & WHC-SD-WM-ER-409 & \\
DST & & \\
\hline SY-102 & HNF-SD-WM-ER-366 & \\
DST & & \\
\hline SY-103 & WHC-SD-WM-ER-471 & \\
DST & & \\
\hline T-102 & HNF-SD-WM-ER-700 & \\
\hline SST & & \\
\hline T-104 & HNF-SD-WM-ER-372 & \\
SST & & \\
\hline T-105 & HNF-SD-WM-ER-369 & \\
\hline SST & & \\
\hline T-106 & WHC-SD-WM-ER-544 & Used auger samples. \\
SST & & \\
\hline T-107 & HNF-SD-WM-ER-382 & \\
\hline SST & & \\
\hline T-108 & WHC-SD-WM-ER-554 & Used auger samples. \\
SST & & \\
\hline T-109 & WHC-SD-WM-ER-559 & Used auger samples. \\
SST & & \\
\hline T-110 & HNF-SD-WM-ER-686 & \\
SST & & \\
\hline
\end{tabular}


HNF-4232 Rev. 0

Table A-1. Safety Screen Tanks (8 Sheets)

\begin{tabular}{|c|c|c|}
\hline Tank 241- & TCR No. & Comments \\
\hline $\begin{array}{l}\text { T-111 } \\
\text { SST }\end{array}$ & HNF-SD-WM-ER-540 & \\
\hline $\begin{array}{l}\text { T-112 } \\
\text { SST }\end{array}$ & HNF-SD-WM-ER-699 & \\
\hline $\begin{array}{l}\text { T-201 } \\
\text { SST }\end{array}$ & HNF-1501 & \\
\hline $\begin{array}{c}\mathrm{T}-202 \\
\text { SST }\end{array}$ & HNF-1501 & \\
\hline $\begin{array}{l}\text { T-203 } \\
\text { SST }\end{array}$ & HNF-1501 & \\
\hline $\begin{array}{c}\mathrm{T}-204 \\
\text { SST }\end{array}$ & HNF-1501 & \\
\hline $\begin{array}{c}\text { TX-104 } \\
\text { SST }\end{array}$ & HNF-SD-WM-ER-672 & \\
\hline $\begin{array}{c}\text { TX-107 } \\
\text { SST }\end{array}$ & WHC-SD-WM-ER-584 & Used auger samples. \\
\hline $\begin{array}{c}\text { TY-104 } \\
\text { SST }\end{array}$ & WHC-SD-WM-ER-481 & Used auger samples. \\
\hline $\begin{array}{c}\text { TY-106 } \\
\text { SST }\end{array}$ & WHC-SD-WM-ER-482 & Used auger samples. \\
\hline $\begin{array}{l}\text { U-102 } \\
\text { SST }\end{array}$ & HNF-SD-WM-ER-618 & \\
\hline $\begin{array}{l}\text { U-103 } \\
\text { SST }\end{array}$ & HNF-SD-WM-ER-712 & \\
\hline $\begin{array}{c}\text { U-105 } \\
\text { SST }\end{array}$ & WHC-SD-WM-ER-617 & \\
\hline $\begin{array}{c}\text { U-106 } \\
\text { SST }\end{array}$ & HNF-SD-WM-ER-636 & \\
\hline $\begin{array}{l}\text { U-107 } \\
\text { SST }\end{array}$ & WHC-SD-WM-ER-614 & \\
\hline $\begin{array}{l}\text { U-108 } \\
\text { SST }\end{array}$ & HNF-SD-WM-ER-639 & \\
\hline $\begin{array}{l}\text { U-109 } \\
\text { SST }\end{array}$ & WHC-SD-WM-ER-609 & \\
\hline $\begin{array}{l}\text { U-110 } \\
\text { SST }\end{array}$ & HNF-SD-WM-ER-551 & \\
\hline $\begin{array}{l}\text { U-112 } \\
\text { SST }\end{array}$ & HNF-SD-WM-ER-720 & \\
\hline $\begin{array}{l}\text { U-201 } \\
\text { SST }\end{array}$ & WHC-SD-WM-ER-483 & \\
\hline $\begin{array}{c}\text { U-202 } \\
\text { SST }\end{array}$ & WHC-SD-WM-ER-484 & \\
\hline
\end{tabular}


Table A-1. Safety Screen Tanks (8 Sheets)

\begin{tabular}{|c|c|c|}
\hline Tank 241- & TCR No. & Comments \\
\hline $\begin{array}{c}\text { U-203 } \\
\text { SST }\end{array}$ & WHC-SD-WM-ER-48 & \\
\hline $\begin{array}{c}\text { U-204 } \\
\text { SST }\end{array}$ & WHC-SD-WM-ER-486 & \\
\hline
\end{tabular}

\section{A4.0 TANK DATA EVALUATION RESULTS}

Since Recommendation 93-5 was issued, thousands of waste analyses and resulting data points have been obtained and recorded (LMHC 1999). From these data, individual tank waste composition and behavior can be determined. These data can also be applied to other tanks using historical information and statistical analysis.

Table A-2 shows the waste types found at Hanford, the approximate volume and number of tanks with each waste type, the percent of tanks with that waste sampled, and the representative volume of waste sampled. There are five major waste types at Hanford (Bismuth Phosphate, REDOX, PUREX, Uranium Recovery, and Concentrates). These waste types are associated with the principal separation processes used at Hanford. There are also waste sub-types that are derivatives of (e.g., ferrocyanide, strontium recovery) or associated with (e.g., cladding waste) these major waste types. The miscellaneous category includes small amounts of experimental wastes and the diatomaceous earth/Portland Cement additions that do not fit into the other waste categories.

The percent of volume sampled (Table A-2) was determined using the Best-Basis Inventory volume for each waste type in each tank and assuming a sample of a particular waste type was representative of the waste type in characteristics and composition.

For example, the total Best-Basis Inventory volume for bismuth phosphate waste is $5,273,000$ gallons (Table A-2). The volume of that process waste represented by samples is 4,587,000 gallons (e.g., there are samples and analytical results from tanks that collectively have 4,587,000 gallons of bismuth phosphate waste, based on Best-Basis Inventory estimates). 
Table A-2. Waste Types Sampled

\begin{tabular}{|l|c|c|c|c|}
\hline Process Waste Type & $\begin{array}{c}\text { Number } \\
\text { of Tanks }\end{array}$ & $\begin{array}{c}\text { Volume } \\
\text { (Gallons) }\end{array}$ & $\begin{array}{c}\text { Percent of } \\
\text { Tanks Sampled }\end{array}$ & $\begin{array}{c}\text { Percent of } \\
\text { Volume Sampled }\end{array}$ \\
\hline Bismuth Phosphate & 49 & $5,273,000$ & 67 & 87 \\
\hline REDOX & 36 & $2,932,000$ & 56 & 67 \\
\hline PUREX & 13 & $1,380,000$ & 92 & 99 \\
\hline Uranium Recovery & 21 & 745,000 & 76 & 59 \\
\hline \multicolumn{1}{|c|}{ Sub-Type } & & & & 84 \\
\hline Ferrocyanide & 18 & 957,000 & 83 & 84 \\
\hline B-Plant Reprocessing & 24 & 624,000 & 92 & 97 \\
\hline A1 Cladding & 35 & $2,092,000$ & 89 & 100 \\
\hline Zr Cladding & 4 & 577,000 & 100 & 80 \\
\hline Miscellaneous & 16 & 639,000 & 81 & 40 \\
\hline \multicolumn{1}{|c|}{ Concentrates } & & & & 100 \\
\hline 242-B and 242-T1 & 16 & $1,288,000$ & 63 & 75 \\
\hline BY Saltcake & 14 & $3,922,000$ & 100 & 5 \\
\hline 242-S1 and 242-S2 & 26 & $10,344,000$ & 77 & 97 \\
\hline 242-T2 ${ }^{3}$ & 25 & $5,771,000$ & 20 & 93 \\
\hline 242-A1 and 242-A2 & 27 & $14,651,000$ & 93 & \\
\hline
\end{tabular}

Notes:

PUREX $=$ Plutonium uranium reduction extraction

REDOX $=$ Reduction oxidation

${ }^{1}$ Most tanks have more than one waste type; thus, the "number of tanks" column will not sum to 177

${ }^{2}$ Continuing waste management operations will cause the current total volume of waste in the tanks to vary slightly from the values presented here.

${ }^{3}$ Two additional tanks containing 242-T2 waste have been sampled in fiscal year 1999 (TX-113 and TX-118). Results from these two tanks will increase the percent of tanks sampled to $28 \%$ and the represented volume to $17 \%$ for $242-\mathrm{T} 2$ concentrates. Because of the limited variations exhibited by other concentrated wastes, this degree of representation is considered sufficient.

The information from historical and empirical data indicates that over $90 \%$ of the chemical inventory by mass can be attributed to a select number of common analytes. Water, sodium, nitrate, nitrite, phosphate, aluminum, and hydroxide make up over $80 \%$ of the waste by mass. Over $90 \%$ of the radioactivity can be attributed to a limited number of analytes. Cesium-137, strontium-90, uranium, plutonium, and americium (all isotopes) are the main contributors to the waste activity (Kupfer et al. 1999).

Trace contributors do not change the overall tank mass or activity. However, some of these trace contributors are the analytes of interest for hazard identification and risk estimation (e.g., TOC and total alpha). Figures A-2 through A-15 present the values observed in the tank characterization data (Cebula et al. 1999).

Each figure shows the analytical results (LMHC 1999) versus the documented limits in the safety screening DQO (dashed line) or BIO (solid line). In some cases, the data scale 
is not broad enough to encompass these values, and so only one (or no) lines may be displayed in the figure. Safety screening limits are not safety limits. Therefore, values above the safety screening limits do not necessarily mean an unsafe condition exists. The safety screening limits are conservative thresholds that require additional data to be collected or evaluations to be performed.

All of the safety screening analytical data used to prepare Figures A-2 through A-15 is in the Tank Characterization Database. Primary and duplicate results obtained from segment, subsegment, auger, grab, and composite samples were used. With the exception of energetics, the data were downloaded on January 5, 1999. The energetics data was downloaded on February 2, 1999. For additional information on the development of Figures A-2 through A-15, see Cebula et al. (1999).

Figures A-2 through A-11 show each analyte univariately as a frequency histogram. The inset box on the graphic provides summary statistics for the data evaluated. Figures A-12 through A-15 show the analyte behavior bivariately; thus, relationships between two analytes and their respective safety limits can more easily be seen.

Figure A-2 illustrates the total alpha concentration data in the liquid phase. The low values show the alpha emitters present in the waste are not soluble. The concentration of alpha emitters in the liquid phase never approaches the safety screening limits.

Figure A-3 illustrates the total alpha concentration data in the solid phase. It shows that the alpha emitter concentration in the solids is very low in the vast majority of the tanks. A select number of tanks have concentrations above the safety screening limit. This is expected because these tanks received waste from the Plutonium Finishing Plant. Several factors such as the presence of neutron poisons and unfavorable geometry reduce reactivity. All measurements are below the idealized minimum concentration calculated in the BIO, to maintain the waste in a sub-critical condition.

Figure A-4 illustrates the energy content of the liquid phase. It shows that the exothermic response rarely exceeds the safety screening limit, and does not approach the BIO limit for propagation.

Figure A-5 illustrates the energy content of the solid phase. It shows that the exothermic response rarely exceeds the safety screening limit. However, there are a few outliers with high energy content that exceed the safety screening limit and BIO limit on a dry basis. The presence of water kept these with the authorization basis safety limits. Propagation tests were conducted on the waste from tanks with the highest energy. Direct testing showed the waste would not propagate even when dried (see Section 3.1.3)

Figure A-6 illustrates that most of the liquid phase samples analyzed have TOC concentrations well below the safety screening threshold, and that none of the samples analyzed are above the BIO limit for TOC. 
Figure A-7 illustrates that most of the solid phase samples analyzed have TOC concentrations well below the safety screening and BIO limits. The presence of water kept these results within the authorization basis safety limits. However, there are a few outliers with TOC concentrations above these limits. Propagation tests were conducted on the waste from the tanks with the highest TOC content. Direct testing showed the waste would not propagate even when dried (see Section 3.1.3).

Figure A-8 illustrates the oxalate concentration presented as TOC in the liquid phase. The large number of low values shows the oxalate present in the waste is not soluble. Oxalate docs not contribute much to the TOC content of the liquids.

Figure A-9 illustrates the oxalate concentration presented as TOC in the solid phase. The left side of the histogram mirrors the distribution observed in Figure A-7. This behavior was expected because of the oxidation process the organic materials have undergone as a function of time. Oxalate is a substantial contributor to overall TOC content ranging between $30 \%$ and $40 \%$ of the TOC measured. The presence of large amounts of oxalate in the waste precludes accident scenarios involving propagation (Fauske 1996).

Figure A-10 illustrates the concentration of water in the liquid samples. Over half of the samples taken have water concentrations less than $51 \%$ weight, indicating a significant amount of sample mass is represented by dissolved solids in the liquid phase. However, the minimum water content found $(26.95 \%)$ was above the theoretical minimum for a continuous liquid phase of $20 \%$, which precludes a propagating reaction.

Figure A-11 illustrates the concentration of water in the solid samples. Approximately $10 \%$ of the samples have water concentrations less than $20 \%$, which can influence waste behavior with respect to propagating reactions. Further information such as energetic behavior and TOC content is used to assess the safety condition of these tanks (see Figures A-5 and A-7).

Figure A-12 illustrates the distribution of energetic behavior with respect to water content in liquid samples. The bordered area in the figure shows where the safety screening and BIO limits are with respect to the data. None of the samples enter either bordered area where high energetic behavior and low water concentration would pose a potential hazard.

Figure A-13 illustrates the distribution of energetic behavior with respect to water content in solid samples. The bordered area in the figure shows where the safety screening and BIO limits are with respect to the data. None of the samples enter the bordered area formed by the BIO limits where high energetic behavior and low water concentration would pose a potential hazard. There are some on the border of the safety screening limits, but these samples were analyzed further and found not to propagate. Other samples with high energetic content have water concentrations far above the amount needed to quench any propagating reaction. 
Figure A-14 illustrates the distribution of TOC with respect to water content in liquid samples. The bordered area in the figure shows where the safety screening and BIO limits are with respect to the data. None of the samples enter either bordered area where high TOC and low water concentration would pose a potential hazard.

Figure A-15 illustrates the distribution of TOC with respect to water content in solid samples. The bordered area on the graphic shows where the safety screening and BIO limits are with respect to the data. None of the samples enter the bordered area formed by the BIO limits where high TOC and low water concentration would pose a potential hazard. There are some on the border of the safety screening limits, but these samples were analyzed further and found not to propagate (see Figures A-5 and A-7). Other samples with high TOC content have water concentrations far above the amount needed to quench any propagating reaction.

The data collected represent thousands of individual samples from a wide range of waste and tanks. It provides evidence that the values used for safety analyses assure that the waste is bounded with respect to chemical and radiological hazards. 
Figure A-2

Total Alpha for Liquid Samples

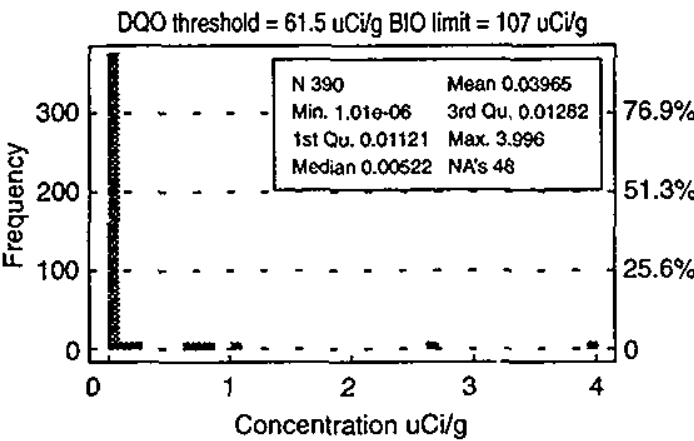

Concentration uCi/g
Figure A-4

Energetics for Liquid Samples DoO threshold $=480 \mathrm{~J} / \mathrm{g}$ BiO limit $=1200 \mathrm{~J} / \mathrm{g}$

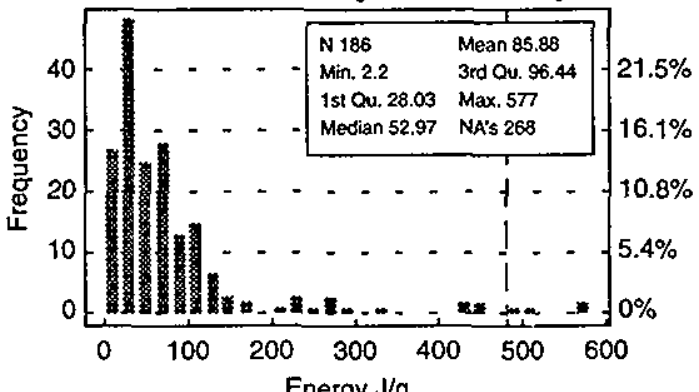

Energy $J / 900 \quad 600$
Figure A-6

TOC for Liquid Samples

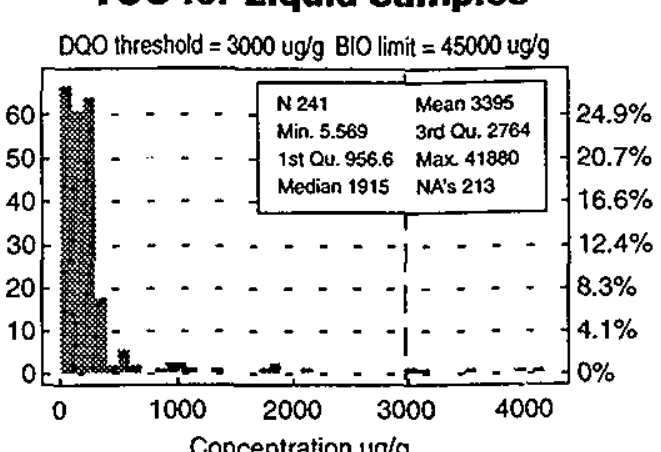

Concentration ug/g
Figure A-8

Oxalate for Liquid Samples

D0O threshold $=30000 \mathrm{ug} / \mathrm{g}$ BlO limit $=45000 \mathrm{ug} / \mathrm{g}$

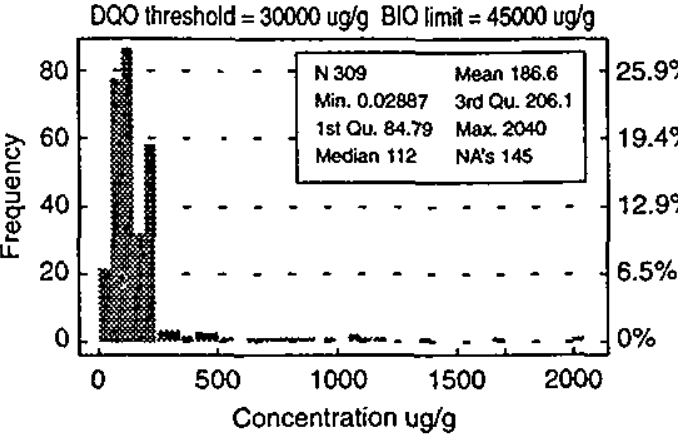

Concentration ug/g
Figure A-10

$\mathrm{H}_{2} \mathrm{O}$ for Liquid Samples

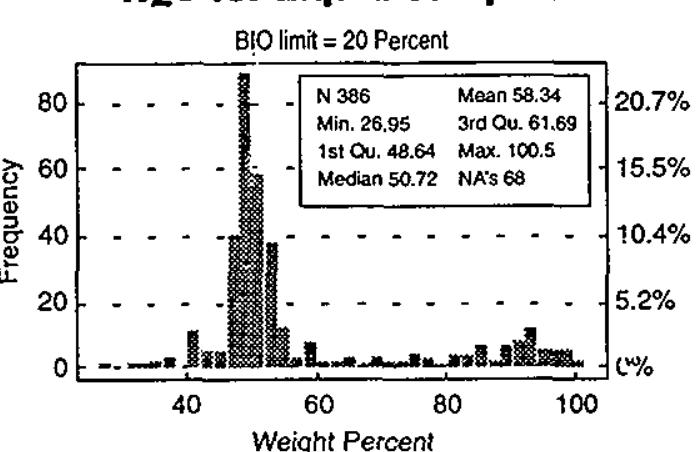

Figure A-3

Total Alpha for Solid Samples

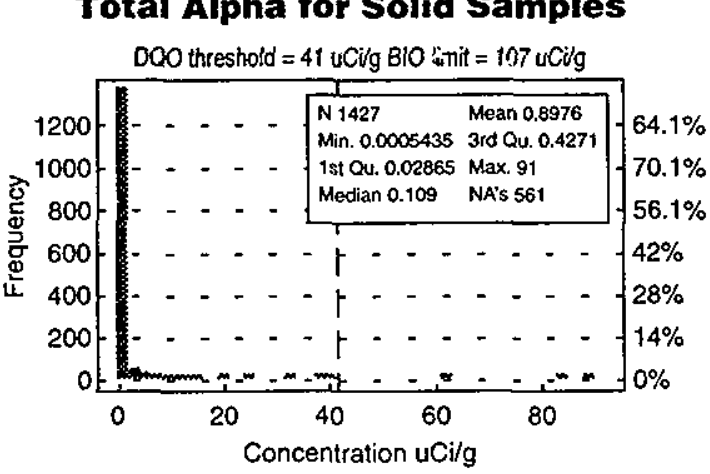

Figure A-12

Energetics vs. $\mathrm{H}_{2} \mathrm{O}$ for Liquid Samples Energetic D0O threshold $=480 \mathrm{~J} / \mathrm{g}$

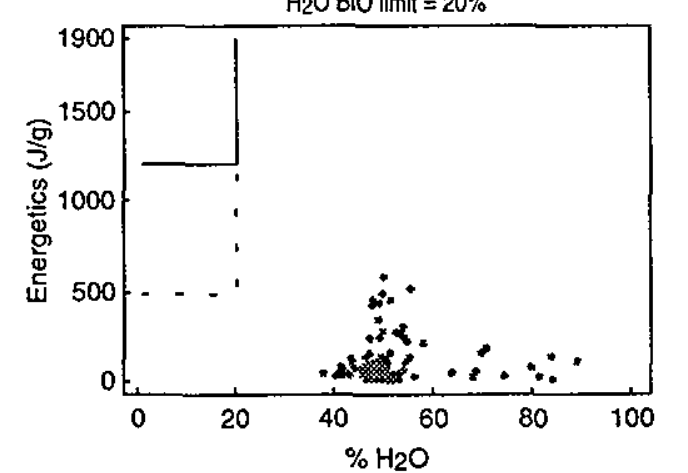

Figure A-5

Eneigetics for Solid Samples DoO thresteld = 400 ing ain int

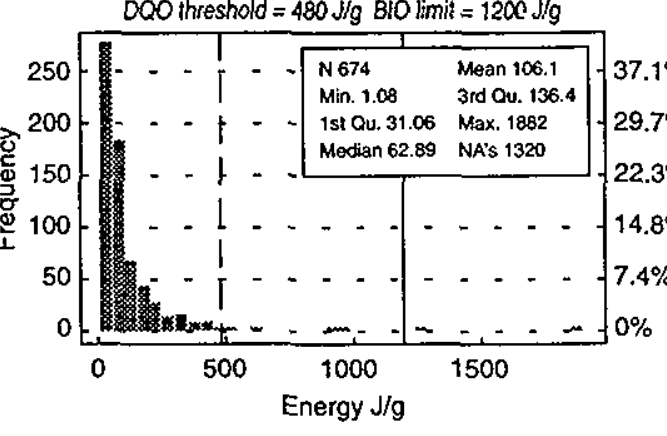

Figure A-13

Energetics vs. $\mathrm{H}_{2} \mathrm{O}$ for Solid Samples Energetic D0O threshold = 480 $\mathrm{J} / 9$

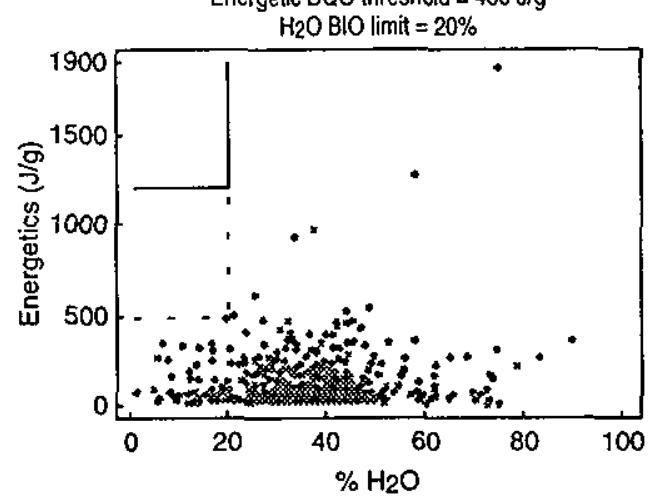

Figure A-7

TOC for Solid Samples

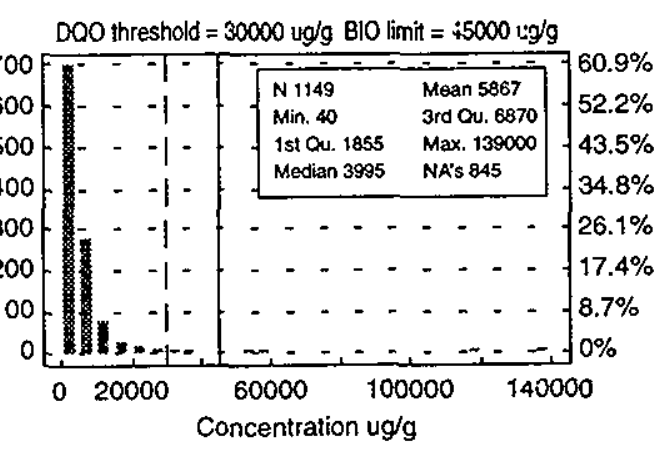

Figure A.9

Oxalaie for Solid Samples DDO threshold $=30000 \mathrm{vg} / \mathrm{g}$ BIO limit $=45000 \mathrm{ug} / \mathrm{g}$

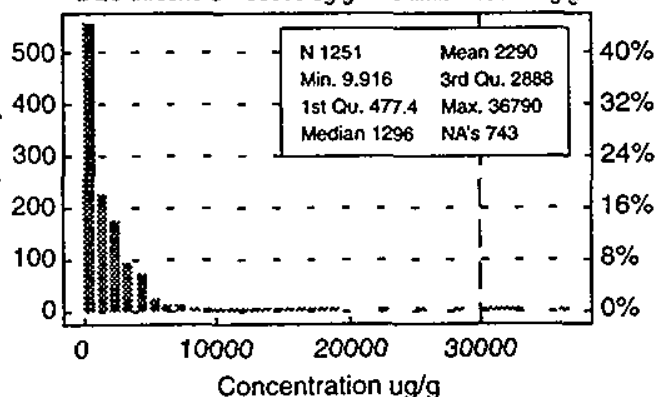

Concentration ug/g

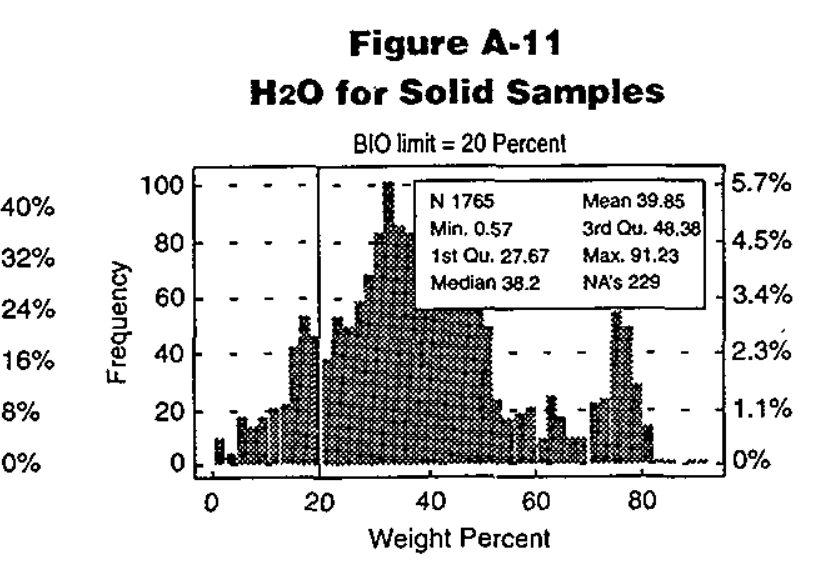

Figure A-15

TOC vs. $\mathrm{H}_{2} \mathrm{O}$ for Solid Samples OCC DoO threshold = 30,000 ugls

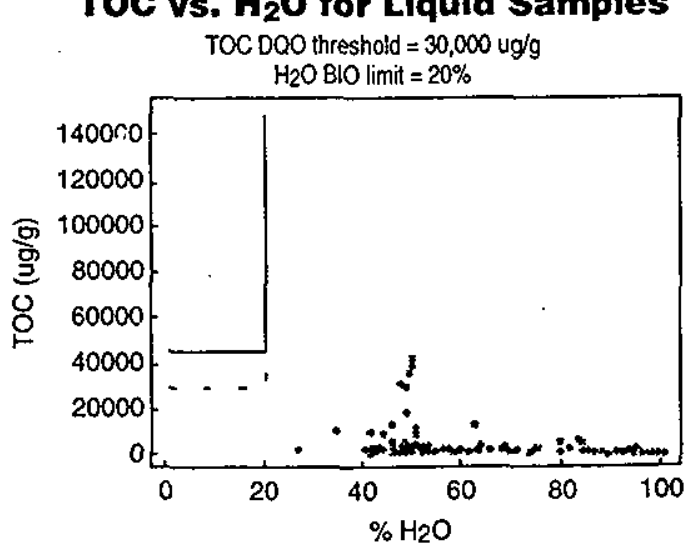




\section{A5.0 REFERENCES}

Agnew, S. F., J. Boyer, R. A. Corbin, T. B. Duran, J. R. FitzPatrick, K. A. Jurgensen, T. P. Ortiz, and B. L. Young, 1997, Hanford Tank Chemical and Radionuclide Inventories: HDW Model Rev. 4, LA-UR-96-3860, Los Alamos National Laboratory, Los Alamos, New Mexico.

Brevick, C. H., J. L. Stroup, and J. W. Funk, 1997a, Historical Tank Content Estimate for the Northeast Quadrant of the Hanford 200 East Area, WHC-SD-WM-ER-349, Rev. 1B, Fluor Daniel Northwest, Inc., for Fluor Daniel Hanford, Inc., Richland, Washington.

Brevick, C. H., J. L. Stroup, and J. W. Funk, 1997b, Historical Tank Content Estimate for the Southeast Quadrant of the Hanford 200 East Area, HNF-SD-WM-ER-350, Rev. 1, Fluor Daniel Northwest, Inc., for Fluor Daniel Hanford, Inc., Richland, Washington.

Brevick, C. H., J. L. Stroup, and J. W. Funk, 1997c, Historical Tank Content Estimate for the Northwest Quadrant of the Hanford 200 East Area, HNF-SD-WM-ER-351, Rev. 1, Fluor Daniel Northwest, Inc., for Fluor Daniel Hanford, Inc., Richland, Washington.

Brevick, C. H., J. L. Stroup, and J. W. Funk, 1997d Historical Tank Content Estimate for the Southwest Quadrant of the Hanford 200 East Area, HNF-SD-WM-ER-352 Rev. 1, Fluor Daniel Northwest, Inc., for Fluor Daniel Hanford, Inc., Richland, Washington.

Cebula, S. T., T. M. Ferryman, C. A. LoPresti, and B. C. Simpson, 1999, Descriptive Display of Total TOC, $\mathrm{H}_{2} \mathrm{O}$, Total Alpha, and Energetics, Pacific Northwest National Laboratory, Richland, Washington.

Conway, J. T., 1993, Defense Nuclear Facilities Safety Board Recommendation 93-5 to the Secretary of Energy, July 19, Defense Nuclear Facilities Safety Board, Washington, District of Columbia.

DOE-RL, 1996, Recommendation 93-5 Implementation Plan, DOE/RL 94-0001, Rev. 1, U.S. Department of Energy, Richland Operations Office, Richland, Washington.

Dukelow, G. T., J. W. Hunt, H. Babad, and J. E. Meacham, 1995, Tank Safety Screening Data Quality Objective, WHC-SD-WM-SP-004, Rev. 2, Westinghouse Hanford Company, Richland, Washington.

Fauske, H. K. 1996, Assessment of Chemical Vulnerabilities in the Hanford High Level Tank Wastes, WHC-SD-WM-ER-543, Rev. 0, Westinghouse Hanford Company, Richland, Washington. 
Kupfer, M. J., A. L. Boldt, B. A. Higley, K. M. Hodgson, L. W. Shelton, B. C. Simpson, R. A. Watrous, S. L. Lambert, D. E. Place, R. M. Orme, G. L. Borsheim, N. G. Colton, M. D. LeClair, R. T. Winward, and W. W. Schulz, 1999, Standard Inventories of Chemicals and Radionuclides in Hanford Site Tank Wastes, HNF-SD-WM-TI-740, Rev. OC Lockheed Martin Hanford Corp. for Fluor Daniel Hanford, Inc., Richland, Washington.

LMHC 1999, Tank Characterization Database, Internet at http://twins.pnl.gov:8001/TCD/main.html.

Reynolds, D. A., 1997, Chemical and Chemically-Related Considerations Associated with Sluicing Tank C-106 Waste to Tank AY-102, HNF-SD-WM-TI-756, Rev. 2, Lockheed Martin Hanford Corp. for Fluor Daniel Hanford, Inc., Richland, Washington.

Reynolds, D. A., W. T. Cowley, J. A. Lechelt, B. C. Simpson, and C. DeFigh- Price, 1999, Evaluation of Tank Data for Safety Screening, HNF-4217, Rev. 0, Lockheed Martin Hanford Corporation, Richland, Washington. 
HNF-4232 Rev. 0

APPENDIX B

SUMMARY OF UNSAMPLED OR INSUFFICIENTLY SAMPLED TANKS

B-1 
HNF-4232 Rev. 0

This page intentionally left blank.

B-2 
HNF-4232 Rev. 0

\section{APPENDIX B \\ SUMMARY OF UNSAMPLED OR INSUFFICIENTLY SAMPLED TANKS}

\section{B1.0 INTRODUCTION}

This appendix summarizes information on the unsampled or incompletely sampled tanks and presents the basis that the intent of DNFSB 93-5 milestone 5.6.3.1j has been met. Section B2.0 describes the logic and steps used to evaluate the 45 unsampled or incompletely sampled tanks with respect to the safety issues.

Section B3.0, discusses the general information used to support the individual tank evaluations. This includes a discussion on the use of data from sampled tanks with similar waste material. It addresses why this data can be used as evidence to demonstrate that the incompletely sampled tanks are within the authorization basis. For each of the safety issues the tanks are to be evaluated against, there is a discussion of the specific criteria that is used to support the evaluation.

Section B4.0 presents the detailed tank-by-tank evaluation of the remaining 45 tanks, providing:

- Background information,

- The issues the tank was evaluated against,

- A brief explanation of why the remaining issues do not apply to this tank,

- A list and description of tanks with similar wastes that have been sampled, and

- An evaluation of the data available to determine if additional core sampling is required.

\section{B2.0 APPROACH FOR EVALUATION}

The evaluation of the remaining 45 unsampled or incompletely sampled tanks to ensure that wastes can be safely stored and that operations can be conducted safely focused on the following factors:

- Use of the Waste Status and Transaction Record Summary (WSTRS) to predict the quantities and types of waste layers in each of these 45 tanks. 
- Use of the Best Basis Inventory for the 45 tanks, which combined WSTRS, sampling data for the 132 sampled tanks, general chemical and physical information, documented chemical and radionuclide inputs, and pre-1989 sampling/analytic data for the 45 tanks, to predict the specific waste types layered in each of these 45 tanks.

- Use of sampling, analytic, and surveillance data from the 132 adequately sampled tanks to predict the behavior and composition of each of waste type, and to verify that each of the waste types is adequately encompassed by the source terms and hazard assessment evaluation contained in the current Authorization Basis (BIO).

- Use of surveillance data from these 45 tanks to determine whether observed behavior varied from predicted behavior for any of these tanks.

Section B2.1 discusses the logic used to evaluate the remaining 45 unsampled and incompletely sampled tanks. One key element of the logic is the definition of the specific safety issues against which the tanks were evaluated. The approach and methods used are defined in Section B.2.2. In addition, the detailed technical basis and process for grouping these issues are presented.

\section{B2.1 LOGIC USED TO EVALUATE TANKS}

Figure $\mathrm{B}-1$ shows the steps (logic chart) used to evaluate each of the 45 unsampled or incompletely sampled tanks. The evaluation determined if any of the 45 tanks require additional sampling or if the tank is bounded, in terms of hazard definition and safety controls, using existing data. The results of the evaluation for each tank are described in detail in Section B4.0.

To facilitate the discussion the ten steps of the logic chart in Figure B-1 are numbered and relate to the following discussion. 
Figure B-1 Logic for Assessing Tank Data for Safety Screening

From (Continued from Figure A-1)

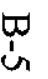

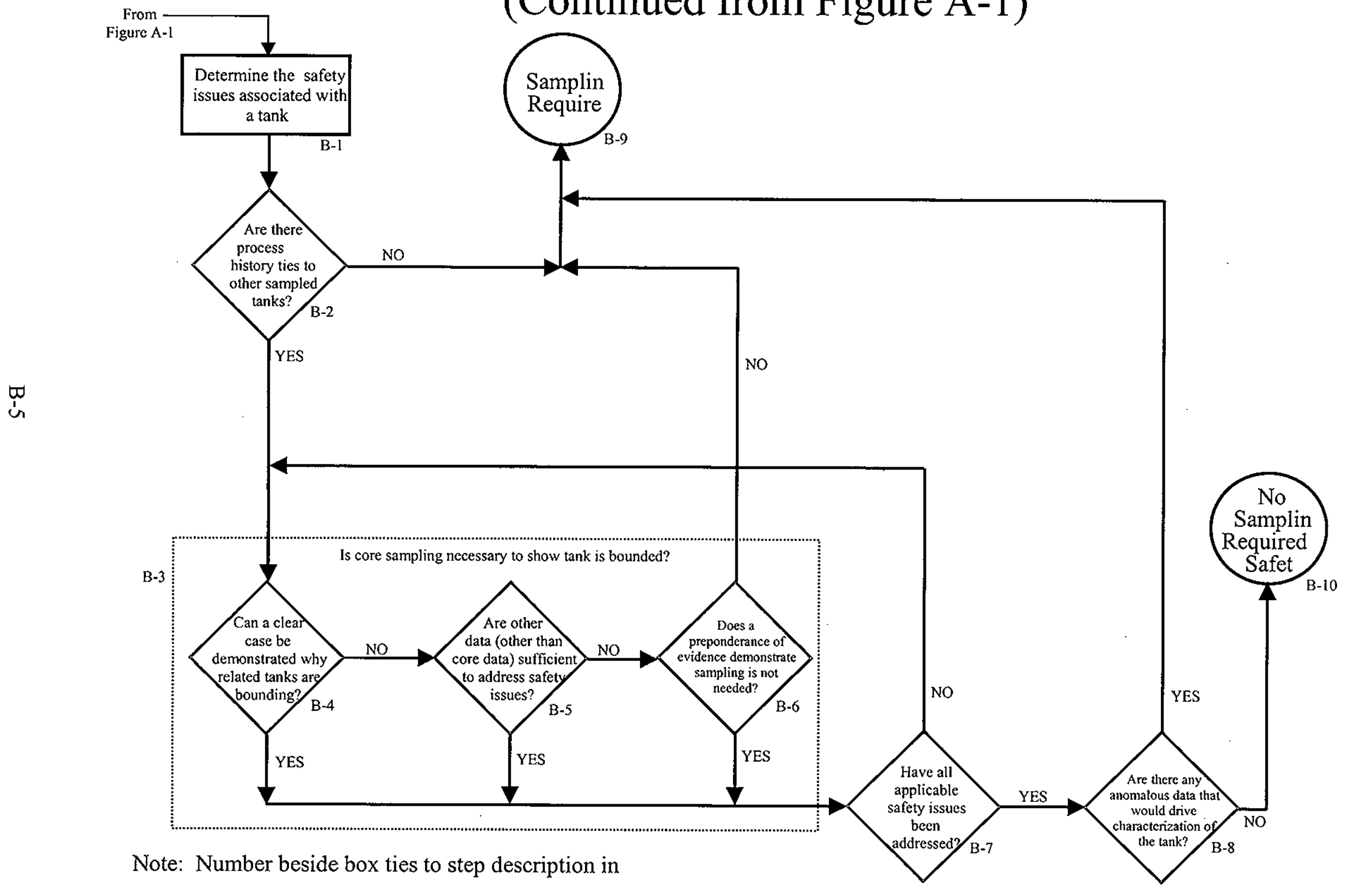

Note: Number beside box ties to step description in 
- Step B-1: At this step, the potential safety issues that apply to each of the tanks were identified based on the BIO. This selection started with the list of accident scenarios identified in the BIO and their associated safety issues as defined in Section B2.2. For any issue that is not selected, a justification was provided.

- Step B-2: In this step the existence of a sampled tank, with the same waste types as the tank being evaluated, was determined. This determination was based on the BestBasis Inventory predictions for waste layers in each of the 45 unsampled or incompletely sampled tanks. The correlation of waste types between sampled and unsampled tanks may be based on physical constraints linking the tanks, or on convincing evidence such as transaction and process history. If any of these tanks contained a waste type that was not similar to the waste types in the 132 adequately sampled tanks, core sampling is required and no further review was necessary.

- Step B-3: This is a decision step that asks if core sampling is necessary to verify that each of the waste types in each tank is adequately encompassed by the source terms, hazard assessment evaluation, and safety controls contained in the current authorization basis, the BIO. Step B-3 is composed of three sub-criteria (steps B-4 through B-6). There is an iterative loop (step B-7) through step B-3 to confirm all safety issues associated with each tank were reviewed.

- Step B-4: This step asks if there were physical constraints that prove that the waste layers in the unsampled tank are similar to wastes in tanks that have been core sampled and analyzed. An example of this situation is the third (last) tank in a cascade that only received waste from the upstream tanks in the cascade. If the tanks upstream had been characterized, the waste in the unsampled tank contains the same material. The only difference being settling of the larger particle material in the upstream tanks.

- Step B-5: This step asks if data, other than core sample data, was adequate to address the safety issue. Examples where data from sources other than core sampling was adequate to address safety issues for individual tanks included:

- Standard Hydrogen Monitoring System (SHMS) monitoring data for hydrogen and other flammable gases (flammable gas safety issue),

- Waste level monitoring data, especially changes attributed to the barometric pressure effect (flammable gas safety issue),

- Temperature and ventilation monitoring data (high heat safety issue), and

- Partial samples of the waste to evaluate for criticality and organic-nitrate reactions. 
- Step B-6: This step asks if there was convincing evidence to demonstrate that the waste layers in the unsampled tank are similar to wastes in 132 tanks that have been core sampled and analyzed, even if these tanks were not connected directly to each other. Examples of evidence used in this step includes:

- Use of WSTRS, as refined by data from the 132 adequately sampled tanks, to construct the Best Basis Inventory of quantities and waste types in the unsampled tanks,

- In-tank photography,

- Vapor sampling data,

- Data from pre-1989 core sampling

- Experimental data from simulants and models

- Data from a tank identified in a safety issue topical report are considered to represent the limiting conditions that exist in tank farms. These tanks have been demonstrated to be within the authorization basis, and are thus bounded in terms of hazard definition and safety controls.

Step B-6 was not used if either step B-4 or B-5 was answered affirmatively (an asterisk, *, was put in the table if another logic box satisfied the issue).

- Step B-7: This step asks if each of the safety issues identified in step B-1 and associated with the tank being evaluated have been reviewed to determine that the source term, hazards assessment, and safety controls specified in the BIO are adequate for that tank. The review continued (iteration through step B-3) until all safety issues associated with that tank were addressed.

- Step B-8: After each of the applicable safety issues were reviewed for the individual tank, the last step (decision step B-8) determined if there were any other additional data that would reduce or increase the need for core sampling to ensure that the wastes can be safely stored and that operations can be conducted safely. Examples of additional data include:

- Unique waste additions, such as cement or unprocessed fuel rods.

- Unique occurrences associated with individual tanks, such as the steam bump in A-105.

- Step B-9: Tanks that required additional characterization through sampling and analysis to obtain adequate technical understanding of the tank.

- Step B-10: Tanks that did not require additional sampling to ensure that interim storage controls are appropriate. 


\section{B2.2. SAFETY ISSUE AND ACCIDENT EVALUATION}

Box B-1 of Figure B-1 requires that applicable safety issues be identified that are associated with the specific tank being evaluated. To determine what safety issues should be considered, the staff started with the list of 28 representative accidents in the BIO (Noorani 1999, page ES-17). This list, shown as Table B-1, is the product of a thorough hazard assessment evaluation. The hazard assessment evaluation covers types of accidents that could result in potential radiological exposures to on-site workers, the public, and the environment. The representative accidents were broken into three categories (shown in the second column of Table B-1).

Table B-1. Representative Accidents Evaluated in the Authorization Basis (Noorani 1999) (2 Sheets)

\begin{tabular}{|c|c|}
\hline Representative Accidents & Category \\
\hline 1. Nuclear Criticality & C - Criticality \\
\hline 2. In-Tank Fuel Fire/Deflagration & $\mathrm{B}$ \\
\hline 3. Mixing of Incompatible Material - Tank Pressurization & $\mathrm{B}$ \\
\hline 4. Flammable Gas Deflagrations & C - Flammable Gas \\
\hline $\begin{array}{l}\text { 5. HEPA Filter Failure - Exposure to High Temperature or } \\
\text { Pressure }\end{array}$ & $\mathrm{B}$ \\
\hline 6. Fire in Contaminated Area & A \\
\hline 7. Waste Transport Vehicle Accident & $\bar{B}$ \\
\hline 8. Organic Solvent Fire/Organic Salt-Nitrate Reaction & $\begin{array}{l}\text { C - Ferrocyanide, } \\
\text { Organic Complexant, } \\
\text { Organic Solvent }\end{array}$ \\
\hline 9. Natural Phenomena - High wind & $\mathrm{B}$ \\
\hline 10. Natural Phenomena - Lightning & $\begin{array}{c}\text { C - Organic Complexant } \\
\text { Organic Solvents, } \\
\text { Flammable Gas }\end{array}$ \\
\hline 11. Tank Failure Due to Excessive Loads & $\mathrm{B}$ \\
\hline 12. Tank Failures due to Vacuum or Degradation & B \\
\hline 13. Natural Phenomena - Seismic & B \\
\hline $\begin{array}{l}\text { 14. Spray Leak in Structure or from Overground Waste } \\
\text { Transfer Lines }\end{array}$ & $\mathrm{B}$ \\
\hline 15. Spray Leak from Underground Waste Transfer Lines & $\mathrm{B}$ \\
\hline 16. Caustic Spray Leak & A \\
\hline 17. Tank Bump & C - High Heat \\
\hline 18. Unfiltered Release & $\mathrm{B}$ \\
\hline 19. Subsurface Leak Resulting from Pool & $\mathrm{B}$ \\
\hline 20. Evaporator Dump & B \\
\hline $\begin{array}{l}\text { 21. Mixing of Incompatible material - Toxic Vapor } \\
\text { Generator }\end{array}$ & $\bar{A}$ \\
\hline 22. Leak from Railcar/Tank Trailer & B \\
\hline 23. Surface Leak Resulting in Pool & B \\
\hline
\end{tabular}


HNF-4232 Rev. 0

Table B-1. Representative Accidents Evaluated in the Authorization Basis (Noorani 1999) (2 Sheets)

\begin{tabular}{|l|c|}
\hline \multicolumn{1}{|c|}{ Representative Accidents } & Category \\
\hline 24. Unplanned Excavation/Drilling in Pond/Ditch/Crib & $\mathrm{A}$ \\
\hline 25. Subsurface Leak Remaining Subsurface & $\mathrm{B}$ \\
\hline 26. Sodium Fire & $\mathrm{A}$ \\
\hline 27. Above Ground Structure Failure & $\mathrm{A}$ \\
\hline 28. Steam Intrusion from Interfacing Systems & $\mathrm{B}$ \\
\hline
\end{tabular}

The accidents in the first category (coded as A in Table B-1) involve other structures assigned to TWRS, such as ponds, ditches, cribs, evaporator, surface contamination, vehicles, and above ground storage tanks and do not involve tank waste. Core sample data from the tanks will not help refine Category A accident analyses.

The second category of accidents (coded as B in Table B-1) involves events that trigger the release of DST or SST waste (Noorani 1999). The source term used for these accidents was non-tank specific and assumes a maximum concentration of each radionuclide existing in tank farms at the time of the postulated tank farm accident. Based on the accident assumptions, a specific fraction of that calculated inventory is dispersed to the environment (Van Keuren et al. 1995). This worst-case source term was developed using the available sample data through 1996 and historical information. Applying the highest potential hazard to an accident scenario by combining the highest tank waste concentration of each radionuclide and chemical analyte to make a comprehensive waste composition, a source term and was defined and found to be bounding when applied to accident analyses (Dineen et al. 1996). Additional waste characterization of other tanks would not provide information that would change the concentrations assumed in the source term. Therefore, the hazards analysis provides conservative results, and additional sampling would not affect the assumptions used to develop the existing hazard controls. .

The accidents in the third category (coded as C in Table B-1) require specific understanding of nuclear or chemical waste properties. They can all be tied to the initial safety concerns identified in 1993. These safety concerns are criticality, flammable gas, organic solvents, organic complexants, ferrocyanide, and high heat. These safety issues were reviewed for the 45 unsampled or incompletely sampled tanks to ensure an adequate understanding of the waste material in these tanks. This could allow sampling to be deferred until it is needed to support disposal decisions.

Each of the accidents in category $\mathrm{C}$ is associated with one or more of the six safety issues discussed in Section 3.1. The relationship follows:

- The criticality safety issue relates to the "Nuclear Criticality Safety Accident." 
- The ferrocyanide safety issue relates to "Organic Solvent Fire/Organic SaltNitrate Reaction." The authorization basis accident scenario indicates the worstcase issue is a propagating organic salt-nitrate reaction, and that the ferrocyanide reaction would produce a less energetic reaction. However, for the purpose of screening the unsampled or incompletely sampled tanks, the ferrocyanide safety issue is treated separately.

- The organic complexant safety issue relates to the "Organic Solvent Fire/Organic Salt-Nitrate Reaction Accident."

- The organic solvent safety issue relates to the "Organic Solvent Fire/Organic SaltNitrate Reaction Accident."

- The flammable gas safety issue relates to the "Flammable Gas Deflagration Accident".

- The high heat safety issue relates to the "Tank Bump Safety Issue."

The four BIO accident scenarios, that represent the six safety issues, assume worst-case values in the safety analyses to support the authorization basis. Table B-2 shows the limits (Noorani 1999) for the four accident scenarios. These limits were developed assuming ideal conditions for a potential accident and thus have a great deal of conservatism factored into them.

Table B-2. Limits of Concern for Safety Issues

\begin{tabular}{|c|c|}
\hline Criticality & $\begin{array}{l}2.6 \mathrm{~g} / \mathrm{L} \mathrm{Pu}-239 \\
\text { (approximately } 107 \mu \mathrm{Ci} / \mathrm{g} \text { minimum). }\end{array}$ \\
\hline Organic-Nitrate Reaction & $\begin{array}{l}4.5 \text { weight percent total organic carbon and } \\
\text { less than } 20 \text { weight percent water. }\end{array}$ \\
\hline Organic Solvent Fire $^{I}$ & 1 meter square pool organic solvent. ${ }^{2}$ \\
\hline Flammable Gas Deflagration ${ }^{1}$ & $\begin{array}{l}25 \text { percent of the lower flammability limit } \\
\text { in the tank dome space. }\end{array}$ \\
\hline
\end{tabular}

${ }^{\mathrm{I}}$ Core sampling does not provide direct information regarding the organic solvent and flammable gas accident scenarios. Vapor sampling is used to address these issues more directly. However, core sampling can provide information regarding the presence and energetic potential of organic solvents (Meacham et al. 1998) or waste properties that contribute to the generation and accumulation of flammable gases in the waste (Hodgson 1998; Hopkins 1996).

${ }^{2}$ The need to determine if a one meter square pool is present no longer exists (Cowley et al. 1999) (see Section 3.1.2). An authorization basis amendment to the BIO is currently under DOE review. 
HNF-4232 Rev. 0

\section{B3.0 TANK CHEMISTRY AND DATA OBSERVATIONS}

There are physical and chemical limits imposed on the behavior of the waste. These can come from process input limits, waste transaction limits, or basic chemistry of reactions. This section presents information to support the use of related tank sample data to evaluate the remaining 45 tanks and provides some general information on the types of waste and what is known about their key properties.

Section B3.1 provides general information on the analysis performed to date and how it compares to the historical record information (Agnew et al. 1997b). The degree of qualitative agreement observed between the historical information and the sample data provided the basis for using previously obtained tank data in the individual tank evaluations presented in Section B4.0.

Sections B3.2 through B3.7 provide specific information related to evaluating each of the six safety issues. This general data supports the tank specific evaluations that follow in Section B4.0.

\section{B3.1 TANK WASTE VARIATION LIMITS}

The waste streams coming from the various separation plants, reprocessing plants, and evaporator campaigns were well defined. There was a total inventory of the species (chemical and radionuclide) used or processed at Hanford. This total inventory was derived from invoices, manifests, and operating manuals (for the chemicals), or from reactor fuel bumup and reactor simulation computer codes (for the radionuclides) (Kupfer et al. 1999). Process knowledge, specifications, and operating procedures are also known. This information was used to develop concentration limits of the various waste components. These worst-case concentrations were used to evaluate waste data.

The tank waste came from a limited number of sources. Four separation processes are responsible for the majority of the insoluble waste (see Table A-2). The insoluble wastes are distinctive in composition and can be distinguished from each other and from the soluble wastes using sample analysis (Remund and Simpson 1997, Chen et al. 1998). However, the soluble wastes have much more in common compositionally with each other than the insoluble wastes. The soluble wastes are similar because of aqueous solution chemistry, mixing, and evaporation.

The operating histories of tanks have been researched and documented to determine the type and number of transfers in and out of the tanks (Agnew et al. 1997b). The confidence level in the transaction records has improved to the point that this data can be used to define relationships between tanks, in terms of overall waste types. The confidence level has improved because the general agreement between sample data and transaction records for the waste types has been observed to be reasonably reliable. This information is used when inferring waste composition and properties from sampled tanks to unsampled tanks. 
Though sample data often showed variation from the computerized predictions in Agnew et al. (1997a), especially with respect to specific composition (Harmsen et al. 1998), there was consistent agreement between known types of waste, their general properties, and their location. Specifically, evaporator waste exhibited a high salt content, little heavy metals or transuranics, usually contained soluble organic complexants, were often the last wastes placed in the tank, and were the top layer. The bismuth phosphate sludges from the various tanks exhibited similar general characteristics. They were low in fission products and organics, high in bismuth, aluminum, iron, and phosphate, and were usually the bottom layer in the tanks in the older tank farms (B, BX, C, T, TX, and U). The presence or absence of particular analytes, such as lanthanum, bismuth, and aluminum, distinguish distinct process variants. Other waste types such as REDOX and PUREX have similar discriminating features. REDOX wastes have extremely high aluminum levels (often greater than 10 weight percent), and are generally restricted to $200 \mathrm{West}$ area tanks. PUREX wastes have elevated iron, fission product, and alpha levels, and are generally restricted to the 200 East area tanks.

All but one of the safety issues are limited (in waste quantity and location) because of process input constraints. Ferrocyanide, organic-nitrate, organic complexants, high heat, and criticality safety issues can be traced to specific processes/tanks. The flammable gas safety issue is not process-specific. It is more closely related to features that were created in concentrated wastes during waste management processes that occurred after the wastes were in the tanks. Wastes exhibiting flammable gas retention and release characteristics appear to be confined to certain highly concentrated evaporator products.

Because of the constraints on composition and the documented process history, the unsampled tanks do not represent an unknown condition. As shown in Appendix A, most of the waste has been sampled, regardless of its location in the tank farms. Only 25 percent of the tanks and 25 percent of the representative waste volume have not been sampled. The characteristics and constraints that have been observed in sampled tanks are present in unsampled tanks and using observations from sampled tanks to evaluate unsampled tanks is valid. Because of the emphasis on sampling and analyzing the high priority tanks (Brown 1998), the data is biased high with regard to the safety issue analytes.

\section{B3.2 FERROCYANIDE}

Ferrocyanide materials were used for a short length of time (1954 to 1957), and the wastes were limited to 18 tanks. A detailed discussion of the ferrocyanide waste transfer records is presented in Borsheim and Simpson (1991). In screening the remaining 45 tanks, that list was compared to the 18 ferrocyanide tanks. If one of the unsampled tanks is a ferrocyanide tank, then the issue was identified as applying to the tank. Of the 18 tanks, 13 have been satisfactorily sampled (see Section 3.1 .1 of this document). The remaining five (BY-105, BY-106, TY-101, TY-103, and TX-118) were evaluated in

Section B4.0. The initial ten tanks sampled were identified as containing the highest 
estimated ferrocyanide material (see Section 3.1.1). The evaluation of the remaining tanks focused on the data that would support the results that the sampled tanks had a greater potential ferrocyanide hazard than the unsampled tanks.

\section{B3.2.1 Phase Limits on Ferrocyanide Waste Location}

Greater than 99 percent of the ferrocyanide used in the scavenging process was precipitated. Ferrocyanide cannot exist in tanks that are entirely evaporator concentrates or liquid because of solubility constraints. Small amounts of degraded ferrocyanide sludge can be found in certain concentrates. These concentrates may have a small amount of insoluble sludge in them, present as entrained particles. The entrained particles are too dilute to pose a hazard.

\section{B3.2.2 Physical Limits on Ferrocyanide Waste Transport}

The ferrocyanide safety issue has specific transactions that only occurred from 1954 to 1957. There were several physical limits involved in the transfer of waste. Most insoluble materials in the tank (depending on settling properties) are not carried over in cascades. The pumps used to transfer waste from tank-to-tank do not mobilize waste solids during routine transfers. Waste slurries from the plants were generally not more than 30 percent suspended solids. The solids were kept below 30 percent because of mechanical limitations of the pumps and to prevent fouling and clogging of the transfer lines. The ferrocyanide waste was insoluble and formed highly cohesive sludge, once settled in the receiving tanks. These properties made sludge unlikely to be transferred during routine tank farm operations, although intentional movement of these materials has been documented.

\section{B3.2.3 Physical and Chemical Limits on Ferrocyanide Waste Concentration}

The ferrocyanide safety issue was impacted by the initial precipitation and settling of the insoluble solids. The ferrocyanide was precipitated with other inert, insoluble compounds, and no plausible concentration mechanism exists to further concentrate the fuel.

Ferrocyanide has degraded over time due to the harsh chemical and radiological environment of the tanks. The tanks that had the highest ferrocyanide concentration were identified from process records and were sampled. The sample data found that nearly all of the ferrocyanide had decomposed (Meacham 1996).

\section{B3.3 FLAMMABLE GAS}

As was presented in Section 3.1.4 of this report, tank wastes generate flammable gas mixtures. However, there is not a safety concern unless the gases are retained and then episodically released at concentrations exceeding the LFL. Tanks that exhibit this behavior show slow waste surface level growth (measured in months or years) followed 
by a relatively sudden (measured in hours to several days) surface level drop. The episodes of gas accumulation and release can occur on a frequency from several months to 1-2 years. One of the tools used to address this safety issue is the continuous SHMS or its equivalent. The SHMS provides necessary information on the concentration and frequency of released gases. Tanks whose waste surface exhibits level fluctuations relative to changes in barometric pressure also have been shown to retain gases.

The evaluation of the remaining 45 unsampled tanks against this issue involves reviewing the waste depth versus the headspace volume criteria first. If the waste volume was insufficient to cause a concern, then this was considered direct evidence from other data instruments (surface level devices) to eliminate a tank from consideration for this safety issue. Similarly, if a SHMS has been installed on the tank, and sufficient measured data have been obtained, this also provides necessary direct data to address this safety issue.

If sufficient waste exists and there is no SHMS data, then surface level data was reviewed. This includes comparing waste surface level changes to barometric pressure changes. If the tank does not exhibit any surface level changes as a function of barometric pressure changes or changes indicative of episodic releases (Hodgson 1998), then this information, when taken with the knowledge of the flammable gas safety issue (DOE-RL 1998), provides sufficient information that the Facility Group 3 controls are adequate.

If the tank does exhibit surface level changes with barometric pressure changes or indicative of episodic releases, then the magnitude, duration (how long it takes for the surface level to drop) and frequency of the changes are evaluated against similarly characterized tanks. This is done to determine if the data from the characterized tanks bound the expected gas release. If the tank shows surface level fluctuations less than a sampled tank with similar waste types and volumes, then the sampled tank should provide comparable information.

\section{B3.3.1 Phase Limits on Flammable Gas Waste Location}

The flammable gas safety issue is constrained by phase limitations. Flammable gas retention and release behavior is observed solely in evaporator concentrates. The insoluble sludge does not appear to have the necessary characteristics for gas accumulation and release as observed in the tanks having gas release events. Most of the inventory of the unsampled tanks $(74 \%)$ consists of concentrated salt solutions (both solids and liquids). However, because of waste volume surveillance and in-tank monitoring of the head space, the tanks exhibiting the greatest degree of flammable gas behavior have been noted and are monitored closely. 


\section{B3.3.2 Physical Limits on Flammable Gas Waste Transport}

The waste that exhibits flammable gas behavior is highly concentrated solutions. These solutions were formed in one of the evaporators and delivered to their tanks at relatively high temperatures, or were generated by self-concentration.

The evaporator wastes had several characteristics that limited their movement. Waste slurries from the evaporators were generally not more than 30 volume percent suspended solids because of mechanical limitations of the pumps. Furthermore, because of the degree of concentration that occurred in these wastes, line clogging and fouling was frequently observed when these slurries were transferred. This would occur because the wastes would solidify from the heat loss during the transfer from the evaporator to the tank. Most waste was added via underground pipes. These pipes only go between certain buildings and tanks, even with jumper and diversion boxes to facilitate transfers between . tanks. Thus, proximity between process plant and tank farms often figured into waste management strategy, and identification of tanks with likely flammable gas characteristics is simplified.

\section{B3.3.3 Physical and Chemical Limits on Flammable Gas Waste Properties}

Dilution effects have a direct impact on the flammable gas safety issue. Detailed calculations (Hodgson 1998) have shown that if the waste in a standard 75-foot diameter tank is less than 40 inches deep (approximately 110,000 gallons), the flammable gas problem described above will not exist. The problem will not exist because the amount of gas that could be accumulated and released by the waste volume is not sufficient to exceed the LFL in the headspace. The relative volume of the headspace, compared to the volume of waste is such that the released gases would always dilute below $25 \%$ of the LFL.

\section{B3.4 ORGANIC COMPLEXANTS}

Organic complexants were used at Hanford from 1969 to 1979. The complexants were sent to the tanks as dilute aqueous waste streams. Subsequent tank-to-tank transfers distributed the waste among the tanks. Tanks were grouped based on historical records into five groups (see Table 3-2 from Section 3.1.3 of this report). Those with the projected highest category were sampled, as were those in the 'special cases' category. Some tanks in all other categories listed were sampled.

\section{B3.4.1 Phase Limits to Organic Complexant Location}

Organic complexant wastes are prevalent throughout the tank farms. Hence historical records cannot be used to exclude this issue, but they can provide information on the expected relative concentration (e.g., data to place the tank in one of the grouping shown in Table 3-2). The sampling performed to support resolution of this safety issue (see 
Section 3.1.3) showed excellent correlation with the projected groupings based on historical information. The tanks with similar waste data can be compared and a determination made if sufficient information exists to bound specific tanks in terms of hazard definition and safety controls for the organic complexant issue.

The original process chemicals (glycolic acid, citric acid, hydroxyacetic acid, HEDTA, and EDTA) were mixed with waste that included inert components and diluents (e.g., water, sodium carbonate, bismuth phosphate, sodium sulfate, and hydroxides of aluminum, iron, and silicon). The organic (or other fuel) material presently in the tanks is not sufficiently energetic or present in high enough concentrations to sustain a propagating exothermic reaction (Meacham et al. 1998).

\section{B3.4.2 Physical Limits to Organic Complexant Transport}

Organic complexants were not transaction limited. These materials were highly soluble and could move freely during routine waste management operations. Their movement generally led to dilution as complexant waste was mixed with non-complexed waste.

\section{B.3.4.3 Physical and Chemical Limits to Organic Complexant Concentration}

Organic complexants can be found in both concentrated tank waste (liquids and saltcake) and insoluble waste (sludge). Organic-nitrate safety issues are limited in both evaporator concentrates and sludges because of the degradation of the organic complexants attributable to elevated temperatures. The organic complexants in the sludges are associated with the interstitial liquid. The insoluble TOC is oxalate, which is not a complexing agent. Because of the harsh chemical and radiological environment of the tanks, the organic complexants have degraded and continue to degrade over time. In some cases (AN-102, AN-107, SY-101, SY-103), organic complexants were concentrated as a function of evaporator operations and are slowly degrading. The tanks that had the highest concentration were identified from process records and were sampled (Agnew et al. 1996).

\section{B3.5 ORGANIC SOLVENTS}

Various separation processes involving organic solvents were used at the Hanford Site. The solvent extraction processes predominantly used a solution of tributyl phosphate (TBP) in normal paraffin hydrocarbons. Other solvents used on site include hexone and carbon tetrachloride, although the bulk of the remaining organic solvents are believed to be TBP and NPH. The solvent streams were washed and the organic wash waste, which contained entrained solvent, was disposed to the tank farms (Sederburg and Reddick 1994). Subsequent tank-to-tank transfers distributed organic solvents among the tanks.

Section 3.1.2 describes the approach used to resolve the organic solvent safety issue. This safety issue was initially addressed using headspace vapor samples to identify tanks with sufficient quantities (i.e., greater than a one square meter pool) to pose a potential 
problem. Thirteen of the 110 tanks sampled potentially contained organic solvent pools (puddles) larger than one square meter. Three of the thirteen tanks were core sampled. These core samples confirmed solvents were present and the vapor measurements accurately identified them (Cowley et al. 1999).

Controls were placed on the tanks and will continue to be required for this safety issue and additional tank characterization will not change that requirement.

\section{B3.5.1 Phase Limits to Organic Solvent Location}

The organic solvents are hydrophobic and separate when mixed with aqueous waste. Organic solvents are limited in evaporator concentrates because some of these materials volatilize when exposed to the elevated temperatures. The elevated temperatures of the evaporator strips off the volatile organic solvents, removing them from the waste and the combination of high temperatures and high alkalinity in the tanks degrades TBP and other non-volatile organics.

Large quantities of organic solvents are generally confined to tanks that received waste types containing organic solvents, with very simple process histories (e.g., small numbers of transfers, limited process sources), and limited exposure to high temperatures.

\section{B3.5.2 Physical Limits to Organic Solvent Transport}

Organic solvents were not transaction limited. These materials are fluid and can and did move freely during routine waste management operations with the waste liquid.

\section{B3.5.3 Physical and Chemical Limits to Organic Solvent Concentration}

Simple settling and evaporation are the only separation processes at work in the tanks. Settling allows the solids and liquids to largely separate. Within a tank, the lack of agitation and cohesiveness of the solid waste prevented different waste from mixing, resulting in a system that could only move liquids and was generally diffusion-limited. This action does allow immiscible liquids such as the organic solvents to separate and generally rise to the surface. However, evaporation can remove the solvents from the tank slowly over time.

\section{B3.6 HIGH HEAT}

High heat is a potential problem because of the possibility for a tank bump to occur. A tank bump occurs when steam stored in the waste causes a waste rollover and a rapid pressurization of the tank headspace. If the waste contains a sufficient heat load, steam bubbles are trapped in sludge and then suddenly released to the tank dome space because of buoyant instabilities. This is a safety concern because of the potential for a release of aerosolized waste to the environment. 
For a tank bump to occur, the waste temperature must be at or above the local saturation temperature; this requires a heat generation rate greater than $7,600 \mathrm{~W}(26,000 \mathrm{Btu} / \mathrm{hr})$, assuming no active ventilation. Saturation temperature of tank liquid waste is $104{ }^{\circ} \mathrm{C}$ $\left(220^{\circ} \mathrm{F}\right.$ ) at atmospheric pressure because of dissolved salt content (Sathyanarayana et al. 1994). At heat generation rates below $7,600 \mathrm{~W}(26,000 \mathrm{Btu} / \mathrm{hr})$, sufficient heat is transferred by natural conduction to the surrounding soil to maintain waste temperature below $104{ }^{\circ} \mathrm{C}\left(220^{\circ} \mathrm{F}\right)$ (Noorani 1999).

An amount of sludge is also required for a tank bump to occur. Tank sludge contains the highest density of heat-producing isotopes, is highly viscous, and is generally nonconvective. The heat source in the sludge provides a location for steam to generate. The high viscosity and hydrostatic head trap the steam generated in the sludge.

Presently, the only SST that requires water additions to adequately cool the waste to prevent a potential tank bump is C-106. Other SSTs that have a heat generation rate greater than 7,600 W (26,000 Btu/hr) are A-104, A-105, and tanks in the SX tank farm. However, tanks A-104 and A-105 are passively ventilated, and the waste temperature has stabilized below $104^{\circ} \mathrm{C}\left(220^{\circ} \mathrm{F}\right)$. Tanks in $\mathrm{SX}$ farm are actively ventilated to maintain the tanks at temperatures below $104^{\circ} \mathrm{C}\left(220^{\circ} \mathrm{F}\right)$. Although these tanks have heat loads in excess of $26,000 \mathrm{Btu} / \mathrm{hr}$, they have adequate controls specified in the authorization basis. Some double-shell tanks also have higher heat loading based on the tank-specific design or the type of forced ventilation used that are explicitly allowed in the authorization basis. Since there are no DSTs in the 45 unsampled tanks, these tanks are not part of this evaluation.

Tanks that have a potential high heat problem are determined by thermocouple and ventilation information and not through core sampling.

\section{B3.6.1 Phase Limits to High Heat Location}

High heat is not necessarily constrained by phase because the two primary heat-producing radionuclides (strontium-90 and cesium-137) are pervasive and have different solubility properties. They can be found in sufficient quantity to exceed the safety issue criteria in either insoluble materials or soluble concentrates. Much of the strontium-90 and cesium-137 produced was recovered and encapsulated at the Waste Encapsulation Storage Facility.

\section{B3.6.2 Physical Limits to High Heat Transport}

The high heat safety issue has several specific process source transactions associated with them. Furthermore, there were several physical limits involved in the transfer of waste. Most insoluble materials in the tank (depending on settling properties) are not carried over in cascades. The pumps used to transfer waste from tank-to-tank do not mobilize waste solids during routine transfers. The strontium- 90 bearing high heat generating wastes were generally insoluble and formed compact volumes of highly cohesive sludge, once they settled in the receiving tanks. These properties made them very unlikely to be 
transferred during routine tank farm operations, although intentional movement of these materials has been documented (e.g., sluicing). These same properties of strontium-90 bearing sludges cause them to have a high energy per unit volume. These wastes are responsible for past tank bumps.

PUREX, REDOX, and reprocessing wastes are the wastes that generate high heat. No PUREX high level waste was sent to the tanks in the 200 West area. All were limited to the A (A-, AX-, AW-, AY-, AZ) and the C series of tanks. Similarly, REDOX waste was generally limited to the $\mathrm{S}, \mathrm{SX}$, and U Farms.

Wastes with high cesium-137 content were generally not transaction limited. These materials are highly soluble and can move freely during routine waste management operations with the liquid waste. Therefore, if the tank has been interim stabilized, much of the cesium-137-bearing material would have been removed to the DSTs in the pumping process, leaving only a small residue behind.

\section{B3.6.3 Physical and Chemical Limits to High Heat Concentration}

The inert impurities mixed in the soluble (saltcake and liquids) waste matrices limit the amount of fission products in these wastes. The high solubility of cesium-137-bearing wastes usually means that substantial water is present, reducing the degree to which that heat source can be concentrated. The presence of large amounts of water, sodium, hydroxide, iron, aluminum, nitrate, and bismuth in the various wastes limits the amount of energy per unit volume that can be achieved with cesium-137 bearing wastes (LMHC 1999, Kupfer et al. 1999). These inert components of the waste make up over 75 weight percent of its composition. However, these wastes contribute to the necessary hydrostatic head and incremental heat load required for a bump.

Even when there was active mixing, such as sluicing, operating airlift circulators or selfboiling tanks, there was no separation mechanism beyond simple settling. In addition, sluicing tanks to recover uranium or fission products introduced additional water to the wastes, diluting and removing radionuclides.

\section{B3.7 CRITICALITY}

A criticality accident in a waste tank has been determined to be incredible (see Section 3.1.6). However, for the evaluation shown in Section B4.0, if a tank was anticipated to have high total alpha (or plutonium) inventory, this issue was applied. If the tank under review received waste from the Plutonium Finishing Plant (PFP) process, it was assumed to have high total alpha. If the tank did not receive waste from the PFP process, then no further evaluation against this issue was performed. Though all the process plants produced waste with some alpha-emitting waste, only the PFP process generated significant volumes of wastes with an elevated plutonium or americium content. 
The prime evaluation technique for the tanks was to determine if information existed that would estimate the volume and concentration of plutonium versus assumed worst-case values in the BIO. This could be a partial waste sample that was evaluated or some other instrumented reading. It could include a more detailed evaluation of the estimated volume of plutonium in this tank based on both records and similarly sampled tanks.

\section{B3.7.1 Phase Limits to the Criticality Safety Issue}

High alpha concentration conditions cannot exist in tanks that are entirely evaporator concentrates or liquid because of solubility constraints. Regardless of how concentrated the waste becomes, it is not capable of having sufficient amounts of fissionable material in solution to present a credible criticality hazard (see Section 3.1.6). Small amounts of fissionable material (see Figure A-3), such as plutonium, are found in the concentrates, as they do not dissolve under water-based, alkaline conditions. Most of the inventory of the unsampled tanks ( $74 \%$ ) consists of concentrated salt solutions (both solids and liquids). Nearly all of the alpha emitters were precipitated. Small amounts of concentrates with alpha concentrations have been observed in all tanks sampled. PFP waste was neutralized with 242-T Evaporator feed which went to TX farm tanks. Tank TX-118 contains the most PFP waste in TX farm according to Agnew et al. (1997b). These concentrates have a small amount of insoluble sludge in them, present as entrained particles. The level of alpha concentration in these concentrates is too dilute to pose a hazard.

\section{B3.7.2 Physical Limits to Transporting Wastes with Criticality Potential}

Transfers involving wastes from PFP are the only materials with plutonium content high enough to approach the criticality control limit established in the BIO. PFP wastes were first cribbed in the Z-9 trench. PFP transfers to the tanks were limited to the TX Farm initially, and later transferred to AZ-102 (supernatant only) and SY Farms. The operating histories for these tanks have been extensively researched and documented to determine the type and number of transfers in and out of the tanks (Agnew et al. 1997b). The confidence level in the transaction records has improved to the point that this data provides clear relationships between tanks, in terms of general types of waste because the agreement between sample data and transaction records for the general waste types has been observed to be reliable. This information is used when inferring waste composition and properties from sampled tanks to unsampled tanks.

\section{B3.7.3 Physical and Chemical Limits to Concentration of Waste with Criticality Potential}

The criticality safety issue is impacted by the initial precipitation and settling of the insoluble solids. The plutonium and americium were usually well mixed with other inert, insoluble compounds, and no plausible separation and concentration mechanism exists to further concentrate them. The inert impurities mixed in the sludge hamper self-sustaining energetic nuclear reactions. The presence of water, sodium, hydroxide, iron, aluminum, 
and bismuth in the various wastes stops neutrons and inhibit the energy release mechanisms from occurring (LMHC 1999, Kupfer et al. 1999).

Within a tank, the lack of agitation and cohesiveness of the solid waste prevented different wastes from mixing. The ability to selectively separate and concentrate plutonium-bearing solids does not exist in the tanks. This is evident in the historical information that defined the chemistry of the various evaporator operations (Agnew et al. 1997a), as well as the empirical data from the tanks (LMHC 1999). Independent reviewers (Antizzo 1995; Braddy-Rapp and Vail 1998; Bratzel et al. 1996; Braun et al. 1994; O'Dell 1994; Serne et al. 1996) have rigorously evaluated the potential for criticality in Hanford wastes and found it to be not credible.

\section{B3.8 ANOMALOUS DATA REVIEW}

At the end of the tank-by-tank evaluation (Section B4.0), there is a discussion of any anomalies that have been or are still associated with the specific tank waste. Anomalies are defined as measured behavior that is not explained. Examples are changes in temperature or surface level that are not explainable based on known waste properties or tank conditions. This could include unexplained raises in temperature, even though the temperature is below the level of concern for a high heat tank. It could also include increases or decreases in surface level that cannot be explained based on evaporation, tank leak integrity reviews, barometric changes, or known gas release events.

An anomaly could also include anomalous waste types such as special waste additions of samarium balls, whole or broken fuel rods (not processed), cement, or diatomaceous earth. It could also include a special occurrence associated with the tank (such as the breach in the bottom of tank A-105). The historical records had been reviewed in the past for unique additions to the waste as well as standard waste transfers. If an anomaly exists or has existed in the past, evidence is presented as to why core-sampling data is not needed to address this anomaly.

\section{B4.0 TANK BY TANK EVALUATION}

The following provides an assessment of each of the 45 tanks that have either not been core-sampled (39) or the six that were incompletely sampled. Table B-3 lists the remaining tanks to be sampled. For each tank, there is a short summary of the physical information (size, amount of waste, types of waste, operating history). There is also a list of the issues that were identified with this tank (Field 1998). The status of whether the tank has been stabilized and when is also presented (Hanlon 1999). The section after the summary identifies which of the six safety issues (correlating to the applicable authorization basis accidents) apply. For those that do not apply, a brief discussion of the reason why is presented. After that, tanks with similar waste types that have been sampled are discussed, along with more information about what is known about the waste in the tank. 
There is an evaluation, using the logic presented in Figure B-1, for each of the applicable safety issues. A table for each tank summarizes which issue is evaluated and which decision approach is used. The text that follows the table describes the rationale for the decision. Finally, there is a discussion of anomalies, as described in Section B3.8, that have been associated with the specific tank.

This format is repeated for each of the 45 tanks. The tanks are presented in alphanumeric order.

Table B-3. Remaining Tanks to be Sampled (2 Sheets)

\begin{tabular}{|c|c|c|c|c|c|c|c|c|}
\hline $\begin{array}{c}\text { Tank } \\
\text { Number }\end{array}$ & $\begin{array}{c}\text { Waste } \\
\text { Volume } \\
\text { (Gal) }\end{array}$ & $\begin{array}{c}\text { Interim } \\
\text { Stabilized }\end{array}$ & $\begin{array}{c}\text { Flammable } \\
\text { Gas }\end{array}$ & $\begin{array}{c}\text { Organic } \\
\text { Nitrate }\end{array}$ & $\begin{array}{c}\text { Organic } \\
\text { Solvent }\end{array}$ & $\begin{array}{l}\text { High } \\
\text { Heat } \\
\end{array}$ & Ferrocyanide & Criticality \\
\hline A-103 & 371,000 & Yes & $\bar{x}$ & $\mathrm{X}$ & & & & \\
\hline A-104 & 28,000 & Yes & $\mathrm{X}$ & $\mathrm{X}$ & $\mathrm{X}$ & $\mathrm{X}$ & & \\
\hline A-105 & 19,000 & Yes & $\mathrm{X}$ & $\mathrm{X}$ & $X$ & $X$ & & \\
\hline A-106 & 125,000 & Yes & $\mathrm{X}$ & $X$ & & & & \\
\hline B-105 & 158,000 & Yes & $\mathrm{X}$ & X & & & & \\
\hline BX-102 & 96,000 & Yes & $\mathrm{X}$ & $\mathrm{X}$ & & & & \\
\hline BY-105 & 503,000 & Partial & $X$ & $\mathrm{X}$ & & & $X$ & \\
\hline BY-106 & 642,000 & Partial & $\mathrm{X}$ & $\mathrm{X}$ & & & $\mathrm{X}$ & \\
\hline C-102 & 402,000 & Yes & $\bar{X}$ & $\mathrm{X}$ & & & & \\
\hline S-103 & 248,000 & Partial & $\bar{X}$ & $\mathrm{X}$ & & & & \\
\hline S-105 & 455,000 & Yes & $\mathrm{X}$ & $\mathrm{X}$ & & & & \\
\hline S-108 & 502,000 & Yes & $\bar{X}$ & $\mathrm{X}$ & & & & \\
\hline S-112 & 523,000 & Partial & $\mathrm{X}$ & $\mathrm{X}$ & & & & \\
\hline SX-104 & 614,000 & Partial & $\mathrm{X}$ & $\underline{X}$ & $\mathrm{X}$ & & & \\
\hline SX-107 & 109,000 & Yes & $\mathrm{X}$ & $\mathrm{X}$ & $\mathrm{X}$ & $\mathrm{X}$ & & \\
\hline SX-109 & 250,000 & Yes & 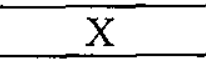 & $\mathrm{X}$ & $\mathrm{X}$ & $\mathrm{X}$ & & \\
\hline SX-110 & 72,000 & Yes & $\mathrm{X}$ & $\mathrm{X}$ & $X$ & $\mathrm{X}$ & & \\
\hline SX-111 & 122,000 & Yes & $\mathrm{X}$ & $\mathrm{X}$ & $\mathrm{X}$ & $\mathrm{X}$ & & \\
\hline SX-112 & 107,000 & Yes & $X$ & $\mathrm{X}$ & $X$ & $\mathrm{X}$ & & \\
\hline SX-114 & 181,000 & Yes & $\mathrm{X}$ & $\mathrm{X}$ & $X$ & $\mathrm{X}$ & & \\
\hline $\mathrm{T}-101$ & 102,000 & Yes & $\mathrm{X}$ & $\mathrm{X}$ & $\mathrm{X}$ & & $\mathrm{X}$ & \\
\hline $\mathrm{T}-103$ & 27,000 & Yes & $\mathrm{X}$ & $\mathrm{X}$ & $X$ & & & \\
\hline $\mathrm{TX}-101$ & 87,000 & Yes & $\mathrm{X}$ & $\mathrm{X}$ & $X$ & & & \\
\hline TX-102 & 217,000 & Yes & $\mathrm{X}$ & $\mathrm{X}$ & $x$ & & & \\
\hline TX-103 & 157,000 & Yes & $\mathrm{X}$ & $\mathrm{X}$ & $\mathrm{X}$ & & & \\
\hline TX-105 & 609,000 & Yes & $X$ & $\mathrm{X}$ & & & & \\
\hline $\mathrm{TX}-106$ & 341,000 & Yes & $X$ & $\mathrm{X}$ & $X$ & & & \\
\hline TX-108 & 134,000 & Yes & $\mathrm{X}$ & $\mathrm{X}$ & $\mathrm{X}$ & & & \\
\hline TX-109 & 384,000 & Yes & $\underline{X}$ & $X$ & $\bar{X}$ & & & \\
\hline TX-110 & 462,000 & Yes & $X$ & $X$ & $\mathrm{X}$ & & & \\
\hline
\end{tabular}


HNF-4232 Rev. 0

Table B-3. Remaining Tanks to be Sampled (2 Sheets)

\begin{tabular}{|c|c|c|c|c|c|c|c|c|}
\hline $\begin{array}{c}\text { Tank } \\
\text { Number }\end{array}$ & $\begin{array}{c}\text { Waste } \\
\text { Volume } \\
\text { (Gal) }\end{array}$ & $\begin{array}{c}\text { Interim } \\
\text { Stabilized }\end{array}$ & $\begin{array}{c}\text { Flammable } \\
\text { Gas }\end{array}$ & $\begin{array}{c}\text { Organic } \\
\text { Nitrate }\end{array}$ & $\begin{array}{c}\text { Organic } \\
\text { Solvent }\end{array}$ & $\begin{array}{c}\text { High } \\
\text { Heat }\end{array}$ & Ferrocyanide & Criticality \\
\hline TX-111 & 370,000 & Yes & $\mathrm{X}$ & $\mathrm{X}$ & & & & \\
\hline $\mathrm{TX}-112$ & 649,000 & Yes & $\mathrm{X}$ & $\mathrm{X}$ & $\mathrm{X}$ & & & \\
\hline $\mathrm{TX}-113$ & 607,000 & Yes & $\mathrm{X}$ & $\mathrm{X}$ & $\mathrm{X}$ & & & \\
\hline $\mathrm{TX}-114$ & 535,000 & Yes & $\mathrm{X}$ & $\mathrm{X}$ & $\mathrm{X}$ & & & \\
\hline TX-115 & 568,000 & Yes & $\mathrm{X}$ & $\mathrm{X}$ & $\mathrm{X}$ & & & \\
\hline TX-116 & 631,000 & Yes & $\mathrm{X}$ & $\mathrm{X}$ & $\mathrm{X}$ & & & \\
\hline TX-117 & 626,000 & Yes & $\mathrm{X}$ & $\mathrm{X}$ & $\mathrm{X}$ & & & \\
\hline TX-118 & 347,000 & Yes & $\mathrm{X}$ & $\mathrm{X}$ & & & $\mathrm{X}$ & $\mathrm{X}$ \\
\hline $\mathrm{TY}-101$ & 118,000 & Yes & $\mathrm{X}$ & $\mathrm{X}$ & & & $\mathrm{X}$ & \\
\hline TY-102 & 64,000 & Yes & $\mathrm{X}$ & $\mathrm{X}$ & & & & \\
\hline TY-103 & 162,000 & Yes & $\mathrm{X}$ & $\mathrm{X}$ & $\mathrm{X}$ & & $\mathrm{X}$ & \\
\hline TY-105 & 231,000 & Yes & $\mathrm{X}$ & $\mathrm{X}$ & $\mathrm{X}$ & & & \\
\hline $\mathrm{U}-101$ & 25,000 & Yes & $\mathrm{X}$ & $\mathrm{X}$ & $\mathrm{X}$ & & & \\
\hline $\mathrm{U}-104$ & 122,000 & Yes & $\mathrm{X}$ & $\mathrm{X}$ & $\mathrm{X}$ & & & \\
\hline $\mathrm{U}-111$ & 329,000 & Yes & $\mathrm{X}$ & $\mathrm{X}$ & & & & \\
\hline
\end{tabular}


Tank Name: A-103

Tank Parameters:

Tank Type: SST

Ventilation: Passive

Tank Capacity: $1,000,000$ gallons

Interim stabilized: Yes (1988) Service History: Inactive (1979)

Tank Integrity: Assumed leaker (1987)

Waste Parameters:

Total waste:

371,000 gallons

Waste types:

368,000 gallons 242-A Evaporator concentrate (1980)

3,000 gallons washed PUREX sludge and strontium

recovery waste (1974-1975)

( Lambert 1998a)

Waste Temperature: $113^{\circ} \mathrm{F}$ (May 1999) (LMHC 1999)

Safety Issue Status:

Watch List: None

USQs: $\quad$ Flammable gas (now closed), Organic nitrate (now closed)

Determination of the Safety Issues Associated with This Tank:

- Flammable gas

- Organic nitrate

\section{Safety Issues Excluded from This Tank:}

- Ferrocyanide has been excluded. Tank A-103 is not identified as one of the 18 ferrocyanide tanks (Postma et al. 1994).

- Organic solvent has been excluded. Tank has been demonstrated to not be in scope of organic solvent issue by vapor sampling (Noorani 1999, pp. 5.3.2.15-16). Furthermore, analytical results show that organic solvents are difficult to ignite, and credible ignition sources have been narrowed to robust energy sources such as lightning strikes and large hot metal cuttings from welding (Cowley et al. 1999).

- Criticality has been excluded. This tank did not receive any PFP waste (Agnew et al. 1997b). Criticality is not considered to be a credible accident scenario for safe storage of waste in tanks (Noorani 1999, pp. 5.3.2.1-4).

- High heat has been excluded. Estimated thermal load is approximately 11,800 BTU/hr. This is insufficient to classify this tank as a high-heat tank (Kummerer 1995 and Noorani 1999, pp. 5.3.2.22-1). Present maximum temperature of $113^{\circ} \mathrm{F}$ in the waste confirms heat load classification. 


\section{Are there process history ties to other sampled tanks?}

Yes. Related tanks that have been sampled are A-101, AX-101, AX-104, and C-106. Tanks A-101 and AX-101 both have a similar process history to that of A-103. Both tanks were sluiced of their original contents and used to store 242-A Evaporator concentrates. These concentrates were produced from 1978 to 1980 and comprise the bulk of the waste inventory. Evaporator concentrates from 242-A have limited compositional variation as evidenced from historical evaluation and analysis of tank waste (Agnew et al. 1997b; LoPresti et al. 1997; Hendrickson et al. 1998). The data from tanks A-101 and AX-101 do not exhibit behavior that triggers safety screening limits (LMHC 1999 and Appendix A). Because of the degree of similarity in process history, the material in A-103 is not expected to exhibit behavior different from that observed in A-101 or AX-101.

A small residue of washed PUREX sludge is expected in the bottom of tank A-103. Tank C-106 has waste that resembles the sludge heel expected in tank A-103. Residues from past sluicing operations have been observed in other sampled tanks (e.g., AX-104). The wastes in the heel of tank A-103 and the middle of tank C-106 have a common process origin, washed PUREX high level waste sludge (Agnew et al. 1997a). Because of the degree of similarity in process history, the sludge in A-103 is not expected to exhibit behavior different from that observed in C-106 (LMHC 1999 and Appendix A).

Core samples were taken from tank A-103 in 1986 (Weiss and Schull 1988a). Although not part of the contemporary characterization program, the results are consistent with process knowledge regarding the tank's contents. High sodium and nitrate concentrations with low transition metal concentrations indicate evaporator concentrate, as indicated from Agnew et al. (1997b). 
Is core sampling necessary to show tank is bounded?

Table B-4 illustrates this statement using the logic chart (Figure B-1)

Table B-4. Safety Issue Logic for Tank A-103

\begin{tabular}{|l|l|l|l|l|l|l|}
\hline \multicolumn{1}{|c|}{ Issue } & $\begin{array}{c}\text { Organic } \\
\text { Complexant }\end{array}$ & $\begin{array}{c}\text { Organic } \\
\text { Solvent }\end{array}$ & Ferrocyanide & $\begin{array}{c}\text { Flammable } \\
\text { Gas }\end{array}$ & High Heat & Criticality \\
\hline $\begin{array}{l}\text { Can a case be } \\
\text { demonstrated why } \\
\text { related tanks are } \\
\text { bounding? }\end{array}$ & No & Excluded & Excluded & No & Excluded & Excluded \\
\hline $\begin{array}{l}\text { Are other data (other } \\
\text { than core sampling) } \\
\text { sufficient to address } \\
\text { safety issues? }\end{array}$ & No & Excluded & Excluded & No & Excluded & Excluded \\
\hline $\begin{array}{l}\text { Does a preponderance } \\
\text { of evidence demonstrate } \\
\text { sampling is not needed? }\end{array}$ & Yes & Excluded & Excluded & Yes & Excluded & Excluded \\
\hline
\end{tabular}

Safety Issues Associated with Tank:

Organic Complexants:

Evidence from theoretical considerations, empirical simulant studies, and evaluation of related tanks shows the hazards from organic complexants are adequately controlled. Tanks A-101 and AX-101 were categorized as having high concentrations of organic complexant waste. Tank A-103 was also categorized as having high concentrations of organic complexant waste. Section 3.1.3 and Meacham et al. (1998) describe the organic complexant evaluation more thoroughly. The upper layer of waste in tank A-103 (368,000 gallons, or $99.2 \%$ by volume) is composed of 242-A Evaporator concentrate. This waste is projected to be similar in composition and behavior to evaporator concentrate waste in tanks A-101 and AX-101, which have been sampled and analyzed. Based on these analytical results, organic complexants have been determined to not be a safety issue for the evaporator concentrate waste layer in tank A-103 (Appendix A, Figures A-12 to A-15, and LMHC 1999).

The lower layer of waste in A-103 (3,000 gallons, or $0.8 \%$ by volume) is composed of washed PUREX sludge and strontium recovery waste. This waste is projected to be similar in composition and behavior to washed PUREX sludge and strontium recovery waste found in tanks AX-104 and C-106, which have been sampled and analyzed. Wastes from A-103 and C-106 were categorized as having high concentrations of organic complexant waste (Meacham et al. 1998). Based on the analytical results from $\mathrm{C}-106$ showing that the elevated TOC values observed in the C-106 samples were within the authorization basis, organic complexants have been determined to not be a safety issue for the washed 
PUREX sludge and strontium recovery waste layer in tank A-103 (Appendix A, Figures A-12 to A-15, and LMHC 1999).

\section{Flammable Gas:}

Tank A-103 exhibited changes in surface level as a function of barometric pressure that met the criteria to qualify for inclusion as flammable gas tank. The tank does not currently exhibit a surface level rise (Hodgson 1998). Because of the barometric response behavior observed, the tank is considered Facility Group 2. Facility Group 2 tanks are conservatively postulated to have the potential for small spontaneous and large induced gas release events (GREs) (Funderburke 1997). In addition, the tank was interim stabilized in 1988. Interim stabilization has been shown to significantly reduce the potential for trapping and periodically releasing flammable gas (Stewart et al. 1996). Other tanks, such as AN-105 or AW-101, have exhibited much stronger indications of flammable gas behavior and have been extensively sampled to provide data to address the safety issue. Section 3.1.4 and Johnson et al. (1997) describe the flammable gas data evaluation more thoroughly. Further sampling and analysis of the waste in tank A-103 is not expected to change the safety classification of the tank or the controls applied with respect to this safety issue.

\section{Are there any anomalous data that would drive characterization of the tank?}

No. Hodgson (1998) has reviewed the available surveillance data for surface level and temperature anomalies. None were observed beyond those already noted. 
Tank Name: A-104

Tank Parameters:

Tank Type: SST

Ventilation: Passive

Tank Capacity: $1,000,000$ gallons

Interim stabilized: Yes (1978) Service History: Inactive (1979)

Tank Integrity: Assumed leaker (1975)

Waste Parameters:

Total waste:

28,000 gallons

Waste types:

28,000 gallons PUREX sludge and strontium recovery waste (1972-1975) (Lambert 1998b)

Waste Temperature: $164^{\circ} \mathrm{F}$ (May 1999) (LMHC 1999)

Safety Issue Status:

Watch List: None

USQs: $\quad$ Flammable gas (now closed), Organic nitrate (now closed), Organic solvent

Determination of the Safety Issues Associated with This Tank:

- Flammable gas

- Organic nitrate

- Organic solvent

- High heat

Safety Issues Excluded from This Tank:

- Ferrocyanide has been excluded. Tank A-104 is not identified as one of the 18 ferrocyanide tanks (Postma et al. 1994).

- Criticality has been excluded. This tank did not receive any PFP waste (Agnew et al. 1997b). Criticality is not considered to be a credible accident scenario for safe storage of waste in tanks (Noorani 1999, pp. 5.3.2.1-4). 


\section{Are there process history ties to other sampled tanks?}

Yes. Related tanks that have been sampled are $\mathrm{C}-106$ and $\mathrm{AX}-104$. The sludge in tank C-106 resembles the sludge heel expected in tank A-104. A small residue of washed PUREX sludge is expected in the bottom of tank A-104. Residues from past sluicing operations have been observed in other sampled tanks (e.g., AX-104). The wastes in the heel of tank A-104 and the middle of C-106 and that remaining in $\mathrm{AX}-104$ have a common process origin, washed PUREX sludge for cesium and strontium recovery (Agnew et al.1997b). Because of the degree of similarity in process history, the sludge in A-104 is expected to exhibit behavior similar to that observed in C-106 and AX-104 (LMHC 1999 and Appendix A).

\section{Is core sampling necessary to show tank is bounded?}

Table B-5 illustrates this statement using the logic chart (Figure B-1).

Furthermore, core sampling would probably gather little material because there is less than I segment of waste depth. Past attempts to sample this tank did not obtain any material.

Table B-5. Safety Issue Logic for Tank A-104

\begin{tabular}{|l|l|l|l|l|l|l|}
\hline \multicolumn{1}{|c|}{ Issue } & $\begin{array}{c}\text { Organic } \\
\text { Complexant }\end{array}$ & $\begin{array}{l}\text { Organic } \\
\text { Solvent }\end{array}$ & Ferrocyanide & $\begin{array}{l}\text { Flammable } \\
\text { Gas }\end{array}$ & High Heat & Criticality \\
\hline $\begin{array}{l}\text { Can a case be } \\
\text { demonstrated } \\
\text { why related } \\
\text { tanks are } \\
\text { bounding? }\end{array}$ & No & No & Excluded & No & No & Excluded \\
\hline $\begin{array}{l}\text { Are other data } \\
\text { (other than core } \\
\text { sampling) } \\
\text { sufficient to } \\
\text { address safety } \\
\text { issues? }\end{array}$ & No & Yes & Excluded & Yes & Yes & Excluded \\
\hline $\begin{array}{l}\text { Does a } \\
\text { preponderance } \\
\text { of evidence } \\
\text { demonstrate } \\
\text { sampling is not } \\
\text { needed? }\end{array}$ & Yes & $*$ & Excluded & $*$ & & \\
\hline
\end{tabular}

Notes:

* = If a previous box provides necessary data for a yes, this logic box does not need to be addressed. 


\section{Safety Issues Associated with Tank:}

\section{Organic Complexants:}

Evidence from theoretical considerations, empirical simulant studies, and evaluation of related tanks show the hazards from organic complexants are adequately controlled. Tank $\mathrm{C}-106$ was categorized as having high concentrations of organic complexant waste. Wastes from A-104 and AX-104 were categorized as having low concentrations of organic complexant waste. Section 3.1.3 and Meacham et al. (1998) describe the organic complexant evaluation more thoroughly. The TOC data from a related tank (C-106) indicates that organic complexant concentration is potentially high for the waste in tank A-104 but within the authorization basis. The TOC data in AX-104 was very low (LMHC 1999, Appendix A, and Figures A-12 to A-15). Further core sampling and analysis of the waste in this tank will not change the safety classification or the controls applied to tank A-104 with respect to this safety issue.

\section{Organic Solvents:}

Analytical results show that organic solvents are difficult to ignite, and credible ignition sources have been narrowed to robust energy sources such as lightning strikes and large hot metal cuttings from welding (Cowley et al. 1999). Additional core sampling and analyses are not warranted, because additional core sample data will not eliminate the need for controls or further resolve the safety issue.

\section{Flammable Gas:}

Tank A-104 has less than 110,000 gallons of waste. Therefore, there is not sufficient waste volume to accumulate enough flammable gas to present a hazard (see Section B3.3). This tank is in Facility Group 3.

\section{High Heat:}

This tank is considered a high heat tank. Estimated thermal load is approximately 52,000 BTU/hr. From May 1996 to May 1999, the temperature has decreased from $182^{\circ} \mathrm{F}$ to $164^{\circ} \mathrm{F}$. Present maximum temperature of $164^{\circ} \mathrm{F}$ in the waste confirms heat load classification. The tank has also not exhibited any waste instability indicating a tank bump phenomenon. Further core sampling and analysis of the waste in this tank will not change the safety classification or the controls applied to tank A-104 with respect to this safety issue.

\section{Are there any anomalous data that would drive characterization of the tank?}

No. Hodgson (1998) has reviewed the available surveillance data for surface level and temperature anomalies. None were observed. 
Tank Name: A-105

Tank Parameters:

Tank Type: SST

Ventilation: Passive

Tank Capacity: $1,000,000$ gallons

Interim stabilized: Yes (1979)

Service History: Inactive (1979)

Tank Integrity： Assumed leaker (1963)

Waste Parameters:

Total waste:

19,000 gallons

Waste types: $\quad 19,000$ gallons PUREX sludge (1962-1967)

(Lambert 1998c)

Waste Temperature: $134^{\circ} \mathrm{F}$ (May 1999) (LMHC 1999)

Safety Issue Status:

Watch List: None

USQs: $\quad$ Flammable gas (now closed), Organic nitrate (now closed)

Determination of the Safety Issues Associated with This Tank:

- Flammable gas

- Organic nitrate

- Organic solvent

- High heat

Safety Issues Excluded from This Tank:

- Ferrocyanide has been excluded. Tank A-105 is not identified as one of the 18 ferrocyanide tanks (Postma et al. 1994).

- Criticality has been excluded. This tank did not receive any PFP waste (Agnew et al. 1997b). Criticality is not considered to be a credible accident scenario for safe storage of waste in tanks (Noorani 1999, pp. 5.3.2.1-4).

Are there process history ties to other sampled tanks?

Yes. A related tank that has been sampled is AX-104. Tank AX-104 has waste that resembles the sludge expected in tank A-105. The wastes in tanks A-105 and AX-104 have a common process origin, high level PUREX sludge (Agnew et al. 1997b). The data from AX-104 does not exhibit behavior that triggers safety screening limits for organics or exotherms (LMHC 1999 and Appendix A). Tanks A-105 and AX-104 were expected to have elevated alpha values. However, the results from AX-104 are within the authorization basis limits. 
Because of the degree of similarity in process history, the sludge in A-105 is not expected to exhibit behavior different from that observed in AX-104.

\section{Is core sampling necessary to show tank is bounded?}

Table B-6 illustrates this statement using the logic chart (Figure B-1).

Furthermore, core sampling would probably gather little material because there is less than 1 segment of waste depth.

Table B-6. Safety Issue Logic for Tank A-105

\begin{tabular}{|l|l|l|l|l|l|l|}
\hline \multicolumn{1}{|c|}{ Issue } & $\begin{array}{c}\text { Organic } \\
\text { Complexant }\end{array}$ & $\begin{array}{l}\text { Organic } \\
\text { Solvent }\end{array}$ & Ferrocyanide & $\begin{array}{l}\text { Flammable } \\
\text { Gas }\end{array}$ & High Heat & Criticality \\
\hline $\begin{array}{l}\text { Can a case be } \\
\text { demonstrated } \\
\text { why related } \\
\text { tanks are } \\
\text { bounding? }\end{array}$ & No & No & Excluded & No & No & Excluded \\
\hline $\begin{array}{l}\text { Are other data } \\
\text { (other than core } \\
\text { sampling) } \\
\text { sufficient to } \\
\text { address safety } \\
\text { issues? }\end{array}$ & No & Yes & Excluded & Yes & Yes & Excluded \\
\hline $\begin{array}{l}\text { Does a } \\
\text { preponderance } \\
\text { of evidence } \\
\text { demonstrate } \\
\text { sampling is not } \\
\text { needed? }\end{array}$ & Yes & $*$ & Excluded & $*$ & & \\
\hline
\end{tabular}

Notes:

* = If a previous box provides necessary data for a yes, this logic box does not need to be addressed.

\section{Safety Issues Associated with Tank:}

\section{Organic Complexants:}

Evidence from theoretical considerations, empirical simulant studies, and evaluation of related tanks show the hazards from organic complexants are adequately controlled. Wastes from tank AX-104 were categorized as having low concentrations of organic complexant waste. Tank A-105 was classified as having no organic complexant waste. Section 3.1.3 and Meacham et al. (1998) describe the organic complexant evaluation more thoroughly. The data from a related tank (AX-104) indicates that the TOC concentration is low for the waste in this tank (LMHC 1999, Appendix A, and Figures A-12 to A-15). Further core sampling and analysis of the waste in tank A-105 will not change the safety 
classification or the controls applied to tank A-105 with respect to this safety issue.

\section{Organic Solvents:}

Analytical results show that organic solvents are difficult to ignite, and credible ignition sources have been narrowed to robust energy sources such as lightning strikes and large hot metal cuttings from welding (Cowley et al. 1999).

Additional core sampling and analyses are not warranted, because additional core sample data will not eliminate the need for controls or further resolve the safety issue.

\section{High Heat:}

Estimated thermal load is approximately 50,000 BTU/hr. This is greater than the 26,000 BTU criteria used to classify tanks as high-heat (Kummerer 1995 and Noorani 1999, pp. 5.3.2.22-1). From May 1996 to May 1999 the temperature in this tank has remained stable. Present maximum temperature of $134^{\circ} \mathrm{F}$ in the waste confirms heat load classification. The tank has also not exhibited any waste instability indicating a tank bump phenomena. Further core sampling and analysis of the waste in this tank will not change the safety classification or the controls applied to tank A-105 with respect to this safety issue.

\section{Flammable Gas:}

Tank A-105 has less than 110,000 gallons of waste. Therefore, there is not sufficient waste volume to accumulate enough flammable gas to present a hazard (see Section B3.3). This tank is in Facility Group 3.

\section{Are there any anomalous data that would drive characterization of the tank?}

None are found with the tank data. Hodgson (1998) has reviewed the available surveillance data for surface level and temperature anomalies. None were observed. However, this tank's bottom buckled and leaked in 1968. There may be as much as 32,000 gallons of waste directly under the tank or trapped in the bulge between the carbon steel tank liner and concrete. 
Tank Name: A-106

Tank Parameters:

Tank Type: SST

Ventilation: Passive

Interim stabilized: Yes (1982)
Tank Capacity: $1,000,000$ gallons

Service History: Inactive (1980)

Tank Integrity: Sound

\section{Waste Parameters:}

Total waste:

Waste types:

125,000 gallons

75,000 gallons 242-A Evaporator concentrate (1980)

29,000 gallons strontium recovery waste (1974-1975)

21,000 gallons washed PUREX sludge (1978)

(Lambert 1998d)

Waste Temperature: $130^{\circ} \mathrm{F}$ (Jan. 1999) (LMHC 1999)

\section{Safety Issue Status:}

Watch List: None

USQs: $\quad$ Flammable gas (now closed), Organic nitrate (now closed)

\section{Determination of the Safety Issues Associated with This Tank:}

- Flammable gas

- Organic nitrate

\section{Safety Issues Excluded from This Tank:}

- Ferrocyanide has been excluded. Tank A-106 is not identified as one of the 18 ferrocyanide tanks (Postma et al. 1994).

- Organic solvent has been excluded. Tank has been demonstrated to not be in scope of organic solvent issue by vapor sampling (Viswanath et al. 1997; Meacham et al. 1998). Analytical results show that organic solvents are difficult to ignite, and credible ignition sources have been narrowed to robust energy sources such as lightning strikes and large hot metal cuttings from welding (Cowley et al. 1999).

- Criticality has been excluded. This tank did not receive any PFP waste (Agnew et al. 1997b). Criticality is not considered to be a credible accident scenario for safe storage of waste in tanks (Noorani 1999, pp. 5.3.2.1-4).

- High heat has been excluded. Estimated thermal load is $19,000 \mathrm{BTU} / \mathrm{hr}$. This is insufficient to classify this tank as a high-heat tank (Kummerer 1995 and Noorani 1999, pp. 5.3.2.22-1). Present maximum temperature of $130^{\circ} \mathrm{F}$ in the waste confirms heat load classification. 
Are there process history ties to other sampled tanks?

Yes. Related tanks that have been sampled are A-101, AX-101, AX-104, and C-106. Tanks A-101 and AX-101 both have a similar process history to that of A-106. Both tanks were sluiced of their original contents and used to store 242-A Evaporator concentrates. These concentrates were produced from 1978 to 1980 and comprise the bulk of the waste inventory. Evaporator concentrates from 242-A have limited compositional variation as evidenced from historical evaluation and analysis of tank waste (Agnew et al. 1997b; LoPresti et al. 1997; Hendrickson et al. 1998). The data from tanks A-101 and AX-101 do not exhibit behavior that triggers safety screening limits (LMHC 1999 and Appendix A). Because of the degree of similarity in process history, the evaporator waste in A-106 is not expected to exhibit behavior different from that observed in A-101 or AX-101.

A small residue of washed PUREX sludge is expected in the bottom of tank A-106. Tanks C-106 and AX-104 have waste that resembles the sludge heel expected in tank A-106. The wastes in the heel of tank A-106, the heel of tank AX-104, and the middle of tank $\mathrm{C}-106$ have a common process origin, washed PUREX sludge for cesium and strontium recovery. (Agnew et al. 1997b). Because of the degree of similarity in process history, the sludge in A-106 is not expected to exhibit behavior different from that observed in C-106 and AX-104 (LMHC 1999 and Appendix A).

\section{Is core sampling necessary to show tank is bounded?}

Table B-7 illustrates this statement using the logic chart (Figure B-1). Furthermore, core sampling would probably be unsuccessful in a tank with less than 1 segment of waste depth.

Table B-7. Safety Issue Logic for Tank A-106

\begin{tabular}{|l|l|l|l|l|l|l|}
\hline \multicolumn{1}{|c|}{ Issue } & $\begin{array}{c}\text { Organic } \\
\text { Complexant }\end{array}$ & $\begin{array}{c}\text { Organic } \\
\text { Solvent }\end{array}$ & Ferrocyanide & $\begin{array}{c}\text { Flammable } \\
\text { Gas }\end{array}$ & High Heat & Criticality \\
\hline $\begin{array}{l}\text { Can a case be } \\
\text { demonstrated why } \\
\text { related tanks are } \\
\text { bounding? }\end{array}$ & No & Excluded & Excluded & No & Excluded & Excluded \\
\hline $\begin{array}{l}\text { Are other data (other } \\
\text { than core sampling) } \\
\text { sufficient to address } \\
\text { safety issues? }\end{array}$ & No & Excluded & Excluded & Yes & Excluded & Excluded \\
\hline $\begin{array}{l}\text { Does a preponderance } \\
\text { of evidence } \\
\text { demonstrate sampling } \\
\text { is not needed? }\end{array}$ & Yes & Excluded & Excluded & $*$ & Excluded & Excluded \\
\hline
\end{tabular}

Notes:

* = If a previous box provides necessary data for a yes, this logic box does not need to be addressed. 
HNF-4232 Rev. 0

\section{Safety Issues Associated with Tank:}

\section{Organic Complexants:}

Evidence from theoretical considerations, empirical simulant studies, and evaluation of related tanks shows the hazards from organic complexants are adequately controlled. Tanks A-101 and AX-101 were categorized as having high concentrations of organic complexant waste. Tank A-106 was also categorized as having high concentrations of organic complexant waste. Section 3.1.3 and Meacham et al. (1998) describe the organic complexant evaluation more thoroughly. The upper layer of waste in tank A-106 (75,000 gallons, or $60 \%$ by volume) is composed of 242-A Evaporator concentrate. This waste is projected to be similar in composition and behavior to evaporator concentrate waste in tanks A-101 and AX-101, which have been sampled and analyzed. Based on these analytical results, organic complexants have been determined to not be a safety issue for the evaporator concentrate waste layer in tank A-106 (Appendix A, Figures A-12 to A-15, and LMHC 1999).

The lower layer of waste in A-106 (50,000 gallons, or $40 \%$ by volume) is composed of washed PUREX sludge and strontium recovery waste. This waste is projected to be similar in composition and behavior to washed PUREX sludge and strontium recovery waste found in tanks AX-104 and C-106, which have been sampled and analyzed. Waste from tank AX-104 was categorized as having low concentrations of organic complexant waste. A-106 and C-106 were categorized as having high concentrations of organic complexant wastes (Meacham et al. 1998). Based on the analytical results from C-106 showing that the elevated TOC values observed in the $\mathrm{C}-106$ samples were within the authorization basis and the TOC data from AX-104 was very low, organic complexants have been determined to not be a safety issue for the washed PUREX sludge and strontium recovery waste layer in tank A-106 (Appendix A, Figures A-12 to A-15, and LMHC 1999.

\section{Flammable Gas:}

Tank A-106 is not considered a hazard with respect to the flammable gas safety issue (Hodgson 1998). Because no surface level rise or barometric response behavior has been observed, the tank is considered Facility Group 3. Facility Group 3 tanks are conservatively postulated to have the potential for small, induced GREs (Funderburke 1997). In addition, the tank was interim stabilized in 1982. Interim stabilization has been shown to significantly reduce the potential for trapping and periodically releasing flammable gas (Stewart et al. 1996). Other tanks, as shown in Section 3.1.4, have exhibited much stronger indications of flammable gas behavior and have been extensively sampled to provide data to address the safety issue (Johnson et al. 1997). Further sampling and analysis of the waste in tank A-106 will not change the safety classification of the tank or the controls applied with respect to this safety issue. 
Are there any anomalous data that would drive characterization of the tank?

No. Hodgson (1998) has reviewed the available surveillance data for surface level and temperature anomalies. None were observed. 
Tank Name: B-105

Tank Parameters:

Tank Type: SST

Ventilation: Passive

Interim stabilized: Yes (1984)
Tank Capacity: 530,000 gallons

Service History: Inactive (1977)

Tank Integrity：Assumed leaker (1978)

Waste Parameters:

Total waste:

Waste types:

158,000 gallons

130,000 gallons 242-B Evaporator concentrate (1951-1953) 28,000 gallons B Plant second-cycle bismuth phosphate waste (1953-1954)

(Higley 1998a)

Waste Temperature: $64.9^{\circ} \mathrm{F}$ (July 1998) (LMHC 1999)

Safety Issue Status:

Watch List: None

USQs: $\quad$ Flammable gas (now closed), Organic nitrate (now closed)

Determination of the Safety Issues Associated with This Tank:

- Flammable gas

- Organic nitrate

\section{Safety Issues Excluded from This Tank:}

- Ferrocyanide has been excluded. Tank B-105 is not identified as one of the 18 ferrocyanide tanks (Postma et al. 1994).

- Organic solvent has been excluded. Tank has been demonstrated to not be in scope of organic solvent issue by vapor sampling (Meacham et al. 1998).

Furthermore, analytical results show that organic solvents are difficult to ignite, and credible ignition sources have been narrowed to robust energy sources such as lightning strikes and large hot metal cuttings from welding (Cowley et al. 1999).

- Criticality has been excluded. This tank did not receive any PFP waste (Agnew et al. 1997b). Criticality is not considered to be a credible accident scenario for safe storage of waste in tanks (Noorani 1999, pp. 5.3.2.1-4).

- High heat has been excluded. Estimated thermal load is 2,580 BTU/hr. This is insufficient to classify this tank as a high-heat tank (Kummerer 1995 and Noorani 1999 , pp. 5.3.2.22-1). Present maximum temperature of $64.9^{\circ} \mathrm{F}$ in the waste confirms heat load classification. 
Are there process history ties to other sampled tanks?

Yes. Tanks B-104 and B-106 have similar process histories to that of B-105. Tanks B-105 and B-106 were used to store 242-B Evaporator concentrates. These concentrates were produced from 1951 to 1953 and comprise the bulk of the waste inventory in tank B-105. The evaporator concentrates from 242-B have limited compositional variation as evidenced from historical evaluation and analysis of tank waste (Agnew et al. 1997b; LoPresti et al. 1997; Hendrickson et al. 1998). The 242-B Evaporator wastes were cascaded directly from tank B-105 into B-106. The data from tank B-106 does not exhibit behavior that triggers safety screening limits (LMHC 1999 and Appendix A). Because of the degree of similarity in process history, the evaporator waste in B-105 is not expected to exhibit behavior different from that observed in B-106.

Tanks B-104 and B-105 were used to store second-cycle bismuth phosphate waste from B Plant. Bismuth phosphate wastes from B Plant have limited compositional variation as evidenced from historical evaluation and analysis of tank waste (Agnew et al. 1997b; Remund and Simpson 1998; Hendrickson et al. 1998), and were cascaded directly into B-105 from B-104. The data from tank B-104 does not exhibit behavior that triggers safety screening limits (LMHC 1999 and Appendix A). Because of the degree of similarity in process history, the bismuth phosphate waste in B-105 is not expected to exhibit behavior different from that observed in B-104.

Is core sampling necessary to show tank is bounded?

Table B-8 illustrates this statement using the logic chart (Figure B-1).

Table B-8. Safety Issue Logic for Tank B-105

\begin{tabular}{|l|l|l|l|l|l|l|}
\hline \multicolumn{1}{|c|}{ Issue } & $\begin{array}{c}\text { Organic } \\
\text { Complexant }\end{array}$ & $\begin{array}{c}\text { Organic } \\
\text { Solvent }\end{array}$ & Ferrocyanide & $\begin{array}{l}\text { Flammable } \\
\text { Gas }\end{array}$ & High Heat & Criticality \\
\hline $\begin{array}{l}\text { Can a case be } \\
\text { demonstrated why } \\
\text { related tanks are } \\
\text { bounding? }\end{array}$ & Yes & Excluded & Excluded & No & Excluded & Excluded \\
\hline $\begin{array}{l}\text { Are other data (other } \\
\text { than core sampling) } \\
\text { sufficient to address } \\
\text { safety issues? }\end{array}$ & $*$ & Excluded & Excluded & Yes & Excluded & Excluded \\
\hline $\begin{array}{l}\text { Does a preponderance } \\
\text { of evidence } \\
\text { demonstrate sampling } \\
\text { is not needed? }\end{array}$ & $*$ & Excluded & Excluded & $*$ & Excluded & Excluded \\
\hline
\end{tabular}

Notes:

* = If a previous box provides necessary data for a yes, this logic box does not need to be addressed. 


\section{Safety Issues Associated with Tank:}

\section{Organic Complexants:}

The tanks both upstream and downstream in this cascade of tanks have been sampled and been demonstrated to be safe with respect to the organic complexant safety issue. Some of the waste in this tank had origins in tank B-104, which has sample data indicating TOC levels are not elevated in that tank. Tank B-105 served as the source tank for the evaporator concentrates that cascaded to Tank B-106, which has sample data indicating TOC levels are not elevated in that tank.

Furthermore, evidence from theoretical considerations, empirical simulant studies, and evaluation of related tanks shows the hazards from organic complexants are adequately controlled. Wastes from tanks B-104 and B-106 were categorized as having no and low combinations of organic complexant waste, respectively. Tank B-105 was categorized as having low concentrations of organic complexant waste. Section 3.1.3 and Meacham et al. (1998) describe the organic complexant evaluation more thoroughly.

\section{Flammable Gas:}

Tank B-105 is not considered a hazard with respect to the flammable gas safety issue (Hodgson 1998). Because no surface level rise or barometric response behavior has been observed, the tank is considered Facility Group 3. Facility Group 3 tanks are conservatively postulated to have the potential for small, induced GREs (Funderburke 1997). In addition, the tank was interim stabilized in 1985. Interim stabilization has been shown to significantly reduce the potential for trapping and periodically releasing flammable gas (Stewart et al. 1996). Other tanks, as shown in Section 3.1.4, have exhibited much stronger indications of flammable gas behavior and have been extensively sampled to provide data to address the safety issue (Johnson et al. 1997). Further sampling and analysis of the waste in tank B-105 will not change the safety classification of the tank or the controls applied with respect to this safety issue.

\section{Are there any anomalous data that would drive characterization of the tank?}

No. This tank does exhibit a substantial salt shelf that rings the perimeter of the tank interior. This feature leads to highly inconsistent volume estimates using conventional volume calculation methods. The center of the tank waste surface is much lower than the surface around the edge. Photographs have been used to more precisely estimate the tank volume. Hodgson (1998) has reviewed the available surveillance data for other surface level irregularities and temperature anomalies. None were observed. 
Tank Name: $B X-102$

Tank Parameters:

Tank Type: SST

Ventilation: Passive

Interim stabilized: Yes (1978)

Tank Capacity: 530,000 gallons

Service History: Inactive (1971)

Tank Integrity：Assumed leaker (1971)

Waste Parameters:

Total waste: $\quad 96,000$ gallons

Waste types: $\quad 68,000$ gallons diatomaceous earth (1971)

28,000 gallons PUREX cladding and uranium recovery

waste (1970)

(Lambert 1998e)

Waste Temperature: $63.5^{\circ} \mathrm{F}$ (May 1999) (LMHC 1999)

Safety Issue Status:

Watch List: None

USQs: $\quad$ Flammable gas (now closed), Organic nitrate (now closed)

Determination of the Safety Issues Associated with This Tank:

- Flammable gas

- Organic nitrate

\section{Safety Issues Excluded from This Tank:}

- Ferrocyanide has been excluded. Tank BX-102 is not identified as one of the 18 ferrocyanide tanks (Postma et al. 1994).

- Organic solvent has been excluded. Tank has been demonstrated to not be in scope of organic solvent issue by vapor sampling (Meacham et al. 1998).

Furthermore, analytical results show that organic solvents are difficult to ignite, and credible ignition sources have been narrowed to robust energy sources such as lightning strikes and large hot metal cuttings from welding (Cowley et al. 1999).

- Criticality has been excluded. This tank did not receive any PFP waste (Agnew et al. 1997b). Criticality is not considered to be a credible accident scenario for safe storage of waste in tanks (Noorani 1999, pp. 5.3.2.1-4).

- High heat has been excluded. Estimated thermal load is 3,320 BTU/hr. This is insufficient to classify this tank as a high-heat tank (Kummerer 1995 and Noorani 1999 , pp. 5.3.2.22-1). Present maximum temperature of $63.5^{\circ} \mathrm{F}$ in the waste confirms heat load classification. 


\section{Are there process history ties to other sampled tanks?}

Yes. Tanks T-102 and BX-109 have a similar process histories to that of BX-102. Tanks T-102 and BX-102 were used to store PUREX cladding wastes. These wastes were produced and sent to these tanks from 1958 to 1970 . Cladding wastes have limited compositional variation as evidenced from historical evaluation and analysis of tank waste (Agnew et al. 1997b; LoPresti et al. 1997; Hendrickson et al. 1998). The data from tank T-102 does not exhibit behavior that triggers safety screening limits (LMHC 1999 and Appendix A). Because of the degree of similarity in process history, the waste in BX-102 is not expected to exhibit behavior different from that observed in $\mathrm{T}-102$.

Tank BX-109 also has a similar process history to that of BX-102. Both tanks were used to store uranium recovery wastes. These wastes were produced and sent to these tanks in 1954. The data from tank BX-109 does not exhibit behavior that triggers safety screening limits (LMHC 1999 and Appendix A). Because of the degree of similarity in process history, the uranium recovery waste in BX-102 is not expected to exhibit behavior different from that observed in BX-109.

\section{Is core sampling necessary to show tank is bounded?}

Table B-9 illustrates this statement using the logic chart (Figure B-1).

Table B-9. Safety Issue Logic for Tank BX-102

\begin{tabular}{|l|l|l|l|l|l|l|}
\hline \multicolumn{1}{|c|}{ Issue } & $\begin{array}{c}\text { Organic } \\
\text { Complexant }\end{array}$ & $\begin{array}{c}\text { Organic } \\
\text { Solvent }\end{array}$ & Ferrocyanide & $\begin{array}{l}\text { Flammable } \\
\text { Gas }\end{array}$ & High Heat & Criticality \\
\hline $\begin{array}{l}\text { Can a case be } \\
\text { demonstrated } \\
\text { why related } \\
\text { tanks are } \\
\text { bounding? }\end{array}$ & No & Excluded & Excluded & No & Excluded & Excluded \\
\hline $\begin{array}{l}\text { Are other data } \\
\text { (other than core } \\
\text { sampling) } \\
\text { sufficient to } \\
\text { address safety } \\
\text { issues? }\end{array}$ & No & Excluded & Excluded & Yes & Excluded & Excluded \\
\hline $\begin{array}{l}\text { Does a } \\
\text { preponderance } \\
\text { of evidence } \\
\text { demonstrate } \\
\text { sampling is not } \\
\text { needed? }\end{array}$ & Yes & Excluded & Excluded & $*$ & & \\
\hline
\end{tabular}

Notes:

* = If a previous box provides necessary data for a yes, this logic box does not need to be addressed. 
HNF-4232 Rev. 0

\section{Safety Issues Associated with Tank:}

\section{Organic Complexants:}

Evidence from theoretical considerations, empirical simulant studies, and evaluation of related tanks shows the hazards from organic complexants are adequately controlled. Tanks BX-102, BX-109, and T-102 were categorized as having low concentrations of organic complexant waste. Section 3.1.3 and Meacham et al. (1998) describe the organic complexant evaluation more thoroughly. The data from related tanks (T-102 and BX-109) indicate that organic complexants are not an issue for the waste in tank BX-102 (Appendix A and Figures A-12 to A-15). Further core sampling and analysis of the waste in this tank will not change the safety classification or the controls applied to tank $\mathrm{BX}-102$ with respect to this safety issue.

\section{Flammable Gas:}

Tank BX-102 has less than 110,000 gallons of waste. Therefore, there is not sufficient waste volume to accumulate enough flammable gas to present a hazard (see Section B3.3). This tank is in Facility Group 3.

\section{Are there any anomalous data that would drive characterization of the tank?}

No. Hodgson (1998) has reviewed the available surveillance data for surface level irregularities and temperature anomalies. None were observed. However, tank BX-102 contains 68,000 gallons of diatomaceous earth. It was introduced as a means of preventing the tank from leaking. Diatomaceous earth is inert with respect to the flammable gas and organic safety issues. Its composition indicates it has no energetic properties, no flammable gas generation or retention properties, and no alpha content (Buckingham and Metz 1974). 
Tank Name: BY-105

Tank Parameters:

Tank Type: SST

Ventilation: Passive

Tank Capacity: 758,000 gallons

Interim stabilized: Partial (1982)

Service History: Inactive (1974)

Tank Integrity: Assumed leaker (1984)

Waste Parameters:

Total waste:

Waste types:

503,000 gallons

345,000 gallons In-tank solidification concentrate

(1965-1974)

150,000 gallons ferrocyanide waste (1955-1957)

8,000 gallons Portland cement (1977)

(Lambert 1998f) .

Waste Temperature: $107.2^{\circ} \mathrm{F}$ (May 1999) (LMHC 1999)

Safety Issue Status:

Watch List: None

USQs: $\quad$ Flammable gas (now closed), Organic nitrate (now closed)

Determination of the Safety Issues Associated with This Tank:

- Flammable gas

- Organic nitrate

- Ferrocyanide

\section{Safety Issues Excluded from This Tank:}

- Organic solvent has been excluded. Tank has been demonstrated to not be in scope of organic solvent issue by vapor sampling (Noorani 1999, pp. 5.3.2.15-17). Furthermore, analytical results show that organic solvents are difficult to ignite, and credible ignition sources have been narrowed to robust energy sources such as lightning strikes and large hot metal cuttings from welding (Cowley et al. 1999).

- Criticality has been excluded. This tank did not receive any PFP waste (Agnew et al. 1997b). Criticality is not considered to be a credible accident scenario for safe storage of waste in tanks (Noorani 1999, pp. 5.3.2.1-4).

- High heat has been excluded. Estimated thermal load is 8,700 BTU/hr. This is insufficient to classify this tank as a high-heat tank (Kummerer 1995 and Noorani 1999 , pp. 5.3.2.22-1). Present maximum temperature of $107.2^{\circ} \mathrm{F}$ in the waste confirms heat load classification. 


\section{Are there process history ties to other sampled tanks?}

Yes. Tanks BY-108 and BY-110 have similar process histories to that of BY-105. All three tanks were used to store first and second campaign in-tank solidification (ITS) evaporator concentrates and ferrocyanide wastes. The ITS concentrate wastes were produced and sent to these tanks from 1965 to 1974. Evaporator concentrates have limited compositional variation as evidenced from historical evaluation and analysis of tank waste (Agnew et al. 1997b; LoPresti et al. 1997; Hendrickson et al. 1998).

The ferrocyanide wastes were produced and sent to these tanks from 1954 to 1957 (Borsheim and Simpson 1991). The data from tanks BY-108 and BY-110 do not exhibit behavior that triggers safety screening limits (LMHC 1999 and Appendix A). Because of the degree of similarity in process history, the waste in BY-105 is not expected to exhibit behavior different from that observed in BY-108 and BY-110.

\section{Is core sampling necessary to show tank is bounded?}

Table B-10 illustrates this statement using the logic chart (Figure B-1).

Table B-10. Safety Issue Logic for Tank BY-105

\begin{tabular}{|c|c|c|c|c|c|c|}
\hline Issue & $\begin{array}{c}\text { Organic } \\
\text { Complexant }\end{array}$ & $\begin{array}{l}\text { Organic } \\
\text { Solvent }\end{array}$ & Ferrocyanide & $\begin{array}{c}\text { Flammable } \\
\text { Gas }\end{array}$ & High Heat & Criticality \\
\hline $\begin{array}{l}\text { Can a case be } \\
\text { demonstrated } \\
\text { why related } \\
\text { tanks are } \\
\text { bounding? }\end{array}$ & No & Excluded & Yes & No & Excluded & Excluded \\
\hline $\begin{array}{l}\text { Are other data } \\
\text { (other than core } \\
\text { sampling) } \\
\text { sufficient to } \\
\text { address safety } \\
\text { issues? }\end{array}$ & No & Excluded & * & Yes & Excluded & Excluded \\
\hline $\begin{array}{l}\text { Does a } \\
\text { preponderance } \\
\text { of evidence } \\
\text { demonstrate } \\
\text { sampling is not } \\
\text { needed? }\end{array}$ & Yes & Excluded & * & $*$ & Excluded & Excluded \\
\hline
\end{tabular}

Notes:

* = If a previous box provides necessary data for a yes, this logic box does not need to be addressed. 


\section{Safety Issues Associated with Tank:}

\section{Organic Complexants:}

Evidence from theoretical considerations, empirical simulant studies, and evaluation of related tanks shows the hazards from organic complexants are adequately controlled. Tanks BY-105, BY -108 , and BY -110 were categorized as having low concentrations of organic complexant waste. This is shown in Section 3.1.3, Meacham et al. (1998), and in Appendix A (Figures A-12 to A-15). Organic complexant concentrations in tanks BY-108 and BY-110 which have wastes similar to BY-105 (both the concentrated wastes and the ferrocyanide wastes) do not approach the concentration limit in the authorization basis. Further core sampling and analysis of the waste in this tank will not change the safety classification or the controls applied to tank BY-105 with respect to this safety issue.

\section{Ferrocyanide:}

Tank BY-105 is identified as one of 18 ferrocyanide tanks (Postma et al. 1994). However, data from the other ferrocyanide wastes sampled has confirmed it is not energetic (see Section B3.2 for more details on the analysis). The ferrocyanide USQ and safety issue have been closed (Meacham 1996).

\section{Flammable Gas:}

Tank BY-105 is considered a Facility Group 2 tank. Facility Group 2 tanks are conservatively postulated to have the potential for small spontaneous and large induced GREs (Funderburke 1997). Other tanks, such as AN-105 or AW-101, have exhibited much stronger indications of flammable gas behavior and have been extensively sampled to provide data to address the safety issue. Section 3.1.4 and Johnson et al. (1997) describe the flammable gas data evaluation more thoroughly. This tank has a SHMS installed on it for monitoring purposes. From July 1998 to June 1999, the peak hydrogen concentration recorded on the SHMS equipment was $310 \mathrm{ppm}$ in January 1999. Further sampling and analysis of the waste in tank BY-105 will not change the safety classification of the tank or the controls applied with respect to this safety issue.

\section{Are there any anomalous data that would drive characterization of the tank?}

No, not for safety issue resolution. However, tank BY-105 had 8,000 gallons of Portland cement put into it. This may impact future retrieval activities, and sampling for material properties may be needed. However, because it is a Phase II tank, physical properties data is not needed until after 2012. A pair of core samples has been taken recently (July/August 1998), but the final data was not published as of the data cut-off date for this report (October 1998). Hodgson (1998) has reviewed the available surveillance data for surface level irregularities and temperature anomalies. None were found. 
Tank Name: BY-106

Tank Parameters:

Tank Type: SST

Ventilation: Passive

Interim stabilized: Partial (1982)
Tank Capacity: 758,000 gallons

Service History: Inactive (1974)

Tank Integrity: Assumed leaker (1984)

Waste Parameters:

Total waste:

642,000 gallons

Waste types:

547,000 gallons In-tank solidification concentrate

(1965-1974)

95,000 gallons ferrocyanide waste (1955-1957)

(Lambert 1998g)

Waste Temperature: $116.6^{\circ} \mathrm{F}$ (May 1999) (LMHC 1999)

Safety Issue Status:

Watch List: None

USQs: $\quad$ Flammable gas (now closed), Organic nitrate (now closed)

\section{Determination of the Safety Issues Associated with This Tank:}

- Flammable gas

- Organic nitrate

- Ferrocyanide

\section{Safety Issues Excluded from This Tank:}

- Organic solvent has been excluded. Tank has been demonstrated to not be in scope of organic solvent issue by vapor sampling (Noorani 1999, pp. 5.3.2.15-17). Furthermore, analytical results show that organic solvents are difficult to ignite, and credible ignition sources have been narrowed to robust energy sources such as lightning strikes and large hot metal cuttings from welding (Cowley et al. 1999). Additional core sampling and analyses are not warranted, because additional core sample data will not eliminate the need for controls or further resolve the safety issue.

- Criticality has been excluded. This tank did not receive any PFP waste (Agnew et al. 1997b). Criticality is not considered to be a credible accident scenario for safe storage of waste in tanks (Noorani 1999, pp. 5.3.2.1-4).

- High heat has been excluded. Estimated thermal load is $10,000 \mathrm{BTU} / \mathrm{hr}$. This is insufficient to classify this tank as a high-heat tank (Kummerer 1995 and Noorani 1999 , pp. 5.3.2.22-1). Present maximum temperature of $116.6^{\circ} \mathrm{F}$ in the waste confirms heat load classification. 


\section{Are there process history ties to other sampled tanks?}

Yes. Tanks BY-108 and BY-110 have similar process histories to that of BY-106. All three tanks were used to store first and second campaign in-tank solidification (ITS) evaporator concentrates and ferrocyanide wastes. The ITS concentrate wastes were produced and sent to these tanks from 1965 to 1974. Evaporator concentrates have limited compositional variation as evidenced from historical evaluation and analysis of tank waste (Agnew et al. 1997b; LoPresti et al. 1997; Hendrickson et al. 1998). See Section B3.2 for more information on evaporator concentrates.

The ferrocyanide wastes were produced and sent to these tanks from 1954 to 1957 (Borsheim and Simpson 1991). The data from tanks BY-108 and BY-110 do not exhibit behavior that triggers safety screening limits (LMHC 1999 and Appendix A). Because of the degree of similarity in process history, the waste in $B Y-106$ is not expected to exhibit behavior different from that observed in $\mathrm{BY}-108$ and BY-110.

\section{Is core sampling necessary to show tank is bounded?}

Table B-11 illustrates this statement using the logic chart (Figure B-1).

Table B-11. Safety Issue Logic for Tank BY-106

\begin{tabular}{|c|c|c|c|c|c|c|}
\hline Issue & $\begin{array}{c}\text { Organic } \\
\text { Complexant }\end{array}$ & $\begin{array}{l}\text { Organic } \\
\text { Solvent }\end{array}$ & Ferrocyanide & $\begin{array}{c}\text { Flammable } \\
\text { Gas }\end{array}$ & High Heat & Criticality \\
\hline $\begin{array}{l}\text { Can a case be } \\
\text { demonstrated } \\
\text { why related } \\
\text { tanks are } \\
\text { bounding? }\end{array}$ & No & Excluded & Yes & No & Excluded & Excluded \\
\hline $\begin{array}{l}\text { Are other data } \\
\text { (other than core } \\
\text { sampling) } \\
\text { sufficient to } \\
\text { address safety } \\
\text { issues? }\end{array}$ & No & Excluded & $*$ & Yes & Excluded & Excluded \\
\hline $\begin{array}{l}\text { Does a } \\
\text { preponderance } \\
\text { of evidence } \\
\text { demonstrate } \\
\text { sampling is not } \\
\text { needed? }\end{array}$ & Yes & Excluded & $*$ & * & Excluded & Excluded \\
\hline
\end{tabular}

Notes:

$$
\text { * = If a previous box provides necessary data for a yes, this logic box does not need to be }
$$
addressed. 


\section{Safety Issues Associated with Tank:}

\section{Organic Complexants:}

Evidence from theoretical considerations, empirical simulant studies, and evaluation of related tanks shows the hazards from organic complexants are adequately controlled. Tanks BY-106, BY-108, and BY-110 were categorized as having low concentrations of organic complexant waste. This is shown in Section 3.1.3, Meacham et al. (1998), and in Appendix A (Figures A-12 to A-15). Organic complexant concentrations in tanks BY-108 and BY-110 with wastes similar to BY-106 (both the concentrated wastes and the ferrocyanide wastes) do not approach the concentration limit in the authorization basis. Further core sampling and analysis of the waste in this tank will not change the safety classification or the controls applied to tank BY-106 with respect to this safety issue.

\section{Ferrocyanide:}

Tank BY-106 is identified as one of 18 ferrocyanide tanks (Postma et al. 1994). However, data from the other ferrocyanide wastes sampled has confirmed it is not energetic (see Section B3.2 for more details on the analysis). The ferrocyanide USQ and safety issue have been closed (Meacham 1996).

\section{Flammable Gas:}

Tank BY-106 is considered a Facility Group 2 tank. Facility Group 2 tanks are conservatively postulated to have the potential for small spontaneous and large induced gas release events (GREs) (Funderburke 1997). Therefore, more rigorous flammable gas controls as defined in Funderburke (1997) have been applied to this tank. Further sampling and analysis of the waste in tank BY-106 will not change the safety classification of the tank or the controls applied with respect to this safety issue. Other tanks, such as AN-105 or AW-101, have exhibited much stronger indications of flammable gas behavior and have been extensively sampled to provide data to address the safety issue. This tank has a SHMS installed on it for monitoring purposes. From July 1998 to June 1999, the peak hydrogen concentration observed by the SHMS equipment was $780 \mathrm{ppm}$ in August 1998. Section 3.1.4 and Johnson et al. (1997) describe the flammable gas data evaluation more thoroughly.

\section{Are there any anomalous data that would drive characterization of the tank?}

No. Hodgson (1998) has reviewed the available surveillance data for surface level irregularities and temperature anomalies. None were found. 
Tank Name: C-102

Tank Parameters:

Tank Type: SST

Ventilation: Passive

Tank Capacity: 530,000 gallons

Interim stabilized: Yes (1985)

Service History: Inactive (1977)

Tank Integrity: Sound

Waste Parameters:

Total waste:

402,000 gallons

Waste types:

7,500 gallons metal waste from bismuth phosphate (1954)

20,000 gallons uranium recovery waste (1954)

10,000 gallons thoria waste (1966)

365,000 gallons PUREX cladding (1968)

(Place 1998)

Waste Temperature: $80.6^{\circ} \mathrm{F}$ (May 1999) (LMHC 1999)

Safety Issue Status:

Watch List: Organic nitrate (now closed)

USQs: $\quad$ Flammable gas (now closed), Organic nitrate (now closed)

Determination of the Safety Issues Associated with This Tank:

- Flammable gas

- Organic nitrate

Safety Issues Excluded from This Tank:

- Ferrocyanide has been excluded. Tank C-102 is not identified as one of the 18 ferrocyanide tanks (Postma et al. 1994).

- Criticality has been excluded. This tank did not receive any PFP waste (Agnew et al. 1997b). Criticality is not considered to be a credible accident scenario for safe storage of waste in tanks (Noorani 1999, pp. 5.3.2.1-4).

- High heat has been excluded. Estimated thermal load is $13,000 \mathrm{BTU} / \mathrm{hr}$. This is insufficient to classify this tank as a high-heat tank (Kummerer 1995 and Noorani 1999 , pp. 5.3.2.22-1). Present maximum temperature of $80.6^{\circ} \mathrm{F}$ in the waste confirms heat load classification.

Are there process history ties to other sampled tanks?

Yes. Tanks C-104, T-102, BX-104, and BX-109 have similar process histories to that of C-102. Tanks C-102 and C-104 were used to store PUREX cladding wastes and thoria wastes. Tank $T-102$ stored PUREX cladding waste without thoria wastes. Cladding wastes have limited compositional variation as evidenced from historical evaluation and analysis of tank waste (Agnew et al. 1997b; 
LoPresti et al. 1997; Hendrickson et al. 1998). These wastes were produced and sent to these tanks from 1958 to 1970 . Thoria wastes were produced in 1966 and 1970. No isolated samples of thoria waste have been recovered. However, the mixture of thoria and other wastes do not appear to have any distinct properties that would pose a safety hazard.

Some of the data from tank C-104 exhibits behavior that triggers safety screening limits for TOC. Total alpha concentrations are also elevated, but do not exceed the safety screening limit. (LMHC 1999 and Appendix A). Further examination of the data shows that no exotherms above safety screening limits are observed in $\mathrm{C}-104$. Because of the degree of similarity in process history, the waste in C-102 is not expected to exhibit behavior different from that observed in C-104.

Tank BX-109 has a similar process history to that of C-102. Both tanks were used to store uranium recovery wastes. These wastes were produced and sent to these tanks in 1954. The data from tank BX-109 does not exhibit behavior that triggers safety screening limits (LMHC 1999 and Appendix A). Because of the degree of similarity in process history, the waste in C-102 is not expected to exhibit behavior different from that observed in BX-109.

Tank BX-104 has a similar process history to that of C-102. Both tanks were used to store bismuth phosphate metal waste. Metal waste is infrequently sampled because of its relative scarcity and inaccessibility. It was reclaimed during several sluicing campaigns and processed in the uranium recovery operation (Rodenhizer 1987; Agnew et al. 1997b), and subsequent waste management of the tanks has made the remaining metal waste residue difficult to sample successfully with current equipment and riser configurations. Metal waste has compositional features that enable it to be distinguished from evaporator concentrates (Kupfer et al. 1999). The data from tank BX-104 does not exhibit behavior that triggers safety screening limits (LMHC 1999 and Appendix A). Because of the degree of similarity in process history, the waste in C-102 is not expected to exhibit behavior different from that observed in BX-104.

Core samples were taken from tank C-102 in 1986 (Weiss and Schull 1988b). Although not part of the contemporary characterization program, the results are consistent with process knowledge regarding the tank's contents. Relatively low sodium and nitrate concentrations with high transition metal concentrations (particularly aluminum, iron, nickel, and zirconium) indicate cladding waste as indicated from Agnew et al. (1997b). 
Is core sampling necessary to show tank is bounded?

Table B-12 illustrates this statement using the logic chart (Figure B-1).

Table B-12. Safety Issue Logic for Tank C-102

\begin{tabular}{|c|c|c|c|c|c|c|}
\hline Issue & $\begin{array}{c}\text { Organic } \\
\text { Complexant }\end{array}$ & $\begin{array}{l}\text { Organic } \\
\text { Solvent }\end{array}$ & Ferrocyanide & $\begin{array}{c}\text { Flammable } \\
\text { Gas }\end{array}$ & High Heat & Criticality \\
\hline $\begin{array}{l}\text { Can a case be } \\
\text { demonstrated } \\
\text { why related } \\
\text { tanks are } \\
\text { bounding? }\end{array}$ & No & No & Excluded & No & Excluded & Excluded \\
\hline $\begin{array}{l}\text { Are other data } \\
\text { (other than core } \\
\text { sampling) } \\
\text { sufficient to } \\
\text { address safety } \\
\text { issues? }\end{array}$ & No & Yes & Excluded & Yes & Excluded & Excluded \\
\hline $\begin{array}{l}\text { Does a } \\
\text { preponderance } \\
\text { of evidence } \\
\text { demonstrate } \\
\text { sampling is not } \\
\text { needed? }\end{array}$ & Yes & * & Excluded & * & Excluded & Excluded \\
\hline
\end{tabular}

Notes:

* = If a previous box provides necessary data for a yes, this logic box does not need to be addressed.

\section{Safety Issues Associated with Tank:}

\section{Organic Complexants:}

Evidence from theoretical considerations, empirical simulant studies, and evaluation of related tanks shows the hazards from organic complexants are adequately controlled. Tank C-102 was categorized as a special case. Section 3.1.3 and Meacham et al. (1998) describe the organic complexant evaluation more thoroughly. Much of the waste in tank C-102 (372,500 gallons, or $92.7 \%$ by volume) is composed of metal waste or PUREX cladding waste. These wastes are projected to be similar in composition and behavior to waste in tanks BX-104 and C-104, respectively, which have been sampled and analyzed. Based on these analytical results, organic complexants have been determined to not be a safety issue for the evaporator concentrate waste layer in tank C-102 (Appendix A, Figures A-12 to A-15, and LMHC 1999)

The remainder of the waste in C-102 (30,000 gallons, or $7.3 \%$ by volume) is composed of thoria sludge and uranium recovery waste. This waste is projected to be similar in composition and behavior to thoria sludge and uranium recovery 
waste found in tanks BX-109 and C-104, which have been sampled and analyzed. Based on the analytical results from $\mathrm{C}-104$ showing that the elevated TOC values observed in the $\mathrm{C}-104$ samples were within the authorization basis, organic complexants have been determined to not be a safety issue for the thoria sludge and uranium recovery wastes in tank C-102 (Appendix A, Figures A-12 to A-15, and LMHC 1999).

\section{Organic Solvents:}

Analytical results show that organic solvents are difficult to ignite, and credible ignition sources have been narrowed to robust energy sources such as lightning strikes and large hot metal cuttings from welding (Cowley et al. 1999). Additional core sampling and analyses are not warranted, because additional core sample data will not eliminate the need for controls or further resolve the safety issue.

\section{Flammable Gas:}

Because no surface level fluctuation or barometric response behavior has been observed, the tank is considered Facility Group 3. In addition, tank C-102 was interim stabilized in 1985. Interim stabilization has been shown to significantly reduce the potential for trapping and periodically releasing flammable gas (Stewart et al. 1996). Other tanks, as shown in Section 3.1.4, have exhibited much stronger indications of flammable gas behavior and have been extensively sampled to provide data to address the safety issue (Johnson et al. 1997). Further sampling and analysis of the waste in tank C-102 will not change the safety classification of the tank or the controls applied with respect to this safety issue.

\section{Are there any anomalous data that would drive characterization of the tank?}

No. Hodgson (1998) has reviewed the available surveillance data for surface level irregularities and temperature anomalies. None were observed. 
Tank Name: S-103

Tank Parameters:

Tank Type: SST

Ventilation: Passive

Tank Capacity: 758,000 gallons

Interim stabilized: Partial (1982) Tank Integrity: Sound

Waste Parameters:

Total waste:

248,000 gallons

Waste types:

239,000 gallons 242-S Evaporator concentrate (1978-1980)

9,000 gallons REDOX high level waste (1969)

(Place and Pagedor 1998a)

Waste Temperature: $83.8^{\circ} \mathrm{F}$ (May 1999) (LMHC 1999)

Safety Issue Status:

Watch List: None

USQs: $\quad$ Flammable gas (now closed), Organic nitrate (now closed)

Determination of the Safety Issues Associated with This Tank:

- Flammable gas

- Organic nitrate

Safety Issues Excluded from This Tank:

- Ferrocyanide has been excluded. Tank S-103 is not identified as one of the 18 ferrocyanide tanks (Postma et al. 1994).

- Organic solvent has been excluded. Tank has been demonstrated to not be in scope of organic solvent issue by vapor sampling (Meacham et al. 1998).

Furthermore, analytical results show that organic solvents are difficult to ignite, and credible ignition sources have been narrowed to robust energy sources such as lightning strikes and large hot metal cuttings from welding (Cowley et al. 1999).

- Criticality has been excluded. This tank did not receive any PFP waste (Agnew et al. 1997b). Criticality is not considered to be a credible accident scenario for safe storage of waste in tanks (Noorani 1999, pp. 5.3.2.1-4).

- High heat has been excluded. Estimated thermal load is 5,700 BTU/hr. This is insufficient to classify this tank as a high-heat tank (Kummerer 1995 and Noorani 1999 , pp. 5.3.2.22-1). Present maximum temperature of $83.8^{\circ} \mathrm{F}$ in the waste confirms heat load classification. 


\section{Are there process history ties to other sampled tanks?}

Yes. Tanks S-101, S-102, S-107, and SX-108 have similar process histories to that of S-103. Tanks S-101, S-102, and S-103 were used to store second campaign 242-S Evaporator concentrates. These wastes were produced and sent to these tanks from 1977 to 1980 . Evaporator concentrates have limited compositional variation as evidenced from historical evaluation and analysis of tank waste (Agnew et al. 1997b; LoPresti et al. 1997; Hendrickson et al. 1998). The data from tanks S-101 and S-102 do not exhibit behavior that triggers safety screening limits (LMHC 1999 and Appendix A). Because of the degree of similarity in process history, the waste in S-103 is not expected to exhibit behavior different from that observed in S-101 and S-102.

Tank S-107 and SX-108 have similar process histories to that of S-103. All three tanks were used to store REDOX high level waste. These wastes were produced and sent to the tanks in 1953 and 1954 (S-107) and 1955 to 1967 (SX-108). The data from tanks S-107 and SX-108 do not exhibit behavior that triggers safety screening limits (LMHC 1999 and Appendix A). Because of the degree of similarity in process history, the waste in S-103 is not expected to exhibit behavior different from that observed in S-107 and SX-108.

\section{Is core sampling necessary to show tank is bounded?}

Table B-13 illustrates this statement using the logic chart (Figure B-1).

Table B-13. Safety Issue Logic for Tank S-103

\begin{tabular}{|c|c|c|c|c|c|c|}
\hline Issue & $\begin{array}{c}\text { Organic } \\
\text { Complexant }\end{array}$ & $\begin{array}{c}\text { Organic } \\
\text { Solvent }\end{array}$ & Ferrocyanide & $\begin{array}{c}\text { Flammable } \\
\text { Gas }\end{array}$ & High Heat & Criticality \\
\hline $\begin{array}{l}\text { Can a case be } \\
\text { demonstrated } \\
\text { why related } \\
\text { tanks are } \\
\text { bounding? }\end{array}$ & No & Excluded & Excluded & No & Excluded & Excluded \\
\hline $\begin{array}{l}\text { Are other data } \\
\text { (other than core } \\
\text { sampling) } \\
\text { sufficient to } \\
\text { address safety } \\
\text { issues? }\end{array}$ & No & Excluded & Excluded & Yes & Excluded & Excluded \\
\hline $\begin{array}{l}\text { Does a } \\
\text { preponderance } \\
\text { of evidence } \\
\text { demonstrate } \\
\text { sampling is not } \\
\text { needed? }\end{array}$ & Yes & Excluded & Excluded & * & Excluded & Excluded \\
\hline
\end{tabular}

Notes: * = If a previous box provides necessary data for a yes, this logic box does not need to be
addressed. 


\section{Safety Issues Associated with Tank:}

\section{Organic Complexants:}

Evidence from theoretical considerations, empirical simulant studies, and evaluation of related tanks shows the hazards from organic complexants are adequately controlled. Tanks S-101, S-102, and S-103 were categorized as having medium concentrations of organic complexant waste. Tanks S-107 and SX-108 represent more extreme conditions and were categorized as having high and no concentrations of organic complexant waste, respectively. Section 3.1.3 and Meacham et al. (1998) describe the organic complexant evaluation more thoroughly. The data from related tanks (S-101, S-102, S-107, and SX-108) indicate that organic complexants are not an issue for the waste in tank S-103 (Appendix A and Figures A-12 to A-15). Further core sampling and analysis of the waste in this tank will not change the safety classification or the controls applied to tank S-103 with respect to this safety issue.

\section{Flammable Gas:}

Tank S-103 exhibited changes in surface level as a function of barometric pressure that met the criteria to qualify for inclusion as flammable gas tank. Furthermore, the tank exhibits a surface level rise (Hodgson 1998). Because of this behavior, the tank is considered Facility Group 2. Other tanks, such as AN-105 or AW-101, have exhibited much stronger indications of flammable gas behavior and have been extensively sampled to provide data to address the safety issue. Section 3.1.4 and Johnson et al. (1997) describe the flammable gas data evaluation more thoroughly. Further sampling and analysis of the waste in tank S-103 will not change the safety classification of the tank or the controls applied with respect to this safety issue.

\section{Are there any anomalous data that would drive characterization of the tank?}

No. Hodgson (1998) has reviewed the available surveillance data for surface level irregularities and temperature anomalies. As noted previously, tank S-103 exhibited both a surface level rise and barometric pressure effect that met the criteria established for flammable gas evaluation. The surface level fluctuations are similar to those observed in tanks S-101 and S-102. These surface level fluctuations are recognized and understood. Core sampling S-103 will not contribute to resolving the flammable gas safety issue. 
Tank Name: S-105

Tank Parameters:

Tank Type: SST

Ventilation: Passive

Tank Capacity: 758,000 gallons

Interim stabilized: Yes (1988)

Service History: Inactive (1978)

Tank Integrity: Sound

Waste Parameters:

Total waste:

455,000 gallons

Waste types:

453,000 gallons 242-S Evaporator concentrate (1978-1980)

2,000 gallons REDOX high level waste (1969)

(Place and Pagedor 1998b)

Waste Temperature: $75.9^{\circ} \mathrm{F}$ (May 1999) (LMHC 1999)

Safety Issue Status:

Watch List: None

USQs: $\quad$ Flammable gas (now closed), Organic nitrate (now closed)

Determination of the Safety Issues Associated with This Tank:

- Flammable gas

- Organic nitrate

\section{Safety Issues Excluded from This Tank:}

- Ferrocyanide has been excluded. Tank S-105 is not identified as one of the 18 ferrocyanide tanks (Postma et al. 1994).

- Organic solvent has been excluded. Tank has been demonstrated to not be in scope of organic solvent issue by vapor sampling (Noorani 1999, pp. 5.3.2.15-18). Furthermore, analytical results show that organic solvents are difficult to ignite, and credible ignition sources have been narrowed to robust energy sources such as lightning strikes and large hot metal cuttings from welding (Cowley et al. 1999).

- Criticality has been excluded. This tank did not receive any PFP waste (Agnew et al. 1997b). Criticality is not considered to be a credible accident scenario for safe storage of waste in tanks (Noorani 1999, pp. 5.3.2.1-4).

- High heat has been excluded. Estimated thermal load is 3,700 BTU/hr. This is insufficient to classify this tank as a high-heat tank (Kummerer 1995 and Noorani 1999 , pp. 5.3.2.22-1). Present maximum temperature of $75.9^{\circ} \mathrm{F}$ in the waste confirms heat load classification. 


\section{Are there process history ties to other sampled tanks?}

Yes. Tanks S-101, S-102, S-104, and S-107 have similar process histories to that of S-105. Tanks S-101, S-102, and S-105 were used to store first campaign 242-S Evaporator concentrates. These wastes were produced and sent to these tanks from 1973 to 1976. Evaporator concentrates have limited compositional variation as evidenced from historical evaluation and analysis of tank waste (Agnew et al. 1997b; LoPresti et al. 1997; Hendrickson et al. 1998). The data from tanks S-101 and S-102 do not exhibit behavior that triggers safety screening limits (LMHC 1999 and Appendix A). Because of the degree of similarity in process history, the waste in $\mathrm{S}-105$ is not expected to exhibit behavior different from that observed in S-101 and S-102.

Tank S-104 and S-107 have similar process histories to that of S-105. All three tanks were used to store REDOX high level waste. These wastes were produced and sent to the tanks in 1953 and 1954. The data from tanks S-104 and S-107 do not exhibit behavior that triggers safety screening limits (LMHC 1999 and Appendix A). Because of the degree of similarity in process history, the waste in $\mathrm{S}-105$ is not expected to exhibit behavior different from that observed in S-104 and $\mathrm{S}-107$.

Is core sampling necessary to show tank is bounded?

Table B-14 illustrates this statement using the logic chart (Figure B-1).

Table B-14. Safety Issue Logic for Tank S-105

\begin{tabular}{|c|c|c|c|c|c|c|}
\hline Issue & $\begin{array}{c}\text { Organic } \\
\text { Complexant }\end{array}$ & $\begin{array}{l}\text { Organic } \\
\text { Solvent }\end{array}$ & Ferrocyanide & $\begin{array}{c}\text { Flammable } \\
\text { Gas }\end{array}$ & High Heat & Criticality \\
\hline $\begin{array}{l}\text { Can a case be } \\
\text { demonstrated } \\
\text { why related } \\
\text { tanks are } \\
\text { bounding? }\end{array}$ & No & Excluded & Excluded & No & Excluded & Excluded \\
\hline $\begin{array}{l}\text { Are other data } \\
\text { (other than core } \\
\text { sampling) } \\
\text { sufficient to } \\
\text { address safety } \\
\text { issues? }\end{array}$ & No & Excluded & Excluded & Yes & Excluded & Excluded \\
\hline $\begin{array}{l}\text { Does a } \\
\text { preponderance } \\
\text { of evidence } \\
\text { demonstrate } \\
\text { sampling is not } \\
\text { needed? }\end{array}$ & Yes & Excluded & Excluded & $*$ & Excluded & Excluded \\
\hline
\end{tabular}

Notes:

* = If a previous box provides necessary data for a yes, this logic box does not need to be addressed. 


\section{Safety Issues Associated with Tank:}

\section{Organic Complexants:}

Evidence from theoretical considerations, empirical simulant studies, and evaluation of related tanks shows the hazards from organic complexants are adequately controlled. Tanks S-101 and S-102 were categorized as having medium concentrations of organic complexant waste. Tanks S-107 and SX-108 represent more extreme conditions and were categorized as having high and no concentrations of organic complexant waste, respectively. Tank S-105 was categorized as having low concentrations of organic complexant waste. Section 3.1.3 and Meacham et al. (1998) describe the organic complexant evaluation more thoroughly. The data from related tanks (S-101, S-102, S-107, and $\mathrm{SX}-108$ ) indicate that organic complexants are not an issue for the waste in tank S-105 (Appendix A and Figures A-12 to A-15). Further core sampling and analysis of the waste in this tank will not change the safety classification or the controls applied to tank $\mathrm{S}-105$ with respect to this safety issue.

\section{Flammable Gas:}

Tank S-105 is considered a Facility Group 2 tank. Facility Group 2 tanks are conservatively postulated to have the potential for small spontaneous and large induced GREs (Funderburke 1997). In addition, tank S-105 was interim stabilized in 1988 . Interim stabilization has been shown to significantly reduce the potential for trapping and periodically releasing flammable gas (Stewart et al. 1996). Other tanks, such as AN-105 or AW-101, have exhibited much stronger indications of flammable gas behavior and have been extensively sampled to provide data to address the safety issue. Section 3.1.4 and Johnson et al. (1997) describe the flammable gas data evaluation more thoroughly. Further sampling and analysis of the waste in tank S-105 will not change the safety classification of the tank or the controls applied with respect to this safety issue.

\section{Are there any anomalous data that would drive characterization of the tank?}

No. Hodgson (1998) has reviewed the available surveillance data for surface level irregularities and temperature anomalies. None were observed. 
Tank Name: S-108

Tank Parameters:

Tank Type: SST

Ventilation: Passive

Interim stabilized: Yes (1996)
Tank Capacity: 758,000 gallons

Service History: Inactive (1979)

Tank Integrity: Sound

Waste Parameters:

Total waste:

Waste types:

502,000 gallons

497,000 gallons 242-S Evaporator concentrate (1974-1976)

5,000 gallons REDOX high level waste (1969)

(Place and Pagedor 1998c)

Waste Temperature: $81.5^{\circ} \mathrm{F}$ (May 1999) (LMHC 1999)

Safety Issue Status:

Watch List: None

USQs: $\quad$ Flammable gas (now closed), Organic nitrate (now closed)

Determination of the Safety Issues Associated with This Tank:

- Flammable gas

- Organic nitrate

Safety Issues Excluded from This Tank:

- Ferrocyanide has been excluded. Tank S-108 is not identified as one of the 18 ferrocyanide tanks (Postma et al. 1994).

- Organic solvent has been excluded. Tank has been demonstrated to not be in scope of organic solvent issue by vapor sampling (Noorani 1999, pp. 5.3.2.15-18). Furthermore, analytical results show that organic solvents are difficult to ignite, and credible ignition sources have been narrowed to robust energy sources such as lightning strikes and large hot metal cuttings from welding (Cowley et al. 1999).

- Criticality has been excluded. This tank did not receive any PFP waste (Agnew et al. 1997b). Criticality is not considered to be a credible accident scenario for safe storage of waste in tanks (Noorani 1999, pp. 5.3.2.1-4).

- High heat has been excluded. Estimated thermal load is $4,400 \mathrm{BTU} / \mathrm{hr}$. This is insufficient to classify this tank as a high-heat tank (Kummerer 1995 and Noorani 1999, pp. 5.3.2.22-1). Present maximum temperature of $81.5^{\circ} \mathrm{F}$ in the waste confirms heat load classification. 


\section{Are there process history ties to other sampled tanks?}

Yes. Tanks S-101, S-102, S-104, and S-107 have similar process histories to that of S-108. Tanks S-101, S-102, and S-108 were used to store first campaign 242-S Evaporator concentrates. These wastes were produced and sent to these tanks from 1973 to 1976. Evaporator concentrates have limited compositional variation as evidenced from historical evaluation and analysis of tank waste (Agnew et al. 1997b; LoPresti et al. 1997; Hendrickson et al. 1998). The data from tanks S-101 and S-102 do not exhibit behavior that triggers safety screening limits (LMHC 1999 and Appendix A). Because of the degree of similarity in process history, the waste in S-108 is not expected to exhibit behavior different from that observed in S-101 and S-102.

Tank S-104 and S-107 have similar process histories to that of S-108. All three tanks were used to store REDOX high level waste. These wastes were produced and sent to the tanks in 1953 and 1954. The data from tanks S-104 and S-107 do not exhibit behavior that triggers safety screening limits (LMHC 1999 and Appendix A). Because of the degree of similarity in process history, the waste in $\mathrm{S}-108$ is not expected to exhibit behavior different from that observed in S-104 and $\mathrm{S}-107$.

\section{Is core sampling necessary to show tank is bounded?}

Table B-15 illustrates this statement using the logic chart (Figure B-1).

Table B-15. Safety Issue Logic for Tank S-108

\begin{tabular}{|c|c|c|c|c|c|c|}
\hline Issue & $\begin{array}{c}\text { Organic } \\
\text { Complexant }\end{array}$ & $\begin{array}{l}\text { Organic } \\
\text { Solvent }\end{array}$ & Ferrocyanide & $\begin{array}{c}\text { Flammable } \\
\text { Gas }\end{array}$ & High Heat & Criticality \\
\hline $\begin{array}{l}\text { Can a case be } \\
\text { demonstrated } \\
\text { why related } \\
\text { tanks are } \\
\text { bounding? }\end{array}$ & No & Excluded & Excluded & No & Excluded & Excluded \\
\hline $\begin{array}{l}\text { Are other data } \\
\text { (other than core } \\
\text { sampling) } \\
\text { sufficient to } \\
\text { address safety } \\
\text { issues? }\end{array}$ & No & Excluded & Excluded & Yes & Excluded & Excluded \\
\hline $\begin{array}{l}\text { Does a } \\
\text { preponderance } \\
\text { of evidence } \\
\text { demonstrate } \\
\text { sampling is not } \\
\text { needed? }\end{array}$ & Yes & Excluded & Excluded & * & Excluded & Excluded \\
\hline
\end{tabular}

Notes: $*=$ If a previous box provides necessary data for a yes, this logic box does not need to be
addressed. 


\section{Safety Issues Associated with Tank:}

\section{Organic Complexants:}

Evidence from theoretical considerations, empirical simulant studies, and evaluation of related tanks shows the hazards from organic complexants are adequately controlled. Tanks S-101 and S-102 were categorized as having medium concentrations of organic complexant waste. Tanks S-107 and SX-108 represent more extreme conditions and were categorized as having high and no concentrations of organic complexant waste, respectively. Tank S-108 was categorized as having low concentrations of organic complexant waste. Section 3.1.3 and Meacham et al. (1998) describe the organic complexant evaluation more thoroughly. The data from related tanks (S-101, S-102, S-107, and SX-108) indicate that organic complexants are not an issue for the waste in tank S-108 (Appendix A and Figures A-12 to A-15). Further core sampling and analysis of the waste in this tank will not change the safety classification or the controls applied to tank S-108 with respect to this safety issue.

\section{Flammable Gas:}

Because no surface level fluctuation or barometric response behavior has been observed, the tank is considered Facility Group 3. Facility Group 3 tanks are conservatively postulated to have the potential for small, induced GREs (Funderburke 1997). In addition, tank S-108 was interim stabilized in 1996. Interim stabilization has been shown to significantly reduce the potential for trapping and periodically releasing flammable gas (Stewart et al. 1996). Other tanks, as shown in Section 3.1.4, have exhibited much stronger indications of flammable gas behavior and have been extensively sampled to provide data to address the safety issue (Johnson et al. 1997). Further sampling and analysis of the waste in tank S-108 will not change the safety classification of the tank or the controls applied with respect to this safety issue.

\section{Are there any anomalous data that would drive characterization of the tank?}

No. Hodgson (1998) has reviewed the available surveillance data for surface level irregularities and temperature anomalies. None were observed. 
Tank Name: S-112

Tank Parameters:

Tank Type: SST

Ventilation: Passive

Interim stabilized: Partial (1982)
Tank Capacity: 758,000 gallons

Service History: Inactive (1976)

Tank Integrity: Sound

Waste Parameters:

Total waste:

Waste types:

523,000 gallons

517,000 gallons 242-S Evaporator concentrate (1974-1976)

6,000 gallons REDOX high level waste (1969)

(Place and Pagedor 1998d)

Waste Temperature: $82.6^{\circ} \mathrm{F}$ (May 1999) (LMHC 1999)

Safety Issue Status:

Watch List: Flammable gas

USQs: $\quad$ Flammable gas (now closed), Organic nitrate (now closed)

\section{Determination of the Safety Issues Associated with This Tank:}

- Flammable gas

- Organic nitrate

\section{Safety Issues Excluded from This Tank:}

- Ferrocyanide has been excluded. Tank S-112 is not identified as one of the 18 ferrocyanide tanks (Postma et al. 1994).

- Organic solvent has been excluded. Tank has been demonstrated to not be in scope of organic solvent issue by vapor sampling (Noorani 1999, pp. 5.3.2.15-18). Furthermore, analytical results show that organic solvents are difficult to ignite, and credible ignition sources have been narrowed to robust energy sources such as lightning strikes and large hot metal cuttings from welding (Cowley et al. 1999).

- Criticality has been excluded. This tank did not receive any PFP waste (Agnew et al. 1997b). Criticality is not considered to be a credible accident scenario for safe storage of waste in tanks (Noorani 1999, pp. 5.3.2.1-4).

- High heat has been excluded. Estimated thermal load is $4,470 \mathrm{BTU} / \mathrm{hr}$. This is insufficient to classify this tank as a high-heat tank (Kummerer 1995 and Noorani 1999 , pp. 5.3.2.22-1). Present maximum temperature of $82.6^{\circ} \mathrm{F}$ in the waste confirms heat load classification. 


\section{Are there process history ties to other sampled tanks?}

Yes. Tanks S-101 and S-102 have similar process histories to that of S-112.

Tanks S-101, S-102, and S-112 were used to store first campaign 242-S

Evaporator concentrates. These wastes were produced and sent to these tanks from 1973 to 1976 . Evaporator concentrates have limited compositional variation as evidenced from historical evaluation and analysis of tank waste (Agnew et al. 1997b; LoPresti et al. 1997; Hendrickson et al. 1998). The data from tanks S-101 and S-102 do not exhibit behavior that triggers safety screening limits (LMHC 1999 and Appendix A). Because of the degree of similarity in process history, the waste in S-112 is not expected to exhibit behavior different from that observed in S-101 and S-102.

Tank S-111 has a similar process history to that of S-112. Both tanks were used to store REDOX high level waste. These wastes were produced and sent to these tanks from 1965 to 1971 . Some solids from S-111 cascaded through to S-112. The data from tank S-111 does not exhibit behavior that triggers safety screening limits (LMHC 1999 and Appendix A). Because of the degree of similarity in process history, the waste in $S-112$ is not expected to exhibit behavior different from that observed in $\mathrm{S}-111$.

\section{Is core sampling necessary to show tank is bounded?}

Table B-16 illustrates this statement using the logic chart (Figure B-1).

Table B-16. Safety Issue Logic for Tank S-112

\begin{tabular}{|c|c|c|c|c|c|c|}
\hline Issue & $\begin{array}{c}\text { Organic } \\
\text { Complexant }\end{array}$ & $\begin{array}{l}\text { Organic } \\
\text { Solvent }\end{array}$ & Ferrocyanide & $\begin{array}{c}\text { Flammable } \\
\text { Gas }\end{array}$ & High Heat & Criticality \\
\hline $\begin{array}{l}\text { Can a case be } \\
\text { demonstrated } \\
\text { why related } \\
\text { tanks are } \\
\text { bounding? }\end{array}$ & No & Excluded & Excluded & No & Excluded & Excluded \\
\hline $\begin{array}{l}\text { Are other data } \\
\text { (other than core } \\
\text { sampling) } \\
\text { sufficient to } \\
\text { address safety } \\
\text { issues? }\end{array}$ & No & Excluded & Excluded & Yes & Excluded & Excluded \\
\hline $\begin{array}{l}\text { Does a } \\
\text { preponderance } \\
\text { of evidence } \\
\text { demonstrate } \\
\text { sampling is not } \\
\text { needed? }\end{array}$ & Yes & Excluded & Excluded & $*$ & Excluded & Excluded \\
\hline
\end{tabular}

Notes:

\footnotetext{
* = If a previous box provides necessary data for a yes, this logic box does not need to be addressed.
} 
HNF-4232 Rev. 0

\section{Safety Issues Associated with Tank:}

\section{Organic Complexants:}

Evidence from theoretical considerations, empirical simulant studies, and evaluation of related tanks shows the hazards from organic complexants are adequately controlled. Tanks S-101 and S-102 were categorized as having medium concentrations of organic complexant waste. Tank S-111 was categorized as having low concentrations of organic complexant waste. Tank S-112 was also categorized as having low concentrations of organic complexant waste. Section 3.1.3 and Meacham et al. (1998) describe the organic complexant evaluation more thoroughly. The data from related tanks (S-101, S-102, and S-111) indicate that organic complexants are not an issue for the waste in tank S-112 (Appendix A and Figures A-12 to A-15). Further core sampling and analysis of the waste in this tank will not change the safety classification or the controls applied to tank S-112 with respect to this safety issue.

\section{Flammable Gas:}

Tank S-112 is not considered a hazard with respect to flammable gas. Because no surface level fluctuation or barometric response behavior has been observed, tank S-112 is considered Facility Group 3. Facility Group 3 tanks are conservatively postulated to have the potential for small, induced GREs (Funderburke 1997). This tank has a SHMS installed on it for monitoring purposes. From July 1998 to June 1999, no GRE or peak hydrogen concentration was observed. The concentration has remained steady at $130 \mathrm{ppm}$. Other tanks, as shown in Section 3.1.4, have exhibited much stronger indications of flammable gas behavior and have been extensively sampled to provide data to address the safety issue (Johnson et al. 1997). Further sampling and analysis of the waste in tank S-112 will not change the safety classification of the tank or the controls applied with respect to this safety issue.

\section{Are there any anomalous data that would drive characterization of the tank?}

No. Hodgson (1998) has reviewed the available surveillance data for surface level irregularities and temperature anomalies. None were observed. 
Tank Name: SX-104

Tank Parameters:

Tank Type: SST

Ventilation: Active

Interim stabilized: Partial (1985)
Tank Capacity: 1,000,000 gallons

Service History: Inactive (1980)

Tank Integrity：Assumed leaker (1988)

Waste Parameters:

Total waste:

Waste types:

614,000 gallons

478,000 gallons 242-S Evaporator concentrate (1974-1976)

136,000 gallons REDOX high level waste (1956)

(Hendrickson 1998a)

Waste Temperature: $143.2^{\circ} \mathrm{F}$ (May 1999) (LMHC 1999)

Safety Issue Status:

Watch List: Flammable gas

USQs: $\quad$ Flammable gas (now closed), Organic nitrate (now closed)

\section{Determination of the Safety Issues Associated with This Tank:}

- Flammable gas

- Organic nitrate

- Organic solvent

Safety Issues Excluded from This Tank:

- Ferrocyanide has been excluded. Tank SX-104 is not identified as one of the 18 ferrocyanide tanks (Postma et al. 1994).

- Criticality has been excluded. This tank did not receive any PFP waste (Agnew et al. 1997b). Criticality is not considered to be a credible accident scenario for safe storage of waste in tanks (Noorani 1999, pp. 5.3.2.1-4).

- High heat has been excluded. Estimated thermal load is 12,200 BTU/hr. This is insufficient to classify this tank as a high-heat tank (Kummerer 1995 and Noorani 1999, pp. 5.3.2.22-1). Present maximum temperature of $143.2^{\circ} \mathrm{F}$ in the waste confirms heat load classification. However, this tank did self-boil in the past, and is currently on active ventilation.

Are there process history ties to other sampled tanks?

Yes. Tanks S-101, S-108, and SX-105 have similar characteristics to tank SX-104. Tanks S-101 and S-102 have similar process histories to that of SX-104. All three tanks were used to store first campaign 242-S Evaporator concentrates. These wastes were produced and sent to these tanks from 1973 to 1976.

Evaporator concentrates have limited compositional variation as evidenced from 
historical evaluation and analysis of tank waste (Agnew et al. 1997b; LoPresti et al. 1997; Hendrickson et al. 1998). The data from tanks S-101 and S-102 do not exhibit behavior that triggers safety screening limits (LMHC 1999 and Appendix A). Because of the degree of similarity in process history, the waste in SX-104 is not expected to exhibit behavior different from that observed in S-101 and $\mathrm{S}-102$.

Tank SX-105 has a similar process history to that of SX-104. Both tanks were used to store REDOX high level waste. These wastes were produced and sent to these tanks from 1955 to 1967. The data from tank SX-105 does not exhibit behavior that triggers safety screening limits (LMHC 1999 and Appendix A). Because of the degree of similarity in process history, the waste in SX-104 is not expected to exhibit behavior different from that observed in SX-105.

\section{Is core sampling necessary to show tank is bounded?}

Table B-17 illustrates this statement using the logic chart (Figure B-1).

Table B-17. Safety Issue Logic for Tank SX-104

\begin{tabular}{|l|l|l|l|l|l|l|}
\hline \multicolumn{1}{|c|}{ Issue } & $\begin{array}{c}\text { Organic } \\
\text { Complexant }\end{array}$ & $\begin{array}{l}\text { Organic } \\
\text { Solvent }\end{array}$ & Ferrocyanide & $\begin{array}{l}\text { Flammable } \\
\text { Gas }\end{array}$ & High Heat & Criticality \\
\hline $\begin{array}{l}\text { Can a case be } \\
\text { demonstrated } \\
\text { why related } \\
\text { tanks are } \\
\text { bounding? }\end{array}$ & No & No & Excluded & No & Excluded & Excluded \\
\hline $\begin{array}{l}\text { Are other data } \\
\text { (other than core } \\
\text { sampling) } \\
\text { sufficient to } \\
\text { address safety } \\
\text { issues? }\end{array}$ & No & Yes & Excluded & Yes & Excluded & Excluded \\
\hline $\begin{array}{l}\text { Does a } \\
\text { preponderance } \\
\text { of evidence } \\
\text { demonstrate } \\
\text { sampling is not } \\
\text { needed? }\end{array}$ & Yes & $*$ & Excluded & $*$ & Excluded & Excluded \\
Notes: $*$ If a previous box provides necessary data for a yes, this logic box does not need to be \\
\hline
\end{tabular}


HNF-4232 Rev. 0

\section{Safety Issues Associated with Tank:}

\section{Organic Complexants:}

Evidence from theoretical considerations, empirical simulant studies, and evaluation of related tanks shows the hazards from organic complexants are adequately controlled. Tanks S-101, S-102, and SX-105 were categorized as having medium concentrations of organic complexant waste. Tank SX-104 was also categorized as having medium concentrations of organic complexant waste. Section 3.1.3 and Meacham et al. (1998) describe the organic complexant evaluation more thoroughly. The data from related tanks (S-101, S-102, and $S X-105)$ indicate that organic complexants are not an issue for the waste in tank SX-104 (Appendix A and Figures A-12 to A-15). Further core sampling and analysis of the waste in this tank will not change the safety classification or the controls applied to tank SX-104 with respect to this safety issue.

\section{Organic Solvents:}

Analytical results show that organic solvents are difficult to ignite, and credible ignition sources have been narrowed to robust energy sources such as lightning strikes and large hot metal cuttings from welding (Cowley et al. 1999). Additional core sampling and analyses are not warranted for SX-104, because additional core sample data will not eliminate the need for controls or further resolve the safety issue.

\section{Flammable Gas:}

Tank SX-104 is not considered a hazard with respect to flammable gas. Because no surface level fluctuation or barometric response behavior has been observed, tank SX-104 is considered Facility Group 3. Facility Group 3 tanks are conservatively postulated to have the potential for small, induced GREs (Funderburke 1997). This tank has a SHMS installed on it for monitoring purposes. From July 1998 to June 1999, no GRE or peak hydrogen concentration was observed. Other tanks, as shown in Section 3.1.4, have exhibited much stronger indications of flammable gas behavior and have been extensively sampled to provide data to address the safety issue (Johnson et al. 1997). Further sampling and analysis of the waste in tank SX-104 will not change the safety classification of the tank or the controls applied with respect to this safety issue.

\section{Are there any anomalous data that would drive characterization of the tank?}

No. Hodgson (1998) has reviewed the available surveillance data for surface level irregularities and temperature anomalies. None were observed. 
Tank Name: SX-107

Tank Parameters:

Tank Type: SST

Ventilation: Active

Interim stabilized: Yes (1979)
Tank Capacity: 1,000,000 gallons

Service History: Inactive (1980)

Tank Integrity： Assumed leaker (1964)

Waste Parameters:

Total waste:

109,000 gallons

Waste types:

109,000 gallons REDOX high level waste (1957-1967)

(Hendrickson 1998b)

Waste Temperature: $153.7^{\circ} \mathrm{F}$ (May 1999) (LMHC 1999)

Safety Issue Status:

Watch List: None. However, this tank is considered to have a high heat load.

USQs: $\quad$ Flammable gas (now closed), Organic nitrate (now closed)

Determination of the Safety Issues Associated with This Tank:

- Flammable gas

- Organic nitrate

- Organic solvent

- High heat

Safety Issues Excluded from This Tank:

- Ferrocyanide has been excluded. Tank SX-107 is not identified as one of the 18 ferrocyanide tanks (Postma et al. 1994).

- Criticality has been excluded. This tank did not receive any PFP waste (Agnew et al. 1997b). Criticality is not considered to be a credible accident scenario for safe storage of waste in tanks (Noorani 1999, pp. 5.3.2.1-4).

Are there process history ties to other sampled tanks?

Yes. Tank SX-105 and SX-108 have similar process histories to that of SX-107. Both tanks were used to store REDOX high level waste. These wastes were produced and sent to these tanks from 1955 to 1967 . The data from tank SX-105 and SX-108 do not exhibit behavior that triggers safety screening limits (LMHC 1999 and Appendix A). Because of the degree of similarity in process history, the waste in SX-107 is not expected to exhibit behavior different from that observed in SX-105 and SX-108. 


\section{Is core sampling necessary to show tank is bounded?}

Table B-18 illustrates this statement using the logic chart (Figure B-1).

Table B-18. Safety Issue Logic for Tank SX-107

\begin{tabular}{|c|c|c|c|c|c|c|}
\hline Issue & $\begin{array}{c}\text { Organic } \\
\text { Complexant }\end{array}$ & $\begin{array}{l}\text { Organic } \\
\text { Solvent }\end{array}$ & Ferrocyanide & $\begin{array}{c}\text { Flammable } \\
\text { Gas }\end{array}$ & High Heat & Criticality \\
\hline $\begin{array}{l}\text { Can a case be } \\
\text { demonstrated } \\
\text { why related } \\
\text { tanks are } \\
\text { bounding? }\end{array}$ & No & No & Excluded & No & No & Excluded \\
\hline $\begin{array}{l}\text { Are other data } \\
\text { (other than core } \\
\text { sampling) } \\
\text { sufficient to } \\
\text { address safety } \\
\text { issues? }\end{array}$ & No & Yes & Excluded & Yes & Yes & Excluded \\
\hline $\begin{array}{l}\text { Does a } \\
\text { preponderance } \\
\text { of evidence } \\
\text { demonstrate } \\
\text { sampling is not } \\
\text { needed? }\end{array}$ & Yes & $*$ & Excluded & $*$ & $*$ & Excluded \\
\hline
\end{tabular}

Notes:

* = If a previous box provides necessary data for a yes, this logic box does not need to be addressed.

\section{Safety Issues Associated with Tank:}

\section{Organic Complexants:}

Evidence from theoretical considerations, empirical simulant studies, and evaluation of related tanks shows the hazards from organic complexants are adequately controlled. Tanks S-101, S-102, and SX-105 were categorized as having medium concentrations of organic complexant waste. Tank SX-107 was categorized as having no organic complexant waste. Section 3.1.3 and Meacham et al. (1998) describe the organic complexant evaluation more thoroughly. The data from related tanks (S-101, S-102, and SX-105) indicate that organic complexants are not an issue for the waste in tank SX-107 (Appendix A and Figures A-12 to A-15). Further core sampling and analysis of the waste in this tank will not change the safety classification or the controls applied to tank SX107 with respect to this safety issue. 


\section{Organic Solvents:}

Analytical results show that organic solvents are difficult to ignite, and credible ignition sources have been narrowed to robust energy sources such as lightning strikes and large hot metal cuttings from welding (Cowley et al. 1999).

Additional core sampling and analyses are not warranted for SX-107, because additional core sample data will not eliminate the need for controls or further resolve the safety issue.

\section{High Heat:}

Estimated thermal load is approximately $54,800 \mathrm{BTU} / \mathrm{hr}$. This is greater than the 26,000 BTU/hr criteria used to classify tanks as high-heat (Kummerer 1995 and Noorani 1999, pp. 5.3.2.22-1). From May 1996 to May 1999, the temperature has decreased from $167^{\circ} \mathrm{F}$ to $153.7^{\circ} \mathrm{F}$. Present maximum temperature of $153.7^{\circ} \mathrm{F}$ in the waste confirms heat load classification. The tank has not exhibited any waste instability indicating a tank bump phenomena. The tank is actively ventilated which has proven effective at maintaining acceptable temperatures. Further core sampling and analysis of the waste in this tank will not change the safety classification or the controls applied to tank SX-107 with respect to this safety issue.

\section{Flammable Gas:}

Tank SX-107 has less than 110,000 gallons of waste. Therefore, there is not sufficient waste volume to accumulate enough flammable gas to present a hazard (see Section B3.3). This tank is in Facility Group 3.

\section{Are there any anomalous data that would drive characterization of the tank?}

No. Hodgson (1998) has reviewed the available surveillance data for surface level irregularities and temperature anomalies. None were observed. 
Tank Name: SX-109

Tank Parameters:

Tank Type: SST

Ventilation: Active

Interim stabilized: Yes (1981)
Tank Capacity: 1,000,000 gallons

Service History: Inactive (1980)

Tank Integrity: Assumed leaker (1965)

Waste Parameters:

Total waste:

Waste types: 250,000 gallons 250,000 gallons REDOX high level waste (1956-1967) (Hendrickson 1998c)

Waste Temperature: $136.2^{\circ} \mathrm{F}$ (May 1999) (LMHC 1999)

Safety Issue Status:

Watch List: Flammable gas

USQs: $\quad$ Flammable gas (now closed), Organic nitrate (now closed)

\section{Determination of the Safety Issues Associated with This Tank:}

- Flammable gas

- Organic nitrate

- Organic solvent

- High heat

\section{Safety Issues Excluded from This Tank:}

- Ferrocyanide has been excluded. Tank SX-109 is not identified as one of the 18 ferrocyanide tanks (Postma et al. 1994).

- Criticality has been excluded. This tank did not receive any PFP waste (Agnew et al. 1997b). Criticality is not considered to be a credible accident scenario for safe storage of waste in tanks (Noorani 1999, pp. 5.3.2.1-4).

Are there process history ties to other sampled tanks?

Yes. Tanks SX-105 and SX-108 have similar process histories to that of SX-109. Both tanks were used to store REDOX high level waste. These wastes were produced and sent to these tanks from 1955 to 1967. The data from tanks SX-105 and SX-108 do not exhibit behavior that triggers safety screening limits (LMHC 1999 and Appendix A). Because of the degree of similarity in process history, the waste in SX-109 is not expected to exhibit behavior different from that observed in SX-105 and SX-108. 


\section{Is core sampling necessary to show tank is bounded?}

Table B-19 illustrates this statement using the logic chart (Figure B-1).

Table B-19. Safety Issue Logic for Tank SX-109

\begin{tabular}{|l|l|l|l|l|l|l|}
\hline \multicolumn{1}{|c|}{ Issue } & $\begin{array}{c}\text { Organic } \\
\text { Complexant }\end{array}$ & $\begin{array}{c}\text { Organic } \\
\text { Solvent }\end{array}$ & Ferrocyanide & $\begin{array}{l}\text { Flammable } \\
\text { Gas }\end{array}$ & High Heat & Criticality \\
\hline $\begin{array}{l}\text { Can a case be } \\
\text { demonstrated } \\
\text { why related } \\
\text { tanks are } \\
\text { bounding? }\end{array}$ & No & No & Excluded & No & No & Excluded \\
\hline $\begin{array}{l}\text { Are other data } \\
\text { (other than core } \\
\text { sampling) } \\
\text { sufficient to } \\
\text { address safety } \\
\text { issues? }\end{array}$ & No & Yes & Excluded & Yes & Yes & Excluded \\
\hline $\begin{array}{l}\text { Does a } \\
\text { preponderance } \\
\text { of evidence } \\
\text { demonstrate } \\
\text { sampling is not } \\
\text { needed? }\end{array}$ & Yes & $*$ & Excluded & $*$ & $*$ & \\
\hline \begin{tabular}{l} 
Notes: $*$ If a previous box provides necessary data for a yes, this logic box does not need to be \\
\hline
\end{tabular} & & & & & & \\
\hline
\end{tabular}

\section{Safety Issues Associated with Tank:}

\section{Organic Complexants:}

Evidence from theoretical considerations, empirical simulant studies, and evaluation of related tanks shows the hazards from organic complexants are adequately controlled. Tank SX-105 was categorized as having medium concentrations of organic complexant waste. Tank SX-108 was categorized as having no organic complexant waste. Tank SX-109 was also categorized as having no organic complexant waste. Section 3.1.3 and Meacham et al. (1998) describe the organic complexant evaluation more thoroughly. The data from related tanks (SX-105 and SX-108) indicate that organic complexants are not an issue for the waste in tank SX-109 (Appendix A and Figures A-12 to A-15). Further core sampling and analysis of the waste in this tank will not change the safety classification or the controls applied to tank SX-109 with respect to this safety issue. 


\section{Organic Solvents:}

Analytical results show that organic solvents are difficult to ignite, and credible ignition sources have been narrowed to robust energy sources such as lightning strikes and large hot metal cuttings from welding (Cowley et al. 1999). Additional core sampling and analyses are not warranted for SX-109, because additional core sample data will not eliminate the need for controls or further resolve the safety issue.

\section{High Heat:}

Estimated thermal load is approximately $31,000 \mathrm{BTU} / \mathrm{hr}$. This is greater than the 26,000 BTU/hr criteria used to classify tanks as high-heat (Kummerer 1995 and Noorani 1999, pp 5.3.2.22-1). From May 1996 to May 1999, the temperature has decreased from $144^{\circ} \mathrm{F}$ to $136.2^{\circ} \mathrm{F}$. Present maximum temperature of $136.2^{\circ} \mathrm{F}$ in the waste confirms heat load classification. The tank has not exhibited any waste instability indicating a tank bump phenomena. The tank is actively ventilated which has proven effective at maintaining acceptable temperatures. Further core sampling and analysis of the waste in this tank will not change the safety classification or the controls applied to tank SX-109 with respect to this safety issue.

\section{Flammable Gas:}

Although no surface level fluctuation or barometric response behavior has been observed, tank SX-109 is considered Facility Group 2 because other Facility Group 2 tanks are vented through the headspace. Facility Group 2 tanks are conservatively postulated to have the potential for small, spontaneous and large induced GREs (Funderburke 1997). This tank has a SHMS installed on it for monitoring purposes. In addition, tank SX-109 was interim stabilized in 1981. Interim stabilization has been shown to significantly reduce the potential for trapping and periodically releasing flammable gas (Stewart et al. 1996). From July 1998 to June 1999, no GRE or peak hydrogen concentration was observed. Other tanks, as shown in Section 3.1.4, have exhibited much stronger indications of flammable gas behavior and have been extensively sampled to provide data to address the safety issue (Johnson et al. 1997). Further sampling and analysis of the waste in tank SX-109 will not change the safety classification of the tank or the controls applied with respect to this safety issue.

\section{Are there any anomalous data that would drive characterization of the tank?}

No. Hodgson (1998) has reviewed the available surveillance data for surface level irregularities and temperature anomalies. None were observed. 
Tank Name: SX-110

Tank Parameters:

Tank Type: SST

Ventilation: Active

Tank Capacity: $1,000,000$ gallons

Service History: Inactive (1976)

Interim stabilized: Yes (1979)
Tank Integrity： Assumed leaker (1976)

Waste Parameters:

Total waste:

Waste types:

72,000 gallons

72,000 gallons REDOX high level waste (1960-1967)

(Hendrickson 1998d)

Waste Temperature: $154.9^{\circ} \mathrm{F}$ (May 1999) (LMHC 1999)

Safety Issue Status:

Watch List: None. However, this tank is considered to have a high heat load.

USQs: $\quad$ Flammable gas (now closed), Organic nitrate (now closed)

Determination of the Safety Issues Associated with This Tank:

- Flammable gas

- Organic nitrate

- Organic solvent

- High heat

\section{Safety Issues Excluded from This Tank:}

- Ferrocyanide has been excluded. Tank SX-110 is not identified as one of the 18 ferrocyanide tanks (Postma et al. 1994).

- Criticality has been excluded. This tank did not receive any PFP waste (Agnew et al. 1997b). Criticality is not considered to be a credible accident scenario for safe storage of waste in tanks (Noorani 1999, pp. 5.3.2.1-4).

\section{Are there process history ties to other sampled tanks?}

Yes. Tanks SX-105 and SX-108 have a similar process history to that of SX-110. Both tanks were used to store REDOX high level waste. These wastes were produced and sent to these tanks from 1955 to 1967. The data from tank SX-105 and SX-108 do not exhibit behavior that triggers safety screening limits (LMHC 1999 and Appendix A). Because of the degree of similarity in process history, the waste in SX-110 is not expected to exhibit behavior different from that observed in SX-105 and SX-108. 


\section{Is core sampling necessary to show tank is bounded?}

Table B-20 illustrates this statement using the logic chart (Figure B-1).

Table B-20. Safety Issue Logic for Tank SX-110

\begin{tabular}{|c|c|c|c|c|c|c|}
\hline Issue & $\begin{array}{c}\text { Organic } \\
\text { Complexant }\end{array}$ & $\begin{array}{l}\text { Organic } \\
\text { Solvent }\end{array}$ & Ferrocyanide & $\begin{array}{c}\text { Flammable } \\
\text { Gas }\end{array}$ & High Heat & Criticality \\
\hline $\begin{array}{l}\text { Can a case be } \\
\text { demonstrated } \\
\text { why related } \\
\text { tanks are } \\
\text { bounding? }\end{array}$ & No & No & Excluded & No & No & Excluded \\
\hline $\begin{array}{l}\text { Are other data } \\
\text { (other than core } \\
\text { sampling) } \\
\text { sufficient to } \\
\text { address safety } \\
\text { issues? }\end{array}$ & No & Yes & Excluded & Yes & Yes & Excluded \\
\hline $\begin{array}{l}\text { Does a } \\
\text { preponderance } \\
\text { of evidence } \\
\text { demonstrate } \\
\text { sampling is not } \\
\text { needed? }\end{array}$ & Yes & * & Excluded & $*$ & $*$ & Excluded \\
\hline
\end{tabular}

Notes:

* = If a previous box provides necessary data for a yes, this logic box does not need to be addressed.

\section{Safety Issues Associated with Tank:}

\section{Organic Complexants:}

Evidence from theoretical considerations, empirical simulant studies, and evaluation of related tanks shows the hazards from organic complexants are adequately controlled. Tank SX-105 was categorized as having medium concentrations of organic complexant waste. Tank SX-108 was categorized as having no organic complexant waste. Tank SX-110 was categorized as having low concentrations of organic complexant waste. Section 3.1.3 and Meacham et al. (1998) describe the organic complexant evaluation more thoroughly. The data from related tanks (SX-105 and SX-108) indicate that organic complexants are not an issue for the waste in tank SX-110 (Appendix A and Figures A-12 to A-15). Further core sampling and analysis of the waste in this tank will not change the safety classification or the controls applied to tank SX-110 with respect to this safety issue. 


\section{Organic Solvents:}

Analytical results show that organic solvents are difficult to ignite, and credible ignition sources have been narrowed to robust energy sources such as lightning strikes and large hot metal cuttings from welding (Cowley et al. 1999). Additional core sampling and analyses are not warranted for SX-110, because additional core sample data will not eliminate the need for controls or further resolve the safety issue.

\section{High Heat:}

Estimated thermal load is approximately $40,800 \mathrm{BTU} / \mathrm{hr}$. This is greater than the 26,000 BTU/hr criteria used to classify tanks as high-heat (Kummerer 1995 and Noorani 1999, pp. 5.3.2.22-1). From May 1996 to May 1999, the temperature has decreased from $166^{\circ} \mathrm{F}$ to $154.9^{\circ} \mathrm{F}$. Present maximum temperature of $154.9^{\circ} \mathrm{F}$ in the waste confirms heat load classification. The tank has not exhibited any waste instability indicating a tank bump phenomena. The tank is actively ventilated which has proven effective at maintaining acceptable temperatures. Further core sampling and analysis of the waste in this tank will not change the safety classification or the controls applied to tank SX-110 with respect to this safety issue.

\section{Flammable Gas:}

Tank SX-110 has less than 110,000 gallons of waste. Therefore, there is not sufficient waste volume to accumulate enough flammable gas to present a hazard (see Section B3.3). This tank is in Facility Group 3.

\section{Are there any anomalous data that would drive characterization of the tank?}

No. Hodgson (1998) has reviewed the available surveillance data for surface level irregularities and temperature anomalies. None were observed. 
Tank Name: SX-111

Tank Parameters:

Tank Type: SST

Ventilation: Active

Interim stabilized: Yes (1979)
Tank Capacity: 1,000,000 gallons

Service History: Inactive (1979)

Tank Integrity: Assumed leaker (1974)

Waste Parameters:

Total waste:

122,000 gallons

Waste types:

122,000 gallons REDOX high level waste (1956-1965)

(Hendrickson 1998e)

Waste Temperature: $180.7^{\circ} \mathrm{F}$ (May 1999) (LMHC 1999)

Safety Issue Status:

Watch List: None. However, this tank is considered to have a high heat load.

USQs: $\quad$ Flammable gas (now closed), Organic nitrate (now closed)

Determination of the Safety Issues Associated with This Tank:

- Flammable gas

- Organic nitrate

- Organic solvent

- High heat

Safety Issues Excluded from This Tank:

- Ferrocyanide has been excluded. Tank SX-111 is not identified as one of the 18 ferrocyanide tanks (Postma et al. 1994).

- Criticality has been excluded. This tank did not receive any PFP waste (Agnew et al. 1997b). Criticality is not considered to be a credible accident scenario for safe storage of waste in tanks (Noorani 1999, pp. 5.3.2.1-4).

Are there process history ties to other sampled tanks?

Yes. Tanks SX-105 and SX-108 have similar process histories to that of SX-111. Both tanks were used to store REDOX high level waste. These wastes were produced and sent to these tanks from 1955 to 1967 . The data from tanks SX-105 and SX-108 do not exhibit behavior that triggers safety screening limits (LMHC 1999 and Appendix A). Because of the degree of similarity in process history, the waste in SX-111 is not expected to exhibit behavior different from that observed in SX-105 and SX-108. 
Is core sampling necessary to show tank is bounded?

Table B-21 illustrates this statement using the logic chart (Figure B-1).

Table B-21. Safety Issue Logic for Tank SX-111

\begin{tabular}{|c|c|c|c|c|c|c|}
\hline Issue & $\begin{array}{c}\text { Organic } \\
\text { Complexant }\end{array}$ & $\begin{array}{l}\text { Organic } \\
\text { Solvent }\end{array}$ & Ferrocyanide & $\begin{array}{c}\text { Flammable } \\
\text { Gas }\end{array}$ & High Heat & Criticality \\
\hline $\begin{array}{l}\text { Can a case be } \\
\text { demonstrated } \\
\text { why related } \\
\text { tanks are } \\
\text { bounding? }\end{array}$ & No & No & Excluded & No & No & Excluded \\
\hline $\begin{array}{l}\text { Are other data } \\
\text { (other than core } \\
\text { sampling) } \\
\text { sufficient to } \\
\text { address safety } \\
\text { issues? }\end{array}$ & No & Yes & Excluded & Yes & Yes & Excluded \\
\hline $\begin{array}{l}\text { Does a } \\
\text { preponderance } \\
\text { of evidence } \\
\text { demonstrate } \\
\text { sampling is not } \\
\text { needed? }\end{array}$ & Yes & * & Excluded & * & $*$ & Excluded \\
\hline
\end{tabular}

Notes:

* = If a previous box provides necessary data for a yes, this logic box does not need to be addressed.

\section{Safety Issues Associated with Tank:}

\section{Organic Complexants:}

Evidence from theoretical considerations, empirical simulant studies, and evaluation of related tanks shows the hazards from organic complexants are adequately controlled. Tank SX-105 was categorized as having medium concentrations of organic complexant waste. Tank SX-108 was categorized as having no organic complexant waste. Tank SX-111 was categorized as having low concentrations of organic complexant waste. Section 3.1.3 and Meacham et al. (1998) describe the organic complexant evaluation more thoroughly. The data from related tanks (SX-105 and SX-108) indicate that organic complexants are not an issue for the waste in tank SX-111 (Appendix A and Figures A-12 to A-15). Further core sampling and analysis of the waste in this tank will not change the safety classification or the controls applied to tank SX-111 with respect to this safety issue. 


\section{Organic Solvents:}

Analytical results show that organic solvents are difficult to ignite, and credible ignition sources have been narrowed to robust energy sources such as lightning strikes and large hot metal cuttings from welding (Cowley et al. 1999). Additional core sampling and analyses are not warranted for SX-111, because additional core sample data will not eliminate the need for controls or further resolve the safety issue.

\section{High Heat:}

Estimated thermal load is approximately $61,000 \mathrm{BTU} / \mathrm{hr}$. This is greater than the 26,000 BTU/hr criteria used to classify tanks as high-heat (Kummerer 1995 and Noorani 1999, pp. 5.2.3.22-1). From May 1996 to May 1999, the temperature has decreased from $190^{\circ} \mathrm{F}$ to $180.7^{\circ} \mathrm{F}$. Present maximum temperature of $180.7^{\circ} \mathrm{F}$ in the waste confirms heat load classification. The tank has not exhibited any waste instability indicating a tank bump phenomena. The tank is actively ventilated which has proven effective at maintaining acceptable temperatures. Further core sampling and analysis of the waste in this tank will not change the safety classification or the controls applied to tank SX-111 with respect to this safety issue.

\section{Flammable Gas:}

Facility Group 2 tanks are conservatively postulated to have the potential for small, spontaneous and large induced GREs (Funderburke 1997). This tank has a SHMS installed on it for monitoring purposes. In addition, tank SX-111 was interim stabilized in 1979. Interim stabilization has been shown to significantly reduce the potential for trapping and periodically releasing flammable gas (Stewart et al. 1996). Other tanks, as shown in Section 3.1.4, have exhibited much stronger indications of flammable gas behavior and have been extensively sampled to provide data to address the safety issue (Johnson et al. 1997). Further sampling and analysis of the waste in tank SX-111 will not change the safety classification of the tank or the controls applied with respect to this safety issue.

\section{Are there any anomalous data that would drive characterization of the tank?}

No. Hodgson (1998) has reviewed the available surveillance data for surface level irregularities and temperature anomalies. None were observed. 
Tank Name: SX-112

Tank Parameters:

Tank Type: SST

Ventilation: Active

Interim stabilized: Yes (1979)
Tank Capacity: 1,000,000 gallons

Service History: Inactive (1979)

Tank Integrity: Assumed leaker (1969)

Waste Parameters:

Total waste:

Waste types:

107,000 gallons

107,000 gallons REDOX high level waste (1956-1965)

(Hendrickson 1998f)

Waste Temperature: $144^{\circ} \mathrm{F}$ (May 1999) (LMHC 1999)

\section{Safety Issue Status:}

Watch List: None. However, this tank is considered to have a high heat load.

USQs: $\quad$ Flammable gas (now closed), Organic nitrate (now closed)

Determination of the Safety Issues Associated with This Tank:

- Flammable gas

- Organic nitrate

- Organic solvent

- High heat

\section{Safety Issues Excluded from This Tank:}

- Ferrocyanide has been excluded. Tank SX-112 is not identified as one of the 18 ferrocyanide tanks (Postma et al. 1994).

- Criticality has been excluded. This tank did not receive any PFP waste (Agnew et al. 1997b). Criticality is not considered to be a credible accident scenario for safe storage of waste in tanks (Noorani 1999, pp. 5.3.2.1-4).

\section{Are there process history ties to other sampled tanks?}

Yes. Tanks SX-105 and SX-108 share characteristics with tank SX-112. Tank SX-105 has a similar process history to that of SX-112. Both tanks were used to store REDOX high level waste. These wastes were produced and sent to these tanks from 1955 to 1967 . The data from tank SX-105 does not exhibit behavior that triggers safety screening limits (LMHC 1999 and Appendix A). Because of the degree of similarity in process history, the waste in SX-112 is not expected to exhibit behavior different from that observed in SX-105.

Tank SX-108 has a similar process history to that of SX-112. Both tanks were used to store REDOX high level waste. These wastes were produced and sent to 
these tanks from 1955 to 1967 . The data from tank SX-108 does not exhibit behavior that triggers safety screening limits (LMHC 1999 and Appendix A). Because of the degree of similarity in process history, the waste in SX-112 is not expected to exhibit behavior different from that observed in SX-108.

\section{Is core sampling necessary to show tank is bounded?}

Table B-22 illustrates this statement using the logic chart (Figure B-1).

Table B-22. Safety Issue Logic for Tank SX-112

\begin{tabular}{|c|c|c|c|c|c|c|}
\hline Issue & $\begin{array}{c}\text { Organic } \\
\text { Complexant }\end{array}$ & $\begin{array}{l}\text { Organic } \\
\text { Solvent }\end{array}$ & Ferrocyanide & $\begin{array}{c}\text { Flammable } \\
\text { Gas }\end{array}$ & High Heat & Criticality \\
\hline $\begin{array}{l}\text { Can a case be } \\
\text { demonstrated } \\
\text { why related } \\
\text { tanks are } \\
\text { bounding? }\end{array}$ & No & No & Excluded & No & No & Excluded \\
\hline $\begin{array}{l}\text { Are other data } \\
\text { (other than core } \\
\text { sampling) } \\
\text { sufficient to } \\
\text { address safety } \\
\text { issues? }\end{array}$ & No & Yes & Excluded & Yes & Yes & Excluded \\
\hline $\begin{array}{l}\text { Does a } \\
\text { preponderance } \\
\text { of evidence } \\
\text { demonstrate } \\
\text { sampling is not } \\
\text { needed? }\end{array}$ & Yes & $*$ & Excluded & * & * & Excluded \\
\hline
\end{tabular}

Notes:

* = If a previous box provides necessary data for a yes, this logic box does not need to be addressed.

\section{Safety Issues Associated with Tank:}

\section{Organic Complexants:}

Evidence from theoretical considerations, empirical simulant studies, and evaluation of related tanks shows the hazards from organic complexants are adequately controlled. Tank SX-105 was categorized as having medium concentrations of organic complexant waste. Tank SX-108 was categorized as having no organic complexant waste. Tank SX-112 was categorized as having no organic complexant waste. Section 3.1.3 and Meacham et al. (1998) describe the organic complexant evaluation more thoroughly. The data from related tanks (SX-105 and SX-108) indicate that organic complexants are not an issue for the waste in tank SX-112 (Appendix A and Figures A-12 to A-15). Further core sampling and analysis of the waste in this tank will not change the safety 
classification or the controls applied to tank SX-112 with respect to this safety issue.

\section{Organic Solvents:}

Analytical results show that organic solvents are difficult to ignite, and credible ignition sources have been narrowed to robust energy sources such as lightning strikes and large hot metal cuttings from welding (Cowley et al. 1999).

Additional core sampling and analyses are not warranted for SX-112, because additional core sample data will not eliminate the need for controls or further resolve the safety issue.

\section{High Heat:}

Estimated thermal load is approximately $41,600 \mathrm{BTU} / \mathrm{hr}$. This is greater than the $26,000 \mathrm{BTU} / \mathrm{hr}$ criteria used to classify tanks as high-heat (Kummerer 1995 and Noorani 1999, pp. 5.2.3.22-1). From May 1996 to May 1999, the temperature has decreased from $147.6^{\circ} \mathrm{F}$ to $144^{\circ} \mathrm{F}$. Present maximum temperature of $144^{\circ} \mathrm{F}$ in the waste confirms heat load classification. The tank has not exhibited any waste instability indicating a tank bump phenomena. The tank is actively ventilated which has proven effective at maintaining acceptable temperatures. Further core sampling and analysis of the waste in this tank will not change the safety classification or the controls applied to tank SX-112 with respect to this safety issue.

\section{Flammable Gas:}

Tank SX-112 has less than 110,000 gallons of waste. Therefore, there is not sufficient waste volume to accumulate enough flammable gas to present a hazard (see Section B3.3). This tank is in Facility Group 3.

\section{Are there any anomalous data that would drive characterization of the tank?}

No. Hodgson (1998) has reviewed the available surveillance data for surface level irregularities and temperature anomalies. None were observed. 
Tank Name: SX-114

Tank Parameters:

Tank Type: SST

Ventilation: Active

Tank Capacity: $1,000,000$ gallons

Interim stabilized: Yes (1979)

Service History: Inactive (1977)

Tank Integrity: Assumed leaker (1972)

Waste Parameters:

Total waste:

181,000 gallons

Waste types:

181,000 gallons REDOX high level waste (1956-1965)

(Hendrickson 1998g)

Waste Temperature: $172^{\circ} \mathrm{F}$ (May 1999) (LMHC 1999)

Safety Issue Status:

Watch List: None. However, this tank is considered to have a high heat load.

USQs: $\quad$ Flammable gas (now closed), Organic nitrate (now closed)

Determination of the Safety Issues Associated with This Tank:

- Flammable gas

- Organic nitrate

- Organic solvent

- High heat

Safety Issues Excluded from This Tank:

- Ferrocyanide has been excluded. Tank SX-114 is not identified as one of the 18 ferrocyanide tanks (Postma et al. 1994).

- Criticality has been excluded. This tank did not receive any PFP waste (Agnew et al. 1997b). Criticality is not considered to be a credible accident scenario for safe storage of waste in tanks (Noorani 1999, pp. 5.3.2.1-4).

Are there process history ties to other sampled tanks?

Yes. Tanks SX-108 and SX-115 have a similar process histories to that of SX-114. Both tanks were used to store REDOX high level waste. These wastes were produced and sent to these tanks from 1955 to 1967. The data from tanks SX-108 and SX-115 do not exhibit behavior that triggers safety screening limits (LMHC 1999 and Appendix A). Because of the degree of similarity in process history, the waste in SX-114 is not expected to exhibit behavior different from that observed in SX-108 and SX-115. 
HNF-4232 Rev. 0

\section{Is core sampling necessary to show tank is bounded?}

Table B-23 illustrates this statement using the logic chart (Figure B-1).

Table B-23. Safety Issue Logic for Tank SX-114

\begin{tabular}{|l|l|l|l|l|l|l|}
\hline & $\begin{array}{c}\text { Organic } \\
\text { Complexant }\end{array}$ & $\begin{array}{l}\text { Organic } \\
\text { Solvent }\end{array}$ & Ferrocyanide & $\begin{array}{l}\text { Flammable } \\
\text { Gas }\end{array}$ & High Heat & Criticality \\
\hline $\begin{array}{l}\text { Can a case be } \\
\text { demonstrated } \\
\text { why related } \\
\text { tanks are } \\
\text { bounding? }\end{array}$ & No & No & Excluded & No & No & Excluded \\
\hline $\begin{array}{l}\text { Are other data } \\
\text { (other than core } \\
\text { sampling) } \\
\text { sufficient to } \\
\text { address safety } \\
\text { issues? }\end{array}$ & No & Yes & Excluded & Yes & Yes & Excluded \\
\hline $\begin{array}{l}\text { Does a } \\
\text { preponderance } \\
\text { of evidence } \\
\text { demonstrate } \\
\text { sampling is not } \\
\text { needed? }\end{array}$ & Yes & $*$ & Excluded & $*$ & $*$ & \\
\hline
\end{tabular}

Notes:

* = If a previous box provides necessary data for a yes, this logic box does not need to be addressed.

\section{Safety Issues Associated with Tank:}

\section{Organic Complexants:}

Evidence from theoretical considerations, empirical simulant studies, and evaluation of related tanks shows the hazards from organic complexants are adequately controlled. Tank SX-108 was categorized as having no organic complexant waste. Tank SX-115 was categorized as having low concentrations of organic complexant waste. Tank SX-114 was categorized as having low concentrations of organic complexant waste. Section 3.1.3 and Meacham et al. (1998) describe the organic complexant evaluation more thoroughly. The data from related tanks (SX-115 and SX-108) indicate that organic complexants are not an issue for the waste in tank SX-114 (Appendix A and Figures A-12 to A-15). Further core sampling and analysis of the waste in this tank will not change the safety classification or the controls applied to tank SX-114 with respect to this safety issue. 


\section{Organic Solvents:}

Analytical results show that organic solvents are difficult to ignite, and credible ignition sources have been narrowed to robust energy sources such as lightning strikes and large hot metal cuttings from welding (Cowley et al. 1999). Additional core sampling and analyses are not warranted for SX-114, because additional core sample data will not eliminate the need for controls or further resolve the safety issue.

\section{High Heat:}

Estimated thermal load is approximately $58,700 \mathrm{BTU} / \mathrm{hr}$. This is greater than the 26,000 BTU/hr criteria used to classify tanks as high-heat (Kummerer 1995 and Noorani 1999, pp. 5.2.3.22-1). From May 1996 to May 1999, the temperature has decreased from $184^{\circ} \mathrm{F}$ to $172^{\circ} \mathrm{F}$. Present maximum temperature of $172{ }^{\circ} \mathrm{F}$ in the waste confirms heat load classification. The tank has not exhibited any waste instability indicating a tank bump phenomena. The tank is actively ventilated which has proven effective at maintaining acceptable temperatures. . Further core sampling and analysis of the waste in this tank will not change the safety classification or the controls applied to tank SX-114 with respect to this safety issue.

\section{Flammable Gas:}

Tank SX-114 is not considered a hazard with respect to flammable gas. Because no surface level rise or barometric response behavior has been observed, the tank is considered Facility Group 3. Facility Group 3 tanks are conservatively postulated to have the potential for small, induced GREs (Funderburke 1997). In addition, tank SX-114 was interim stabilized in 1979. Interim stabilization has been shown to significantly reduce the potential for trapping and periodically releasing flammable gases (Stewart et al. 1996). Other tanks, as shown in Section 3.1.4, have exhibited much stronger indications of flammable gas behavior and have been extensively sampled to provide data to address the safety issue (Johnson et al. 1997). Further sampling and analysis of the waste in tank SX-114 will not change the safety classification of the tank or the controls applied with respect to this safety issue.

\section{Are there any anomalous data that would drive characterization of the tank?}

No. Hodgson (1998) has reviewed the available surveillance data for surface level irregularities and temperature anomalies. None were observed. 
Tank Name: T-101

Tank Parameters:

Tank Type: SST

Ventilation: Passive

Tank Capacity: 530,000 gallons

Interim stabilized: Yes (1993)

Service History: Inactive (1979)

Tank Integrity: Assumed leaker (1992)

Waste Parameters:

Total waste: $\quad 102,000$ gallons

Waste types: $\quad 65,000$ gallons 242-T Evaporator concentrate

(1965-1976)

35,000 gallons REDOX cladding waste (1969)

2,000 gallons bismuth phosphate metal waste (1956)

(Hohl 1998a)

Waste Temperature: $64.9^{\circ} \mathrm{F}$ (May 1999) (LMHC 1999)

Safety Issue Status:

Watch List: None

USQs: $\quad$ Flammable gas (now closed), Organic nitrate (now closed)

Determination of the Safety Issues Associated with This Tank:

- Ferrocyanide

- Organic nitrate

- Organic solvent

- Flammable gas

Safety Issues Excluded from This Tank:

- Criticality has been excluded. This tank did not receive any PFP waste (Agnew et al. 1997b). Criticality is not considered to be a credible accident scenario for safe storage of waste in tanks (Noorani 1999, pp. 5.3.2.1-4).

- High heat has been excluded. Estimated thermal load is 4,190 BTU/hr. This is insufficient to classify this tank as a high-heat tank (Kummerer 1995 and Noorani 1999 , pp. 5.2.3.22-1). Present maximum temperature of $64.9^{\circ} \mathrm{F}$ in the waste confirms heat load classification. 


\section{Are there process history ties to other sampled tanks?}

Yes. Tanks U-102, U-105, S-104, and BX-104 have process wastes in common with tank T-101. Tanks U-102 and U-105 has a similar process history to that of $\mathrm{T}-101$. All three tanks were used to store second campaign 242- $T$ Evaporator concentrates. Tanks U-105 and T-101 were also used to store REDOX cladding waste. Evaporator concentrates have limited compositional variation as evidenced from historical evaluation and analysis of tank waste (Agnew et al. 1997b; LoPresti et al. 1997; Hendrickson et al. 1998). REDOX cladding waste has compositional features that enable it to be distinguished from evaporator concentrates (Kupfer et al. 1999). The data from tank U-102 and U-105 do not exhibit behavior that triggers safety screening limits (LMHC 1999 and Appendix A). Because of the degree of similarity in process history, the waste in $\mathrm{T}-101$ is not expected to exhibit behavior different from that observed in U-102 and $\mathrm{U}-105$.

Tank S-104 has a similar process history to that of $\mathrm{T}-101$. Both tanks were used to store REDOX cladding waste. REDOX cladding waste has compositional features that enable it to be distinguished from evaporator concentrates (Kupfer et al. 1999). The data from tank S-104 does not exhibit behavior that triggers safety screening limits (LMHC 1999 and Appendix A). Because of the degree of similarity in process history, the waste in T-101 is not expected to exhibit behavior different from that observed in S-104.

Tank BX-104 has a similar process history to that of T-101. Both tanks were used to store bismuth phosphate metal waste. Metal waste is infrequently sampled because of its relative scarcity and inaccessibility. It was reclaimed during several sluicing campaigns and processed in the uranium recovery operation (Rodenhizer 1987; Agnew et al. 1997b), and subsequent waste management of the tanks has made the remaining metal waste residue difficult to sample successfully with current equipment and riser configurations. Metal waste has compositional features that enable it to be distinguished from evaporator concentrates (Kupfer et al. 1999). The data from tank BX-104 does not exhibit behavior that triggers safety screening limits (LMHC 1999 and Appendix A). Because of the degree of similarity in process history, the waste in $\mathrm{T}-101$ is not expected to exhibit behavior different from that observed in $\mathrm{BX}-104$. 
Is core sampling necessary to show tank is bounded?

Table B-24 illustrates this statement using the logic chart (Figure B-1).

Table B-24. Safety Issue Logic for Tank T-101

\begin{tabular}{|l|l|l|l|l|l|l|}
\hline \multicolumn{1}{|c|}{ Issue } & $\begin{array}{c}\text { Organic } \\
\text { Complexant }\end{array}$ & $\begin{array}{l}\text { Organic } \\
\text { Solvent }\end{array}$ & Ferrocyanide & $\begin{array}{l}\text { Flammable } \\
\text { Gas }\end{array}$ & High Heat & Criticality \\
\hline $\begin{array}{l}\text { Can a case be } \\
\text { demonstrated why } \\
\text { related tanks are } \\
\text { bounding? }\end{array}$ & No & No & Yes & No & Excluded & Excluded \\
\hline $\begin{array}{l}\text { Are other data (other } \\
\text { than core sampling) } \\
\text { sufficient to address } \\
\text { safety issues? }\end{array}$ & No & Yes & $*$ & Yes & Excluded & Excluded \\
\hline $\begin{array}{l}\text { Does a preponderance } \\
\text { of evidence demonstrate } \\
\text { sampling is not needed? }\end{array}$ & Yes & $*$ & $*$ & $*$ & Excluded & Excluded \\
\hline
\end{tabular}

Notes:

* = If a previous box provides necessary data for a yes, this logic box does not need to be addressed.

\section{Safety Issues Associated with Tank:}

\section{Ferrocyanide:}

Tank T-101 is identified as one of 18 ferrocyanide tanks (Postma et al. 1994). However, data from the other ferrocyanide wastes sampled has confirmed it is not energetic (see Section B3.2 for more details of the analysis). The ferrocyanide USQ and safety issue have been closed (Meacham 1996).

\section{Organic Complexants:}

Evidence from theoretical considerations, empirical simulant studies, and evaluation of related tanks shows the hazards from organic complexants are adequately controlled. Tanks BX-104 and U-105 were categorized as having high concentrations of organic complexant waste. Tanks S-104 and U-102 were categorized as having medium concentrations of organic complexant waste. Tank $\mathrm{T}-101$ was also categorized as having medium concentrations of organic complexant waste. Section 3.1.3 and Meacham et al. (1998) describe the organic complexant evaluation more thoroughly. The data from related tanks (U-102, $\mathrm{U}-105, \mathrm{~S}-104$, and BX-104) indicate that organic complexants are not an issue for the waste in tank T-101 (Appendix A and Figures A-12 to A-15). Further core sampling and analysis of the waste in this tank will not change the safety 
HNF-4232 Rev. 0

classification or the controls applied to tank T-101 with respect to this safety issue.

\section{Organic Solvents:}

Analytical results show that organic solvents are difficult to ignite, and credible ignition sources have been narrowed to robust energy sources such as lightning strikes and large hot metal cuttings from welding (Cowley et al. 1999). Additional core sampling and analyses are not warranted for $\mathrm{T}-101$, because additional core sample data will not eliminate the need for controls or further resolve the safety issue.

\section{Flammable Gas:}

Tank $T-101$ is not considered a hazard with respect to flammable gas. Because no surface level rise or barometric response behavior has been observed, the tank is considered Facility Group 3. Facility Group 3 tanks are conservatively postulated to have the potential for small, induced GREs (Funderburke 1997). In addition, tank T-101 was interim stabilized in 1993. Interim stabilization has been shown to significantly reduce the potential for trapping and periodically releasing flammable gas (Stewart et al. 1996). Other tanks, as shown in Section 3.1.4, have exhibited much stronger indications of flammable gas behavior and have been extensively sampled to provide data to address the safety issue (Johnson et al. 1997). Further sampling and analysis of the waste in tank $T-101$ will not change the safety classification of the tank or the controls applied with respect to this safety issue.

\section{Are there any anomalous data that would drive characterization of the tank?}

No. Hodgson (1998) has reviewed the available surveillance data for surface level irregularities and temperature anomalies. None were found. 
Tank Name: $\mathrm{T}-103$

Tank Parameters:

Tank Type: SST

Ventilation: Passive

Interim stabilized: Yes (1983)
Tank Capacity: 530,000 gallons

Service History: Inactive (1976)

Tank Integrity： Assumed leaker (1994)

Waste Parameters:

Total waste:

27,000 gallons

Waste types:

9,000 gallons 242-T Evaporator concentrate

(1965-1976)

17,000 gallons PUREX cladding waste (1969)

1,000 gallons bismuth phosphate metal waste (1956)

(Hohl 1998b)

Waste Temperature: $58.8^{\circ} \mathrm{F}$ (May 1999) (LMHC 1999)

Safety Issue Status:

Watch List: None

USQs: $\quad$ Flammable gas (now closed), Organic nitrate (now closed)

Determination of the Safety Issues Associated with This Tank:

- Flammable gas

- Organic nitrate

- Organic solvent

Safety Issues Excluded from This Tank:

- Ferrocyanide has been excluded. Tank T-103 is not identified as one of the 18 ferrocyanide tanks (Postma et al. 1994).

- Criticality has been excluded. This tank did not receive any PFP waste (Agnew et al. 1997b). Criticality is not considered to be a credible accident scenario for safe storage of waste in tanks (Noorani 1999, pp. 5.3.2.1-4).

- High heat has been excluded. Estimated thermal load is 1,080 BTU/hr. This is insufficient to classify this tank as a high-heat tank (Kummerer 1995 and Noorani 1999 , pp. 5.2.3.22-1). Present maximum temperature of $58.8^{\circ} \mathrm{F}$ in the waste confirms heat load classification. 


\section{Are there process history ties to other sampled tanks?}

Yes. Tanks U-102, C-104, and BX-104 have process wastes in common with tank T-101. Tank U-102 has a similar process history to that of T-103. Both tanks were used to store second campaign 242-T Evaporator concentrates. The tanks' evaporator concentrates have limited compositional variation as evidenced from historical evaluation and analysis of tank waste (Agnew et al. 1997b; LoPresti et al. 1997; Hendrickson et al. 1998). The data from tank U-102 does not exhibit behavior that triggers safety screening limits (LMHC 1999 and Appendix A). Because of the degree of similarity in process history, the waste in $\mathrm{T}-101$ is not expected to exhibit behavior different from that observed in U-102.

Tank C-104 has a similar process history to that of T-103. Both tanks were used to store PUREX cladding wastes. These wastes were produced and sent to these tanks from 1958 to 1970 . Cladding wastes have limited compositional variation as evidenced from historical evaluation and analysis of tank waste (Agnew et al. 1997b; LoPresti et al. 1997; Hendrickson et al. 1998). The data from tank C-104 cladding wastes does not exhibit behavior that triggers safety screening limits (LMHC 1999 and Appendix A). Because of the degree of similarity in process history, the waste in T-103 is not expected to exhibit behavior different from that observed in C-104.

Tank BX-104 has a similar process history to that of T-103. Both tanks were used to store bismuth phosphate metal waste. Metal waste is infrequently sampled because of its relative scarcity and inaccessibility. It was reclaimed during several sluicing campaigns and processed in the uranium recovery operation (Rodenhizer 1987; Agnew et al. 1997b), and subsequent waste management of the tanks has made the remaining metal waste residue difficult to sample successfully with current equipment and riser configurations. Metal waste has compositional features that enable it to be distinguished from evaporator concentrates (Kupfer et al. 1999). The data from tank BX-104 does not exhibit behavior that triggers safety screening limits (LMHC 1999 and Appendix A). Because of the degree of similarity in process history, the waste in $\mathrm{T}-103$ is not expected to exhibit behavior different from that observed in BX-104. 


\section{Is core sampling necessary to show tank is bounded?}

Table B-25 illustrates this statement using the logic chart (Figure B-1).

Table B-25. Safety Issue Logic for Tank T-103

\begin{tabular}{|l|l|l|l|l|l|l|}
\hline \multicolumn{1}{|c|}{ Issue } & $\begin{array}{c}\text { Organic } \\
\text { Complexant }\end{array}$ & $\begin{array}{l}\text { Organic } \\
\text { Solvent }\end{array}$ & Ferrocyanide & $\begin{array}{l}\text { Flammable } \\
\text { Gas }\end{array}$ & High Heat & Criticality \\
\hline $\begin{array}{l}\text { Can a case be } \\
\text { demonstrated why } \\
\text { related tanks are } \\
\text { bounding? }\end{array}$ & No & No & Excluded & No & Excluded & Excluded \\
\hline $\begin{array}{l}\text { Are other data (other } \\
\text { than core sampling) } \\
\text { sufficient to address } \\
\text { safety issues? }\end{array}$ & No & Yes & Excluded & Yes & Excluded & Excluded \\
\hline $\begin{array}{l}\text { Does a preponderance } \\
\text { of evidence demonstrate } \\
\text { sampling is not needed? }\end{array}$ & Yes & $*$ & Excluded & $*$ & Excluded & Excluded \\
\hline
\end{tabular}

Notes:

* = If a previous box provides necessary data for a yes, this logic box does not need to be addressed.

\section{Safety Issues Associated with Tank:}

\section{Organic Complexants:}

Evidence from theoretical considerations, empirical simulant studies, and evaluation of related tanks shows the hazards from organic complexants are adequately controlled. Tanks BX-104 and C-104 were categorized as having high concentrations of organic complexant waste. Tank U-102 was categorized as having medium concentrations of organic complexant waste. Tank T-103 was categorized as having low concentrations of organic complexant waste. Section 3.1.3 and Meacham et al. (1998) describe the organic complexant evaluation more thoroughly. The data from related tanks (U-102, C-104 and $\mathrm{BX}-104)$ indicate that organic complexants are not an issue for the waste in tank T-103 (Appendix A and Figures A-12 to A-15). Further core sampling and analysis of the waste in this tank will not change the safety classification or the controls applied to tank $T-103$ with respect to this safety issue.

\section{Organic Solvents:}

Analytical results show that organic solvents are difficult to ignite, and credible ignition sources have been narrowed to robust energy sources such as lightning strikes and large hot metal cuttings from welding (Cowley et al. 1999). Additional core sampling and analyses are not warranted for $\mathrm{T}-103$, because 
additional core sample data will not eliminate the need for controls or further resolve the safety issue.

\section{Flammable Gas:}

Tank T-103 has less than 110,000 gallons of waste. Therefore, there is not sufficient waste volume to accumulate enough flammable gas to present a hazard (see Section B3.3). This tank is in Facility Group 3.

Are there any anomalous data that would drive characterization of the tank?

No. Hodgson (1998) has reviewed the available surveillance data for surface level irregularities and temperature anomalies. None were found. 
Tank Name: TX-101

Tank Parameters:

Tank Type: SST

Ventilation: Passive

Interim stabilized: Yes (1984)
Tank Capacity: 758,000 gallons

Service History: Inactive (1977)

Tank Integrity: Sound

Waste Parameters:

Total waste:

Waste types:

87,000 gallons

13,000 gallons 242-T Evaporator concentrate

(1965-1976)

74,000 gallons REDOX high level waste (1965-1972)

(Hohl 1998c)

Waste Temperature: Not available. No active sensors in tank (Hanlon 1999)

Safety Issue Status:

Watch List: None

USQs: $\quad$ Flammable gas (now closed), Organic nitrate (now closed)

\section{Determination of the Safety Issues Associated with This Tank:}

- Flammable gas

- Organic nitrate

- Organic solvent

\section{Safety Issues Excluded from This Tank:}

- Ferrocyanide has been excluded. Tank TX-101 is not identified as one of the 18 ferrocyanide tanks (Postma et al. 1994).

- Criticality has been excluded. This tank received a small amount (1,000 gallons, or approximately 0.36 inches of depth) of PFP waste (Agnew et al. 1997b). This waste volume is considered to be too small to influence the overall inventory of the tank and is not considered in the inventory calculations (Hohl 1998c). Furthermore, sampling is not likely to detect this waste layer because of the coarseness of the analytical horizon (usually about 9 inches in depth, which is then homogenized). Criticality is not considered to be a credible accident scenario for safe storage of waste in tanks (Noorani 1999, pp. 5.3.2.1-4).

- High heat has been excluded. Thermal load based on estimated radionuclide content is 6,860 BTU/hr (Hohl 1998c). This is insufficient to classify this tank as a high-heat tank (Kummerer 1995 and Noorani 1999, pp. 5.2.3.22-1). 


\section{Are there process history ties to other sampled tanks?}

Yes. Tanks U-102, S-104, and S-107 have process wastes in common with tank TX-101. Tank U-102 has a similar process history to that of TX-101. Both tanks were used to store second campaign 242-T Evaporator concentrates. Evaporator concentrates have limited compositional variation as evidenced from historical evaluation and analysis of tank waste (Agnew et al. 1997b; LoPresti et al. 1997; Hendrickson et al. 1998). The data from tank U-102 does not exhibit behavior that triggers safety screening limits (LMHC 1999 and Appendix A). Because of the degree of similarity in process history, the waste in T-101 is not expected to exhibit behavior different from that observed in U-102.

Tanks S-104 and S-107 have similar process histories to that of TX-101. All three tanks were used to store REDOX high level waste and REDOX cladding waste. REDOX high level waste has compositional features that enable it to be distinguished from evaporator concentrates (Kupfer et al. 1999). However, waste layers historically designated REDOX high-level waste and REDOX cladding waste may not be distinguishable analytically because they share many of the same properties (Simpson 1996). The data from tanks S-104 and S-107 do not exhibit behavior that triggers safety screening limits (LMHC 1999 and Appendix A). Because of the degree of similarity in process history, the waste in TX-101 is not expected to exhibit behavior different from that observed in S-104 and S-107.

\section{Is core sampling necessary to show tank is bounded?}

Table B-26 illustrates this statement using the logic chart (Figure B-1).

Table B-26. Safety Issue Logic for Tank TX-101

\begin{tabular}{|l|l|l|l|l|l|l|}
\hline \multicolumn{1}{|c|}{ Issue } & $\begin{array}{c}\text { Organic } \\
\text { Complexant }\end{array}$ & $\begin{array}{l}\text { Organic } \\
\text { Solvent }\end{array}$ & Ferrocyanide & $\begin{array}{c}\text { Flammable } \\
\text { Gas }\end{array}$ & High Heat & Criticality \\
\hline $\begin{array}{l}\text { Can a case be } \\
\text { demonstrated why } \\
\text { related tanks are } \\
\text { bounding? }\end{array}$ & No & No & Excluded & No & Excluded & Excluded \\
\hline $\begin{array}{l}\text { Are other data (other } \\
\text { than core sampling) } \\
\text { sufficient to address } \\
\text { safety issues? }\end{array}$ & No & Yes & Excluded & Yes & Excluded & Excluded \\
\hline $\begin{array}{l}\text { Does a preponderance } \\
\text { of evidence demonstrate } \\
\text { sampling is not needed? }\end{array}$ & Yes & $*$ & Excluded & $*$ & Excluded & Excluded \\
\hline
\end{tabular}

Notes:

$$
\text { * = If a previous box provides necessary data for a yes, this logic box does not need to be }
$$
addressed. 


\section{Safety Issues Associated with Tank:}

\section{Organic Complexants:}

Evidence from theoretical considerations, empirical simulant studies, and evaluation of related tanks shows the hazards from organic complexants are adequately controlled. Tanks S-104 and U-102 were categorized as having medium concentrations of organic complexant waste. Tank S-107 was categorized as having high concentrations of organic complexant waste. Tank TX-101 was categorized as having low concentrations of organic complexant waste. Section 3.1.3 and Meacham et al. (1998) describe the organic complexant evaluation more thoroughly. The data from related tanks (U-102, S-104 and $S$-107) indicate that organic complexants are not an issue for the waste in tank TX-101 (Appendix A and Figures A-12 to A-15). Further core sampling and analysis of the waste in this tank will not change the safety classification or the controls applied to tank TX-101 with respect to this safety issue.

\section{Organic Solvents:}

Analytical results show that organic solvents are difficult to ignite, and credible ignition sources have been narrowed to robust energy sources such as lightning strikes and large hot metal cuttings from welding (Cowley et al. 1999).

Additional core sampling and analyses are not warranted for TX-101, because additional core sample data will not eliminate the need for controls or further resolve the safety issue.

\section{Flammable Gas:}

Tank TX-101 has less than 110,000 gallons of waste. Therefore, there is not sufficient waste volume to accumulate enough flammable gas to present a hazard (see Section B3.3). This tank is in Facility Group 3.

\section{Are there any anomalous data that would drive characterization of the tank?}

No. Hodgson (1998) has reviewed the available surveillance data for surface level irregularities. None were found. There is no contemporary temperature data for this tank. 
Tank Name: TX-102

Tank Parameters:

Tank Type: SST

Ventilation: Passive

Interim stabilized: Yes (1983)
Tank Capacity: 758,000 gallons

Service History: Inactive (1977)

Tank Integrity: Sound

Waste Parameters:

Total waste:

Waste types:

217,000 gallons

217,000 gallons 242-T Evaporator concentrate

(1965-1976)

(Hohl 1998d)

Waste Temperature: $79.7^{\circ} \mathrm{F}$ (May 1999) (LMHC 1999)

Safety Issue Status:

Watch List: None

USQs: $\quad$ Flammable gas (now closed), Organic nitrate (now closed)

Determination of the Safety Issues Associated with This Tank:

- Flammable gas

- Organic nitrate

- Organic solvent

\section{Safety Issues Excluded from This Tank:}

- Ferrocyanide has been excluded. Tank TX-102 is not identified as one of the 18 ferrocyanide tanks (Postma et al. 1994).

- Criticality has been excluded. This tank did not receive any PFP waste (Agnew et al. 1997b). Criticality is not considered to be a credible accident scenario for safe storage of waste in tanks (Noorani 1999, pp. 5.3.2.1-4).

- High heat has been excluded. Estimated thermal load is approximately 4,800 BTU/hr. This is insufficient to classify this tank as a high-heat tank (Kummerer 1995 and Noorani 1999, pp. 5.2.3.22-1). Present maximum temperature of $79.7^{\circ} \mathrm{F}$ in the waste confirms heat load classification. 


\section{Are there process history ties to other sampled tanks?}

Yes. Tanks U-102 and U-105 have similar process histories to that of TX-102. All three tanks were used to store second campaign 242-T Evaporator concentrates. Tank U-105 was also used to store REDOX cladding waste. Evaporator concentrates have limited compositional variation as evidenced from historical evaluation and analysis of tank waste (Agnew et al. 1997b; LoPresti et al. 1997; Hendrickson et al. 1998). REDOX cladding waste has compositional features that enable it to be distinguished from evaporator concentrates (Kupfer et al. 1999). The data from tank U-102 and U-105 do not exhibit behavior that triggers safety screening limits (LMHC 1999 and Appendix A). Because of the degree of similarity in process history, the waste in TX-102 is not expected to exhibit behavior different from that observed in U-102 and U-105.

\section{Is core sampling necessary to show tank is bounded?}

Table B-27 illustrates this statement using the logic chart (Figure B-1).

Table B-27. Safety Issue Logic for Tank TX-102

\begin{tabular}{|l|l|l|l|l|l|l|}
\hline \multicolumn{1}{|c|}{ Issue } & $\begin{array}{c}\text { Organic } \\
\text { Complexant }\end{array}$ & $\begin{array}{c}\text { Organic } \\
\text { Solvent }\end{array}$ & Ferrocyanide & $\begin{array}{l}\text { Flammable } \\
\text { Gas }\end{array}$ & High Heat & Criticality \\
\hline $\begin{array}{l}\text { Can a case be } \\
\text { demonstrated why } \\
\text { related tanks are } \\
\text { bounding? }\end{array}$ & No & No & Excluded & No & Excluded & Excluded \\
\hline $\begin{array}{l}\text { Are other data (other } \\
\text { than core sampling) } \\
\text { sufficient to address } \\
\text { safety issues? }\end{array}$ & No & Yes & Excluded & No & Excluded & Excluded \\
\hline $\begin{array}{l}\text { Does a preponderance } \\
\text { of evidence demonstrate } \\
\text { sampling is not needed? }\end{array}$ & Yes & $*$ & Excluded & Yes & Excluded & Excluded \\
\hline
\end{tabular}

Notes:

* = If a previous box provides necessary data for a yes, this logic box does not need to be addressed. 


\section{Safety Issues Associated with Tank:}

\section{Organic Complexants:}

Evidence from theoretical considerations, empirical simulant studies, and evaluation of related tanks shows the hazards from organic complexants are adequately controlled. Tank U-105 was categorized as having high concentrations of organic complexant waste. Tank U-102 was categorized as having medium concentrations of organic complexant waste. Tank TX-102 was also categorized as having medium concentrations of organic complexant waste. Section 3.1.3 and Meacham et al. (1998) describe the organic complexant evaluation more thoroughly. The data from related tanks (U-102 and U-105) indicate that organic complexants are not an issue for the waste in tank TX-102 (Appendix A and Figures A-12 to A-15). Further core sampling and analysis of the waste in this tank will not change the safety classification or the controls applied to tank TX-102 with respect to this safety issue.

\section{Organic Solvents:}

Analytical results show that organic solvents are difficult to ignite, and credible ignition sources have been narrowed to robust energy sources such as lightning strikes and large hot metal cuttings from welding (Cowley et al. 1999). Additional core sampling and analyses are not warranted for TX-102, because additional core sample data will not eliminate the need for controls or further resolve the safety issue.

\section{Flammable Gas:}

The tank is considered Facility Group 2. Facility Group 2 tanks are conservatively postulated to have the potential for small spontaneous and large induced GREs (Funderburke 1997). Tank TX-102 was interim stabilized in 1983. Interim stabilization has been shown to significantly reduce the potential for trapping and periodically releasing flammable gas (Stewart et al. 1996). Other tanks, such as AN-105 or AW-101, have exhibited much stronger indications of flammable gas behavior and have been extensively sampled to provide data to address the safety issue. Section 3.1.4 and Johnson et al. (1997) describe the flammable gas data evaluation more thoroughly. Further sampling and analysis of the waste in tank TX-102 will not change the safety classification of the tank or the controls applied with respect to this safety issue.

\section{Are there any anomalous data that would drive characterization of the tank?}

No. Hodgson (1998) has reviewed the available surveillance data for surface level irregularities and temperature anomalies. None were found. 
Tank Name: TX-103

Tank Parameters:

Tank Type: SST

Ventilation: Passive

Interim stabilized: Yes (1983)
Tank Capacity: 758,000 gallons

Service History: Inactive (1980)

Tank Integrity: Sound

Waste Parameters:

Total waste:

Waste types: $\quad 157,000$ gallons 242-T Evaporator concentrate $(1965-1976)$

(Hohl 1998e)

Waste Temperature: $70^{\circ} \mathrm{F}$ (May 1999) (LMHC 1999)

Safety Issue Status:

Watch List: None

USQs: $\quad$ Flammable gas (now closed), Organic nitrate (now closed)

Determination of the Safety Issues Associated with This Tank:

- Flammable gas

- Organic nitrate

- Organic solvent

\section{Safety Issues Excluded from This Tank:}

- Ferrocyanide has been excluded. Tank TX-103 is not identified as one of the 18 ferrocyanide tanks (Postma et al. 1994).

- Criticality has been excluded. This tank did not receive any PFP waste (Agnew et al. 1997b). Criticality is not considered to be a credible accident scenario for safe storage of waste in tanks (Noorani 1999, pp. 5.3.2.1-4).

- High heat has been excluded. Estimated thermal load is $642 \mathrm{BTU} / \mathrm{hr}$. This is insufficient to classify this tank as a high-heat tank (Kummerer 1995 and Noorani 1999, pp. 5.2.3.22-1). Present maximum temperature of $70^{\circ} \mathrm{F}$ in the waste confirms heat load classification. 


\section{Are there process history ties to other sampled tanks?}

Yes. Tanks U-102 and U-105 have similar process histories to that of TX-103. All three tanks were used to store second campaign 242-T Evaporator concentrates. Tank U-105 was also used to store REDOX cladding waste. Evaporator concentrates have limited compositional variation as evidenced from historical evaluation and analysis of tank waste (Agnew et al. 1997b; LoPresti et al. 1997; Hendrickson et al. 1998). REDOX cladding waste has compositional features that enable it to be distinguished from evaporator concentrates (Kupfer et al. 1999). The data from tank U-102 and U-105 do not exhibit behavior that triggers safety screening limits (LMHC 1999 and Appendix A). Because of the degree of similarity in process history, the waste in TX-103 is not expected to exhibit behavior different from that observed in U-102 and U-105.

\section{Is core sampling necessary to show tank is bounded?}

Table B-28 illustrates this statement using the logic chart (Figure B-1).

Table B-28. Safety Issue Logic for Tank TX-103

\begin{tabular}{|l|l|l|l|l|l|l|}
\hline \multicolumn{1}{|c|}{ Issue } & $\begin{array}{c}\text { Organic } \\
\text { Complexant }\end{array}$ & $\begin{array}{l}\text { Organic } \\
\text { Solvent }\end{array}$ & Ferrocyanide & $\begin{array}{l}\text { Flammable } \\
\text { Gas }\end{array}$ & High Heat & Criticality \\
\hline $\begin{array}{l}\text { Can a case be } \\
\text { demonstrated why } \\
\text { related tanks are } \\
\text { bounding? }\end{array}$ & No & No & Excluded & No & Excluded & Excluded \\
\hline $\begin{array}{l}\text { Are other data (other } \\
\text { than core sampling) } \\
\text { sufficient to address } \\
\text { safety issues? }\end{array}$ & No & Yes & Excluded & Yes & Excluded & Excluded \\
\hline $\begin{array}{l}\text { Does a preponderance } \\
\text { of evidence demonstrate } \\
\text { sampling is not needed? }\end{array}$ & Yes & $*$ & Excluded & $*$ & Excluded & Excluded \\
\hline
\end{tabular}

Notes:

\footnotetext{
* = If a previous box provides necessary data for a yes, this logic box does not need to be addressed.
} 


\section{Safety Issues Associated with Tank:}

\section{Organic Complexants:}

Evidence from theoretical considerations, empirical simulant studies, and evaluation of related tanks shows the hazards from organic complexants are adequately controlled. Tank U- 105 was categorized as having high concentrations of organic complexant waste. Tank U-102 was categorized as having medium concentrations of organic complexant waste. Tank TX-103 was categorized as having low concentrations of organic complexant waste. Section 3.1.3 and Meacham et al. (1998) describe the organic complexant evaluation more thoroughly. The data from related tanks (U-102 and U-105) indicate that organic complexants are not an issue for the waste in tank TX-103 (Appendix A and Figures A-12 to A-15). Further core sampling and analysis of the waste in this tank will not change the safety classification or the controls applied to tank TX-103 with respect to this safety issue.

\section{Organic Solvents:}

Analytical results show that organic solvents are difficult to ignite, and credible ignition sources have been narrowed to robust energy sources such as lightning strikes and large hot metal cuttings from welding (Cowley et al. 1999). Additional core sampling and analyses are not warranted for TX-103, because additional core sample data will not eliminate the need for controls or further resolve the safety issue.

\section{Flammable Gas:}

Tank TX-103 is not considered a hazard with respect to flammable gas. Because no surface level fluctuation or barometric response behavior has been observed, the tank is considered Facility Group 3. Facility Group 3 tanks are conservatively postulated to have the potential for small, induced GREs (Funderburke 1997). Tank TX-103 was interim stabilized in 1983. Interim stabilization has been shown to significantly reduce the potential for trapping and periodically releasing flammable gas (Stewart et al. 1996). Other tanks, as shown in Section 3.1.4, have exhibited much stronger indications of flammable gas behavior and have been extensively sampled to provide data to address the safety issue (Johnson et al. 1997). Further sampling and analysis of the waste in tank TX-103 will not change the safety classification of the tank or the controls applied with respect to this safety issue.

\section{Are there any anomalous data that would drive characterization of the tank?}

No. Hodgson (1998) has reviewed the available surveillance data for surface level irregularities and temperature anomalies. None were found. 
Tank Name: TX-105

Tank Parameters:

Tank Type: SST

Ventilation: Passive

Interim stabilized: Yes (1983)
Tank Capacity: 758,000 gallons

Service History: Inactive (1977)

Tank Integrity: Assumed leaker (1977)

Waste Parameters:

Total waste: $\quad 609,000$ gallons

Waste types: $\quad 609,000$ gallons 242-T Evaporator concentrate

(1965-1976)

(Hohl 1998f)

Waste Temperature: $97^{\circ} \mathrm{F}$ (May 1999) (LMHC 1999)

Safety Issue Status:

Watch List: Organic-nitrate (now closed)

USQs: $\quad$ Flammable gas (now closed), Organic nitrate (now closed)

\section{Determination of the Safety Issues Associated with This Tank:}

- Flammable gas

- Organic nitrate

Safety Issues Excluded from This Tank:

- Ferrocyanide has been excluded. Tank TX-105 is not identified as one of the 18 ferrocyanide tanks (Postma et al. 1994).

- Organic solvent has been excluded. Tank has been demonstrated to not be in scope of organic solvent issue by vapor sampling (Noorani 1999, pp. 5.3.2.15-19). Furthermore, analytical results show that organic solvents are difficult to ignite, and credible ignition sources have been narrowed to robust energy sources such as lightning strikes and large hot metal cuttings from welding (Cowley et al. 1999).

- Criticality has been excluded. This tank did not receive any PFP waste (Agnew et al. 1997b). Criticality is not considered to be a credible accident scenario for safe storage of waste in tanks (Noorani 1999, pp. 5.3.2.1-4).

- High heat has been excluded. Estimated thermal load is $6,780 \mathrm{BTU} / \mathrm{hr}$. This is insufficient to classify this tank as a high-heat tank (Kummerer 1995 and Noorani 1999, pp. 5.2.3.22-1). Present maximum temperature of $97^{\circ} \mathrm{F}$ in the waste confirms heat load classification. 
HNF-4232 Rev. 0

\section{Are there process history ties to other sampled tanks?}

Yes. Tanks U-102 and U-105 have similar process histories to that of TX-105. All three tanks were used to store second campaign 242-T Evaporator concentrates. Tank U-105 was also used to store REDOX cladding waste. Evaporator concentrates have limited compositional variation as evidenced from historical evaluation and analysis of tank waste (Agnew et al. 1997b; LoPresti et al. 1997; Hendrickson et al. 1998). REDOX cladding waste has compositional features that enable it to be distinguished from evaporator concentrates (Kupfer et al. 1999). The data from tank U-102 and U-105 do not exhibit behavior that triggers safety screening limits (LMHC 1999 and Appendix A). Because of the degree of similarity in process history, the waste in TX-105 is not expected to exhibit behavior different from that observed in U-102 and U-105.

\section{Is core sampling necessary to show tank is bounded?}

Table B-29 illustrates this statement using the logic chart (Figure B-1).

Table B-29. Safety Issue Logic for Tank TX-105

\begin{tabular}{|l|l|l|l|l|l|l|}
\hline \multicolumn{1}{|c|}{ Issue } & $\begin{array}{c}\text { Organic } \\
\text { Complexant }\end{array}$ & $\begin{array}{c}\text { Organic } \\
\text { Solvent }\end{array}$ & Ferrocyanide & $\begin{array}{c}\text { Flammable } \\
\text { Gas }\end{array}$ & $\begin{array}{c}\text { High } \\
\text { Heat }\end{array}$ & Criticality \\
\hline $\begin{array}{l}\text { Can a case be } \\
\text { demonstrated why } \\
\text { related tanks are } \\
\text { bounding? }\end{array}$ & No & Excluded & Excluded & No & Excluded & Excluded \\
\hline $\begin{array}{l}\text { Are other data (other } \\
\text { than core sampling) } \\
\text { sufficient to address } \\
\text { safety issues? }\end{array}$ & No & Excluded & Excluded & Yes & Excluded & Excluded \\
\hline $\begin{array}{l}\text { Does a preponderance } \\
\text { of evidence demonstrate } \\
\text { sampling is not needed? }\end{array}$ & Yes & Excluded & Excluded & $*$ & Excluded & Excluded \\
\hline
\end{tabular}

Notes:

* = If a previous box provides necessary data for a yes, this logic box does not need to be addressed. 
HNF-4232 Rev. 0

\section{Safety Issues Associated with Tank:}

\section{Organic Complexants:}

Evidence from theoretical considerations, empirical simulant studies, and evaluation of related tanks shows the hazards from organic complexants are adequately controlled. Tank U-105 was categorized as having high concentrations of organic complexant waste. Tank U-102 was categorized as having medium concentrations of organic complexant waste. Tank TX-105 was categorized as having low concentrations of organic complexant waste. Section 3.1.3 and Meacham et al. (1998) describe the organic complexant evaluation more thoroughly. The data from related tanks (U-102 and U-105) indicate that organic complexants are not an issue for the waste in tank TX-105 (Appendix A and Figures A-12 to A-15). Further core sampling and analysis of the waste in this tank will not change the safety classification or the controls applied to tank TX-105 with respect to this safety issue.

\section{Flammable Gas:}

Tank TX-105 is not considered a hazard with respect to flammable gas. Because no surface level fluctuation or barometric response behavior has been observed, the tank is considered Facility Group 3. Facility Group 3 tanks are conservatively postulated to have the potential for small, induced GREs (Funderburke 1997). Tank TX-105 was interim stabilized in 1983. Interim stabilization has been shown to significantly reduce the potential for trapping and periodically releasing flammable gas (Stewart et al. 1996). Other tanks, as shown in Section 3.1.4, have exhibited much stronger indications of flammable gas behavior and have been extensively sampled to provide data to address the safety issue (Johnson et al. 1997). Further sampling and analysis of the waste in tank TX-105 will not change the safety classification of the tank or the controls applied with respect to this safety issue.

\section{Are there any anomalous data that would drive characterization of the tank?}

No. Hodgson (1998) has reviewed the available surveillance data for surface level irregularities and temperature anomalies. None were found. 
Tank Name: TX-106

Tank Parameters:

Tank Type: SST

Ventilation: Passive

Interim stabilized: Yes (1983)
Tank Capacity: 758,000 gallons

Service History: Inactive (1977)

Tank Integrity: Sound

Waste Parameters:

Total waste: $\quad 341,000$ gallons

Waste types: $\quad 341,000$ gallons 242-T Evaporator concentrate (1965-1976)

(Hohl 1998g)

Waste Temperature: $79.5^{\circ} \mathrm{F}$ (March 1998) (LMHC 1999)

Safety Issue Status:

Watch List: None

USQs: $\quad$ Flammable gas (now closed), Organic nitrate (now closed)

Determination of the Safety Issues Associated with this Tank:

- Flammable gas

- Organic nitrate

- Organic solvent

\section{Safety Issues Excluded from This Tank:}

- Ferrocyanide has been excluded. Tank TX-106 is not identified as one of the 18 ferrocyanide tanks (Postma et al. 1994).

- Criticality has been excluded. This tank did not receive any PFP waste (Agnew et al. 1997b). Criticality is not considered to be a credible accident scenario for safe storage of waste in tanks (Noorani 1999, pp. 5.3.2.1-4).

- High heat has been excluded. Estimated thermal load is $1,070 \mathrm{BTU} / \mathrm{hr}$. This is insufficient to classify this tank as a high-heat tank (Kummerer 1995 and Noorani 1999 , pp. 5.2.3.22-1). Past maximum temperature of $79.5^{\circ} \mathrm{F}$ in the waste confirms heat load classification. 
HNF-4232 Rev. 0

\section{Are there process history ties to other sampled tanks?}

Yes. Tanks U-102 and U-105 have similar process histories to that of TX-106. All three tanks were used to store second campaign 242-T Evaporator concentrates. Tank U-105 was also used to store REDOX cladding waste. Evaporator concentrates have limited compositional variation as evidenced from historical evaluation and analysis of tank waste (Agnew et al. 1997b; LoPresti et al. 1997; Hendrickson et al. 1998). REDOX cladding waste has compositional features that enable it to be distinguished from evaporator concentrates (Kupfer et al. 1999). The data from tank U-102 and U-105 do not exhibit behavior that triggers safety screening limits (LMHC 1999 and Appendix A). Because of the degree of similarity in process history, the waste in TX-106 is not expected to exhibit behavior different from that observed in U-102 and U-105.

\section{Is core sampling necessary to show tank is bounded?}

Table B-30 illustrates this statement using the logic chart (Figure B-1).

Table B-30. Safety Issue Logic for Tank TX-106

\begin{tabular}{|l|l|l|l|l|l|l|}
\hline \multicolumn{1}{|c|}{ Issue } & $\begin{array}{c}\text { Organic } \\
\text { Complexant }\end{array}$ & $\begin{array}{c}\text { Organic } \\
\text { Solvent }\end{array}$ & Ferrocyanide & $\begin{array}{c}\text { Flammable } \\
\text { Gas }\end{array}$ & High Heat & Criticality \\
\hline $\begin{array}{l}\text { Can a case be } \\
\text { demonstrated why } \\
\text { related tanks are } \\
\text { bounding? }\end{array}$ & No & No & Excluded & No & Excluded & Excluded \\
\hline $\begin{array}{l}\text { Are other data (other } \\
\text { than core sampling) } \\
\text { sufficient to address } \\
\text { safety issues? }\end{array}$ & No & Yes & Excluded & Yes & Excluded & Excluded \\
\hline $\begin{array}{l}\text { Does a preponderance } \\
\text { of evidence demonstrate } \\
\text { sampling is not needed? }\end{array}$ & Yes & $*$ & Excluded & $*$ & Excluded & Excluded \\
\hline
\end{tabular}

Notes:

* = If a previous box provides necessary data for a yes, this logic box does not need to be addressed. 


\section{Safety Issues Associated with Tank:}

\section{Organic Complexants:}

Evidence from theoretical considerations, empirical simulant studies, and evaluation of related tanks shows the hazards from organic complexants are adequately controlled. Tank U-105 was categorized as having high concentrations of organic complexant waste. Tank U-102 was categorized as having medium concentrations of organic complexant waste. Tank TX-106 was categorized as having low concentrations of organic complexant waste.

Section 3.1.3 and Meacham et al. (1998) describe the organic complexant evaluation more thoroughly. The data from related tanks (U-102 and U-105) indicate that organic complexants are not an issue for the waste in tank TX-106 (Appendix A and Figures A-12 to A-15). Further core sampling and analysis of the waste in this tank will not change the safety classification or the controls applied to tank TX-106 with respect to this safety issue.

\section{Organic Solvents:}

Analytical results show that organic solvents are difficult to ignite, and credible ignition sources have been narrowed to robust energy sources such as lightning strikes and large hot metal cuttings from welding (Cowley et al. 1999). Additional core sampling and analyses are not warranted for TX-106, because additional core sample data will not eliminate the need for controls or further resolve the safety issue.

\section{Flammable Gas:}

Tank TX-106 is not considered a hazard with respect to flammable gas. Because no surface level fluctuation or barometric response behavior has been observed, the tank is considered Facility Group 3. Facility Group 3 tanks are conservatively postulated to have the potential for small, induced GREs (Funderburke 1997). Tank TX-106 was interim stabilized in 1983. Interim stabilization has been shown to significantly reduce the potential for trapping and periodically releasing flammable gas (Stewart et al. 1996). Other tanks, as shown in Section 3.1.4, have exhibited much stronger indications of flammable gas behavior and have been extensively sampled to provide data to address the safety issue (Johnson et al. 1997). Further sampling and analysis of the waste in tank TX-106 will not change the safety classification of the tank or the controls applied with respect to this safety issue.

\section{Are there any anomalous data that would drive characterization of the tank?}

No. Hodgson (1998) has reviewed the available surveillance data for surface level irregularities and temperature anomalies. None were found. 
Tank Name: TX-108

Tank Parameters:

Tank Type: SST

Ventilation: Passive

Interim stabilized: Yes (1983)
Tank Capacity: 758,000 gallons

Service History: Inactive (1977)

Tank Integrity: Sound

Waste Parameters:

Total waste:

Waste types:

134,000 gallons

128,000 gallons 242-T Evaporator concentrate

(1965-1976)

6,000 gallons uranium recovery waste (1956-1965)

(Hohl 1998h)

Waste Temperature: $62.1^{\circ} \mathrm{F}$ (May 1999) (LMHC 1999)

Safety Issue Status:

Watch List: None

USQs: $\quad$ Flammable gas (now closed), Organic nitrate (now closed)

Determination of the Safety Issues Associated with This Tank:

- Flammable gas

- Organic nitrate

- Organic solvent

\section{Safety Issues Excluded from This Tank:}

- Ferrocyanide has been excluded. Tank TX-108 is not identified as one of the 18 ferrocyanide tanks (Postma et al. 1994).

- Criticality has been excluded. This tank did not receive any PFP waste (Agnew et al. 1997b). Criticality is not considered to be a credible accident scenario for safe storage of waste in tanks (Noorani 1999, pp. 5.3.2.1-4).

- High heat has been excluded. Estimated thermal load is 1,390 BTU/hr. This is insufficient to classify this tank as a high-heat tank (Kummerer 1995 and Noorani 1999 , pp. 5.2.3.22-1). Present maximum temperature of $62.1^{\circ} \mathrm{F}$ in the waste confirms heat load classification. 
HNF-4232 Rev. 0

\section{Are there process history ties to other sampled tanks?}

Yes. Tanks U-102, U-105, and BX-109 have process wastes in common with tank TX-108. Tanks U-102 and U-105 have similar process histories to that of TX-108. All three tanks were used to store second campaign 242-T Evaporator concentrates. Tank U-105 was also used to store REDOX cladding waste.

Evaporator concentrates have limited compositional variation as evidenced from historical evaluation and analysis of tank waste (Agnew et al. 1997b; LoPresti et al. 1997; Hendrickson et al. 1998). REDOX cladding waste has compositional features that enable it to be distinguished from evaporator concentrates (Kupfer et al. 1999). The data from tank U-102 and U-105 do not exhibit behavior that triggers safety screening limits (LMHC 1999 and Appendix A). Because of the degree of similarity in process history, the waste in TX-108 is not expected to exhibit behavior different from that observed in U-102 and U-105.

Tank BX-109 has a similar process history to that of TX-108. Both tanks were used to store uranium recovery wastes. The data from tank BX-109 does not exhibit behavior that triggers safety screening limits (LMHC 1999and Appendix A). Because of the degree of similarity in process history, the waste in TX-108 is not expected to exhibit behavior different from that observed in BX-109.

Is core sampling necessary to show tank is bounded?

Table B-31 illustrates this statement using the logic chart (Figure B-1).

Table B-31. Safety Issue Logic for Tank TX-108

\begin{tabular}{|l|l|l|l|l|l|l|}
\hline \multicolumn{1}{|c|}{ Issue } & $\begin{array}{c}\text { Organic } \\
\text { Complexant }\end{array}$ & $\begin{array}{l}\text { Organic } \\
\text { Solvent }\end{array}$ & Ferrocyanide & $\begin{array}{l}\text { Flammable } \\
\text { Gas }\end{array}$ & High Heat & Criticality \\
\hline $\begin{array}{l}\text { Can a case be } \\
\text { demonstrated why } \\
\text { related tanks are } \\
\text { bounding? }\end{array}$ & No & No & Excluded & No & Excluded & Excluded \\
\hline $\begin{array}{l}\text { Are other data (other } \\
\text { than core sampling) } \\
\text { sufficient to address } \\
\text { safety issues? }\end{array}$ & No & Yes & Excluded & Yes & Excluded & Excluded \\
\hline $\begin{array}{l}\text { Does a preponderance } \\
\text { of evidence demonstrate } \\
\text { sampling is not needed? }\end{array}$ & Yes & $*$ & Excluded & $*$ & Excluded & Excluded \\
\hline
\end{tabular}

Notes:

* = If a previous box provides necessary data for a yes, this logic box does not need to be addressed. 


\section{Safety Issues Associated with Tank:}

\section{Organic Complexants:}

Evidence from theoretical considerations, empirical simulant studies, and evaluation of related tanks shows the hazards from organic complexants are adequately controlled. Tank U-105 was categorized as having high concentrations of organic complexant waste. Tank U-102 was categorized as having medium concentrations of organic complexant waste. Tanks BX-109 and TX-108 were classified as having low concentrations of organic complexant waste. Section 3.1.3 and Meacham et al. (1998) describe the organic complexant evaluation more thoroughly. The data from related tanks (U-102, U-105, and $\mathrm{BX}-109)$ indicate that organic complexants are not an issue for the waste in tank TX-108 (Appendix A and Figures A-12 to A-15). Further core sampling and analysis of the waste in this tank will not change the safety classification or the controls applied to tank TX-108 with respect to this safety issue.

\section{Organic Solvents:}

Analytical results show that organic solvents are difficult to ignite, and credible ignition sources have been narrowed to robust energy sources such as lightning strikes and large hot metal cuttings from welding (Cowley et al. 1999). Additional core sampling and analyses are not warranted for TX-108, because additional core sample data will not eliminate the need for controls or further resolve the safety issue.

\section{Flammable Gas:}

Tank TX-108 is not considered a hazard with respect to flammable gas. Because no surface level fluctuation or barometric response behavior has been observed, the tank is considered Facility Group 3. Facility Group 3 tanks are conservatively postulated to have the potential for small, induced GREs (Funderburke 1997). Tank TX-108 was interim stabilized in 1983. Interim stabilization has been shown to significantly reduce the potential for trapping and periodically releasing flammable gas (Stewart et al. 1996). Other tanks, as shown in Section 3.1.4, have exhibited much stronger indications of flammable gas behavior and have been extensively sampled to provide data to address the safety issue (Johnson et al. 1997). Further sampling and analysis of the waste in tank TX-108 will not change the safety classification of the tank or the controls applied with respect to this safety issue.

\section{Are there any anomalous data that would drive characterization of the tank?}

No. Hodgson (1998) has reviewed the available surveillance data for surface level irregularities and temperature anomalies. None were found. 
Tank Name: TX-109

Tank Parameters:

Tank Type: SST

Ventilation: Passive

Interim stabilized: Yes (1983)
Tank Capacity: 758,000 gallons

Service History: Inactive (1977)

Tank Integrity: Sound

Waste Parameters:

Total waste:

Waste types:

384,000 gallons

384,000 gallons T Plant first cycle waste (1950-1954)

(Hohl 1998i)

Waste Temperature: $93.6^{\circ} \mathrm{F}$ (Jan. 1999) (LMHC 1999)

Safety Issue Status:

Watch List: None

USQs: $\quad$ Flammable gas (now closed), Organic nitrate (now closed)

Determination of the Safety Issues Associated with This Tank:

- Flammable gas

- Organic nitrate

- Organic solvent

Safety issues excluded from this tank:

- Ferrocyanide has been excluded. Tank TX-109 is not identified as one of the 18 ferrocyanide tanks (Postma et al. 1994).

- Criticality has been excluded. This tank did not receive any PFP waste (Agnew et al. 1997b). Criticality is not considered to be a credible accident scenario for safe storage of waste in tanks (Noorani 1999, pp. 5.3.2.1-4).

- High heat has been excluded. Estimated thermal load is 2,240 BTU/hr. This is insufficient to classify this tank as a high-heat tank (Kummerer 1995 and Noorani 1999, pp. 5.2.3.22-1). Past maximum temperature of $93.6^{\circ} \mathrm{F}$ in the waste confirms heat load classification. 


\section{Are there process history ties to other sampled tanks?}

Yes. Tanks T-104 and BX-112 have similar process histories to that of TX-109. All three tanks were used to store first cycle waste from the bismuth phosphate process (Agnew et al. 1997b). The data from tanks T-104 and BX-112 do not exhibit behavior that triggers safety screening limits (LMHC 1999 and Appendix A). Because of the degree of similarity in process history, the waste in TX-109 is not expected to exhibit behavior different from that observed in T-104 and $\mathrm{BX}-112$.

\section{Is core sampling necessary to show tank is bounded?}

Table B-32 illustrates this statement using the logic chart (Figure B-1).

Table B-32. Safety Issue Logic for Tank TX-109

\begin{tabular}{|l|l|l|l|l|l|l|}
\hline \multicolumn{1}{|c|}{ Issue } & $\begin{array}{c}\text { Organic } \\
\text { Complexant }\end{array}$ & $\begin{array}{c}\text { Organic } \\
\text { Solvent }\end{array}$ & Ferrocyanide & $\begin{array}{c}\text { Flammable } \\
\text { Gas }\end{array}$ & High Heat & Criticality \\
\hline $\begin{array}{l}\text { Can a case be } \\
\text { demonstrated why } \\
\text { related tanks are } \\
\text { bounding? }\end{array}$ & No & No & Excluded & No & Excluded & Excluded \\
\hline $\begin{array}{l}\text { Are other data (other } \\
\text { than core sampling) } \\
\text { sufficient to address } \\
\text { safety issues? }\end{array}$ & No & Yes & Excluded & Yes & Excluded & Excluded \\
\hline $\begin{array}{l}\text { Does a preponderance } \\
\text { of evidence demonstrate } \\
\text { sampling is not needed? }\end{array}$ & Yes & $*$ & Excluded & $*$ & Excluded & Excluded \\
\hline
\end{tabular}

Notes:

* = If a previous box provides necessary data for a yes, this logic box does not need to be addressed. 


\section{Safety Issues Associated with Tank:}

\section{Organic Complexants:}

Evidence from theoretical considerations, empirical simulant studies, and evaluation of related tanks shows the hazards from organic complexants are adequately controlled. Tank BX-112 was categorized as having medium concentrations of organic complexant waste. Tank T-104 was categorized as having no organic complexant waste. Tank TX-109 was classified as having low concentrations of organic complexant waste. Section 3.1.3 and Meacham et al. (1998) describe the organic complexant evaluation more thoroughly. The data from related tanks (T-104 and BX-112) indicate that organic complexants are not an issue for the waste in tank TX-109 (Appendix A and Figures A-12 to A-15). Further core sampling and analysis of the waste in this tank will not change the safety classification or the controls applied to tank TX-109 with respect to this safety issue.

\section{Organic Solvents:}

Analytical results show that organic solvents are difficult to ignite, and credible ignition sources have been narrowed to robust energy sources such as lightning strikes and large hot metal cuttings from welding (Cowley et al. 1999). Additional core sampling and analyses are not warranted for TX-109, because additional core sample data will not eliminate the need for controls or further resolve the safety issue.

\section{Flammable Gas:}

Tank TX-109 is not considered a hazard with respect to flammable gas. Because no surface level fluctuation or barometric response behavior has been observed, the tank is considered Facility Group 3. Facility Group 3 tanks are conservatively postulated to have the potential for small, induced GREs (Funderburke 1997). Tank TX-109 was interim stabilized in 1983. Interim stabilization has been shown to significantly reduce the potential for trapping and periodically releasing flammable gas (Stewart et al. 1996). Other tanks, as shown in Section 3.1.4, have exhibited much stronger indications of flammable gas behavior and have been extensively sampled to provide data to address the safety issue (Johnson et al. 1997). Further sampling and analysis of the waste in tank TX-109 will not change the safety classification of the tank or the controls applied with respect to this safety issue.

\section{Are there any anomalous data that would drive characterization of the tank?}

No. Hodgson (1998) has reviewed the available surveillance data for surface level irregularities and temperature anomalies. None were found. 
Tank Name: TX-110

Tank Parameters:

Tank Type: SST

Ventilation: Passive

Interim stabilized: Yes (1983)
Tank Capacity: 758,000 gallons

Service History: Inactive (1977)

Tank Integrity： Assumed leaker (1977)

Waste Parameters:

Total waste:

Waste types:

462,000 gallons

425,000 gallons 242-T Evaporator concentrate

(1965-1976)

37,000 gallons T Plant first cycle waste (1950-1954)

(Hohl 1998j)

Waste Temperature: $77.4^{\circ} \mathrm{F}$ (April 1991) (LMHC 1999)

Safety Issue Status:

Watch List: None

USQs: $\quad$ Flammable gas (now closed), Organic nitrate (now closed)

Determination of the Safety Issues Associated with This Tank:

- Flammable gas

- Organic nitrate

- Organic solvent

\section{Safety Issues Excluded from This Tank:}

- Ferrocyanide has been excluded. Tank TX-110 is not identified as one of the 18 ferrocyanide tanks (Postma et al. 1994).

- Criticality has been excluded. This tank did not receive any PFP waste (Agnew et al. 1997b). Criticality is not considered to be a credible accident scenario for safe storage of waste in tanks (Noorani 1999, pp. 5.3.2.1-4).

- High heat has been excluded. Estimated thermal load is 9,840 BTU/hr. This is insufficient to classify this tank as a high-heat tank (Kummerer 1995 and Noorani 1999 , pp. 5.2.3.22-1). Past maximum temperature of $77.4^{\circ} \mathrm{F}$ in the waste confirms heat load classification. 


\section{Are there process history ties to other sampled tanks?}

Yes. Tanks T-104, BX-112, and U-102 all share characteristics with tank TX-110. Tanks T-104 and BX-112 have similar process histories to that of TX-110. All three tanks were used to store first cycle waste from the bismuth phosphate process (Agnew et al. 1997b). The data from tanks T-104 and BX-112 do not exhibit behavior that triggers safety screening limits (LMHC 1999 and Appendix A). Because of the degree of similarity in process history, the waste in TX-110 is not expected to exhibit behavior different from that observed in T-104 and $\mathrm{BX}-112$.

Tank U-102 has a similar process history to that of TX-110. Both tanks were used to store second campaign 242-T Evaporator concentrates. Evaporator concentrates have limited compositional variation as evidenced from historical evaluation and analysis of tank waste (Agnew et al. 1997b; LoPresti et al. 1997; Hendrickson et al. 1998). The data from tank U-102 does not exhibit behavior that triggers safety screening limits (LMHC 1999 and Appendix A). Because of the degree of similarity in process history, the waste in TX-110 is not expected to exhibit behavior different from that observed in U-102.

\section{Is core sampling necessary to show tank is bounded?}

Table B-33 illustrates this statement using the logic chart (Figure B-1).

Table B-33. Safety Issue Logic for Tank TX-110

\begin{tabular}{|l|l|l|l|l|l|l|}
\hline \multicolumn{1}{|c|}{ Issue } & $\begin{array}{c}\text { Organic } \\
\text { Complexant }\end{array}$ & $\begin{array}{l}\text { Organic } \\
\text { Solvent }\end{array}$ & Ferrocyanide & $\begin{array}{l}\text { Flammable } \\
\text { Gas }\end{array}$ & High Heat & Criticality \\
\hline $\begin{array}{l}\text { Can a case be } \\
\text { demonstrated why } \\
\text { related tanks are } \\
\text { bounding? }\end{array}$ & No & No & Excluded & No & Excluded & Excluded \\
\hline $\begin{array}{l}\text { Are other data (other } \\
\text { than core sampling) } \\
\text { sufficient to address } \\
\text { safety issues? }\end{array}$ & No & Yes & Excluded & Yes & Excluded & Excluded \\
\hline $\begin{array}{l}\text { Does a preponderance } \\
\text { of evidence demonstrate } \\
\text { sampling is not needed? }\end{array}$ & Yes & $*$ & Excluded & $*$ & Excluded & Excluded \\
\hline
\end{tabular}

Notes:

* = If a previous box provides necessary data for a yes, this logic box does not need to be addressed. 


\section{Safety Issues Associated with Tank:}

\section{Organic Complexants:}

Evidence from theoretical considerations, empirical simulant studies, and evaluation of related tanks shows the hazards from organic complexants are adequately controlled. Tank BX-112 was categorized as having medium concentrations of organic complexant waste. Tank $\mathrm{T}-104$ was categorized as having no organic complexant waste. Tank TX-110 was classified as having low concentrations of organic complexant waste. Section 3.1.3 and Meacham et al. (1998) describe the organic complexant evaluation more thoroughly. The data from related tanks (T-104 and BX-112) indicate that organic complexants are not an issue for the waste in tank TX-110 (Appendix A and Figures A-12 to A-15). Further core sampling and analysis of the waste in this tank will not change the safety classification or the controls applied to tank TX-110 with respect to this safety issue.

\section{Organic Solvent:}

Analytical results show that organic solvents are difficult to ignite, and credible ignition sources have been narrowed to robust energy sources such as lightning strikes and large hot metal cuttings from welding (Cowley et al. 1999). Additional core sampling and analyses are not warranted for TX-110, because additional core sample data will not eliminate the need for controls or further resolve the safety issue.

\section{Flammable Gas:}

Because no surface level rise or barometric response behavior has been observed, the tank is considered Facility Group 3. Facility Group 3 tanks are conservatively postulated to have the potential for small, induced GREs (Funderburke 1997). Tank TX-110 was interim stabilized in 1983. Interim stabilization has been shown to significantly reduce the potential for trapping and periodically releasing flammable gas (Stewart et al. 1996). Other tanks, as shown in Section 3.1.4, have exhibited much stronger indications of flammable gas behavior and have been extensively sampled to provide data to address the safety issue (Johnson et al. 1997). Further sampling and analysis of the waste in tank TX-110 will not change the safety classification of the tank or the controls applied with respect to this safety issue.

\section{Are there any anomalous data that would drive characterization of the tank?}

No. Hodgson (1998) has reviewed the available surveillance data for surface level irregularities and temperature anomalies. None were found. 
Tank Name: TX-111

Tank Parameters:

Tank Type: SST

Ventilation: Passive

Tank Capacity: 758,000 gallons

Interim stabilized: Yes (1983)

Service History: Inactive (1977)

Tank Integrity: Sound

Waste Parameters:

Total waste:

370,000 gallons

Waste types:

327,000 gallons 242-T Evaporator concentrate

(1965-1976)

43,000 gallons T Plant first cycle waste (1950-1954)

(Hohl 1998k)

Waste Temperature: $78.4^{\circ} \mathrm{F}$ (May 1999) (LMHC 1999)

Safety Issue Status:

Watch List: None

USQs: $\quad$ Flammable gas (now closed), Organic nitrate (now closed)

Determination of the Safety Issues Associated with This Tank:

- Flammable gas

- Organic nitrate

\section{Safety Issues Excluded from This Tank:}

- Ferrocyanide has been excluded. Tank TX-111 is not identified as one of the 18 ferrocyanide tanks (Postma et al. 1994).

- Organic solvent has been excluded. Tank has been demonstrated to not be in scope of organic solvent issue by vapor sampling (Noorani 1999, pp. 5.3.2.15-19). Furthermore, analytical results show that organic solvents are difficult to ignite, and credible ignition sources have been narrowed to robust energy sources such as lightning strikes and large hot metal cuttings from welding (Cowley et al. 1999).

- Criticality has been excluded. This tank did not receive any PFP waste (Agnew et al. 1997b). Criticality is not considered to be a credible accident scenario for safe storage of waste in tanks (Noorani 1999, pp. 5.3.2.1-4).

- High heat has been excluded. Estimated thermal load is 6,160 BTU/hr. This is insufficient to classify this tank as a high-heat tank (Kummerer 1995 and Noorani 1999 , pp. 5.2.3.22-1). Present maximum temperature of $78.4^{\circ} \mathrm{F}$ in the waste confirms heat load classification. 


\section{Are there process history ties to other sampled tanks?}

Yes. Tanks T-104, BX-112, and U-102 all share characteristics with TX-111. Tanks $\mathrm{T}-104$ and $\mathrm{BX}-112$ have similar process histories to that of TX-111. All three tanks were used to store first cycle waste from the bismuth phosphate process (Agnew et al. 1997b). The data from tanks T-104 and BX-112 do not exhibit behavior that triggers safety screening limits (LMHC 1999 and Appendix A). Because of the degree of similarity in process history, the waste in TX-111 is not expected to exhibit behavior different from that observed in T-104 and $\mathrm{BX}-112$.

Tank U-102 has a similar process history to that of TX-111. Both tanks were used to store second campaign 242-T Evaporator concentrates. Evaporator concentrates have limited compositional variation as evidenced from historical evaluation and analysis of tank waste (Agnew et al. 1997b; LoPresti et al. 1997; Hendrickson et al. 1998). The data from tank U-102 does not exhibit behavior that triggers safety screening limits (LMHC 1999 and Appendix A). Because of the degree of similarity in process history, the waste in TX-111 is not expected to exhibit behavior different from that observed in $U-102$.

\section{Is core sampling necessary to show tank is bounded?}

Table B-34 illustrates this statement using the logic chart (Figure B-1).

Table B-34. Safety Issue Logic for Tank TX-111

\begin{tabular}{|l|l|l|l|l|l|l|}
\hline \multicolumn{1}{|c|}{ Issue } & $\begin{array}{c}\text { Organic } \\
\text { Complexant }\end{array}$ & $\begin{array}{c}\text { Organic } \\
\text { Solvent }\end{array}$ & Ferrocyanide & $\begin{array}{c}\text { Flammable } \\
\text { Gas }\end{array}$ & High Heat & Criticality \\
\hline $\begin{array}{l}\text { Can a case be } \\
\text { demonstrated why } \\
\text { related tanks are } \\
\text { bounding? }\end{array}$ & No & Excluded & Excluded & No & Excluded & Excluded \\
\hline $\begin{array}{l}\text { Are other data (other } \\
\text { than core sampling) } \\
\text { sufficient to address } \\
\text { safety issues? }\end{array}$ & No & Excluded & Excluded & No & Excluded & Excluded \\
\hline $\begin{array}{l}\text { Does a preponderance } \\
\text { of evidence demonstrate } \\
\text { sampling is not needed? }\end{array}$ & Yes & Excluded & Excluded & Yes & Excluded & Excluded \\
\hline
\end{tabular}




\section{Safety Issues Associated with Tank:}

\section{Organic Complexants:}

Evidence from theoretical considerations, empirical simulant studies, and evaluation of related tanks shows the risks from organic complexants are bounded, and, thus, the hazards are adequately controlled. Tank T-104 was categorized as having no organic complexant waste. Tanks BX-112 and U-102 were categorized as having medium concentrations of organic complexant waste. Tank TX-111 was also classified as having medium concentrations of organic complexant waste. Section 3.1.3 and Meacham et al. (1998) describe the organic complexant evaluation more thoroughly. The data from related tanks (T-104, BX-112, and U-102) indicate that organic complexants are not an issue for the waste in tank TX-111 (Appendix A and Figures A-12 to A-15). Further core sampling and analysis of the waste in this tank will not change the safety classification or the controls applied to tank TX-111 with respect to this safety issue.

\section{Flammable Gas:}

TX-111 is currently classified as a Facility Group 2 tank. This classification was a result of the finding (Hodgson 1998) that this tank failed the barometric pressure evaluation (BPE) analysis with a $43 \%$ LFL potential based on neutron interstitial liquid level (NILL) readings. A thorough review (Johnson 1996) found that BPE analysis by NILL is not valid, and as a result, is not a satisfactory basis to review the tanks. Recent observations have supported this conclusion since the solids porosity is unknown at the interstitial liquid level and has been observed to decrease over time. The current understanding of the tank structure shows that tank TX-111 is a saltwell pumped tank with a liquid level about 80 inches below the solid surface. Pacific Northwest National Laboratory evaluations (Stewart et al. 1996) show that a tank with this configuration has little chance of producing a GRE because of the volume and strength of the dry over-burden. Tank TX-111 has not been re-evaluated at this time, but a re-evaluation of this tank would produce the conclusions presented above classifying this tank as a Facility Group 3 tank.

\section{Are there any anomalous data that would drive characterization of the tank?}

No. Hodgson (1998) has reviewed the available surveillance data for surface level irregularities and temperature anomalies. None were found. 
Tank Name: TX-112

Tank Parameters:

Tank Type: SST

Ventilation: Passive

Tank Capacity: 758,000 gallons

Interim stabilized: Yes (1983)

Service History: Inactive (1976)

Tank Integrity: Sound

Waste Parameters:

Total waste: 649,000 gallons

Waste types:

625,000 gallons 242-T Evaporator concentrate

(1965-1976)

24,000 gallons 242-T Evaporator concentrate (1951-1953) (Hohl 1.9981)

Waste Temperature: $72.1^{\circ} \mathrm{F}$ (May 1999) (LMHC 1999)

Safety Issue Status:

Watch List: None

USQs: $\quad$ Flammable gas (now closed), Organic nitrate (now closed)

Determination of the Safety Issues Associated with This Tank:

- Flammable gas

- Organic nitrate

- Organic solvent

Safety Issues Excluded from This Tank:

- Ferrocyanide has been excluded. Tank TX-112 is not identified as one of the 18 ferrocyanide tanks (Postma et al. 1994).

- Criticality has been excluded. This tank did not receive any PFP waste (Agnew et al. 1997b). Criticality is not considered to be a credible accident scenario for safe storage of waste in tanks (Noorani 1999, pp. 5.3.2.1-4).

- High heat has been excluded. Estimated thermal load is 9,730 BTU/hr. This is insufficient to classify this tank as a high-heat tank (Kummerer 1995 and Noorani 1999 , pp. 5.2.3.22-1). Present maximum temperature of $72.1^{\circ} \mathrm{F}$ in the waste confirms heat load classification. 


\section{Are there process history ties to other sampled tanks?}

Yes. Tanks U-102, U-105, T-108, and T-109 have process wastes in common with tank TX-112. Tanks U-102 and U-105 have similar process histories to that of TX-112. All three tanks were used to store second campaign 242-T Evaporator concentrates. Tank U-105 was also used to store REDOX cladding waste. Evaporator concentrates have limited compositional variation as evidenced from historical evaluation and analysis of tank waste (Agnew et al. 1997b; LoPresti et al. 1997; Hendrickson et al. 1998). REDOX cladding waste has compositional features that enable it to be distinguished from evaporator concentrates (Kupfer et al. 1999). The data from tank U-102 and U-105 do not exhibit behavior that triggers safety screening limits (LMHC 1999 and Appendix A). Because of the degree of similarity in process history, the waste in TX-112 is not expected to exhibit behavior different from that observed in U-102 and U-105.

Tanks T-108 and T-109 have similar process histories to that of TX-112 as well. All three tanks were used to store first campaign 242-T Evaporator concentrates. Evaporator concentrates have limited compositional variation as evidenced from historical evaluation and analysis of tank waste (Agnew et al. 1997b; LoPresti et al. 1997; Hendrickson et al. 1998). The data from tank T-108 and T-109 do not exhibit behavior that triggers safety screening limits (LMHC 1999 and Appendix A). Because of the degree of similarity in process history, the waste in TX-112 is not expected to exhibit behavior different from that observed in T-108 and $\mathrm{T}-109$.

\section{Is core sampling necessary to show tank is bounded?}

Table B-35 illustrates this statement using the logic chart (Figure B-1).

Table B-35. Safety Issue Logic for Tank TX-112

\begin{tabular}{|l|l|l|l|l|l|l|}
\hline \multicolumn{1}{|c|}{ Issue } & $\begin{array}{c}\text { Organic } \\
\text { Complexant }\end{array}$ & $\begin{array}{l}\text { Organic } \\
\text { Solvent }\end{array}$ & Ferrocyanide & $\begin{array}{l}\text { Flammable } \\
\text { Gas }\end{array}$ & High Heat & Criticality \\
\hline $\begin{array}{l}\text { Can a case be } \\
\text { demonstrated why } \\
\text { related tanks are } \\
\text { bounding? }\end{array}$ & No & No & Excluded & No & Excluded & Excluded \\
\hline $\begin{array}{l}\text { Are other data (other } \\
\text { than core sampling) } \\
\text { sufficient to address } \\
\text { safety issues? }\end{array}$ & No & Yes & Excluded & No & Excluded & Excluded \\
\hline $\begin{array}{l}\text { Does a preponderance } \\
\text { of evidence demonstrate } \\
\text { sampling is not needed? }\end{array}$ & Yes & $*$ & Excluded & Yes & Excluded & Excluded \\
\hline
\end{tabular}

Notes:

* $=$ If a previous box provides necessary data for a yes, this logic box does not need to be addressed. 


\section{Safety Issues Associated with Tank:}

\section{Organic Complexants:}

Evidence from theoretical considerations, empirical simulant studies, and evaluation of related tanks shows the hazards from organic complexants are adequately controlled. Tank U- 105 was categorized as having high concentrations of organic complexant waste. Tank U-102 was categorized as having medium concentrations of organic complexant waste. Tanks T-108 and $\mathrm{T}-109$ were categorized as having low concentrations of organic complexant waste. Tank TX-112 was also classified as having low concentrations of organic complexant waste. Section 3.1.3 and Meacham et al. (1998) describe the organic complexant evaluation more thoroughly. The data from related tanks (U-102, $\mathrm{U}-105, \mathrm{~T}-108$, and $\mathrm{T}-109$ ) indicate that organic complexants are not an issue for the waste in tank TX-112 (Appendix A and Figures A-12 to A-15). Further core sampling and analysis of the waste in this tank will not change the safety classification or the controls applied to tank TX-112 with respect to this safety issue.

\section{Organic Solvent:}

Analytical results show that organic solvents are difficult to ignite, and credible ignition sources have been narrowed to robust energy sources such as lightning strikes and large hot metal cuttings from welding (Cowley et al. 1999). Additional core sampling and analyses are not warranted for TX-112, because additional core sample data will not eliminate the need for controls or further resolve the safety issue.

\section{Flammable Gas:}

TX-112 is currently classified as a Facility Group 2 tank. This classification was a result of the finding (Hodgson 1998) that this tank failed the BPE analysis with a $195 \%$ LFL potential based on NILL readings and failed the Surface Level Rise Evaluation with a $66 \%$ LFL potential based on NILL readings. A thorough review (Johnson 1996) found that BPE analysis by NILL is not valid, and as a result, is not a satisfactory basis to review the tanks. In addition, recent observations have supported the conclusion that the BPE of surface level rise by NILL is not a valid test for flammable gas accumulation since the solids porosity is unknown at the interstitial liquid level and has been observed to decrease over time, thus affecting any NILL readings. The current understanding of the tank structure shows that tank TX-112 is a saltwell pumped tank with a liquid level about 12 inches below the solid surface. Pacific Northwest National Laboratory evaluations (Stewart et al. 1996) show that tank with this configuration has little chance of producing a gas release event because of the volume and strength of the dry over-burden. Tank TX-112 has not been re-evaluated at this time, but a re-evaluation of this tank would produce the conclusions presented above classifying it as a Facility Group 3 tank. 
HNF-4232 Rev. 0

Are there any anomalous data that would drive characterization of the tank?

No. Hodgson (1998) has reviewed the available surveillance data for surface level irregularities and temperature anomalies. None were found. 
Tank Name: TX-113

Tank Parameters:

Tank Type: SST

Ventilation: Passive

Interim stabilized: Yes (1983)
Tank Capacity: 758,000 gallons

Service History: Inactive (1977)

Tank Integrity： Assumed leaker (1974)

Waste Parameters:

Total waste:

607,000 gallons

Waste types:

424,000 gallons 242-T Evaporator concentrate

(1965-1976)

183,000 gallons T Plant first cycle waste (1950-1954)

(Hohl 1998m)

Waste Temperature: $72.5^{\circ} \mathrm{F}$ (May 1999) (LMHC 1999)

Safety Issue Status:

Watch List: None

USQs: $\quad$ Flammable gas (now closed), Organic nitrate (now closed)

Determination of the Safety Issues Associated with This Tank:

- Flammable gas

- Organic nitrate

- Organic solvent

Safety Issues Excluded from This Tank:

- Ferrocyanide has been excluded. Tank TX-113 is not identified as one of the 18 ferrocyanide tanks (Postma et al. 1994).

- Criticality has been excluded. This tank did not receive any PFP waste (Agnew et al. 1997b). Criticality is not considered to be a credible accident scenario for safe storage of waste in tanks (Noorani 1999, pp. 5.3.2.1-4).

- High heat has been excluded. Estimated thermal load is 5,590 BTU/hr. This is insufficient to classify this tank as a high-heat tank (Kummerer 1995 and Noorani 1999 , pp. 5.2.3.22-1). Present maximum temperature of $72.5^{\circ} \mathrm{F}$ in the waste confirms heat load classification. 


\section{Are there process history ties to other sampled tanks?}

Yes. Tanks T-104, BX-112, and U-102 all share characteristics with tank TX-113. Tanks T-104 and BX-112 have similar process histories to that of TX-113. All three tanks were used to store first cycle waste from the bismuth phosphate process (Agnew et al. 1997b). The data from tanks T-104 and BX-112 do not exhibit behavior that triggers safety screening limits (LMHC 1999 and Appendix A). Because of the degree of similarity in process history, the waste in TX-113 is not expected to exhibit behavior different from that observed in T-104 and $\mathrm{BX}-112$.

Tank U-102 has a similar process history to that of TX-113. Both tanks were used to store second campaign 242-T Evaporator concentrates. Evaporator concentrates have limited compositional variation as evidenced from historical evaluation and analysis of tank waste (Agnew et al. 1997b; LoPresti et al. 1997; Hendrickson et al. 1998). The data from tank U-102 does not exhibit behavior that triggers safety screening limits (LMHC 1999 and Appendix A). Because of the degree of similarity in process history, the waste in TX-113 is not expected to exhibit behavior different from that observed in U-102.

\section{Is core sampling necessary to show tank is bounded?}

Table B-36 illustrates this statement using the logic chart (Figure B-1).

Table B-36. Safety Issue Logic for Tank TX-113

\begin{tabular}{|l|l|l|l|l|l|l|}
\hline \multicolumn{1}{|c|}{ Issue } & \multicolumn{1}{|c|}{$\begin{array}{c}\text { Organic } \\
\text { Complexant }\end{array}$} & $\begin{array}{l}\text { Organic } \\
\text { Solvent }\end{array}$ & Ferrocyanide & $\begin{array}{l}\text { Flammable } \\
\text { Gas }\end{array}$ & High Heat & Criticality \\
\hline $\begin{array}{l}\text { Can a case be } \\
\text { demonstrated why } \\
\text { related tanks are } \\
\text { bounding? }\end{array}$ & No & No & Excluded & No & Excluded & Excluded \\
\hline $\begin{array}{l}\text { Are other data (other } \\
\text { than core sampling) } \\
\text { sufficient to address } \\
\text { safety issues? }\end{array}$ & No & Yes & Excluded & No & Excluded & Excluded \\
\hline $\begin{array}{l}\text { Does a preponderance } \\
\text { of evidence demonstrate } \\
\text { sampling is not needed? }\end{array}$ & Yes & $*$ & Excluded & Yes & Excluded & Excluded \\
\hline
\end{tabular}

Notes:

* = If a previous box provides necessary data for a yes, this logic box does not need to be addressed. 


\section{Safety Issues Associated with Tank:}

\section{Organic Complexants:}

Evidence from theoretical considerations, empirical simulant studies, and evaluation of related tanks shows the hazards from organic complexants are adequately controlled. Tank T-104 was categorized as having no organic complexant waste. Tanks BX-112 and U-102 were categorized as having medium concentrations of organic complexant waste. Tank TX-113 was also classified as having medium concentrations of organic complexant waste. Section 3.1.3 and Meacham et al. (1998) describe the organic complexant evaluation more thoroughly. The data from related tanks (T-104, BX-112, and U-102) indicate that organic complexants are not an issue for the waste in tank TX-113 (Appendix A and Figures A-12 to A-15). Further core sampling and analysis of the waste in this tank will not change the safety classification or the controls applied to tank TX-113 with respect to this safety issue.

\section{Organic Solvent:}

Analytical results show that organic solvents are difficult to ignite, and credible ignition sources have been narrowed to robust energy sources such as lightning strikes and large hot metal cuttings from welding (Cowley et al. 1999).

Additional core sampling and analyses are not warranted for TX-113, because additional core sample data will not eliminate the need for controls or further resolve the safety issue.

\section{Flammable Gas:}

TX-113 is currently classified as a Facility Group 2 tank. This classification is a result of the finding (Hodgson 1998) that this tank failed the BPE analysis with a $84 \%$ LFL potential based on NILL readings. A thorough review (Johnson 1996) found that BPE analysis by NILL is not valid, and as a result, is not a satisfactory basis to review the tanks. Recent observations have supported this conclusion since the solids porosity is unknown at the interstitial liquid level and has been observed to decrease over time. The current understanding of the tank structure shows that tank TX-113 is a saltwell pumped tank with a liquid level about 145 inches below the solid surface. Pacific Northwest National Laboratory evaluations (Stewart et al. 1996) show that a tank with this configuration has little chance of producing a gas release event because of the volume and strength of the dry over-burden. Tank TX-113 has not been re-evaluated at this time, but a re-evaluation of this tank would support the conclusions presented above classifying this tank as a Facility Group 3 tank.

\section{Are there any anomalous data that would drive characterization of the tank?}

No. Hodgson (1998) has reviewed the available surveillance data for surface level irregularities and temperature anomalies. None were found. This tank has been sampled recently, October 1998 to May 1999, and analytical data will be available in fiscal year 2000 . 
Tank Name: TX-114

Tank Parameters:

Tank Type: SST

Ventilation: Passive

Tank Capacity: 758,000 gallons

Interim stabilized: Yes (1983)

Service History: Inactive (1976)

Tank Integrity: Assumed leaker (1974)

Waste Parameters:

Total waste:

Waste types:

535,000 gallons

473,000 gallons 242-T Evaporator concentrate

(1965-1976)

58,000 gallons 242-T Evaporator concentrate (1951-1953)

4,000 gallons T Plant first cycle waste (1950-1954)

(Hohl 1998n)

Waste Temperature: $90^{\circ} \mathrm{F}$ (May 1982) (LMHC 1999)

Safety Issue Status:

Watch List: None

USQs: $\quad$ Flammable gas (now closed), Organic nitrate (now closed)

Determination of the Safety Issues Associated with This Tank:

- Flammable gas

- Organic nitrate

- Organic solvent

\section{Safety Issues Excluded from This Tank:}

- Ferrocyanide has been excluded. Tank TX-114 is not identified as one of the 18 ferrocyanide tanks (Postma et al. 1994).

- Criticality has been excluded. This tank did not receive any PFP waste (Agnew et al. 1997b). Criticality is not considered to be a credible accident scenario for safe storage of waste in tanks (Noorani 1999, pp. 5.3.2.1-4).

- High heat has been excluded. Estimated thermal load is approximately $9,810 \mathrm{BTU} / \mathrm{hr}$ from estimated radionuclide inventories. This is insufficient to classify this tank as a high-heat tank (Kummerer 1995 and Noorani 1999, pp. 5.2.3.22-1). Past maximum temperature of $90^{\circ} \mathrm{F}$ in the waste confirms heat load classification. 


\section{Are there process history ties to other sampled tanks?}

Yes. Tanks T-104, BX-112, U-102, T-108, and T-109 have process wastes in common with tank TX-114. Tanks T-104 and BX-112 have similar process histories to that of TX-114. All three tanks were used to store first cycle waste from the bismuth phosphate process (Agnew et al. 1997b). The data from tanks T-104 and BX-112 do not exhibit behavior that triggers safety screening limits (LMHC 1999 and Appendix A). Because of the degree of similarity in process history, the waste in TX-114 is not expected to exhibit behavior different from that observed in T-104 and BX-112.

Tank U-102 has a similar process history to that of TX-114. Both tanks were used to store second campaign 242-T Evaporator concentrates. Evaporator concentrates have limited compositional variation as evidenced from historical evaluation and analysis of tank waste (Agnew et al. 1997b; LoPresti et al. 1997; Hendrickson et al. 1998). The data from tank U-102 does not exhibit behavior that triggers safety screening limits (LMHC 1999 and Appendix A). Because of the degree of similarity in process history, the waste in TX-114 is not expected to exhibit behavior different from that observed in U-102.

Tanks T-108 and T-109 have similar process histories to that of TX-114 as well. All three tanks were used to store first campaign 242-T Evaporator concentrates. Evaporator concentrates have limited compositional variation as evidenced from historical evaluation and analysis of tank waste (Agnew et al. 1997b; LoPresti et al. 1997; Hendrickson et al. 1998). The data from tank T-108 and T-109 do not exhibit behavior that triggers safety screening limits (LMHC 1999and Appendix A). Because of the degree of similarity in process history, the waste in TX-114 is not expected to exhibit behavior different from that observed in T-108 and $\mathrm{T}-109$. 


\section{Is core sampling necessary to show tank is bounded?}

Table B-37 illustrates this statement using the logic chart (Figure B-1).

Table B-37. Safety Issue Logic for Tank TX-114

\begin{tabular}{|l|l|l|l|l|l|l|}
\hline \multicolumn{1}{|c|}{ Issue } & $\begin{array}{c}\text { Organic } \\
\text { Complexant }\end{array}$ & $\begin{array}{c}\text { Organic } \\
\text { Solvent }\end{array}$ & Ferrocyanide & $\begin{array}{l}\text { Flammable } \\
\text { Gas }\end{array}$ & High Heat & Criticality \\
\hline $\begin{array}{l}\text { Can a case be } \\
\text { demonstrated why } \\
\text { related tanks are } \\
\text { bounding? }\end{array}$ & No & No & Excluded & No & Excluded & Excluded \\
\hline $\begin{array}{l}\text { Are other data (other } \\
\text { than core sampling) } \\
\text { sufficient to address } \\
\text { safety issues? }\end{array}$ & No & Yes & Excluded & Yes & Excluded & Excluded \\
\hline $\begin{array}{l}\text { Does a preponderance } \\
\text { of evidence demonstrate } \\
\text { sampling is not needed? }\end{array}$ & Yes & $*$ & Excluded & $*$ & Excluded & Excluded \\
\hline
\end{tabular}

Notes:

* = If a previous box provides necessary data for a yes, this logic box does not need to be addressed.

\section{Safety Issues Associated with Tank:}

\section{Organic Complexants:}

Evidence from theoretical considerations, empirical simulant studies, and evaluation of related tanks shows the hazards from organic complexants are adequately controlled. Tanks BX-112 and U-102 were categorized as having medium concentrations of organic complexant waste. Tanks T-108 and T-109 were categorized as having low concentrations of organic complexant waste. Tank T-104 was classified as having no organic complexant waste. Tank TX-114 was categorized as having low concentrations of organic complexant waste. Section 3.1.3 and Meacham et al. (1998) describe the organic complexant evaluation more thoroughly. The data from related tanks (T-104, BX-112, U-102, $\mathrm{T}-108$, and T-109) indicate that organic complexants are not an issue for the waste in tank TX-114 (Appendix A and Figures A-12 to A-15). Further core sampling and analysis of the waste in this tank will not change the safety classification or the controls applied to tank TX-114 with respect to this safety issue.

\section{Organic Solvent:}

Analytical results show that organic solvents are difficult to ignite, and credible ignition sources have been narrowed to robust energy sources such as lightning strikes and large hot metal cuttings from welding (Cowley et al. 1999). Additional core sampling and analyses are not warranted for TX-114, because 
additional core sample data will not eliminate the need for controls or further resolve the safety issue.

\section{Flammable Gas:}

Because no surface level rise or barometric response behavior has been observed, the tank is considered Facility Group 3. Facility Group 3 tanks are conservatively postulated to have the potential for small, induced GREs (Funderburke 1997). Tank TX-114 was interim stabilized in 1983. Interim stabilization has been shown to significantly reduce the potential for trapping and periodically releasing flammable gas (Stewart et al. 1996). Other tanks, as shown in Section 3.1.4, have exhibited much stronger indications of flammable gas behavior and have been extensively sampled to provide data to address the safety issue (Johnson et al. 1997). Further sampling and analysis of the waste in tank TX-114 will not change the safety classification of the tank or the controls applied with respect to this safety issue.

\section{Are there any anomalous data that would drive characterization of the tank?}

No. Hodgson (1998) has reviewed the available surveillance data for surface level irregularities and temperature anomalies. No contemporary temperature data is available. 
Tank Name: TX-115

Tank Parameters:

Tank Type: SST

Ventilation: Passive

Tank Capacity: 758,000 gallons

Interim stabilized: Yes (1983)

Service History: Inactive (1977)

Tank Integrity: Assumed leaker (1977)

Waste Parameters:

Total waste:

568,000 gallons

Waste types:

568,000 gallons 242-T Evaporator concentrate

(1965-1976)

(Hohl 19980)

Waste Temperature: $70.5^{\circ} \mathrm{F}$ (May 1999) (LMHC 1999)

Safety Issue Status:

Watch List: None

USQs: $\quad$ Flammable gas (now closed), Organic nitrate (now closed)

Determination of the Safety Issues Associated with This Tank:

- Flammable gas

- Organic nitrate

- Organic solvent

\section{Safety Issues Excluded from This Tank:}

- Ferrocyanide has been excluded. Tank TX-115 is not identified as one of the 18 ferrocyanide tanks (Postma et al. 1994).

- Criticality has been excluded. This tank did not receive any PFP waste (Agnew et al. 1997b). Criticality is not considered to be a credible accident scenario for safe storage of waste in tanks (Noorani 1999, pp. 5.3.2.1-4).

- High heat has been excluded. Estimated thermal load is 5,620 BTU/hr. This is insufficient to classify this tank as a high-heat tank (Kummerer 1995 and Noorani 1999, pp. 5.2.3.22-1). Present maximum temperature of $70.5^{\circ} \mathrm{F}$ in the waste confirms heat load classification. 


\section{Are there process history ties to other sampled tanks?}

Yes. Tanks U-102 and U-105 have similar process histories to that of TX-115. All three tanks were used to store second campaign 242-T Evaporator concentrates. Tank U-105 was also used to store REDOX cladding waste.

Evaporator concentrates have limited compositional variation as evidenced from historical evaluation and analysis of tank waste (Agnew et al. 1997b; LoPresti et al. 1997; Hendrickson et al. 1998). REDOX cladding waste has compositional features that enable it to be distinguished from evaporator concentrates (Kupfer et al. 1999). The data from tank U-102 and U-105 do not exhibit behavior that triggers safety screening limits (LMHC 1999 and Appendix A). Because of the degree of similarity in process history, the waste in TX-115 is not expected to exhibit behavior different from that observed in U-102 and U-105.

\section{Is core sampling necessary to show tank is bounded?}

Table B-38 illustrates this statement using the logic chart (Figure B-1).

Table B-38. Safety Issue Logic for Tank TX-115

\begin{tabular}{|l|l|l|l|l|l|l|}
\hline \multicolumn{1}{|c|}{ Issue } & $\begin{array}{c}\text { Organic } \\
\text { Complexant }\end{array}$ & $\begin{array}{c}\text { Organic } \\
\text { Solvent }\end{array}$ & Ferrocyanide & $\begin{array}{l}\text { Flammable } \\
\text { Gas }\end{array}$ & High Heat & Criticality \\
\hline $\begin{array}{l}\text { Can a case be } \\
\text { demonstrated why } \\
\text { related tanks are } \\
\text { bounding? }\end{array}$ & No & No & Excluded & No & Excluded & Excluded \\
\hline $\begin{array}{l}\text { Are other data (other } \\
\text { than core sampling) } \\
\text { sufficient to address } \\
\text { safety issues? }\end{array}$ & No & Yes & Excluded & No & Excluded & Excluded \\
\hline $\begin{array}{l}\text { Does a preponderance } \\
\text { of evidence demonstrate } \\
\text { sampling is not needed? }\end{array}$ & Yes & $*$ & Excluded & Yes & Excluded & Excluded \\
\hline
\end{tabular}

Notes:

* $=$ If a previous box provides necessary data for a yes, this logic box does not need to be addressed.

\section{Safety Issues Associated with Tank:}

\section{Organic Complexants:}

Evidence from theoretical considerations, empirical simulant studies, and evaluation of related tanks shows the hazards from organic complexants are adequately controlled. Tank U-105 was categorized as having high concentrations of organic complexant waste. Tank U-102 was categorized as having medium concentrations of organic complexant waste. Tank TX-115 was classified as having low concentrations of organic complexant waste. 
Section 3.1.3 and Meacham et al. (1998) describe the organic complexant evaluation more thoroughly. The data from related tanks (U-102 and U-105) indicate that organic complexants are not an issue for the waste in tank TX-115 (Appendix A and Figures A-12 to A-15). Further core sampling and analysis of the waste in this tank will not change the safety classification or the controls applied to tank TX-115 with respect to this safety issue.

\section{Organic Solvent:}

Analytical results show that organic solvents are difficult to ignite, and credible ignition sources have been narrowed to robust energy sources such as lightning strikes and large hot metal cuttings from welding (Cowley et al. 1999). Additional core sampling and analyses are not warranted for $\mathrm{TX}-115$, because additional core sample data will not eliminate the need for controls or further resolve the safety issue.

\section{Flammable Gas:}

TX-115 is currently classified as a Facility Group 2 tank. This classification was a result of the finding (Hodgson 1998) that this tank failed the BPE analysis with a 94\% LFL potential based on NILL readings and failed the Surface Level Rise Evaluation with a $45 \%$ LFL potential based on NILL readings. A thorough review (Johnson 1996) found that BPE analysis by NILL is not valid, and as a result, is not a satisfactory basis to review the tanks. In addition, recent observations have supported the conclusion that the BPE of surface level rise by NILL is not a valid test for flammable gas accumulation since the solids porosity is unknown at the interstitial liquid level and has been observed to decrease over time thus affecting any NILL readings. The current understanding of the tank structure shows that tank TX-115 is a saltwell pumped tank with a liquid level about 119 inches below the solid surface. Pacific Northwest National Laboratory evaluations (Stewart et al. 1996) show that a tank with this configuration ahs little chance of producing a gas release event because of the volume and strength of the dry over-burden. Tank TX-115 has not been re-evaluated at this time, but a re-evaluation of this tank would produce the conclusions presented above classifying this tank as a Facility Group 3tank.

\section{Are there any anomalous data that would drive characterization of the tank?}

No. Hodgson (1998) has reviewed the available surveillance data for surface level irregularities and temperature anomalies. None were found. 
Tank Name: TX-116

Tank Parameters:

Tank Type: SST

Ventilation: Passive

Interim stabilized: Yes (1983)
Tank Capacity: 758,000 gallons

Service History: Inactive (1977)

Tank Integrity：Assumed leaker (1977)

Waste Parameters:

Total waste:

Waste types:

631,000 gallons

240,000 gallons 242-T Evaporator concentrate

(1965-1976)

323,000 gallons 242-T Evaporator concentrate (1951-1953)

68,000 gallons of diatomaceous earth (1970)

(Hohl 1998p)

Waste Temperature: Not available. No active sensors in tank (Hanlon 1999)

Safety Issue Status:

Watch List: None

USQs: $\quad$ Flammable gas (now closed), Organic nitrate (now closed)

Determination of the Safety Issues Associated with This Tank:

- Flammable gas

- Organic nitrate

- Organic solvent

Safety Issues Excluded from This Tank:

- Ferrocyanide has been excluded. Tank TX-116 is not identified as one of the 18 ferrocyanide tanks (Postma et al. 1994).

- Criticality has been excluded. This tank did not receive any PFP waste (Agnew et al. 1997b). Criticality is not considered to be a credible accident scenario for safe storage of waste in tanks (Noorani 1999, pp. 5.3.2.1-4).

- High heat has been excluded. Thermal load based on estimated radionuclide content is 5,480 BTU/hr (Hohl 1998p). This is insufficient to classify this tank as a high-heat tank (Kummerer 1995 and Noorani 1999, pp. 5.2.3.22-1).

\section{Are there process history ties to other sampled tanks?}

Yes. Tanks U-102, U-105, T-108, and T-109 have process wastes in common with tank TX-116. Tanks U-102 and U-105 have similar process histories to that 
of TX-116. All three tanks were used to store second campaign 242-T Evaporator concentrates. Tank U-105 was also used to store REDOX cladding waste.

Evaporator concentrates have limited compositional variation as evidenced from historical evaluation and analysis of tank waste (Agnew et al. 1997b; LoPresti et al. 1997; Hendrickson et al. 1998). REDOX cladding waste has compositional features that enable it to be distinguished from evaporator concentrates (Kupfer et al. 1999). The data from tank U-102 and U-105 do not exhibit behavior that triggers safety screening limits (LMHC 1999 and Appendix A). Because of the degree of similarity in process history, the waste in TX-116 is not expected to exhibit behavior different from that observed in U-102 and U-105.

Tanks T-108 and T-109 have similar process histories to that of TX-116 as well. All three tanks were used to store first campaign 242-T Evaporator concentrates. Evaporator concentrates have limited compositional variation as evidenced from historical evaluation and analysis of tank waste (Agnew et al. 1997b; LoPresti et al. 1997; Hendrickson et al. 1998). The data from tank T-108 and T-109 do not exhibit behavior that triggers safety screening limits (LMHC 1999 and Appendix A). Because of the degree of similarity in process history, the waste in TX-116 is not expected to exhibit behavior different from that observed in T-108 and $\mathrm{T}-109$.

\section{Is core sampling necessary to show tank is bounded?}

Table B-39 illustrates this statement using the logic chart (Figure B-1).

Table B-39. Safety Issue Logic for Tank TX-116

\begin{tabular}{|l|l|l|l|l|l|l|}
\hline \multicolumn{1}{|c|}{ Issue } & \multicolumn{1}{c|}{$\begin{array}{c}\text { Organic } \\
\text { Complexant }\end{array}$} & $\begin{array}{c}\text { Organic } \\
\text { Solvent }\end{array}$ & Ferrocyanide & $\begin{array}{c}\text { Flammable } \\
\text { Gas }\end{array}$ & High Heat & Criticality \\
\hline $\begin{array}{l}\text { Can a case be } \\
\text { demonstrated why } \\
\text { related tanks are } \\
\text { bounding? }\end{array}$ & No & No & Excluded & No & Excluded & Excluded \\
\hline $\begin{array}{l}\text { Are other data (other } \\
\text { than core sampling) } \\
\text { sufficient to address } \\
\text { safety issues? }\end{array}$ & No & Yes & Excluded & Yes & Excluded & Excluded \\
\hline $\begin{array}{l}\text { Does a preponderance } \\
\text { of evidence demonstrate } \\
\text { sampling is not needed? }\end{array}$ & Yes & $*$ & Excluded & $*$ & Excluded & Excluded \\
\hline
\end{tabular}

Notes:

* = If a previous box provides necessary data for a yes, this logic box does not need to be addressed. 


\section{Safety Issues Associated with Tank:}

\section{Organic Complexants:}

Evidence from theoretical considerations, empirical simulant studies, and evaluation of related tanks shows the hazards from organic complexants are adequately controlled. Tank U-105 was categorized as having high concentrations of organic complexant waste. Tank U-102 was categorized as having medium concentrations of organic complexant waste. Tanks T-108 and $\mathrm{T}-109$ were categorized as having low concentrations of organic complexant waste. Tank TX-116 was also classified as having low concentrations of organic complexant waste. Section 3.1.3 and Meacham et al. (1998) describe the organic complexant evaluation more thoroughly. The data from related tanks (U-102, $\mathrm{U}-105, \mathrm{~T}-108$, and $\mathrm{T}-109$ ) indicate that organic complexants are not an issue for the waste in tank TX-116 (Appendix A and Figures A-12 to A-15). Further core sampling and analysis of the waste in this tank will not change the safety classification or the controls applied to tank TX-116 with respect to this safety issue.

\section{Organic Solvent:}

Analytical results show that organic solvents are difficult to ignite, and credible ignition sources have been narrowed to robust energy sources such as lightning strikes and large hot metal cuttings from welding (Cowley et al. 1999). Additional core sampling and analyses are not warranted for TX-116, because additional core sample data will not eliminate the need for controls or further resolve the safety issue.

\section{Flammable Gas:}

Tank TX-116 is not considered a hazard with respect to flammable gas. Because no surface level fluctuation or barometric response behavior has been observed, the tank is considered Facility Group 3. Facility Group 3 tanks are conservatively . postulated to have the potential for small, induced GREs (Funderburke 1997). Tank TX-116 was interim stabilized in 1983. Interim stabilization has been shown to significantly reduce the potential for trapping and periodically releasing flammable gas (Stewart et al. 1996). Other tanks, as shown in Section 3.1.4, have exhibited much stronger indications of flammable gas behavior and have been extensively sampled to provide data to address the safety issue (Johnson et al. 1997). Further sampling and analysis of the waste in tank TX-116 will not change the safety classification of the tank or the controls applied with respect to this safety issue. 


\section{Are there any anomalous data that would drive characterization of the tank?}

No. Hodgson (1998) has reviewed the available surveillance data for surface level irregularities and temperature anomalies. There are no contemporary temperature data for this tank. However, tank TX-116 contains 68,000 gallons of diatomaceous earth. Diatomaceous earth was introduced as a means of preventing the tank from leaking. Diatomaceous earth is inert with respect to the flammable gas and organic safety issues. Its composition indicates it has no energetic properties, no flammable gas generation or retention properties, and no alpha content (Buckingham and Metz 1974). 
Tank Name: TX-117

Tank Parameters:

Tank Type: SST

Ventilation: Passive

Interim stabilized: Yes (1983)
Tank Capacity: 758,000 gallons

Service History: Inactive (1977)

Tank Integrity: Assumed leaker (1977)

Waste Parameters:

Total waste:

Waste types:

626,000 gallons

400,000 gallons 242-T Evaporator concentrate

(1965-1976)

197,000 gallons 242-T Evaporator concentrate (1951-1953)

29,000 gallons of diatomaceous earth (1970)

(Hohl 1998q)

Waste Temperature: Not available. No active sensors in tank (Hanlon 1999)

Safety Issue Status:

Watch List: None

USQs: $\quad$ Flammable gas (now closed), Organic nitrate (now closed)

Determination of the Safety Issues Associated with This Tank:

- Flammable gas

- Organic nitrate

- Organic solvent

Safety Issues Excluded from This Tank:

- Ferrocyanide has been excluded. Tank TX-117 is not identified as one of the 18 ferrocyanide tanks (Postma et al. 1994).

- Criticality has been excluded. This tank did not receive any PFP waste (Agnew et al. 1997b). Criticality is not considered to be a credible accident scenario for safe storage of waste in tanks (Noorani 1999, pp. 5.3.2.1-4).

- High heat has been excluded. Thermal load based on estimated radionuclide content is 7,030 BTU/hr (Hohl 1998q). This is insufficient to classify this tank as a high-heat tank (Kummerer 1995 and Noorani 1999, pp. 5.2.3.22-1). 
HNF-4232 Rev. 0

\section{Are there process history ties to other sampled tanks?}

Yes. Tanks U-102, U-105, T-108, and T-109 have process wastes in common with tank TX-117. Tanks U-102 and U-105 have similar process histories to that of TX-117. All three tanks were used to store second campaign 242-T Evaporator concentrates. Tank U-105 was also used to store REDOX cladding waste.

Evaporator concentrates have limited compositional variation as evidenced from historical evaluation and analysis of tank waste (Agnew et al. 1997b; LoPresti et al. 1997; Hendrickson et al. 1998). REDOX cladding waste has compositional features that enable it to be distinguished from evaporator concentrates (Kupfer et al. 1999). The data from tank U-102 and U-105 do not exhibit behavior that triggers safety screening limits (LMHC 1999 and Appendix A). Because of the degree of similarity in process history, the waste in TX-117 is not expected to exhibit behavior different from that observed in U-102 and U-105.

Tanks T-108 and T-109 have similar process histories to that of TX-117 as well. All three tanks were used to store first campaign 242-T Evaporator concentrates. Evaporator concentrates have limited compositional variation as evidenced from historical evaluation and analysis of tank waste (Agnew et al. 1997b; LoPresti et al. 1997; Hendrickson et al. 1998). The data from tank T-108 and T-109 do not exhibit behavior that triggers safety screening limits (LMHC 1999 and Appendix A). Because of the degree of similarity in process history, the waste in TX-117 is not expected to exhibit behavior different from that observed in T-108 and $\mathrm{T}-109$.

Is core sampling necessary to show tank is bounded?

Table B-40 illustrates this statement using the logic chart (Figure B-1).

Table B-40. Safety Issue Logic for Tank TX-117

\begin{tabular}{|l|l|l|l|l|l|l|}
\hline \multicolumn{1}{|c|}{ Issue } & $\begin{array}{c}\text { Organic } \\
\text { Complexant }\end{array}$ & $\begin{array}{l}\text { Organic } \\
\text { Solvent }\end{array}$ & Ferrocyanide & $\begin{array}{l}\text { Flammable } \\
\text { Gas }\end{array}$ & High Heat & Criticality \\
\hline $\begin{array}{l}\text { Can a case be } \\
\text { demonstrated why } \\
\text { related tanks are } \\
\text { bounding? }\end{array}$ & No & No & Excluded & No & Excluded & Excluded \\
\hline $\begin{array}{l}\text { Are other data (other } \\
\text { than core sampling) } \\
\text { sufficient to address } \\
\text { safety issues? }\end{array}$ & No & Yes & Excluded & Yes & Excluded & Excluded \\
\hline $\begin{array}{l}\text { Does a preponderance } \\
\text { of evidence demonstrate } \\
\text { sampling is not needed? }\end{array}$ & Yes & $*$ & Excluded & $*$ & Excluded & Excluded \\
\hline
\end{tabular}

Notes:

* = If a previous box provides necessary data for a yes, this logic box does not need to be addressed. 


\section{Safety Issues Associated with Tank:}

\section{Organic Complexants:}

Evidence from theoretical considerations, empirical simulant studies, and evaluation of related tanks shows the hazards from organic complexants are adequately controlled. Tank U-105 was categorized as having high concentrations of organic complexant waste. Tank U-102 was categorized as having medium concentrations of organic complexant waste. Tanks T-108 and $\mathrm{T}-109$ were categorized as having low concentrations of organic complexant waste. Tank TX-117 was also classified as having low concentrations of organic complexant waste. Section 3.1.3 and Meacham et al. (1998) describe the organic complexant evaluation more thoroughly. The data from related tanks ( $\mathrm{U}-102$, $\mathrm{U}-105, \mathrm{~T}-108$, and T-109) indicate that organic complexants are not an issue for the waste in tank TX-117 (Appendix A and Figures A-12 to A-15). Further core sampling and analysis of the waste in this tank will not change the safety classification or the controls applied to tank TX-117 with respect to this safety issue.

\section{Organic Solvent:}

Analytical results show that organic solvents are difficult to ignite, and credible ignition sources have been narrowed to robust energy sources such as lightning strikes and large hot metal cuttings from welding (Cowley et al. 1999). Additional core sampling and analyses are not warranted for TX-117, because additional core sample data will not eliminate the need for controls or further resolve the safety issue.

\section{Flammable Gas:}

Tank TX-117 is not considered a hazard with respect to flammable gas. Because no surface level fluctuation or barometric response behavior has been observed, the tank is considered Facility Group 3. Facility Group 3 tanks are conservatively postulated to have the potential for small, induced GREs (Funderburke 1997). Tank TX-117 was interim stabilized in 1983. Interim stabilization has been shown to significantly reduce the potential for trapping and periodically releasing flammable gas (Stewart et al. 1996). Other tanks, as shown in Section 3.1.4, have exhibited much stronger indications of flammable gas behavior and have been extensively sampled to provide data to address the safety issue (Johnson et al. 1997). Further sampling and analysis of the waste in tank TX-117 will not change the safety classification of the tank or the controls applied with respect to this safety issue. 
HNF-4232 Rev. 0

Are there any anomalous data that would drive characterization of the tank?

No. Hodgson (1998) has reviewed the available surveillance data for surface level irregularities and temperature anomalies. No contemporary temperature data are available. The last temperature measurement was $97^{\circ} \mathrm{F}$ in 1982 . However, tank TX-117 contains 29,000 gallons of diatomaceous earth. Diatomaceous earth was introduced as a means of preventing the tank from leaking. Its composition indicates it is inert with respect to the flammable gas and organic safety issues. It has no energetic properties, no flammable gas generation or retention properties, and no alpha content (Buckingham and Metz 1974). 
Tank Name: TX-118

Tank Parameters:

Tank Type: SST

Ventilation: Passive

Interim stabilized: Yes (1983)
Tank Capacity: 758,000 gallons

Service History: Inactive (1980)

Tank Integrity: Sound

Waste Parameters:

Total waste:

Waste types:

300,000 gallons

260,000 gallons 242-T Evaporator concentrate

(1965-1976)

6,000 gallons 242-T Evaporator concentrate (1951-1953)

34,500 gallons of $Z$ Plant waste (1976)

(Hohl 1998r)

Waste Temperature: $73.4^{\circ} \mathrm{F}$ (May 1999) (LMHC 1999)

Safety Issue Status:

Watch List: Organic nitrate (now closed)

USQs: $\quad$ Flammable gas (now closed), Organic nitrate (now closed)

Determination of the Safety Issues Associated with This Tank:

- Ferrocyanide

- Criticality

- Flammable gas

- Organic nitrate

Safety Issues Excluded from This Tank:

- Organic solvent has been excluded. Tank has been demonstrated to not be in scope of organic solvent issue by vapor sampling (Noorani 1999, pp. 5.3.2.15-19). Furthermore, analytical results show that organic solvents are difficult to ignite, and credible ignition sources have been narrowed to robust energy sources such as lightning strikes and large hot metal cuttings from welding (Cowley et al. 1999).

- High heat has been excluded. Estimated thermal load is 4,790 BTU/hr. This is insufficient to classify this tank as a high-heat tank (Kummerer 1995 and Noorani 1999 , pp. 5.2.3.22-1). Present maximum temperature of $73.4^{\circ} \mathrm{F}$ in the waste confirms heat load classification. 


\section{Are there process history ties to other sampled tanks?}

Yes. Tanks U-102, U-105, T-108, and T-109 have process wastes in common with tank TX-118. Tanks U-102 and U-105 have similar process histories to that of TX-118. All three tanks were used to store second campaign 242-T Evaporator concentrates. Tank U-105 was also used to store REDOX cladding waste.

Evaporator concentrates have limited compositional variation as evidenced from historical evaluation and analysis of tank waste (Agnew et al. 1997b; LoPresti et al. 1997; Hendrickson et al. 1998). REDOX cladding waste has compositional features that enable it to be distinguished from evaporator concentrates (Kupfer et al. 1999). The data from tank U-102 and U-105 do not exhibit behavior that triggers safety screening limits (LMHC 1999 and Appendix A). Because of the degree of similarity in process history, the waste in TX-118 is not expected to exhibit behavior different from that observed in U-102 and U-105.

Tanks T-108 and T-109 have similar process histories to that of TX-118 as well. All three tanks were used to store first campaign 242-T Evaporator concentrates. Evaporator concentrates have limited compositional variation as evidenced from historical evaluation and analysis of tank waste (Agnew et al. 1997b; LoPresti et al. 1997; Hendrickson et al. 1998). The data from tank T-108 and T-109 do not exhibit behavior that triggers safety screening limits (LMHC 1999 and Appendix A). Because of the degree of similarity in process history, the waste in TX-118 is not expected to exhibit behavior different from that observed in T-108 and $\mathrm{T}-109$.

\section{Is core sampling necessary to show tank is bounded?}

Table B-41 illustrates this statement using the logic chart (Figure B-1).

Table B-41. Safety Issue Logic for Tank TX-118

\begin{tabular}{|l|l|l|l|l|l|l|}
\hline \multicolumn{1}{|c|}{ Issue } & $\begin{array}{c}\text { Organic } \\
\text { Complexant }\end{array}$ & $\begin{array}{l}\text { Organic } \\
\text { Solvent }\end{array}$ & Ferrocyanide & $\begin{array}{c}\text { Flammable } \\
\text { Gas }\end{array}$ & High Heat & Criticality \\
\hline $\begin{array}{l}\text { Can a case be } \\
\text { demonstrated why } \\
\text { related tanks are } \\
\text { bounding? }\end{array}$ & No & No & Yes & No & Excluded & No \\
\hline $\begin{array}{l}\text { Are other data (other } \\
\text { than core sampling) } \\
\text { sufficient to address } \\
\text { safety issues? }\end{array}$ & No & Yes & $*$ & Yes & Excluded & Yes \\
\hline $\begin{array}{l}\text { Does a preponderance } \\
\text { of evidence demonstrate } \\
\text { sampling is not needed? }\end{array}$ & Yes & $*$ & $*$ & $*$ & Excluded & $*$ \\
\hline
\end{tabular}

Notes:

* = If a previous box provides necessary data for a yes, this logic box does not need to be addressed. 


\section{Safety Issues Associated with Tank:}

\section{Ferrocyanide:}

Tank TX-118 was initially identified as one of 18 ferrocyanide tanks (Postma et al. 1994). However, further review of the transfer records (Borsheim and Simpson 1991) showed it never received ferrocyanide waste. Additionally, data from the other ferrocyanide wastes sampled has confirmed it not energetic (see Section B3.2 for more details on the analysis). The ferrocyanide USQ and safety issue have been closed (Meacham 1996).

\section{Criticality:}

This tank received PFP waste (Agnew et al. 1997b). The PFP waste was the last material sent to the tank, and the evaporator concentrate from 242-T had cooled sufficiently to be cohesive. Tank TX-118 has been sampled recently (LMHC 1999). Surface samples taken from this tank confirm the presence of PFP waste. The total alpha concentration of this particular waste is above the safety screening limits, but below the BIO criticality limit (LMHC 1999). The waste on top of tank TX-118 has an average total alpha concentration of $39.5 \mu \mathrm{Ci} / \mathrm{g}$. The concentration is observed to decrease as a function of depth. The top half of the second segment has an average alpha concentration of $10 \mu \mathrm{Ci} / \mathrm{g}$. The bottom half of the second segment has a total alpha concentration of $1.89 \mu \mathrm{Ci} / \mathrm{g}$. Criticality is not considered to be a credible accident scenario for safe storage of waste in tanks (Noorani 1999, pp. 5.3.2.1-4).

\section{Organic Complexants:}

Evidence from theoretical considerations, empirical simulant studies, and evaluation of related tanks shows the hazards from organic complexants are adequately controlled. Tank U-105 was categorized as having high concentrations of organic complexant waste. Tank U-102 was categorized as having medium concentrations of organic complexant waste. Tanks T-108 and $\mathrm{T}-109$ were categorized as having low concentrations of organic complexant waste. Tank TX-118 was also classified as having low concentrations of organic complexant waste. Section 3.1.3 and Meacham et al. (1998) describe the organic complexant evaluation more thoroughly. The data from related tanks (U-102, $\mathrm{U}-105, \mathrm{~T}-108$, and $\mathrm{T}-109$ ) indicate that organic complexants are not an issue for the waste in tank TX-118 (Appendix A and Figures A-12 to A-15). Further core sampling and analysis of the waste in this tank will not change the safety classification or the controls applied to tank TX-118 with respect to this safety issue. 


\section{Organic Solvent:}

Analytical results show that organic solvents are difficult to ignite, and credible ignition sources have been narrowed to robust energy sources such as lightning strikes and large hot metal cuttings from welding (Cowley et al. 1999). Additional core sampling and analyses are not warranted for TX-118, because additional core sample data will not eliminate the need for controls or further resolve the safety issue.

\section{Flammable Gas:}

Because no surface level fluctuation or barometric response behavior has been observed, the tank is considered Facility Group 3. Facility Group 3 tanks are conservatively postulated to have the potential for small, induced GREs (Funderburke 1997). Tank TX-118 was interim stabilized in 1983. Interim stabilization has been shown to significantly reduce the potential for trapping and periodically releasing flammable gas (Stewart et al. 1996). Other tanks, as shown in Section 3.1.4, have exhibited much stronger indications of flammable gas behavior and have been extensively sampled to provide data to address the safety issue (Johnson et al. 1997). Further sampling and analysis of the waste in tank TX-118 will not change the safety classification of the tank or the controls applied with respect to this safety issue.

\section{Are there any anomalous data that would drive characterization of the tank?}

No. Hodgson (1998) has reviewed the available surveillance data for surface level irregularities and temperature anomalies. None were found. This tank is being resampled (May 1999). Analytical data should be available in fiscal year 2000 . 
Tank Name: TY-101

Tank Parameters:

Tank Type: SST

Ventilation: Passive

Interim stabilized: Yes (1983)
Tank Capacity: 758,000 gallons

Service History: Inactive (1977)

Tank Integrity： Assumed leaker (1973)

Waste Parameters:

Total waste:

Waste types:

118,000 gallons

12,000 gallons 242-T Evaporator concentrate

(1951-1953)

106,000 gallons ferrocyanide scavenged $\mathrm{T}$ Plant first cycle waste (1955-1957)

(Higley 1998b)

Waste Temperature: $64.2^{\circ} \mathrm{F}$ (March 1998) (LMHC 1999)

Safety Issue Status:

Watch List: None

USQs: $\quad$ Flammable gas (now closed), Organic nitrate (now closed)

Determination of the Safety Issues Associated with This Tank:

- Flammable gas

- Ferrocyanide

- Organic nitrate

\section{Safety Issues Excluded from This Tank:}

- Organic solvent has been excluded. Tank has been demonstrated to not be in scope of organic solvent issue by vapor sampling (Noorani 1999, pp. 5.3.2.15-19). Furthermore, analytical results show that organic solvents are difficult to ignite, and credible ignition sources have been narrowed to robust energy sources such as lightning strikes and large hot metal cuttings from welding (Cowley et al. 1999).

- Criticality has been excluded. This tank did not receive any PFP waste (Agnew et al. 1997b). Criticality is not considered to be a credible accident scenario for safe storage of waste in tanks (Noorani 1999, pp. 5.3.2.1-4).

- High heat has been excluded. Estimated thermal load is 3,140 BTU/hr. This is insufficient to classify this tank as a high-heat tank (Kummerer 1995 and Noorani 1999 , pp. 5.2.3.22-1). Present maximum temperature of $64.2^{\circ} \mathrm{F}$ in the waste confirms heat load classification. 


\section{Are there process history ties to other sampled tanks?}

Yes. Tanks T-107, T-108, T-109, and TY-104 share characteristics with tank TY-101. Tanks T-107 and TY-104 have similar process histories to that of TY-101. Both tanks were used to store ferrocyanide scavenged first cycle waste from the bismuth phosphate process (Agnew et al. 1997b). The data from tank T-107 and TY-104 do not exhibit behavior that triggers safety screening limits (LMHC 1999 and Appendix A). Because of the degree of similarity in process history, the waste in TY-101 is not expected to exhibit behavior different from that observed in T-107 and TY-104.

Tanks T-108 and T-109 have similar process histories to that of TY-101 as well. All three tanks were used to store first campaign 242-T Evaporator concentrates. Evaporator concentrates have limited compositional variation as evidenced from historical evaluation and analysis of tank waste (Agnew et al. 1997b; LoPresti et al. 1997; Hendrickson et al. 1998). The data from tank T-108 and T-109 do not exhibit behavior that triggers safety screening limits (LMHC 1999 and Appendix A). Because of the degree of similarity in process history, the waste in TY-101 is not expected to exhibit behavior different from that observed in T-108 and $\mathrm{T}-109$.

Core samples were taken from tank TY-101 in 1985 (Weiss and Mauss 1987a). Although not part of the contemporary characterization program, the results are consistent with process knowledge regarding the tank's contents. Relatively low sodium and nitrate concentrations with high phosphorous and transition metal concentrations (particularly bismuth, iron, and nickel) indicate bismuth phosphate and ferrocyanide waste as indicated from Agnew et al. (1997b). 
HNF-4232 Rev. 0

\section{Is core sampling necessary to show tank is bounded?}

Table B-42 illustrates this statement using the logic chart (Figure B-1).

Table B-42. Safety Issue Logic for Tank TY-101

\begin{tabular}{|c|c|c|c|c|c|c|}
\hline Issue & $\begin{array}{c}\text { Organic } \\
\text { Complexant }\end{array}$ & $\begin{array}{l}\text { Organic } \\
\text { Solvent }\end{array}$ & Ferrocyanide & $\begin{array}{c}\text { Flammable } \\
\text { Gas }\end{array}$ & $\begin{array}{l}\text { High } \\
\text { Heat }\end{array}$ & Criticality \\
\hline $\begin{array}{l}\text { Can a case be } \\
\text { demonstrated why } \\
\text { related tanks are } \\
\text { bounding? }\end{array}$ & No & Excluded & Yes & No & Excluded & Excluded \\
\hline $\begin{array}{l}\text { Are other data (other } \\
\text { than core sampling) } \\
\text { sufficient to address } \\
\text { safety issues? }\end{array}$ & No & Excluded & * & Yes & Excluded & Excluded \\
\hline $\begin{array}{l}\text { Does a preponderance } \\
\text { of evidence demonstrate } \\
\text { sampling is not needed? }\end{array}$ & Yes & Excluded & * & * & Excluded & Excluded \\
\hline
\end{tabular}

Notes:

* = If a previous box provides necessary data for a yes, this logic box does not need to be addressed.

\section{Safety Issues Associated with Tank:}

\section{Organic Complexants:}

Evidence from theoretical considerations, empirical simulant studies, and evaluation of related tanks shows the hazards from organic complexants are adequately controlled. Tanks T-107, TY-104, T-108, and T-109 are all categorized as having low concentrations of organic complexant waste. Tank TY-101 was also categorized as having low concentrations of organic complexant waste. Section 3.1.3 and Meacham et al. (1998) describe the organic complexant evaluation more thoroughly. The data from related tanks (T-107, TY-104, T-108, and $\mathrm{T}-109$ ) indicate that organic complexants are not an issue for the waste in tank TY-101 (Appendix A and Figures A-12 to A-15). Further core sampling and analysis of the waste in this tank will not change the safety classification or the controls applied to tank TY-101 with respect to this safety issue.

\section{Ferrocyanide:}

Tank TY-101 is identified as one of 18 ferrocyanide tanks (Postma et al. 1994). However, data from the other ferrocyanide wastes sampled has confirmed it not energetic (see Section B3.2 for more details of the analysis). The ferrocyanide USQ and safety issue have been closed (Meacham 1996). 


\section{Flammable Gas:}

Because no surface level fluctuation or barometric response behavior has been observed, the tank is considered Facility Group 3. Facility Group 3 tanks are conservatively postulated to have the potential for small, induced GREs (Funderburke 1997). Tank TY-101 was interim stabilized in 1983. Interim stabilization has been shown to significantly reduce the potential for trapping and periodically releasing flammable gas (Stewart et al. 1996). Other tanks, as shown in Section 3.1.4, have exhibited much stronger indications of flammable gas behavior and have been extensively sampled to provide data to address the safety issue (Johnson et al. 1997). Further sampling and analysis of the waste in tank TY-101 will not change the safety classification of the tank or the controls applied with respect to this safety issue.

\section{Are there any anomalous data that would drive characterization of the tank?}

No. Hodgson (1998) has reviewed the available surveillance data for surface level irregularities and temperature anomalies. None were found. 
Tank Name: TY-102

Tank Parameters:

Tank Type: SST

Tank Capacity: 758,000 gallons

Ventilation: Passive

Interim stabilized: Yes (1979)

Service History: Inactive (1979)

Tank Integrity: Sound

Waste Parameters:

Total waste:

Waste types:

64,000 gallons

29,000 gallons 242-T Evaporator concentrate

$(1951-1953)$

35,000 gallons 242-T Evaporator concentrate

(1965-1976) (Higley 1998c)

Waste Temperature: $59.2^{\circ} \mathrm{F}$ (May 1999) (LMHC 1999)

\section{Safety Issue Status:}

Watch List: None

USQs: $\quad$ Flammable gas (now closed), Organic nitrate (now closed)

\section{Determination of the Safety Issues Associated with This Tank:}

- Flammable gas

- Organic nitrate

\section{Safety Issues Excluded from This Tank:}

- Ferrocyanide has been excluded. Tank TY-102 is not identified as one of the 18 ferrocyanide tanks (Postma et al. 1994).

- Organic solvent has been excluded. Tank has been demonstrated to not be in scope of organic solvent issue by vapor sampling (Noorani 1999, pp. 5.3.2.15-19). Furthermore, analytical results show that organic solvents are difficult to ignite, and credible ignition sources have been narrowed to robust energy sources such as lightning strikes and large hot metal cuttings from welding (Cowley et al. 1999).

- Criticality has been excluded. This tank did not receive any PFP waste (Agnew et al. 1997b). Criticality is not considered to be a credible accident scenario for safe storage of waste in tanks (Noorani 1999, pp. 5.3.2.1-4).

- High heat has been excluded. Estimated thermal load is 2,710 BTU/hr. This is insufficient to classify this tank as a high-heat tank (Kummerer 1995 and Noorani 1999, pp. 5.2.3.22-1). Present maximum temperature of $59.2^{\circ} \mathrm{F}$ in the waste confirms heat load classification. 


\section{Are there process history ties to other sampled tanks?}

Yes. Tanks U-102, U-105, T-108, and T-109 have process wastes in common with tank TY-102. Tanks U-102 and U-105 have similar process histories to that of TY-102. All three tanks were used to store second campaign 242-T Evaporator concentrates. Tank U-105 was also used to store REDOX cladding waste. Evaporator concentrates have limited compositional variation as evidenced from historical evaluation and analysis of tank waste (Agnew et al. 1997b; LoPresti et al. 1997; Hendrickson et al. 1998). REDOX cladding waste has compositional features that enable it to be distinguished from evaporator concentrates (Kupfer et al. 1999). The data from tank U-102 and U-105 do not exhibit behavior that triggers safety screening limits (LMHC 1999 and Appendix A). Because of the degree of similarity in process history, the waste in TY-102 is not expected to exhibit behavior different from that observed in U-102 and U-105.

Tanks T-108 and T-109 have similar process histories to that of TY-102 as well. All three tanks were used to store first campaign 242-T Evaporator concentrates. Evaporator concentrates have limited compositional variation as evidenced from historical evaluation and analysis of tank waste (Agnew et al. 1997b; LoPresti et al. 1997; Hendrickson et al. 1998). The data from tank T-108 and T-109 do not exhibit behavior that triggers safety screening limits (LMHC 1999 and Appendix A). Because of the degree of similarity in process history, the waste in TY-102 is not expected to exhibit behavior different from that observed in T-108 and $\mathrm{T}-109$.

Core samples were taken from tank TY-102 in 1985 (Weiss and Mauss 1987b). Although not part of the contemporary characterization program, the results are consistent with process knowledge regarding the tank's contents. High sodium, phosphorous, and nitrate concentrations with low transition metal concentrations indicate early evaporator concentrates as indicated from Agnew et al. (1997b). 
Is core sampling necessary to show tank is bounded?

Table B-43 illustrates this statement using the logic chart (Figure B-1).

Table B-43. Safety Issue Logic for Tank TY-102

\begin{tabular}{|l|l|l|l|l|l|l|}
\hline & $\begin{array}{c}\text { Organic } \\
\text { Complexant }\end{array}$ & $\begin{array}{c}\text { Organic } \\
\text { Solvent }\end{array}$ & Ferrocyanide & $\begin{array}{c}\text { Flammable } \\
\text { Gas }\end{array}$ & $\begin{array}{c}\text { High } \\
\text { Heat }\end{array}$ & Criticality \\
\hline $\begin{array}{l}\text { Can a case be } \\
\text { demonstrated why } \\
\text { related tanks are } \\
\text { bounding? }\end{array}$ & No & Excluded & Excluded & No & Excluded & Excluded \\
\hline $\begin{array}{l}\text { Are other data (other } \\
\text { than core sampling) } \\
\text { sufficient to address } \\
\text { safety issues? }\end{array}$ & No & Excluded & Excluded & Yes & Excluded & Excluded \\
\hline $\begin{array}{l}\text { Does a preponderance } \\
\text { of evidence demonstrate } \\
\text { sampling is not needed? }\end{array}$ & Yes & Excluded & Excluded & $*$ & Excluded & Excluded \\
\hline
\end{tabular}

Notes:

* = If a previous box provides necessary data for a yes, this logic box does not need to be addressed.

\section{Safety Issues Associated with Tank:}

\section{Organic Complexants:}

Evidence from theoretical considerations, empirical simulant studies, and evaluation of related tanks shows the hazards from organic complexants are adequately controlled. Tank U- 105 was categorized as having high concentrations of organic complexant waste. Tank $U-102$ was categorized as having medium concentrations of organic complexant waste. Tanks T-108 and T-109 were categorized as having low concentrations of organic complexant waste. Tank TY-102 was also classified as having low concentrations of organic complexant waste. Section 3.1.3 and Meacham et al. (1998) describe the organic complexant evaluation more thoroughly. The data from related tanks (U-102, $\mathrm{U}-105, \mathrm{~T}-108$, and $\mathrm{T}-109$ ) indicate that organic complexants are not an issue for the waste in tank TY-102 (Appendix A and Figures A-12 to A-15). Further core sampling and analysis of the waste in this tank will not change the safety classification or the controls applied to tank TY-102 with respect to this safety issue.

\section{Flammable Gas:}

Because no surface level rise or barometric response behavior has been observed, the tank is considered Facility Group 3. Facility Group 3 tanks are conservatively postulated to have the potential for small, induced GREs (Funderburke 1997). 
Tank TY-102 was interim stabilized in 1979. Interim stabilization has been shown to significantly reduce the potential for trapping and periodically releasing flammable gas (Stewart et al. 1996). Other tanks, as shown in Section 3.1.4, have exhibited much stronger indications of flammable gas behavior and have been extensively sampled to provide data to address the safety issue (Johnson et al. 1997). Further sampling and analysis of the waste in tank TY-102 will not change the safety classification of the tank or the controls applied with respect to this safety issue.

Are there any anomalous data that would drive characterization of the tank?

No. Hodgson (1998) has reviewed the available surveillance data for surface level irregularities and temperature anomalies. None were found. 
Tank Name: TY-103

Tank Parameters:

Tank Type: SST

Ventilation: Passive

Interim stabilized: Yes (1983)
Tank Capacity: 758,000 gallons

Service History: Inactive (1976)

Tank Integrity： Assumed leaker (1973)

Waste Parameters:

Total waste:

Waste types:

162,000 gallons

61,000 gallons uranium recovery waste (1954)

47,000 gallons ferrocyanide scavenged $T$ Plant first cycle waste (1955-1957)

54,000 gallons 242-T Evaporator concentrate

(1965-1976)

(Higley 1998d)

Waste Temperature: $71.4^{\circ} \mathrm{F}$ (May 1999) (LMHC 1999)

Safety Issue Status:

Watch List: None

USQs: $\quad$ Flammable gas (now closed), Organic nitrate (now closed)

Determination of the Safety Issues Associated with This Tank:

- Flammable gas

- Ferrocyanide

- Organic nitrate

- Organic solvent

\section{Safety Issues Excluded from This Tank:}

- Criticality has been excluded. This tank did not receive any PFP waste (Agnew et al. 1997b). Criticality is not considered to be a credible accident scenario for safe storage of waste in tanks (Noorani 1999, pp. 5.3.2.1-4).

- High heat has been excluded. Estimated thermal load is 3,610 BTU/hr. This is insufficient to classify this tank as a high-heat tank (Kummerer 1995 and Noorani 1999 , pp. 5.2.3.22-1). Present maximum temperature of $71.4^{\circ} \mathrm{F}$ in the waste confirms heat load classification.

Are there process history ties to other sampled tanks?

Yes. Tanks U-102, U-105, T-108, T-109, and BX-109 have process wastes in common with tank TY-103. Tanks U-102 and U-105 have similar process histories to that of TY-103. All three tanks were used to store second campaign 
242-T Evaporator concentrates. Tank U-105 was also used to store REDOX cladding waste. Evaporator concentrates have limited compositional variation as evidenced from historical evaluation and analysis of tank waste (Agnew et al. 1997b; LoPresti et al. 1997; Hendrickson et al. 1998). REDOX cladding waste has compositional features that enable it to be distinguished from evaporator concentrates (Kupfer et al. 1999). The data from tank U-102 and U-105 do not exhibit behavior that triggers safety screening limits (LMHC 1999 and Appendix A). Because of the degree of similarity in process history, the waste in TY -103 is not expected to exhibit behavior different from that observed in U-102 and U-105.

Tanks T-107 and TY-104 have similar process histories to that of TY-103. Both tanks were used to store ferrocyanide scavenged first cycle waste from the bismuth phosphate process (Agnew et al. 1997b). The data from tank T-107 and TY-104 do not exhibit behavior that triggers safety screening limits (LMHC 1999 and Appendix A). Because of the degree of similarity in process history, the waste in TY-103 is not expected to exhibit behavior different from that observed in $\mathrm{T}-107$ and $\mathrm{TY}-104$.

Tank BX-109 has a similar process history to that of TY-103. Both tanks were used to store uranium recovery wastes. The data from tank BX-109 does not exhibit behavior that triggers safety screening limits (LMHC 1999 and Appendix A). Because of the degree of similarity in process history, the waste in TY -103 is not expected to exhibit behavior different from that observed in $\mathrm{BX}-109$.

Core samples were taken from tank TY-103 in 1985 (Weiss and Mauss 1987c). Although not part of the contemporary characterization program, the results are consistent with process knowledge regarding the tank's contents. Relatively low sodium and nitrate concentrations with high phosphorous and transition metal concentrations (particularly bismuth, iron, and nickel) indicate bismuth phosphate and ferrocyanide waste as indicated from Agnew et al. (1997b). 


\section{Is core sampling necessary to show tank is bounded?}

Table B-44 illustrates this statement using the logic chart (Figure B-1).

Table B-44. Safety Issue Logic for Tank TY-103

\begin{tabular}{|l|l|l|l|l|l|l|}
\hline \multicolumn{1}{|c|}{ Issue } & $\begin{array}{c}\text { Organic } \\
\text { Complexant }\end{array}$ & $\begin{array}{l}\text { Organic } \\
\text { Solvent }\end{array}$ & Ferrocyanide & $\begin{array}{c}\text { Flammable } \\
\text { Gas }\end{array}$ & High Heat & Criticality \\
\hline $\begin{array}{l}\text { Can a case be } \\
\text { demonstrated why } \\
\text { related tanks are } \\
\text { bounding? }\end{array}$ & No & No & Yes & No & Excluded & Excluded \\
\hline $\begin{array}{l}\text { Are other data (other } \\
\text { than core sampling) } \\
\text { sufficient to address } \\
\text { safety issues? }\end{array}$ & No & Yes & $*$ & Yes & Excluded & Excluded \\
\hline $\begin{array}{l}\text { Does a preponderance } \\
\text { of evidence demonstrate } \\
\text { sampling is not needed? }\end{array}$ & Yes & $*$ & $*$ & $*$ & Excluded & Excluded \\
\hline
\end{tabular}

Notes:

* = If a previous box provides necessary data for a yes, this logic box does not need to be addressed.

\section{Safety Issues Associated with Tank:}

\section{Organic Complexants:}

Evidence from theoretical considerations, empirical simulant studies, and evaluation of related tanks shows the hazards from organic complexants are adequately controlled. Tank U-105 was categorized as having high concentrations of organic complexant waste. Tank U-107 was categorized as having medium concentrations of organic complexant waste. Tanks T-107, TY-104, and BX-109 were categorized as having low concentrations of organic complexant waste. Tank TY-103 was also classified as having low concentrations of organic complexant waste. Section 3.1.3 and Meacham et al. (1998) describe the organic complexant evaluation more thoroughly. The data from related tanks (U-102, U-105, T-107, TY-104, and BX-109) indicate that organic complexants are not an issue for the waste in tank TY-103 (Appendix A and Figures A-12 to A-15). Further core sampling and analysis of the waste in this tank will not change the safety classification or the controls applied to tank TY-103 with respect to this safety issue.

\section{Organic Solvents:}

Analytical results show that organic solvents are difficult to ignite, and credible ignition sources have been narrowed to robust energy sources such as lightning strikes and large hot metal cuttings from welding (Cowley et al. 1999). 
Additional core sampling and analyses are not warranted for TY-103, because additional core sample data will not eliminate the need for controls or further resolve the safety issue.

\section{Ferrocyanide:}

Tank TY-103 is identified as one of 18 ferrocyanide tanks (Postma et al. 1994). However, data from the other ferrocyanide wastes sampled has confirmed it not energetic (see Section B3.2 for more details of the analysis). The ferrocyanide USQ and safety issue have been closed (Meacham 1996).

\section{Flammable Gas:}

Because no surface level rise or barometric response behavior has been observed, the tank is considered Facility Group 3. Facility Group 3 tanks are conservatively postulated to have the potential for small, induced GREs (Funderburke 1997). Tank TY-103 was interim stabilized in 1983. Interim stabilization has been shown to significantly reduce the potential for trapping and periodically releasing flammable gas (Stewart et al. 1996). Other tanks, as shown in Section 3.1.4, have exhibited much stronger indications of flammable gas behavior and have been extensively sampled to provide data to address the safety issue (Johnson et al. 1997). Further sampling and analysis of the waste in tank TY-103 will not change the safety classification of the tank or the controls applied with respect to this safety issue.

\section{Are there any anomalous data that would drive characterization of the tank?}

No. Hodgson (1998) has reviewed the available surveillance data for surface level irregularities and temperature anomalies. None were found. 
Tank Name: TY-105

Tank Parameters:

Tank Type: SST

Ventilation: Passive

Tank Capacity: 758,000 gallons

Interim stabilized: Yes (1983)

Waste Parameters:

Total waste:

231,000 gallons

Waste types:

231,000 gallons uranium recovery waste (1954)

(Higley 1998e)

Waste Temperature: $77.9^{\circ} \mathrm{F}$ (May 1999) (LMHC 1999)

Safety Issue Status:

Watch List: None

USQs: $\quad$ Flammable gas (now closed), Organic nitrate (now closed)

Determination of the Safety Issues Associated with This Tank:

- Flammable gas

- Organic nitrate

- Organic solvent

\section{Safety Issues Excluded from This Tank:}

- Ferrocyanide has been excluded. Tank TY-105 is not identified as one of the 18 ferrocyanide tanks (Postma et al. 1994).

- Criticality has been excluded. This tank did not receive any PFP waste (Agnew et al. 1997b). Criticality is not considered to be a credible accident scenario for safe storage of waste in tanks (Noorani 1999, pp. 5.3.2.1-4).

- High heat has been excluded. Estimated thermal load is 3,520 BTU/hr. This is insufficient to classify this tank as a high-heat tank (Kummerer 1995 and Noorani 1999 , pp. 5.2.3.22-1). Present maximum temperature of $77.9^{\circ} \mathrm{F}$ in the waste confirms heat load classification. 


\section{Are there process history ties to other sampled tanks?}

Yes. Tank BX-109 has a similar process history to that of TY-105. Both tanks were used to store uranium recovery wastes. The data from tank BX-109 does not exhibit behavior that triggers safety screening limits (LMHC 1999 and Appendix A). Because of the degree of similarity in process history, the waste in TY-105 is not expected to exhibit behavior different from that observed in BX109.

Core samples were taken from tank TY-105 in 1985 (Weiss and Mauss 1987d). Although not part of the contemporary characterization program, the results are consistent with process knowledge regarding the tank's contents. Relatively low sodium and nitrate concentrations with high phosphorous and transition metal concentrations (particularly iron and uranium) indicates uranium recovery waste as indicated from Agnew et al. (1997b).

\section{Is core sampling necessary to show tank is bounded?}

Table B-45 illustrates this statement using the logic chart (Figure B-1).

Table B-45. Safety Issue Logic for Tank TY-105

\begin{tabular}{|l|l|l|l|l|l|l|}
\hline \multicolumn{1}{|c|}{ Issue } & $\begin{array}{c}\text { Organic } \\
\text { Complexant }\end{array}$ & $\begin{array}{l}\text { Organic } \\
\text { Solvent }\end{array}$ & Ferrocyanide & $\begin{array}{l}\text { Flammable } \\
\text { Gas }\end{array}$ & High Heat & Criticality \\
\hline $\begin{array}{l}\text { Can a case be } \\
\text { demonstrated why } \\
\text { related tanks are } \\
\text { bounding? }\end{array}$ & No & No & Excluded & No & Excluded & Excluded \\
\hline $\begin{array}{l}\text { Are other data (other } \\
\text { than core sampling) } \\
\text { sufficient to address } \\
\text { safety issues? }\end{array}$ & No & Yes & Excluded & Yes & Excluded & Excluded \\
\hline $\begin{array}{l}\text { Does a preponderance } \\
\text { of evidence demonstrate } \\
\text { sampling is not needed? }\end{array}$ & Yes & $*$ & Excluded & $*$ & Excluded & Excluded \\
\hline
\end{tabular}

Notes:

* = If a previous box provides necessary data for a yes, this logic box does not need to be addressed. 


\section{Safety Issues Associated with Tank:}

\section{Organic Complexants:}

Evidence from theoretical considerations, empirical simulant studies, and evaluation of related tanks shows the hazards from organic complexants are adequately controlled. Tank BX-109 was categorized as having low concentrations of organic complexant waste. TY-105 was categorized as having no organic complexant waste. Section 3.1.3 and Meacham et al. (1998) describe the organic complexant evaluation more thoroughly. The data from BX-109 indicates that organic complexants are not an issue for the waste in tank TY-105 (Appendix A and Figures A-12 to A-15). Further core sampling and analysis of the waste in this tank will not change the safety classification or the controls applied to tank TY-105 with respect to this safety issue.

\section{Organic Solvents:}

Analytical results show that organic solvents are difficult to ignite, and credible ignition sources have been narrowed to robust energy sources such as lightning strikes and large hot metal cuttings from welding (Cowley et al. 1999). Additional core sampling and analyses are not warranted for TY-105, because additional core sample data will not eliminate the need for controls or further resolve the safety issue.

\section{Flammable Gas:}

Because no surface level fluctuation or barometric response behavior has been observed, the tank is considered Facility Group 3. Facility Group 3 tanks are conservatively postulated to have the potential for small, induced GREs (Funderburke 1997). Tank TY-105 was interim stabilized in 1983. Interim stabilization has been shown to significantly reduce the potential for trapping and periodically releasing flammable gas (Stewart et al. 1996). Other tanks, as shown in Section 3.1.4, have exhibited much stronger indications of flammable gas behavior and have been extensively sampled to provide data to address the safety issue (Johnson et al. 1997). Further sampling and analysis of the waste in tank $\mathrm{TY}-105$ will not change the safety classification of the tank or the controls applied with respect to this safety issue.

\section{Are there any anomalous data that would drive characterization of the tank?}

No. Hodgson (1998) has reviewed the available surveillance data for surface level irregularities and temperature anomalies. None were found. 
Tank Name: U-101

Tank Parameters:

Tank Type: SST

Ventilation: Passive

Tank Capacity: 530,000 gallons

Interim stabilized: Yes (1979)

Service History: Inactive (1976)

Tank Integrity: Assumed leaker (1959)

Waste Parameters:

Total waste:

25,000 gallons

Waste types:

25,000 gallons REDOX high level waste (1956-1965)

(Higley 1998f)

Waste Temperature: $63.7^{\circ} \mathrm{F}$ (May 1999) (LMHC 1999)

Safety Issue Status:

Watch List: None

USQs: $\quad$ Flammable gas (now closed), Organic nitrate (now closed)

Determination of the Safety Issues Associated with This Tank:

- Flammable gas

- Organic nitrate

- Organic solvent

\section{Safety Issues Excluded from This Tank:}

- Ferrocyanide has been excluded. Tank U-101 is not identified as one of the 18 ferrocyanide tanks (Postma et al. 1994).

- Criticality has been excluded. This tank did not receive any PFP waste (Agnew et al. 1997b). Criticality is not considered to be a credible accident scenario for safe storage of waste in tanks (Noorani 1999, pp. 5.3.2.1-4).

- High heat has been excluded. Estimated thermal load is 3,830 BTU/hr. This is insufficient to classify this tank as a high-heat tank (Kummerer 1995 and Noorani 1999 , pp. 5.2.3.22-1). Present maximum temperature of $63.7^{\circ} \mathrm{F}$ in the waste confirms heat load classification. 


\section{Are there process history ties to other sampled tanks?}

Yes. Tanks SX-108 and SX-115 have similar process histories to that of U-101. All three tanks were used to store REDOX high level waste. These wastes were produced and sent to these tanks from 1955 to 1967 . The data from tanks SX-108 and SX-115 do not exhibit behavior that triggers safety screening limits (LMHC 1999 and Appendix A). Because of the degree of similarity in process history, the waste in U-101 is not expected to exhibit behavior different from that observed in SX-108 and SX-115.

\section{Is core sampling necessary to show tank is bounded?}

Table B-46 illustrates this statement using the logic chart (Figure B-1).

Table B-46. Safety Issue Logic for Tank U-101

\begin{tabular}{|l|l|l|l|l|l|l|}
\hline \multicolumn{1}{|c|}{ Issue } & \multicolumn{1}{c|}{$\begin{array}{c}\text { Organic } \\
\text { Complexant }\end{array}$} & \multicolumn{1}{c|}{$\begin{array}{c}\text { Organic } \\
\text { Solvent }\end{array}$} & Ferrocyanide & $\begin{array}{c}\text { Flammable } \\
\text { Gas }\end{array}$ & High Heat & Criticality \\
\hline $\begin{array}{l}\text { Can a case be } \\
\text { demonstrated } \\
\text { why related } \\
\text { tanks are } \\
\text { bounding? }\end{array}$ & No & No & Excluded & No & Excluded & Excluded \\
\hline $\begin{array}{l}\text { Are other data } \\
\text { (other than core } \\
\text { sampling) } \\
\text { sufficient to } \\
\text { address safety } \\
\text { issues? }\end{array}$ & No & Yes & Excluded & Yes & Excluded & Excluded \\
\hline $\begin{array}{l}\text { Does a } \\
\text { preponderance } \\
\text { of evidence } \\
\text { demonstrate } \\
\text { sampling is not } \\
\text { needed? }\end{array}$ & Yes
\end{tabular}

Notes:

* = If a previous box provides necessary data for a yes, this logic box does not need to be addressed. 


\section{Safety Issues Associated with Tank:}

\section{Organic Complexants:}

Evidence from theoretical considerations, empirical simulant studies, and evaluation of related tanks shows the hazards from organic complexants are adequately controlled. Tank SX-115 was categorized as having low concentration of organic complexant waste. Tank SX-108 was categorized as having no organic complexant waste. Tank U-101 was categorized as having low concentrations of organic complexant waste. Section 3.1.3 and Meacham et al. (1998) describe the organic complexant evaluation more thoroughly. The data from tanks SX-108 and SX-115 indicates that organic complexants are not an issue for the waste in tank U-101 (Appendix A and Figures A-12 to A-15). Further core sampling and analysis of the waste in this tank will not change the safety classification or the controls applied to tank U-101 with respect to this safety issue.

\section{Organic Solvents:}

Analytical results show that organic solvents are difficult to ignite, and credible ignition sources have been narrowed to robust energy sources such as lightning strikes and large hot metal cuttings from welding (Cowley et al. 1999). Additional core sampling and analyses are not warranted for U-101, because additional core sample data will not eliminate the need for controls or further resolve the safety issue.

\section{Flammable Gas:}

Tank U-101 has less than 110,000 gallons of waste. Therefore, there is not sufficient waste volume to accumulate enough flammable gas to present a hazard (see Section B3.3). This tanks is in Facility Group 3.

\section{Are there any anomalous data that would drive characterization of the tank?}

No. Hodgson (1998) has reviewed the available surveillance data for surface level irregularities and temperature anomalies. None were observed. However, this tank has some unconventional contents-six cask loads of experimental fuel elements, shroud tubes, and samarium "poison" ceramic balls, 1,530 g of 4.5 percent enriched uranium and $6 \mathrm{~g}$ plutonium, $180 \mathrm{Ci}$ of ${ }^{60} \mathrm{Co}$ and $130 \mathrm{Ci}$ of mixed fission products, and slugs with $70 \mathrm{Ci}$ of ${ }^{60} \mathrm{Co}$ (Higley 1998f). 
Tank Name: U-104

Tank Parameters:

Tank Type: SST

Ventilation: Passive

Tank Capacity: 530,000 gallons

Interim stabilized: Yes (1978)

Service History: Inactive (1972)

Tank Integrity: Assumed leaker (1961)

Waste Parameters:

Total waste:

122,000 gallons

Waste types:

43,000 gallons 242-T Evaporator concentrate

(1965-1976)

40,000 gallons REDOX high level waste (1956-1970)

39,000 gallons of diatomaceous earth (1972)

(Higley 1998g)

Waste Temperature: Not available. No active sensors in tank (Hanlon 1999)

Safety Issue Status:

Watch List: None

USQs: $\quad$ Flammable gas (now closed), Organic nitrate (now closed)

Determination of the Safety Issues Associated with This Tank:

- Flammable gas

- Organic nitrate

- Organic solvent

Safety Issues Excluded from This Tank:

- Ferrocyanide has been excluded. Tank U-104 is not identified as one of the 18 ferrocyanide tanks (Postma et al. 1994).

- Criticality has been excluded. This tank did not receive any PFP waste (Agnew et al. 1997b). Criticality is not considered to be a credible accident scenario for safe storage of waste in tanks (Noorani 1999, pp. 5.3.2.1-4).

- High heat has been excluded. Thermal loads based on estimated radionuclide content is $2,590 \mathrm{BTU} / \mathrm{hr}$ (Higley 1998g). This is insufficient to classify this tank as a high-heat tank (Kummerer 1995 and Noorani 1999, pp. 5.2.3.22-1).

Are there process history ties to other sampled tanks?

Yes. Tanks U-102, U-105, SX-108, and SX-115 have process wastes in common with tank U-104. Tanks U-102 and U-105 have similar process histories to that of U-104. All three tanks were used to store second campaign 242-T Evaporator 
concentrates. Tank U-105 was also used to store REDOX cladding waste.

Evaporator concentrates have limited compositional variation as evidenced from historical evaluation and analysis of tank waste (Agnew et al. 1997b; LoPresti et al. 1997; Hendrickson et al. 1998). REDOX cladding waste has compositional features that enable it to be distinguished from evaporator concentrates (Kupfer et al. 1999). The data from tank U-102 and U-105 do not exhibit behavior that triggers safety screening limits (LMHC 1999 and Appendix A). Because of the degree of similarity in process history, the waste in U-104 is not expected to exhibit behavior different from that observed in U-102 and U-105.

Tanks SX-108 and SX-115 have similar process histories to that of U-104. All three tanks were used to store REDOX high level waste. The data from tanks SX-108 and SX-115 do not exhibit behavior that triggers safety screening limits (LMHC 1999 and Appendix A). Because of the degree of similarity in process history, the waste in U-104 is not expected to exhibit behavior different from that observed in SX-108 and SX-115.

\section{Is core sampling necessary to show tank is bounded?}

Table B-47 illustrates this statement using the logic chart (Figure B-1).

Table B-47. Safety Issue Logic for Tank U-104

\begin{tabular}{|l|l|l|l|l|l|l|}
\hline \multicolumn{1}{|c|}{ Issue } & $\begin{array}{c}\text { Organic } \\
\text { Complexant }\end{array}$ & $\begin{array}{l}\text { Organic } \\
\text { Solvent }\end{array}$ & Ferrocyanide & $\begin{array}{c}\text { Flammable } \\
\text { Gas }\end{array}$ & High Heat & Criticality \\
\hline $\begin{array}{l}\text { Can a case be } \\
\text { demonstrated why } \\
\text { related tanks are } \\
\text { bounding? }\end{array}$ & No & Excluded & Excluded & No & Excluded & Excluded \\
\hline $\begin{array}{l}\text { Are other data (other } \\
\text { than core sampling) } \\
\text { sufficient to address } \\
\text { safety issues? }\end{array}$ & No & Excluded & Excluded & Yes & Excluded & Excluded \\
\hline $\begin{array}{l}\text { Does a preponderance } \\
\text { of evidence } \\
\text { demonstrate sampling } \\
\text { is not needed? }\end{array}$ & Yes & Excluded & Excluded & $*$ & Excluded & Excluded \\
\hline
\end{tabular}

Notes:

* = If a previous box provides necessary data for a yes, this logic box does not need to be addressed.

\section{Safety Issues Associated with Tank:}

\section{Organic Complexants:}

Evidence from theoretical considerations, empirical simulant studies, and evaluation of related tanks shows the hazards from organic complexants are adequately controlled. Tank U-105 was categorized as having high 
concentrations of organic complexant waste. Tank U-102 was categorized as having medium concentrations of organic complexant waste. Tank SX-115 was categorized as having low concentration of organic complexant waste. Tank SX-108 was categorized as having no organic complexant waste. Tank U-104 was categorized as having low concentrations of organic complexant waste. Section 3.1.3 and Meacham et al. (1998) describe the organic complexant evaluation more thoroughly. The data from related tanks (U-102, U-105, SX-108 and SX-115) indicates that organic complexants are not an issue for the waste in tank U-104 (Appendix A and Figures A-12 to A-15). Further core sampling and analysis of the waste in this tank will not change the safety classification or the controls applied to tank U-104 with respect to this safety issue.

\section{Organic Solvents}

Analytical results show that organic solvents are difficult to ignite, and credible ignition sources have been narrowed to robust energy sources such as lightning strikes and large hot metal cuttings from welding (Cowley et al. 1999). Additional core sampling and analyses are not warranted for U-104, because additional core sample data will not eliminate the need for controls or further resolve the safety issue.

\section{Flammable Gas:}

Because no surface level fluctuation or barometric response behavior has been observed, the tank is considered Facility Group 3. Facility Group 3 tanks are conservatively postulated to have the potential for small, induced GREs (Funderburke 1997). Tank U-104 was interim stabilized in 1978. Interim stabilization has been shown to significantly reduce the potential for trapping and periodically releasing flammable gas (Stewart et al. 1996). Other tanks, as shown in Section 3.1.4, have exhibited much stronger indications of flammable gas behavior and have been extensively sampled to provide data to address the safety issue (Johnson et al. 1997). Further sampling and analysis of the waste in tank U104 will not change the safety classification of the tank or the controls applied with respect to this safety issue.

\section{Are there any anomalous data that would drive characterization of the tank?}

No. Hodgson (1998) has reviewed the available surveillance data for surface level irregularities and temperature anomalies. There are no contemporary temperature data available for this tank. However, tank U-104 contains 39,000 gallons of diatomaceous earth. Diatomaceous earth was introduced as a means of preventing the tank from leaking. Its composition indicates it is inert with respect to the flammable gas and organic safety issues. It has no energetic properties, no flammable gas generation or retention properties, and no alpha content (Buckingham and Metz 1974). 
Tank Name: U-111

Tank Parameters:

Tank Type: SST

Ventilation: Passive

Interim stabilized: Partial (1982)
Tank Capacity: 530,000 gallons

Service History: Inactive (1980)

Tank Integrity: Sound

Waste Parameters:

Total waste:

Waste types:

329,000 gallons

193,000 gallons 242-S Evaporator concentrate (1978-1980)

110,000 gallons 242-S Evaporator concentrate (1973-1976)

26,000 gallons REDOX high level waste and first-cycle

bismuth phosphate waste mixture (1969)

(Higley 1998h)

Waste Temperature: $77.9^{\circ} \mathrm{F}$ (May 1999) (LMHC 1999)

Safety Issue Status:

Watch List: None

USQs: $\quad$ Flammable gas (now closed), Organic nitrate (now closed)

Determination of the Safety Issues Associated with This Tank:

- Flammable gas

- Organic nitrate

\section{Safety Issues Excluded from This Tank:}

- Ferrocyanide has been excluded. Tank U-111 is not identified as one of the 18 ferrocyanide tanks (Postma et al. 1994).

- Organic solvent has been excluded. Tank has been demonstrated to not be in scope of organic solvent issue by vapor sampling (Noorani 1999, pp. 5.3.2.15-20). Furthermore, analytical results show that organic solvents are difficult to ignite, and credible ignition sources have been narrowed to robust energy sources such as lightning strikes and large hot metal cuttings from welding (Cowley et al. 1999).

- Criticality has been excluded. This tank did not receive any PFP waste (Agnew et al. 1997b). Criticality is not considered to be a credible accident scenario for safe storage of waste in tanks (Noorani 1999, pp. 5.3.2.1-4).

- High heat has been excluded. Estimated thermal load is 5,040 BTU/hr. This is insufficient to classify this tank as a high-heat tank (Kummerer 1995 and Noorani 1999 , pp. 5.2.3.22-1). Present maximum temperature of $77.9^{\circ} \mathrm{F}$ in the waste confirms heat load classification. 


\section{Are there process history ties to other sampled tanks?}

Yes. Tanks S-101, S-102, and U-110 share characteristics with tank U-111. Tanks S-101 and S-102 have similar process histories to that of U-111. All three tanks were used to store first and second campaign 242-S Evaporator concentrates. These wastes were produced and sent to these tanks from 1973 to 1976 and from 1978 to 1980 . Evaporator concentrates have limited compositional variation as evidenced from historical evaluation and analysis of tank waste (Agnew et al. 1997b; LoPresti et al. 1997; Hendrickson et al. 1998). The data from tanks S-101 and S-102 do not exhibit behavior that triggers safety screening limits (LMHC 1999 and Appendix A). Because of the degree of similarity in process history, the waste in U-111 is not expected to exhibit behavior different from that observed in S-101 and S-102.

Tank U-110 also has a similar process history to that of U-111. Both tanks were used to store REDOX high level waste and first-cycle bismuth phosphate wastes. Some solids from U-110 cascaded through to U-111. The data from tank U-110 does not exhibit behavior that triggers safety screening limits (LMHC 1999 and Appendix A). Because of the degree of similarity in process history, the waste in U-111 is not expected to exhibit behavior different from that observed in U-110.

\section{Is core sampling necessary to show tank is bounded?}

Table B-48 illustrates this statement using the logic chart (Figure B-1).

Table B-48. Safety Issue Logic for Tank U-111

\begin{tabular}{|c|c|c|c|c|c|c|}
\hline Issue & $\begin{array}{c}\text { Organic } \\
\text { Complexant }\end{array}$ & $\begin{array}{c}\text { Organic } \\
\text { Solvent }\end{array}$ & Ferrocyanide & $\begin{array}{c}\text { Flammable } \\
\text { Gas }\end{array}$ & High Heat & Criticality \\
\hline $\begin{array}{l}\text { Can a case be } \\
\text { demonstrated } \\
\text { why related } \\
\text { tanks are } \\
\text { bounding? }\end{array}$ & No & No & Excluded & No & Excluded & Excluded \\
\hline $\begin{array}{l}\text { Are other data } \\
\text { (other than core } \\
\text { sampling) } \\
\text { sufficient to } \\
\text { address safety } \\
\text { issues? }\end{array}$ & No & Yes & Excluded & Yes & Excluded & Excluded \\
\hline $\begin{array}{l}\text { Does a } \\
\text { preponderance } \\
\text { of evidence } \\
\text { demonstrate } \\
\text { sampling is not } \\
\text { needed? }\end{array}$ & Yes & $*$ & Excluded & * & Excluded & Excluded \\
\hline
\end{tabular}

Notes:

* = If a previous box provides necessary data for a yes, this logic box does not need to be addressed. 


\section{Safety Issues Associated with Tank:}

\section{Organic Complexants:}

Evidence from theoretical considerations, empirical simulant studies, and evaluation of related tanks shows the hazards from organic complexants are adequate controlled. Tanks S-101 and S-102 were categorized as having medium concentrations of organic complexant waste. Tank U-110 was categorized as having low concentration of organic complexant waste. Tank U-111 was categorized as having high concentrations of organic complexant waste. Section 3.1.3 and Meacham et al. (1998) describe the organic complexant evaluation more thoroughly. The data from related tanks (S-101, S-102, and U-110) indicates that organic complexants are not an issue for the waste in tank U-111 (Appendix A and Figures A-12 to A-15). Further core sampling and analysis of the waste in this tank will not change the safety classification or the controls applied to tank U-111 with respect to this safety issue.

\section{Flammable Gas:}

Tank U-111 has a higher level of risk with respect to the flammable gas issue than 43 of the 45 unsampled tanks. The tank exhibits a surface level rise (Hodgson 1998). Because of this behavior, the tank is considered Facility Group 2. Facility Group 2 tanks are conservatively postulated to have the potential for small spontaneous and large induced GREs (Funderburke 1997). Other tanks, such as AN-105 or AW-101, have exhibited much stronger indications of flammable gas behavior and have been extensively sampled to provide data to address the safety issue. Section 3.1.4 and Johnson et al. (1997) describe the flammable gas data evaluation more thoroughly. Further sampling and analysis of the waste in tank U-111 will not change the safety classification of the tank or the controls applied with respect to this safety issue.

\section{Are there any anomalous data that would drive characterization of the tank?}

No. Hodgson (1998) has reviewed the available surveillance data for surface level irregularities and temperature anomalies. This tank exhibits a surface level rise, and met the criteria established for flammable gas evaluation. This behavior is recognized and understood. Core sampling U-111 will not contribute to resolving the flammable gas safety issue. 


\section{B5.0 REFERENCES:}

Agnew, S. F., R. A. Corbin, J. Boyer, T. B. Duran, K. A. Jurgensen, T. P. Ortiz, B. L. Young, R. Anema, and C. Ungerecht, 1996, History of Organic Carbon in Hanford HLW Tanks: HDW Model, Rev. 3, LA-UR-96-989, Los Alamos National Laboratory, Los Alamos, New

Agnew, S. F., J. Boyer, R. A. Corbin, T. B. Duran, J. R. FitzPatrick, K. A. Jurgensen, T. P. Ortiz, and B. L. Young, 1997a, Hanford Tank Chemical and Radionuclide Inventories: HDW Model Rev. 4, LA-UR-96-3860, Los Alamos National Laboratory, Los Alamos, New Mexico.

Agnew, S. F., R. A. Corbin, T. B. Duran, K. A. Jurgensen, T. P. Ortiz, and B. L. Young, 1997b, Waste Status and Transaction Record Summary (WSTRS Rev. 4), LA-UR-97-311, Rev. 0, Los Alamos National Laboratory, Los Alamos, New Mexico.

Antizzo, J. V., 1995, Documentation of Agreements Reached with the Department of Energy, Richland Operations Office and the Westinghouse Hanford Company on the Path Forward for the Resolution of the Hanford Tanks Criticality Safety Issue, (memorandum to J. E. Kinzer, RL, July 14), U.S. Department of Energy, Washington, D.C.

Borsheim, G. L., and B. C. Simpson, 1991, An Assessment of the Inventories of the Inventories of the Ferrocyanide Watchlist Tanks, WHC-SD-WM-ER-133, Rev. 0, Westinghouse Hanford Company, Richland, Washington.

Braddy Raap, M. C., and T. S. Vail, 1998, TWRS Nuclear Criticality Safety Corrective Action Plan, HNF-2927, Rev. 1, DE\&S Hanford, Inc., Richland, Washington.

Bratzel, D. R., W. W. Schulz, and R. Vornehm, 1996, Tank Farm Nuclear Criticality Review, WHC-SD-WM-TI-725, Rev. 0, Westinghouse Hanford Company, Richland, Washington.

Braun, D. J., L. D. Muhlestein, T. B. Powers, and M. D. Zentner, 1994, High-Level Waste Tank Subcriticality Safety Assessment, WHC-SD-WM-SARR-003, Rev. 0, Westinghouse Hanford Company, Richland, Washington, pp. B-9 to B-20.

Brown, T. M., 1998, High Priority Tank Sampling and Analysis Report, HNF-2337, Rev. 1, Lockheed Martin Hanford Corporation, Richland, Washington.

Buckingham, J. S., and W. P. Metz, 1974, Characterization of the Effects of Diatomaceous Earth Additions to Hanford Wastes, ARH-CD-222, Atlantic Richfield Hanford Company, Richland, Washington. 
Byers, S. M., "TWRS Nuclear Criticality Safety Program Assessment," (letter to T. C. Geer, DESH, May 11), Lockheed Martin Hanford Corporation, Richland, Washington.

Chen, G., T. A. Ferrryman, K. M. Remund, S. A. Hartley, F. Gao, C. A. LoPresti, T. J. DeForest, J. G. Hill, C. A. Weier, B. G. Amidan, D. K. Gemeinhart, and B. C. Simpson, 1998, Methodology for Uncertainty Estimation of Hanford Tank Chemical and Radionuclide Inventories and Concentrations, PNNL-11842, Pacific Northwest National Laboratory, Richland, Washington.

Cowley, W. L., J. E. Meacham, J. M. Grigsby, and A. K. Postma, 1999, Organic Solvent Topical Report, HNF-4240, Rev. 0, Fluor Daniel Hanford, Inc., Richland, Washington.

Conway, J. T., 1993, " Defense Nuclear Facilities Safety Board Recommendation 93-5 to the Secretary of Energy," July 19, 1993.

Dineen, G. A., J. E. McEwen, R. W. Kupp, S. N. Maruvada, R. C. Nelson, and E. P Owen, 1996, Safety Evaluation Report, Tank Waste Remediation System Basis for Interim Operation, TWRS-RT-SER-01, U. S. Department of Energy Richland Operations Office, TWRS Office, Richland, Washington.

DOE-RL, 1998, Completion of Hanford Federal Facility Agreement and Consent Order Milestone M-40-09, "Close All Unreviewed Safety Questions for Double Shell and Single Shell Tanks", Letter 98-SCD-125, from G. H. Sanders to Washington State Department of Ecology, U.S. Department of Energy, Richland, Washington.

Ecology, EPA, and DOE, 1997, Hanford Federal Facility Agreement and Consent Order, as amended, Washington State Department of Ecology, U.S. Environmental Protection Agency, and U.S. Department of Energy, Olympia, Washington.

Field, J. G., 1998, Tank-by-Tank Safety Status Evaluation, HNF-2177, Rev. 0B, Lockheed Martin Hanford Corporation, Richland, Washington.

Funderburke, W. M., 1997, Transmittal of Revision 1 to Tank Waste Remediation System East and West Tank Farms Standing Order 97-01, "Compensatory Actions for Open Discovery Unreviewed Safety Questions (USQ)", (Letter LMHC-9752540A R1 to A. M Umek, April 29), Lockheed Martin Hanford Corporation, Richland, Washington.

Hanlon, B. M., 1999, Waste Tank Summary Report for Month Ending January 31, 1999, HNF-EP-0182-130, Lockheed Martin Hanford Corporation, Richland, Washington.

Harmsen, R. W., R. A. Watrous, J. W. Cammann, M. J. Kupfer, S. L. Lambert, 1998, Hanford Defined Waste Limitations and Improvements, HNF-3273, Rev. 0A, Lockheed Martin Hanford Corporation, Richland, Washington. 
Hendrickson, D. W., 1998a, Preliminary Tank Characterization Report for Single-shell Tank 241-SX-104, HNF-SD-WM-ER-643, Rev. 0A, Lockheed Martin Hanford Corporation, Richland, Washington.

Hendrickson, D. W., 1998b, Preliminary Tank Characterization Report for Single-shell Tank 241-SX-107, HNF-SD-WM-ER-671, Rev. 0A, Lockheed Martin Hanford Corporation, Richland, Washington.

Hendrickson, D. W., 1998c, Preliminary Tank Characterization Report for Single-shell Tank 241-SX-109, HNF-SD-WM-ER-706, Rev. 0A, Lockheed Martin Hanford Corporation, Richland, Washington.

Hendrickson, D. W., 1998d, Preliminary Tank Characterization Report for Single-shell Tank 241-SX-110, HNF-SD-WM-ER-681, Rev. 0A, Lockheed Martin Hanford Corporation, Richland, Washington.

Hendrickson, D. W., 1998e, Preliminary Tank Characterization Report for Single-shell Tank 241-SX-111, HNF-SD-WM-ER-682, Rev. 0A, Lockheed Martin Hanford Corporation, Richland, Washington.

Hendrickson, D. W., 1998f, Preliminary Tank Characterization Report for Single-shell Tank 241-SX-112, HNF-SD-WM-ER-683, Rev. OA, Lockheed Martin Hanford Corporation, Richland, Washington.

Hendrickson, D. W., 1998g, Preliminary Tank Characterization Report for Single-shell Tank 241-SX-114, HNF-SD-WM-ER-707, Rev. 0A, Lockheed Martin Hanford Corporation, Richland, Washington.

Hendrickson, D. W, D. E. Place, G. T. MacLean, and S. L. Lambert, 1998, Best Basis Wash and Leach Factor Analysis, HNF-3157, Rev. O-B, Lockheed Martin Hanford Corporation, Richland, Washington.

Higley, B. A., 1998a, Preliminary Tank Characterization Report for Single-shell Tank 241-B-105, HNF-SD-WM-ER-722, Rev. 0A, Lockheed Martin Hanford Corporation, Richland, Washington.

Higley, B. A., 1998b, Preliminary Tank Characterization Report for Single-shell Tank 241-TY-101, HNF-SD-WM-ER-646, Rev. 0A, Lockheed Martin Hanford Corporation, Richland, Washington.

Higley, B. A., 1998c, Preliminary Tank Characterization Report for Single-shell Tank 241-TY-102, HNF-SD-WM-ER-719, Rev. 0A, Lockheed Martin Hanford Corporation, Richland, Washington. 
Higley, B. A., 1998d, Preliminary Tank Characterization Report for Single-shell Tank 241-TY-103, HNF-SD-WM-ER-703, Rev. OA, Lockheed Martin Hanford Corporation, Richland, Washington

Higley, B. A., 1998e, Preliminary Tank Characterization Report for Single-shell Tank 241-TY-105, HNF-SD-WM-ER-652, Rev. 0A, Lockheed Martin Hanford Corporation, Richland, Washington.

Higley, B. A., 1998f, Preliminary Tank Characterization Report for Single-shell Tank 241-U-101, HNF-SD-WM-ER-732, Rev. 0A, Lockheed Martin Hanford Corporation, Richland, Washington.

Higley, B. A., 1998g, Preliminary Tank Characterization Report for Single-shell Tank 241-U-104, HNF-SD-WM-ER-650, Rev. 0A, Lockheed Martin Hanford Corporation, Richland, Washington.

Higley, B. A., 1998h, Preliminary Tank Characterization Report for Single-shell Tank 241-U-111, HNF-SD-WM-ER-713, Rev. 0A, Lockheed Martin Hanford Corporation, Richland, Washington.

Hodgson, K. M., 1998, Evaluation of Hanford Tanks for Trapped Gas, WHC-SD-WM-ER-526, Rev. 1D, Westinghouse Hanford Company, Richland, Washington

Hohl, T. M., 1998a, Preliminary Tank Characterization Report for Single-shell Tank 241-T-101, HNF-SD-WM-ER-710, Rev. 0A, Lockheed Martin Hanford Corporation, Richland, Washington.

Hohl, T. M., 1998b, Preliminary Tank Characterization Report for Single-shell Tank 241-T-103, HNF-SD-WM-ER-725, Rev. 0A, Lockheed Martin Hanford Corporation, Richland, Washington.

Hohl, T. M., 1998c, Preliminary Tank Characterization Report for Single-shell Tank 241-TX-101, HNF-SD-WM-ER-689, Rev. 0A, Lockheed Martin Hanford Corporation, Richland, Washington.

Hohl, T. M., 1998d, Preliminary Tank Characterization Report for Single-shell Tank 241-TX-102, HNF-SD-WM-ER-654, Rev. 0A, Lockheed Martin Hanford Corporation, Richland, Washington.

Hohl, T. M., 1998e, Preliminary Tank Characterization Report for Single-shell Tank 241-TX-103, HNF-SD-WM-ER-704, Rev, 0A, Lockheed Martin Hanford Corporation, Richland, Washington. 
Hohl, T. M., 1998f, Preliminary Tank Characterization Report for Single-shell Tank 241-TX-105, HNF-SD-WM-ER-655, Rev. 0A, Lockheed Martin Hanford Corporation, Richland, Washington.

Hohl, T. M., 1998g, Preliminary Tank Characterization Report for Single-shell Tank 241-TX-106, HNF-SD-WM-ER-656, Rev. 0A, Lockheed Martin Hanford Corporation, Richland, Washington.

Hohl, T. M., 1998h, Preliminary Tank Characterization Report for Single-shell Tank 241-TX-108, HNF-SD-WM-ER-717, Rev. 0A, Lockheed Martin Hanford Corporation, Richland, Washington.

Hohl, T. M., 1998i, Preliminary Tank Characterization Report for Single-shell Tank 241-TX-109, HNF-SD-WM-ER-640, Rev. 0A, Lockheed Martin Hanford Corporation, Richland, Washington.

Hohl, T. M., 1998j, Preliminary Tank Characterization Report for Single-shell Tank 241-TX-110, HNF-SD-WM-ER-658, Rev. 0A, Lockheed Martin Hanford Corporation, Richland, Washington.

Hohl, T. M., 1998k, Preliminary Tank Characterization Report for Single-shell Tank 241-TX-111, HNF-SD-WM-ER-659, Rev. 0A, Lockheed Martin Hanford Corporation, Richland, Washington.

Hohl, T. M., 19981, Preliminary Tank Characterization Report for Single-shell Tank 241-TX-112, HNF-SD-WM-ER-715, Rev. OA, Lockheed Martin Hanford Corporation, Richland, Washington.

Hohl, T. M., 1998m, Preliminary Tank Characterization Report for Single-shell Tank 241-TX-113, HNF-SD-WM-ER-716, Rev. OA, Lockheed Martin Hanford Corporation, Richland, Washington.

Hohl, T. M., 1998n, Preliminary Tank Characterization Report for Single-shell Tank 241-TX-114, HNF-SD-WM-ER-708, Rev. OA, Lockheed Martin Hanford Corporation, Richland, Washington.

Hohl, T. M., 1998o, Preliminary Tank Characterization Report for Single-shell Tank 241-TX-115, HNF-SD-WM-ER-657, Rev. OA, Lockheed Martin Hanford Corporation, Richland, Washington.

Hohl, T. M., 1998p, Preliminary Tank Characterization Report for Single-shell Tank 241-TX-116, HNF-SD-WM-ER-705, Rev. 0A, Lockheed Martin Hanford Corporation, Richland, Washington. 
Hohl, T. M., 1998q, Preliminary Tank Characterization Report for Single-shell Tank 241-TX-117, HNF-SD-WM-ER-711, Rev. 0A, Lockheed Martin Hanford Corporation, Richland, Washington.

Hohl, T. M., 1998r, Preliminary Tank Characterization Report for Single-shell Tank 241-TX-118, HNF-SD-WM-ER-718, Rev. 0A, Lockheed Martin Hanford Corporation, Richland, Washington.

Hopkins, J. D., 1996, Methodology for Flammable Gas Evaluations, WHC-SD-WM-TI-724 Rev. 1, Westinghouse Hanford Company, Richland, Washington

Johnson, G. D., 1996, Evaluation of Recommendation for Addition of Tanks to the Flammable Gas Watch List, WHC-SD-WM-ER-594, Rev. 0, Westinghouse Hanford Company, Richland, Washington.

Johnson, G. D., W. B. Barton, J. W. Brothers, S. A. Bryan, P. A. Gauglitz, R. C. Hill, L. R. Pederson, C. W. Stewart, L. H. Stock, 1997, Flammable Gas Project Topical Report, HNF-SP-1 193, Rev. 2, DE\&S Hanford, Inc., Richland, Washington.

Kummerer, M. 1995, Heat Removal Characteristics of Waste Storage Tanks, WHC-SD-WM-SARR-010, Rev. 1.0, Westinghouse Hanford Company, Richland, Washington.

Kupfer, M. J., A. L. Boldt, B. A. Higley, K. M. Hodgson, L. W. Shelton, B. C. Simpson, R. A. Watrous, S. L. Lambert, D. E. Place, R. M. Orme, G. L. Borsheim, N. G. Colton, M. D. LeClair, R. T. Winward, and W. W. Schulz, 1999, Standard Inventories of Chemicals and Radionuclides in Hanford Site Tank Wastes, HNF-SD-WM-TI-740, Rev. 0C, Lockheed Martin Hanford Corp. for Fluor Daniel Hanford, Inc., Richland, Washington.

Lambert, S. L., 1998a, Preliminary Tank Characterization Report for Single-shell Tank 241-A-103, HNF-SD-WM-ER-709, Rev. 0A, Lockheed Martin Hanford Corporation, Richland, Washington.

Lambert, S. L., 1998b, Preliminary Tank Characterization Report for Single-shell Tank 241-A-104, HNF-SD-WM-ER-666, Rev. 0A, Lockheed Martin Hanford Corporation, Richland, Washington.

Lambert, S. L., 1998c, Preliminary Tank Characterization Report for Single-shell Tank 241-A-105, HNF-SD-WM-ER-667, Rev. 0A, Lockheed Martin Hanford Corporation, Richland, Washington. 
Lambert, S. L., 1998d, Preliminary Tank Characterization Report for Single-shell Tank 241-A-106, HNF-SD-WM-ER-721, Rev. 0A, Lockheed Martin Hanford Corporation, Richland, Washington.

Lambert, S. L., 1998e, Preliminary Tank Characterization Report for Single-shell Tank 241-BX-102, HNF-SD-WM-ER-724, Rev. 0A, Lockheed Martin Hanford Corporation, Richland, Washington.

Lambert, S. L., 1998f, Preliminary Tank Characterization Report for Single-shell Tank 241-BY-105, WHC-SD-WM-ER-598, Rev. 0-B, Lockheed Martin Hanford Corporation, Richland, Washington.

Lambert, S. L., 1998g, Preliminary Tank Characterization Report for Single-shell Tank 241-BY-106, WHC-SD-WM-ER-616, Rev. 0-B, Lockheed Martin Hanford Corporation, Richland, Washington.

Lilga, M. A., E. V. Alderson, R. T. Hallen, M. O. Hogan, T. L. Hubler, G. L. Jones, D. J. Kowalski, M. R. Lumetta, W. F. Riemath, R. A. Romine, G. F. Schiefelbein, M. R. Telander, 1996, Ferrocyanide Safety Project, Ferrocyanide Aging Studies Final Report, PNNL-11211, Pacific Northwest National Laboratory, Richland, Washington

LoPresti , C. A., K. M. Remond, F. M. Ryan, T. A. Ferryman, T. J. DeForest, C. A. Weier, S. A. Hartley, G. Chen, J. G. Hill, F. Gao, and B. C. Simpson, 1997, Identification of Tanks and Analyte Data from TCD, PNNL-1 1792, Pacific Northwest National Laboratory, Richland, Washington.

LMHC 1999, Tank Characterization Database, Internet at http://twins.pnl.gov:8001/TCD/main.html.

Meacham, J. M., 1996, Assessment of the Potential for Ferrocyanide Propagating Reaction Accidents, WHC-SD-WM-SARR-038, Rev. 1, Westinghouse Hanford Company, Richland, Washington

Meacham, J. M., D. B. Bechtold, D. M. Camaioni, W. L. Cowley, F. Gao, R. T. Hallen, P. G. Heasler, J. L. Huckaby, N. W. Kirch, J. A. Lechelt, D. A. Reynolds, R. D. Scheele, C. S. Simmons, L. A. Stauffer, L. M. Stock, J. J. Toth, A. B. Webb, 1998, Organic Complexant Topical Report, HNF-SD-WM-CN-058, Rev. 2, DE\&S Hanford, Inc., Richland, Washington.

Noorani, Y. G., 1999, Tank Waste Remediation System Basis for Interim Operation, HNF-SD-WN-BIO-001, Rev. 1-A, DE\&S Hanford, Inc., Richland, Washington

O'Dell, C. S., 1994, Resolution of the Hanford Criticality Safety Issue, (memorandum to R. E. Gerton, RL, September 20), U.S. Department of Energy, Washington, D.C. 
Owendoff, J. M., 1998, Approval to Close the Organic Complexant Safety Issue and Remove 18 Organic Complexant Tanks from the Watchlist, (memorandum to J. Wagoner, December 9), U.S. Department of Energy, Washington D.C.

Place D. E., 1998, Preliminary Tank Characterization Report for Single-shell Tank 241-C-102, HNF-SD-WM-ER-651, Rev. 0A, Lockheed Martin Hanford Corporation, Richland, Washington.

Place D. E., and M. Pagedor, 1998a, Preliminary Tank Characterization Report for Single-shell Tank 241-S-103, HNF-SD-WM-ER-668, Rev. 0A, Lockheed Martin Hanford Corporation, Richland, Washington.

Place D. E., and M. Pagedor, 1998b, Preliminary Tank Characterization Report for Single-shell Tank 241-S-105, HNF-SD-WM-ER-669, Rev. 0A, Lockheed Martin Hanford Corporation, Richland, Washington.

Place D. E., and M. Pagedor, 1998c, Preliminary Tank Characterization Report for Single-shell Tank 241-S-108, HNF-SD-WM-ER-641, Rev. 0A, Lockheed Martin Hanford Corporation, Richland, Washington.

Place D. E., and M. Pagedor, 1998d, Preliminary Tank Characterization Report for Single-shell Tank 241-S-112, HNF-SD-WM-ER-670, Rev. 0A, Lockheed Martin Hanford Corporation, Richland, Washington.

Postma, A. K., J. E. Meacham, G. S. Barney, G. L. Borsheim, R. J. Cash, M. D. Crippen, D. R. Dickinson, J. M. Grigsby, D. W. Jeppson, M. Kummerer, J. M. McLaren, C. S. Simmons, and B. C. Simpson, 1994, Ferrocyanide Safety Program: Safety Criteria for Ferrocyanide Watch List Tanks, WHC-EP-0691, Westinghouse Hanford Company, Richland, Washington.

Remund, K. M., and B. C. Simpson, 1997, Clustering of Radioactive Tank Waste Data and Comparison with Historical Models, presented at the American Society of Mechanical Engineers Sixth International Conference on Radioactive Waste Management and Environment Remediation in Sinapore, October 12-16, 1997.

Reynolds, D. A., W. T. Cowley, J. A. Lechelt, and B. C. Simpson, 1999, Evaluation of Tank Data Safety Screening, HNF-4217, Rev. 0 (in progress), Lockheed Martin Hanford Corporation, Richland, Washington

Rodenhizer, D. G., 1987, Hanford Waste Tank Sluicing History, SD-WM-TI-302, Rev. 0, Westinghouse Hanford Company, Richland, Washington.

Sathyanarayna, K., M. J. Thurgood, and B. C. Fryer, 1994, Development of a Dynamic Computer Simulator for Aging Waste Tank Operations and Safety Assessment, WHC-SD-WM-ER-198, Rev. 0, Westinghouse Hanford Company, Richland, Washington. 
Sederburg, J. P., and J. A. Reddick, 1994, TBP and Diluent Mass Balances in the Purex Plant at Hanford 1955 - 1991, WHC-MR-0483, Rev. 0, Westinghouse Hanford Company, Richland, Washington.

Serne, R. J., G. A. Whyatt, S. V. Mattigod, Y. Onishi, P. G. Doctor, B. N. Bjornstad, M. R. Powell, L. M. Liljegren, J. H. Westsik, N. J. Aimo, K. P. Recknagle, G. R. Golcar, T. B. Miley, G. R. Holdren, D. W. Jeppson, R. K. Biyani, and G. S. Barney, 1996, Fluid Dynamic Particulate Segregation, Chemical Processes, and Natural Ore Analog Discussions that Relate to the Potential for Criticality in Hanford Tanks, WHC-SD-WM-TI-757, Rev. 0, Westinghouse Hanford Company, Richland, Washington.

Simpson, B. C., 1996, Tank Characterization Report for Single-Shell Tank 241-S-107, WHC-SD-WM-ER-589, Rev. 0, Westinghouse Hanford Company, Richland, Washington.

Stewart, C. W., M. E. Brewster, P. A. Gauglitz, L. A. Mahoney, P. A. Meyer, K. P. Recknagle, and H. C. Reid, 1996, Gas Retention and Release Behavior in Hanford Single-Shell Waste Tanks, PNNL-11391, Pacific Northwest National Laboratory, Richland, Washington.

Van Keuren, J. C., J. S. Davis, M. L. Dentler, 1996, A Method for Analysis of Potential Accidental Toxic Chemical Releases From Hanford Tank Farms, WHC-SA-2845-S, Westinghouse Hanford Company, Richland, Washington.

Viswanath, R. S., G. S. Caprio, J. G. Douglas, M. J. Duchsherer, E. S. Mast, L. A. Pingel, M. Stauffer, D. B. Bonfoey, and G. A. Fies, 1997, Tank Vapor Sampling and Analysis Data Package for Tank 241-A-106, Sampled January 16, 1997, HNF-SD-WM-DP-277, Rev. 0, Numatec Hanford Corporation, Richland, Washington.

Weiss, R. L., and B. M. Mauss, 1987a, Data Transmittal Package for 241-TY-101 Waste Tank Characterization, SD-RE-TI-185, Rev. 0, Rockwell Hanford Operations, Richland, Washington.

Weiss, R. L., and B. M. Mauss, 1987b, Data Transmittal Package for 241-TY-102 Waste Tank Characterization, SD-RE-TI-183, Rev. 0, Rockwell Hanford Operations, Richland, Washington.

Weiss, R. L., and.B. M. Mauss, 1987c, Data Transmittal Package for 241-TY-103 Waste Tank Characterization, SD-RE-TI-184, Rev. 0, Rockwell Hanford Operations, Richland, Washington. 
Weiss, R. L., and B. M. Mauss, 1987d, Data Transmittal Package for 241-TY-105 Waste Tank Characterization, SD-RE-TI-186, Rev. 0, Rockwell Hanford Operations, Richland, Washington.

Weiss, R. L., and K. E. Schull, 1988a, Data Transmittal Package for 241-A-103 Waste Tank Characterization, SD-RE-TI-198, Rev. 0, Rockwell Hanford Operations, Richland, Washington.

Weiss, R. L., and K. E. Schull, 1988b, Data Transmittal Package for 241-C-102 Waste Tank Characterization, SD-RE-TI-209, Rev. 0, Rockwell Hanford Operations, Richland, Washington. 
HNF-4232 Rev. 0

This page intentionally left blank. 


\section{DISTRIBUTION SHEET}

\begin{tabular}{|c|c|c|c|c|c|}
\hline \multirow[b]{2}{*}{ Distribution } & \multirow{2}{*}{\multicolumn{3}{|c|}{ Process Engineering }} & \multicolumn{2}{|l|}{ Page 1 of 1} \\
\hline & & & & \multicolumn{2}{|c|}{ Date $\quad 06 / 23 / 99$} \\
\hline \multicolumn{4}{|l|}{ Project Title/Work Order } & \multicolumn{2}{|c|}{ EDT No. EDT-611472 } \\
\hline \multicolumn{4}{|c|}{$\begin{array}{l}\text { HNF-4232, Rev. 0, "Technical Basis for the Determination That } \\
\text { Current Characterization Data and Processes are Sufficient to } \\
\text { Ensure Safe Storage and to Design Waste Disposal Facilities" }\end{array}$} & \multicolumn{2}{|c|}{ ECN No. N/A } \\
\hline \multicolumn{2}{|l|}{ Name } & $\begin{array}{c}\text { Text } \\
\text { with } \\
\text { All } \\
\text { Attach. }\end{array}$ & Text Only & $\begin{array}{l}\text { Attach./ } \\
\text { Appendix } \\
\text { Only }\end{array}$ & $\begin{array}{c}\text { EDT/ECN } \\
\text { Only }\end{array}$ \\
\hline
\end{tabular}

Office of River Protection

J. A. Poppitti

J. F. Thompson

S7-54 $\quad x$

S7 $-54 \quad x$

N. C. Welliver

DOE Reading Room

S7-54

H2-53

5

Fluor Daniel Hanford

G. R. Franz

S7-40

S7-40 $\quad x$

$x$
$x$
5
$x$

T. R. Pauly

Lockheed Martin Hanford Corp.

D. L. Banning

D. R. Bratzel

R2-12

S7 -73

S7-73

R2-12

R2-12

S7-01

R2-11

$\mathrm{R} 2-58$

$\mathrm{R} 2-12$

R2-11

R2-58

R3-75

R1-49

$\mathrm{R} 2-58$

$\mathrm{R} 2-50$

$\mathrm{R} 2-12$

S7-01

R1-10

X

M. A. Payne

W. E. Ross

B. C. Simpson

G. A. Stanton

T.C.S.R.C.

$x$

Lockheed Martin Services, Inc.

Central Files

B1-07 $\quad X$

Numatec Hanford Corporation

A. F. Choho

R3-73

$x$
$x$
$x$

$x_{20}$

$x$

$\mathrm{X}$

$x$

$x$

$x$

$x$

$x$

$x$

$x$

$x$

$x$

$x$

$x$

Pacific Northwest National Laboratory

T. A. Ferryman

C. A. LoPresti

S. T. Cebula

J. W. Brothers

$\begin{array}{ll}K 5-12 & X \\ K 5-12 & x\end{array}$

$\mathrm{K} 5-12 \quad \mathrm{x}$

$\mathrm{K} 9-20 \quad \mathrm{X}$ 